\title{
Protecting pre-license teens from road risk: identifying risk-contributing factors and quantifying effects of intervention strategies
}

Citation for published version (APA):

Twisk, D. A. M. (2014). Protecting pre-license teens from road risk : identifying risk-contributing factors and quantifying effects of intervention strategies. [Doctoral Thesis, Maastricht University]. SWOV. https://doi.org/10.26481/dis.20140905dt

Document status and date:

Published: 01/01/2014

DOI:

10.26481/dis.20140905dt

Document Version:

Publisher's PDF, also known as Version of record

Please check the document version of this publication:

- A submitted manuscript is the version of the article upon submission and before peer-review. There can be important differences between the submitted version and the official published version of record.

People interested in the research are advised to contact the author for the final version of the publication, or visit the DOI to the publisher's website.

- The final author version and the galley proof are versions of the publication after peer review.

- The final published version features the final layout of the paper including the volume, issue and page numbers.

Link to publication

\footnotetext{
General rights rights.

- You may freely distribute the URL identifying the publication in the public portal. please follow below link for the End User Agreement:

www.umlib.nl/taverne-license

Take down policy

If you believe that this document breaches copyright please contact us at:

repository@maastrichtuniversity.nl

providing details and we will investigate your claim.
}

Copyright and moral rights for the publications made accessible in the public portal are retained by the authors and/or other copyright owners and it is a condition of accessing publications that users recognise and abide by the legal requirements associated with these

- Users may download and print one copy of any publication from the public portal for the purpose of private study or research.

- You may not further distribute the material or use it for any profit-making activity or commercial gain

If the publication is distributed under the terms of Article 25fa of the Dutch Copyright Act, indicated by the "Taverne" license above, 


\section{Protecting pre-license teens from road risk}

Identifying risk-contributing factors and quantifying effects of intervention strategies

Divera A.M. Twisk 
SWOV-Dissertatiereeks, Den Haag, Nederland.

Dit proefschrift is mede tot stand gekomen met steun van het Ministerie van Infrastructuur en Milieu, het Kennisplatform voor Verkeer en Vervoer, de Stichting Wetenschappelijk Onderzoek Verkeersveiligheid SWOV, en de Regionale Organen Verkeersveiligheid.

\section{SWOV-Dissertatiereeks}

Stichting Wetenschappelijk Onderzoek Verkeersveiligheid SWOV Bezuidenhoutseweg 62

PO Box 93113

2509 AC The Hague

E: info@swov.nl

I: www.swov.nl

ISBN: 978-90-73946-13-2

(C) 2014 Divera A.M. Twisk

Omslagillustratie: Divera Twisk

Alle rechten zijn voorbehouden. Niets uit deze uitgave mag worden verveelvoudigd, opgeslagen of openbaar gemaakt op welke wijze dan ook zonder voorafgaande schriftelijke toestemming van de auteur. 


\section{PROTECTING PRE-LICENSE TEENS FROM ROAD RISK}

\section{Identifying risk-contributing factors and quantifying effects of intervention strategies}

\section{DISSERTATION}

to obtain the degree of Doctor at the Maastricht University, on the authority of the Rector Magnificus, Prof. dr. L. L. G. Soete-in accordance with the decision of the Board of Deans, to be defended in public on Friday, $5^{\text {th }}$ of September, 2014, at 14.00 hours

by

Divera Alida Maria Twisk 
Supervisors:

Prof. Dr. G. Kok, Maastricht University

Prof. Dr. J. Thatcher Shope, UMTRI, University of Michigan USA

Assessment Committee:

Prof. dr. R. Ruiter (chairman).

Dr. N.P. Gregersen, Road \& Transport Research Institute (VTI), Sweden Prof. dr. J. Ramaekers

Prof. dr. V.J. Strecher, School of Public Health, University of Michigan, USA. Prof. dr. F.R.H. Zijlstra

Dit proefschrift is mede tot stand gekomen met steun van het Ministerie van Infrastructuur en Milieu, het Kennisplatform voor Verkeer en Vervoer, de Stichting Wetenschappelijk onderzoek Verkeersveiligheid SWOV, en de Regionale Organen Verkeersveiligheid. 


\section{Preface}

The small roadside memorials are silent witnesses of the great human tragedy of young people losing their lives in traffic accidents. Ever since my appointment at SWOV Institute for Road Safety Research, we have been working on the understanding and the prevention of these - often preventable - human losses. I am grateful for Fred Wegman's suggestion - perhaps even challenge - to turn this work into a PhD. After initially rejecting this idea as 'rather ridiculous', I came to realize that - apart from hard work and lots of weekends behind the laptop - it would also give me the opportunity to explore new theories, meet new colleagues, advance my technical understanding of statistical techniques, but most importantly to contribute to the prevention of these losses of young lives. Learning about other research areas, working with colleagues from the United States, and staying in Ann Arbor during the summers of 2008 and 2009 has helped me to develop my professional skills and led to a dissertation with a clear message: "These youngsters deserve better".

I wish to express my gratitude for the support of the Regional Offices of Road Safety in the Netherlands and the Dutch Ministry of Transport. I hope that the conclusions of this dissertation provide further support for the use of evidence-based interventions for young adolescents, especially in schools. Wilma Slinger and Gerard Kern played important roles in getting the evaluation studies going, and colleagues at SWOV - Jacques Commandeur, Willem Vlakveld, Jolieke Mesken, Jane Salomon, and Niels Bos - were all invaluable for meeting the required scientific standards.

A special thanks for Gerjo Kok and Jean Shope, my promotores, who were a 'golden duo' and a 'match made in heaven'. Gerjo, your no-nonsense style is best illustrated by your most rapid but often also shortest possible e-mails. Jean, your keen eye for detail and your great enthusiasm and hospitality has extended far beyond the academic realm. Thanks for coming to my rescue when a broken airco had turned my Ann Arbor apartment into an oven, and for helping me buying a new swimming suit. Ingrid thanks for reading the last versions of the dissertation and Jolanda for all the encouraging words.

In the last months, my paranymphs Marjan Hagenzieker and Hilde Kooistra have supported me in completing the final steps. Marjan, you have been my closest colleague for more than a quarter of a century. Hilde my eldest 
daughter, your birth made me into a mother, and now you helped me with this other important transition in life. Tessa en Nynke - our dear twin daughters - thanks for bearing with a mother who has had too little time for 'fun' things for too long.

I am aware that this dissertation has its roots even further in the past. In this last section I want to pay tribute to some people who have been so important in shaping my future. Without my undergraduate studies at Keele University in England and its great academic staff in those days I would probably not have discovered my passion for research and not have learned how to inspire others. During my post-graduate studies, at the University of Groningen, Bert Mulder was my great mentor. Several of the theoretical concepts in this dissertation originate from his lectures. In the early Eighties, Jacob Hooisma made the difference by offering me a job at TNO to study the influence of low doses of neurotoxins on the brain and by not withdrawing that offer when it became clear that I was pregnant. Due to the economic crisis in those years, starting an academic career was almost impossible. Teake has supported me in many ways during those years. Finally, at SWOV I found the colleagues, the 'bosses' - Peter Wouters, Piet Noordzij, Fred Wegman, Peter van der Knaap, Henk Stipdonk and Rob Eenink - and the atmosphere that makes that most of the days I do my work with an, unfortunately not always visible, smile on my face.

One of the studies in this dissertation illustrates that one's future is partially shaped by one's - lucky - hand in picking one's parents, siblings, and friends. Our parents Afra Kuys en Wim Twisk have shown us, that by endurance, passion, ambition and courage, one can turn a sea into an agricultural heaven, whilst raising six children. My brothers Jan, Sjaak, Henk, and René, and my sister Aletta have surrounded me with their everlasting loyalty and love. My friends Henric and Jacqueline have been my friends for over 40 years, and will surely stay that for as long as we shall live.

I praise my lucky hand.

Divera Twisk, Leiden, $29^{\text {th }}$ of May, 2014 


\section{Table of contents}

1. General introduction $\quad \mathbf{1 1}$

1.1. Scope and objectives of the dissertation 11

1.2. Why this dissertation? 13

1.3. Dissertation outline 16

2. Changing mobility patterns and road mortality among pre-license teens in a late licensing country: An epidemiological study 21

$\begin{array}{ll}\text { Abstract } & 21\end{array}$

2.1. Background 21

2.2. Methods 24

2.3. Results 25

2.4. Discussion 31

2.5. Conclusion 33

3. Theoretical perspectives, conceptual model and research questions 35

$\begin{array}{ll}\text { Abstract } & 35\end{array}$

3.1. Introduction 35

3.2. Theories on safe road systems 36

3.3. The control of danger 37

3.4. Behaviour models of road risk in adolescence 41

3.5. Neuro-psychological theories 47

3.6. Conceptual model and research questions 51

4. The relationships among psychological determinants, risk behaviour, and road crashes: implications for RSE programmes 55

Abstract $\quad 55$

4.1. Introduction 55

4.2. Method 59

4.3. Results 63

$\begin{array}{ll}\text { 4.4. Discussion } & 73\end{array}$ 
5. The co-occurrence of problem behaviours in early adolescence, and the influence of the perceived social environment: Implications for interventions

$\begin{array}{ll}\text { Abstract } & 79\end{array}$

5.1. Introduction 79

5.2. Theoretical framework 81

5.3. Method 82

5.4. Results 86

5.5. Discussion 90

5.6. Conclusions 92

6. Inexperience and risky decisions of young adolescents in interactions with trucks, and the effects of competency versus awareness education $\quad 95$

Abstract $\quad 95$

6.1. Introduction 95

6.2. Method 98

6.3. Results 101

6.4. Discussion 105

7. Five road safety education programmes for young adolescents: a multi-programme evaluation in a field setting 109

$\begin{array}{ll}\text { Abstract } & 109\end{array}$

7.1. Introduction 109

7.2. Method 114

7.3. Results 118

7.4. Discussion 122

$\begin{array}{ll}\text { 7.5. Conclusions } & 125\end{array}$

8. Quantifying the influence of safe road systems and legal licensing age on road mortality among pre-license adolescents $\quad 127$ Abstract 127

8.1. Introduction 128

8.2. Method 131

8.3. Results 135

8.4. Discussion 138

8.5. Conclusions 140 
9. Conclusions, discussion, and recommendations 143

9.1. Conceptual model and research questions $\quad 143$

9.2. Road mortality and impact of changing mobility patterns $\quad 145$

9.3. Road safety education and the predictors of risk behaviour and crashes 150

9.4. Multiple risk behaviours and perceived social environment 155

9.5. Two intervention strategies 157

9.6. Lessons learned 162

9.7. Recommendations for future research 166

9.8. Conclusions 170

$\begin{array}{ll}\text { References } & 171\end{array}$

$\begin{array}{lll}\text { Appendix A } & \text { Questionnaire for age group 12-13 }\end{array}$

$\begin{array}{lll}\text { Appendix B Questionnaire for age group 14-17 } 201 & \end{array}$

$\begin{array}{lll}\text { Appendix C Scenarios for blind spot situations } & 209\end{array}$

$\begin{array}{ll}\text { Summary } & 215\end{array}$

$\begin{array}{ll}\text { Samenvatting } & 223\end{array}$

$\begin{array}{ll}\text { Curriculum Vitae } & 235\end{array}$

$\begin{array}{ll}\text { SWOV-Dissertatiereeks } & 237\end{array}$ 



\section{General introduction}

\subsection{Scope and objectives of the dissertation}

Having overcome the frailty of childhood, in adolescence - the period between the onset of puberty around age 10 and adulthood - youngsters become the healthiest and fittest members of western society (WHO, 2010). Unfortunately, these health gains are partly lost because of a concurrent sharp increase in injury-related mortality (Dahl, 2004; Sleet et al., 2010). Traffic crashes, defined as crashes on public roads involving at least one vehicle, are especially responsible, accounting for approximately 35\% to $40 \%$ of the injury-related mortality among young adolescents in Europe (Kumpula and Paavola, 2008; OECD-ECMT, 2006) and the USA (Sleet et al., 2010). Recognising the great social and economic impact of this preventable loss of young lives, organisations such as the World Health Organisation (WHO) (Sethi et al., 2007), the Organisation for Economic Cooperation and Development (OECD) (OECD-ECMT, 2004, 2006), and the European Transport and Safety Council (ETSC) all call for major efforts to develop effective countermeasures to prevent this loss.

To date, most of these efforts have concentrated on reducing the exceptionally high crash risk among adolescent car drivers (Engström, 2008; OECD-ECMT, 2006; Senserrick, 2006; Siegrist, 1999; Twisk and Stacey, 2007; Vlakveld, 2005). In contrast, relatively little policy and research attention has been devoted to the 10 to 17 year old age group (Kumpula and Paavola, 2008; OECD-ECMT, 2004; Sentinella and Keigan, 2005), possibly because of the belief that being too young to hold a driving license and drive a car, this age group is not yet exposed to a substantially high road risk. This assumption, however, may not hold true. Recent studies on mental and biological development in adolescence and their impacts on risky behaviour suggest that from age 10 elevated levels of road risk are highly probable (Susman and Rogol, 2004). This effect may even be greater in late-licensing countries such as the Netherlands, where 10 to 17 year olds may not drive cars, but use bicycles or mopeds instead. On average, cyclists have a four times higher fatality risk than car occupants (SWOV, 2009b; Wegman et al., 2012), and the trends over time show the safety of cyclists to be less favourable than that of car occupants (Weijermars and Van Schagen, 2009). Because of these developments, the Dutch National Road Safety Plan emphasized the importance of protecting vulnerable road users (Ministerie van Verkeer en 
Waterstaat [Ministery of Trafic and Water works], 2008) and called for the implementation of a wide range of countermeasures.

Among the many possible preventative measures for young adolescents, road safety education (RSE) is one of the most frequently utilized (Dragutinovic and Twisk, 2006; SUPREME, 2007). These education programmes all target different behaviours, but in general aim to achieve the following objectives: (a) to prevent crashes during adolescence by modifying current unsafe behaviours and (b) to invest in future safe adult behaviour by stimulating positive road safety attitudes (Waylen and McKenna, 2008). The question is whether the popularity of RSE is justified by its effects. Because of the absence of evaluation studies to date, reviews show that actually little is known about the effects of RSE (e.g., Dragutinovic and Twisk, 2006; SUPREME, 2007). Possibly, the effects are smaller than generally expected, as the majority of RSE programmes are generally developed based on an intuitive understanding of the problem and effective components of interventions, rather than on a thorough empirical analysis as prescribed by several handbooks on the matter (see Bartholomew et al., 2011 ; Delhomme et al., 2009 for an overview of how to develop such programmes). This combination, of the absence of evaluation studies and the intuitive development of programmes, has the following potential negative consequences. First, policy makers and prevention workers are being left in the dark about the actual outcome of their interventions. Second, ineffective programmes may consume scarce financial resources that could have been used for countermeasures that do have an effect. Finally, possible negative side effects of programmes may go unnoticed, and subsequently deteriorate safety. According to Chalmers (2003), this practice of implementing programmes of unknown quality also creates an ethical dilemma. By including these programmes in school curricula, road safety professionals intervene in the lives of others for their own good, but without their explicit consent, and promote a 'cure' without its effects ever been 'proven'. Poulter and McKenna (2010) also refer to this ethical dilemma, when they warn that "the clear presence of a problem prompts action, but the clear absence of a solution prompts caution" (p. 166).

The series of studies presented in this dissertation aim to contribute to the development of high quality education programmes for young Dutch adolescent road users, in particular cyclists, 10 to 17 years of age. To this end, it focuses on the following objectives: (a) a deeper understanding of the magnitude and nature of road risk in early adolescence; (b) the identification of risk-increasing factors; (c) the 
assessment of the effects of some road safety education programmes applied in Dutch schools and (d) the influence of the safety of the road system on adolescent road mortality.

\subsection{Why this dissertation?}

There are three a reasons, additional to the ones presented in the previous section, to focus on the safety of young adolescent cyclists: (a) the current investments into the promotion of bicycle use in the Netherlands; (b) new insights into the impact of psychophysiological development on adolescent risk behaviour; and finally (c) our current knowledge base on adolescent road users having been largely derived from studies on non-European adolescent road users, and mainly car drivers. In this section, these three reasons are discussed in more detail.

\subsubsection{Promotion of bicycle use and safety}

Aside from the risk of crashes, cycling has many positive effects on society. Based on a review of the literature, Hendriksen \& Van Gijlswijk (2010) concluded that cycling had positive effects on physical health, mood, body weight, traffic congestion, greenhouse gas emissions, and financial costs. Comparing cycling's health benefits to its safety losses, a recent literature review concluded that in terms of life expectancy, health benefits outweighed the safety costs, with a health benefit estimated at 3 to 14 months and a loss because of road crashes estimated at 5 to 9 days (de Hartog, Boogaard, Nijland \& Hoek (2010).

The many benefits of cycling have generated a wide range of activities to promote cycling not only in the Netherlands (see Fietsberaad, 2009 for an overview of these initiatives), but also worldwide. If these initiatives are going to be successful and shift the modal split from car use to cycling, this shift is expected to increase the total number of road fatalities and injuries (Stipdonk and Reurings, 2010). Without additional interventions, this shift may endanger the ambitious Dutch (Ministerie van Verkeer en Waterstaat [Ministery of Trafic and Water works], 2008) and European road safety targets (European Commission, 2010; Jost et al., 2010). To contribute to the development of effective interventions, this study analyses the behaviour of young adolescent road users, assesses the effects of current RSE programmes, and quantifies the effects from safe road systems. 


\subsubsection{New insights into the impact of psychophysiology development}

In developmental psychology, the age period between 10 and 17 is known as early adolescence and youngsters this age as 'young adolescents'. In the dissertation we also refer to this age group as 'teens'. Early adolescence covers roughly the period of puberty, when the bodies of children are transformed into those of sexually and physically mature adults. In addition to these physiological changes, the period is also characterized by changes in psychosocial behaviour (Susman and Rogol, 2004; Westenberg, 2008). Note that in the English language the term 'puberty' only refers to the 'biological' maturation in this period, whereas in the Dutch language the term 'puberteit' not only refers to biological development but also to psychosocial development as well. In Dutch common parlance, a 'puber' is a young adolescent going through puberty.

Only decades ago, little evidence suggested that traffic risks of adolescents could be related to the immaturity of their brains (e.g., Eby and Molnar, 1999; Twisk, 1992, 1995). In those days, the available evidence indicated that by age 4 the structural development of the human brain had already been completed (Susman and Rogol, 2004). Recent observations of the activities and maturation of the living brain, using advanced non-intrusive, harmless, neuro-imaging techniques, have shown this not to be the case. In fact, in adolescence, the brain undergoes major structural changes that are finally completed in their twenties. These changes probably contribute to typical adolescent behavioural patterns such as impulsiveness, moodiness, restlessness, and risky decision making (Blakemore and Choudhury, 2006; Casey et al., 2008). These findings, which are often generated under laboratory conditions, have also been applied to enhance our understanding of adolescent drivers (e.g., Keating, 2007; Keating and Halpern-Felsher, 2008), and to assess their contribution in relation to other risk factors such as inexperience and exposure to risk (Twisk and Vlakveld, 2010). The present study aims to assess the practical implications of these findings in relation to the road behaviour of young adolescents as cyclists, pedestrians and moped riders. 


\subsubsection{Knowledge base about young adolescent road users}

Risky traffic behaviour in adolescence is a well-researched area. A search of databases such as 'PubMed' and 'Science Direct', with keywords 'adolescence', 'risk', and 'traffic', generates an abundance of studies from a wide range of countries. Although this large body of research may suggest that adolescent road risk is well understood and that findings can be applied from one country to another, large differences in traffic conditions, such as traffic laws, safety culture, and road infrastructure, seriously limit the generalisability of these findings (e.g., Koornstra et al., 2003; Lynam et al., 2002; Wegman et al., 2006). These limitations in generalisability of findings across countries raise the question of whether our current understanding of adolescent road behaviour is based on studies from geographical areas with road systems similar to that in Europe and more specifically to the Netherlands. A conclusive answer, however, would require a systematic review of the available studies, which is, unfortunately, outside the scope of this study. But a recent systematic review of 150 peer-reviewed articles written in English on adolescent drivers in the age category 13 to 19 years old, included geographic origins of the studies (Strecher et al., 2007). Although, this review included studies on youngsters slightly older than the age group studied in this dissertation and solely focussed on car drivers, the results may still serve as an indication of the current geographical distribution of studies. To that end, we classified the 150 studies by geographic origin, and found that only a quarter of the studies $(n=42)$ were carried out in the European region, whereas 75\% were carried out in Canada, Australia, the US and New Zealand. Possibly this bias results partly from the selection for studies in the English language, but probably also reflects the fact that the present knowledge base on adolescent road risk and effects of countermeasures is largely based on studies of non-European adolescents. One of the most important differences is the legal driver licensing age, which means that teens in the US, Australia, New Zealand, and Canada are allowed to drive a car at younger ages than in Europe. In order to supplement the current knowledge base on the road risk of young adolescents, the present study addresses the nature of road risk in a late-licensing European country. 


\subsection{Dissertation outline}

The dissertation includes the following chapters:

Chapter 2. Changing mobility patterns and road mortality among pre-license teens in a late-licensing country: An epidemiological study':

Whereas the safety of teens in early-licensing countries has been extensively studied, little is known about the safety of pre-license teens in late-licensing countries. Road risk could be relatively high in comparison to that in childhood because of a combination of factors: a) increasing use of travel modes with a high injury risk, such as bicycles and mopeds, b) inexperience, and c) teens' developmental stage, known to be associated with risk taking and novelty seeking, especially among males. To explore the magnitude and nature of pre-license road risk, Chapter 2 analyses epidemiological data from the Netherlands, and hypothesizes that in this late-licensing country, 'independent travel' and the use of riskier modes of transport increase among pre-license teens of 10 to 17 years of age, resulting in higher fatality rates, with 'inexperience' and 'gender' as risk modifying factors. To test these hypotheses, national travel and fatality data of pre-license adolescents in the Netherlands are analysed by traffic role.

Chapter 3: Theoretical perspectives on risk behaviour in adolescence

The dissertation is set in the practical domain of road safety interventions. With a focus on road safety education (RSE), it aims to understand how RSE may be effective in preventing road injuries and deaths among young adolescents. From this practical perspective, the study draws from a wide range of theoretical fields, such as social, developmental and neuro-psychology, and human factors. Chapter 3 discusses the relevance of these perspectives for understanding adolescent road risk and the prospects for effective RSE. The chapter concludes with a graphic presentation of a theoretical framework for the study of adolescent road risk and an overview of the research questions.

\footnotetext{
${ }^{1}$ This chapter was first published in BMC Public Health: Twisk, D., Bos, N., Shope, J.T., Kok, G., 2013. Changing mobility patterns and road mortality among pre-license teens in a late licensing country: an epidemiological study. BMC Public Health 13 (333).
} 
Chapter 4: The relationships among psychological determinants, risk behaviour, and road crashes: Implications for road safety education programmes ${ }^{2}$

To explore the relationships between unsafe acts and crashes, as well as the relationship between behavioural antecedents and unsafe acts, Chapter 4 analyses the results from a survey of young adolescents. Insight into these relationships provides background information for the development of education programmes, especially regarding which risky behaviours to target, and which antecedents underlying those risky behaviours. By influencing those antecedents, education programmes may reduce the frequency of risky behaviours.

Chapter 5: Co-occurrence of problem behaviours in early adolescence, and the influence of perceived social environment: Implications for interventions

To understand the associations among problem behaviours and the relationship with the perceived social environment, Chapter 5 presents the results from a secondary analysis of the Dutch data from the crossnational 'Health Behaviour in School-aged Children' (HBSC) 1991-1992 study of the World Health Organisation (see Dorsselaer et al., 2007 and www.hbsc.org for general descriptions). This survey periodically gathers information on the incidence of health risks among young adolescents and the incidence of these risks - as perceived by the adolescent - among their parents, siblings, and friends. As an exception, the 1991-1992 Dutch version also included items on risky road behaviour, and is used in Chapter 5 to provide direction as to whether prevention strategies should address multi-problem behaviours and consider elements of perceived social environments as well. Given that these data were gathered two decades ago, the results may only serve as an illustration and cannot be assumed to describe the current situation.

\footnotetext{
2 Submitted for publication as Twisk, D., Vlakveld, W., Commandeur, J., Shope, J. T., \& Kok, G. The relationships among psychological determinants, risk behaviour, and road crashes: Implications for road safety education programmes. Journal of Transport Studies, Part F. (submitted 04-022014).
} 
Chapter 6: The role of task complexity and the effects of education on risky road behaviour of young adolescent cyclists ${ }^{3}$

RSE programmes are frequently based on the assumption that deliberate risk taking, rather than lack of competency, underlies risk behaviour. Chapter 6 reports on a study aimed to test the competency of 10 to 13 year olds, by examining their decisions - as pedestrians and cyclists - in dealing with blind spot areas around trucks. In addition, the effects of an awareness programme and a competency programme on these decisions were evaluated. To that end, table-top models were used, representing seven scenarios that differed in complexity: one basic scenario to test the identification of blind spot areas, and 6 traffic scenarios to test behaviour in traffic situations of low or high task complexity. Using a quasi-experimental design, the programme effects were assessed by requiring participants to show, for each table-top traffic scenario, how they would act if they were in that traffic situation.

Chapter 7: Five road safety education programmes for young adolescents: a multiprogramme evaluation ${ }^{4}$

This study presented in Chapter 7 had two objectives: (a) develop a practical approach to evaluating RSE, and (b) by applying this approach, assess and compare the effects of five short RSE programmes for young adolescents in the age category 12 to 17 . Regarding the evaluation approach, the study concluded that, in line with the use of Safety Performance Indicators (SPIs), Self-Reported Behaviour could serve as an SPI for the effects of RSE. Next, this SPI was used in a quasiexperimental study to assess the effects of five programmes for young adolescents by using the same methodology and measurement instrument across all five programmes.

\footnotetext{
${ }^{3}$ This chapter was published as the following article: Twisk, D., Vlakveld, W., Mesken, J., Shope, J.T. Kok, G, 2013. Inexperience and risky decisions of young adolescents in interactions with lorries, and the effects of competency versus awareness education. Accident Analysis \& Prevention $55,219-225$.

${ }^{4}$ This chapter was first published as: Twisk, D., Vlakveld, W., Commandeur, J.J.F., Shope, J.T., Kok, G. 2014. Five road safety education programmes for young adolescents: a multi-programme evaluation. Accident Analysis \& Prevention 66, 55 - 61.
} 
Chapter 8: Quantifying the influence of safe road systems and legal licensing age on road mortality among pre-license adolescents ${ }^{5}$

Whereas the role of deliberate risk taking (self-induced exposure to risk) on adolescent road mortality is well documented, relatively little is known about the extent to which characteristics of the 'road system' may protect pre-license adolescents from serious harm. Chapter 8 quantifies the influence of safe road systems on young adolescent mortality (10 to 17 years old), by assessing the relative contribution of system-induced exposure to risk (SE) and the additional influence of legal licensing age. To that end, fatality data from early-licensing countries and late-licensing countries, obtained from the IRTAD and the FARS databases, were analysed using multilevel regression techniques.

\section{Chapter 9: Discussion, conclusions and recommendations}

Finally, Chapter 9 summarizes the main findings and draws conclusions about the nature and the incidence of risky acts among young adolescent road users, as pedestrians, cyclists or moped riders and the role and effects of education. These empirical findings, in combination with the theoretical underpinnings, lead to recommendations on how to improve the safety of young adolescent road users and the potential contribution of RSE in that context.

5 This chapter was submitted in a modified version for publication as: Twisk, D., Commandeur, J.J.F., Bos, N., Shope, J.T., Kok, G., Quantifying the influence of safe road systems and legal licensing age on road mortality among pre-license adolescents. Accident Analysis and Prevention. (submitted 20-07-2014) 



\title{
2. Changing mobility patterns and road mortality among pre-license teens in a late licensing country: An epidemiological study ${ }^{6}$
}

\begin{abstract}
Whereas the safety of teens in early licensing countries has been extensively studied, little is known about the safety of pre-license teens in late licensing countries, where these teens also may be at risk. This risk exists because of the combination of a) increasing use of travel modes with a high injury risk, such as bicycles and mopeds, b) inexperience, and c) teens' developmental stage, known to be associated with risk taking and novelty seeking, especially among males. To explore the magnitude and nature of pre-license road risk, this study analysed epidemiological data from the Netherlands, and hypothesized that in this late licensing country, 'independent travel' and the use of riskier modes of transport increase among pre-license teens 10 to 17 years of age, resulting in higher fatality rates, with 'experience' and 'gender' as risk modifying factors.

Method: National travel and fatality data of pre-license adolescents in the Netherlands were analysed by traffic role (cyclist, pedestrian, car passenger and moped rider), and compared to a younger age group (0-9 years) and an older age group (18+ years).

Results: The study of travel data showed that teens migrate from being car occupants to being users of riskier modes of transport, specifically bicycles and mopeds. This migration resulted in a strong rise in road fatalities, illustrating the importance of mobility patterns for understanding changes in road fatalities in this age group. The data further suggested a protective role of early cycle experience for young adolescent cyclists, particularly for young males. But further study into the underlying mechanism is needed to confirm this relationship. Moped risk was extremely high, especially among young males, and even higher than that of young male car drivers.

Conclusions: The study confirmed the importance of changes in mobility patterns for understanding the rising road mortality when youngsters enter into their teens. The focus on fatalities has led to an underestimation of the magnitude of the problem because of the physical resilience of young adolescents that leads to high survival rates but probably also to long term disabilities. In addition, to explore the generalizability of these results, international comparisons among and between early and late licensing countries are necessary, especially in relation to moped riding as an alternative for car driving.
\end{abstract}

\subsection{Background}

Worldwide, road injuries are a leading cause of death among teens, 10 to 17 years of age. The actual rates, however, differ greatly among countries (Sleet

\footnotetext{
${ }^{6}$ This chapter was first published in BMC Public Health: Twisk, D., Bos, N., Shope, J.T., Kok, G., 2013. Changing mobility patterns and road mortality among pre-license teens in a late licensing country: an epidemiological study. BMC Public Health 13 (333).
} 
et al., 2010). One of the factors known to influence these rates is the age at which youngsters are legally allowed to drive a car. Countries that license late, that is from age 18 onwards, have generally better safety records than countries that license early, that is between ages 14 and 17 (see OECD-ECMT, 2006 for an overview). Whereas a wide range of studies has addressed the road risk of 14 to 17 year olds as car drivers, little is known about the road safety of pre-license teens - between 10 to 17 years of age - who, in late licensing countries, are still too young to acquire a driving license. Although this group is not yet exposed to the high risk of car driving, the characteristic psychological and social development associated with the onset of adolescence may have a considerable influence on mobility patterns. Among the many factors that affect road safety levels, changes in mobility patterns are known to be one of the most influential (Christie et al., 2007; Hakkert et al., 2002; Twisk, 2000). Yet to date, studies on 10 to 17 year olds tend to focus on general themes such as deliberate risk taking and peer group influences (e.g., Reyna and Farley, 2006; Tolmie et al., 2009), but seldom the development of mobility patterns by age and subsequent influences on road safety (e.g., OECD-ECMT, 2004). To study these relationships and assess the implications for prevention strategies, the present study analyses the development of mobility patterns and road mortality by age among prelicense teens -10 to 17 year of age - in the Netherlands, where car drivers are licenced at age 18, and riders of mopeds and light-mopeds at 16. Mopeds and light-mopeds are powered two wheelers, with a maximum displacement of $50 \mathrm{cc}$ for internal combustion engines and $4 \mathrm{Kw}$ for electric engines. Mopeds and light-mopeds differ in terms of their legal maximum speeds, which is 45 $\mathrm{km} / \mathrm{h}$ for mopeds and $25 \mathrm{~km} / \mathrm{h}$ for light-mopeds. Helmet wearing and holding a license are compulsory requirements for mopeds, not for lightmopeds.

Besides formal regulations on access to travel modes, the developmental stage of teens also plays a role. In developmental psychology, the age period between 10 and 17 is known as early adolescence and youngsters in this age period are known as 'young adolescents'. Early adolescence covers roughly the period of puberty, when the bodies of children are transformed into those of sexually and physically mature adults. In addition to these physiological changes, this period is also characterized by social, emotional and cognitive changes (Susman and Rogol, 2004; Westenberg, 2008). Among the many changes in behaviour that have been observed for young adolescents, the two that are most prominent across cultures and that are most likely to affect mobility patterns are an increase in novelty seeking, and a shift in social 
attachments from the family unit toward peers (Spear, 2000). Therefore, it was expected that youngsters will travel more frequently independently from caretakers compared to when they were children. Besides these psychological developments, their role in society also changes when they leave primary school and start attending secondary school. In the Netherlands, this transition will affect mobility, as the network of secondary schools is less finely-meshed than that of primary schools, resulting in a longer travel distance between home and school. Therefore, it was expected that car passenger travel would drop, independent travel would increase, and travel distances would rise in early adolescence (H1). Because in late licensing countries, young teens are not allowed to drive cars, the greater need for independent travel can thus only be met by the use of bicycles, walking, or - from age 16 onwards - the use of mopeds or light-mopeds. It is therefore expected that, compared to childhood, in early adolescence the use of these travel modes will increase (H2). In contrast to cars, these modes do not provide any physical protection in a crash, and therefore have higher injury risks. It was, therefore, expected that an increase in travel, combined with travel modes with high injury risks will lead to higher road mortality even when corrected for the travel distance - in early adolescence than in childhood (H3).

In addition to travel distances, and riskier transport modes, trip conditions may also change because of the above mentioned novelty seeking. This greater tendency in early adolescence to search for new, novel and exciting experiences may expose youngsters to new and unfamiliar traffic situations, for which their skills may not yet be sufficiently developed. Inexperience has been shown to be an important factor in road crashes of young drivers (OECD-ECMT, 2006), but as yet only a few studies have looked at this phenomenon for other traffic modes. In the present study, inexperience is predicted to play a role for moped riders from age 16 onwards when they can get licensed for riding a moped, and for cyclists from age 12 onwards, when youngsters start commuting to secondary schools which requires negotiating complex and unfamiliar traffic situations (H4). In epidemiological data, the role of inexperience can be identified by an initial high fatality risk per distance travelled, followed by a steady decline as experience grows (Brown, 1982).

In early adolescence, the detrimental effects of higher mileage, use of riskier transport modes, and inexperience may be amplified by a strong rise in sensation seeking and deliberate risk taking (Spear, 2000), which starts 
around age 10 and reaches its peak around age 16 after which it steadily declines (Brijs et al., 2009). Recent studies on brain development suggest this pattern to be the result of the way in which the structure of the adolescent brain changes as it develops. These are extremely complex processes, but in essence can be described as the 'reward systems' located in the limbic system becoming highly activated under the influence of puberty-related hormones and the 'planning and control systems' located in the prefrontal cortex, developing at a much slower pace and reaching their mature forms in one's early 20's (Brijs et al., 2009; Casey et al., 2008). As a result, young adolescents have difficulty controlling their impulses and are highly flexible in goal attainment, with short term gains being more attractive than long term ones, especially when peer admiration is involved (Crone and Dahl, 2012). These effects are stronger among males than among females (Blakemore and Choudhury, 2006; Lenroot and Giedd, 2010), which might explain why studies on gender differences have found higher risk taking among young males compared to females (Byrnes et al., 1999; Dunlop and Romer, 2010; Reyna and Farley, 2006). Given these gender differences in sensation seeking and their impact on behaviour, fatality rates per distance for young males were expected to be higher than for young females for all travel modes (H5).

\subsection{Methods}

\subsubsection{Data}

Information on adolescent travel in terms of distance and travel mode by age and gender for the years 2002 to 2009 was derived from the Dutch National Travel Statistics (Data source CBS-OVG, IenM-MON), which contains the yearly national averages that are based on a yearly national travel survey of a representative sample of Dutch households. To compare different causes of death, including road crashes by age and gender for the period 2002-2009, the Dutch Mortality Record (DMR source CBS Statistics the Netherlands) was used, which contains information on all causes of death of Dutch citizens, including road crashes.

Information on gender, age by year and traffic mode of road fatalities for the years 2002-2009 was derived from the Dutch Road Crash Data Base, (data source BRON/SWOV Central Bureau of Statistics [CBS], the Netherlands). This data base contains detailed information about crash circumstances, based on police records of road crashes along the entire road network in the Netherlands. The registration rates for road fatalities are satisfactory, as 
approximately $94 \%$ of pedestrian fatalities, $88 \%$ of cyclist fatalities, and $96 \%$ of moped rider fatalities are included in the database (Reurings et al., 2007). There is only a slight difference with the $D M R$, in that the police statistics only include information from accidents on Dutch roads, whereas the DMR also contains information on the few Dutch citizens who died in a road crash outside the Netherlands. However, these differences are too small to be of influence and are therefore not addressed in the study.

\subsubsection{Measures}

The following measures were used in the study:

- Road crash and road fatality. A road crash is defined as '....an event on a public road that results in damage to objects and/or injury to persons and involves at least one moving vehicle, and a road fatality was defined as '.. a person who died within thirty days from injuries sustained in a road crash'. For comparisons among the different causes of death, the Dutch Mortality Records were used and mortality was expressed as the number of fatalities per 100000 inhabitants of that age group.

- $\quad$ Natural and unnatural death. 'Natural death' was defined as mortality caused by disease, and 'unnatural death' was defined as caused by external 'violent' impacts on the body leading to injuries.

- Distance travelled was expressed as kilometres per year per capita of that age group.

- $\quad$ Road risk was expressed as the number of road fatalities per $10^{9}$ kilometres.

- Independent traffic mode meant being in control of a vehicle as the driver instead of being a passenger. In this context, 'walking' is considered an independent traffic mode.

\subsection{Results}

\subsubsection{Changing mobility patterns in early adolescence}

Travel per mode is presented in Figure 2.1, showing that up to age 16 the total distance travelled increases and that the distribution across the different transport modes changes considerably. While children up to age 11 are mainly transported by car, youngsters older than 12 years of age travel more often independently, as cyclist and moped rider while the amount of walking kept rather constant. At age 15, youngsters travel about $2400 \mathrm{~km}$ as cyclists compared to $3000 \mathrm{~km}$ as car passengers. The analyses further showed that, 
with the exception of moped use, which is most popular among males, gender differences in travel patterns are only marginal. The higher use of bicycles and mopeds in combination with the lower mileage as car passenger supports the hypotheses that travel patterns change in early adolescence toward independent travel (H1) and toward more risky modes of transport (H2).

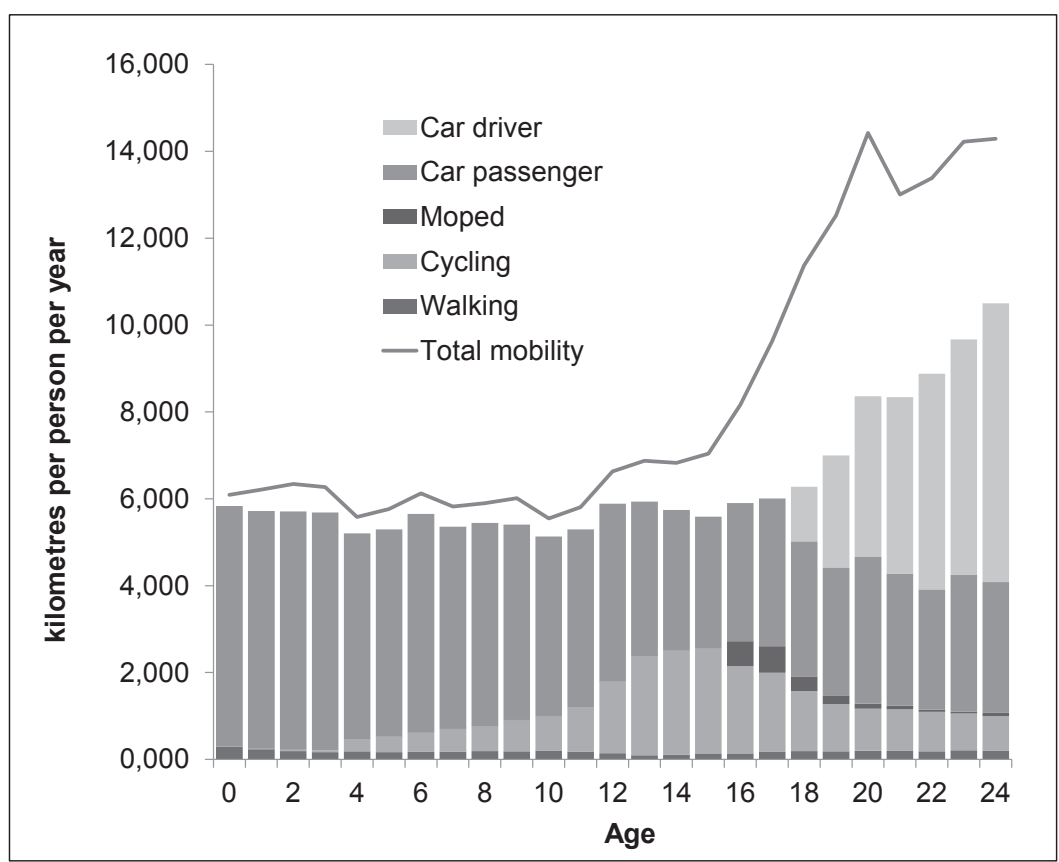

Figure 2.1. Development in mobility patterns with age, years 2002-2009 (Data source CBS-OVG, IenM-MON).

\subsubsection{Mortality causes in early adolescence}

To examine adolescent road mortality from a public health perspective, Figure 2.2 presents the natural and unnatural mortality causes per capita and by age group. For the purpose of the present study, the original age category 15 to 19 available in the DMR was divided into two categories for the road crash data: 15 to 17 and 18 to 19. The Dutch Road Crash Data Base, which contains accurate counts of the fatalities on Dutch roads by age and gender, was used to estimate the distribution of fatalities in the two age groups. The data show that while in the first decade of life, natural death dominates the mortality statistics, in the second decade injuries start to become almost as prominent a mortality cause as disease. Road mortality is responsible for a 
large share of that mortality, not only among the 18 to 24 year olds, the age group in which youngsters get licensed to drive cars, but also in the prelicense period. Road mortality starts to rise from age 10-14 onwards, reaching its peak in the 15 to 17 year old group. This confirms that in a late licensing country, road mortality also becomes a main cause of death among prelicense teens $(\mathrm{H} 3)$.

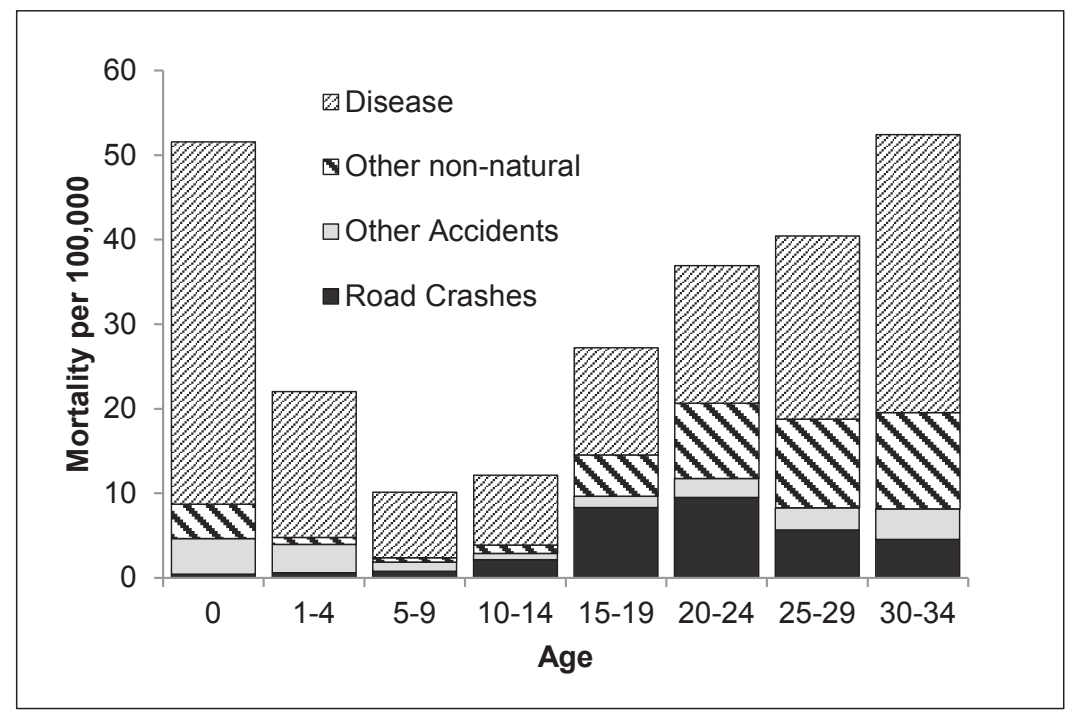

Figure 2.2. Yearly mortality by age and cause of death in the Netherlands for the period 2002-2009 (source Dutch Mortality Records CBS/SWOV). Note: Disease at age 0 is a factor 10 higher than presented here. For definitions of road crash and mortality see method section.

Gender differences in mortality from injuries

The development of unnatural mortality by gender and age are presented in Figure 2.3, and shows that unnatural mortality is higher among males than among females. This difference is already visible at a very early age (1-4 years old), but becomes larger as males get older, reaching its peak around age 20-24. The development of road fatalities reflects this pattern. Up to age $5-9$, road mortality is low and differs only slightly by gender. From age 10-14 it starts to rise for both sexes, but gender differences start to emerge from age 15. From age 15 onwards, road mortality of males is about a factor of three higher than that of females, indicating that already in pre-license teens, males have a higher road mortality rate that in magnitude resembles that of older males. 


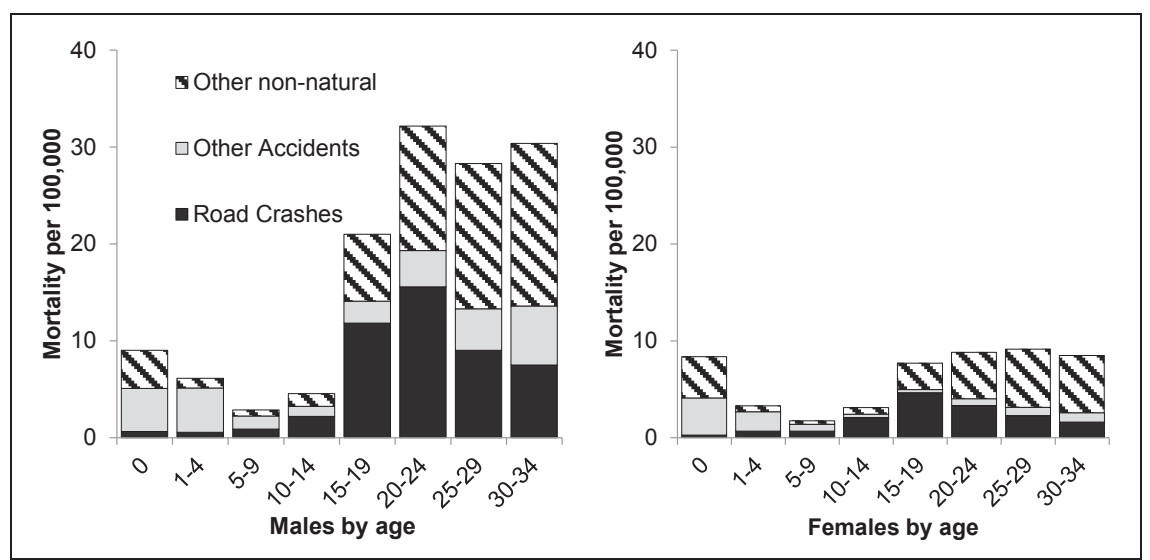

Figure 2.3. Yearly mortality for 'unnatural death' by age and gender per 100000 in each age group for the period 2002-2009 (source Dutch Mortality Records CBS/SWOV).

Road mortality among teens by traffic role, transport mode and gender

In terms of traffic roles - passengers or independent travel - the crash data show that the majority lose their lives travelling independently. Only a quarter of these youngsters die as passengers in cars, whereas the majority (72\%) lose their lives travelling independently as cyclists (40\%), moped riders $(24 \%)$ or as pedestrians $(8 \%)$.

There are also large gender differences (see Figure 2.4). First, males are overrepresented among all independent traffic roles but not in the passengers roles. Second, males are greatly overrepresented among fatally injured moped riders, whereas this is not the case for the other independent travel modes. Thus, hypothesis H5 inferring an overrepresentation of males is only confirmed for moped riders and not for the other independent travel modes. 


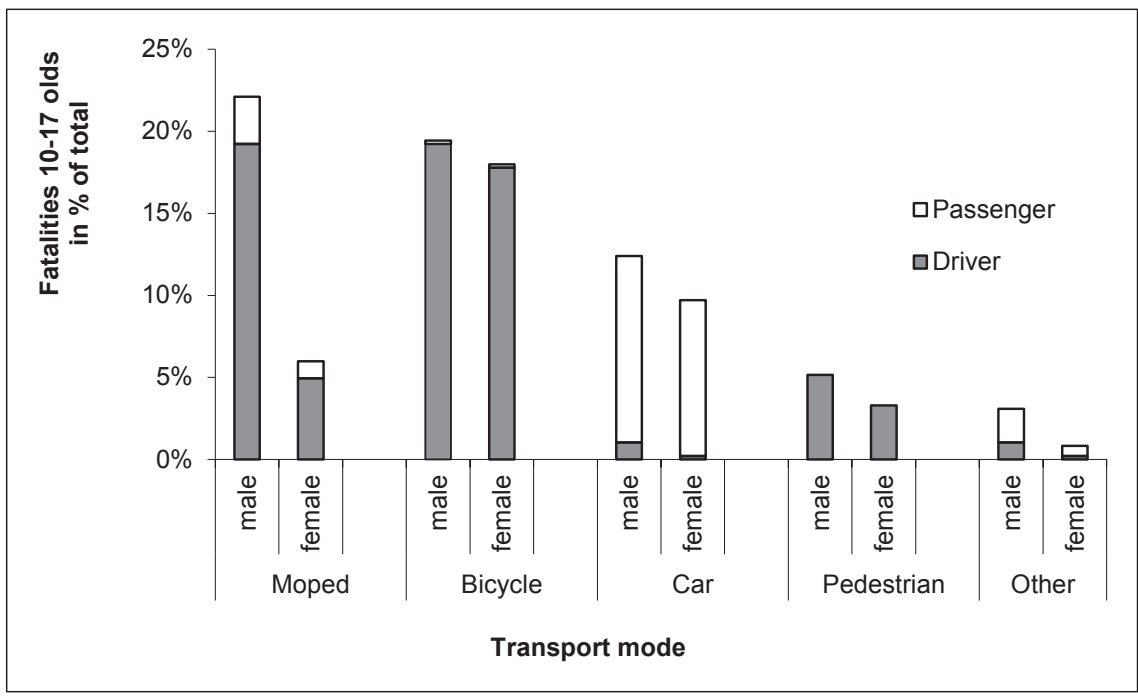

Figure 2.4. The distribution of fatalities among 10-17 year olds by transport mode and gender as a percentage of total road mortality in this age group irrespective of gender in the period 2002-2009 (data source BRON/SWOV).

Road risk: road mortality corrected for exposure

To compare the risk profiles of the different transport modes, fatality rates per distance travelled were calculated for males and females, and compared to the risk averages for the travel mode (see Figure 2.5). These risk averages show that, compared to the fatality risk of car passengers, the fatality risk of vulnerable road users is much higher. For cyclists this is a factor of 6 , for moped riders a factor of 25 , and for pedestrians a factor of 9 higher, which confirms that the earlier observed shift from being a car passenger as child to a vulnerable road user as a young adolescent indeed implies a migration from rather safe to far riskier modes of transport (H2). This is particularly the case for the 10 to 14 year olds because of the extremely low risk of car passengers, and to some lesser extent for the 15 to 17 year olds because of the rising risk of car passengers.

Regarding the role of experience, it was hypothesized that risks for moped riders would peak around age 16 and for cyclists at the start of the secondary school (age category 10-14), which would be followed by a steady decline (H4). Figure 2.5 shows that the initial risk of moped riders is indeed high, but that it differs in magnitude and trajectory for females and males. The initial risk of female moped riders is only half that of males, and whereas female risk steadily declines with age, that of males steadily increases up to age 20- 
24 before then decreasing. Also, cycle risk develops differently than expected. It does not show the expected peak in the age category 10-14, nor the expected gradual decrease because of growing experience in later age periods. Moreover, in contrast to moped risk, cycle risk does not differ in magnitude or in trajectory between males and females. Consequently, the large $40 \%$ share in the cycle fatalities is mainly a result of higher cycle mobility rather than of inexperience. Thus, $\mathrm{H} 4$ was not supported for cycling or for male moped riders. Only the risk trajectory of female moped riders is suggestive of a strong influence of inexperience.

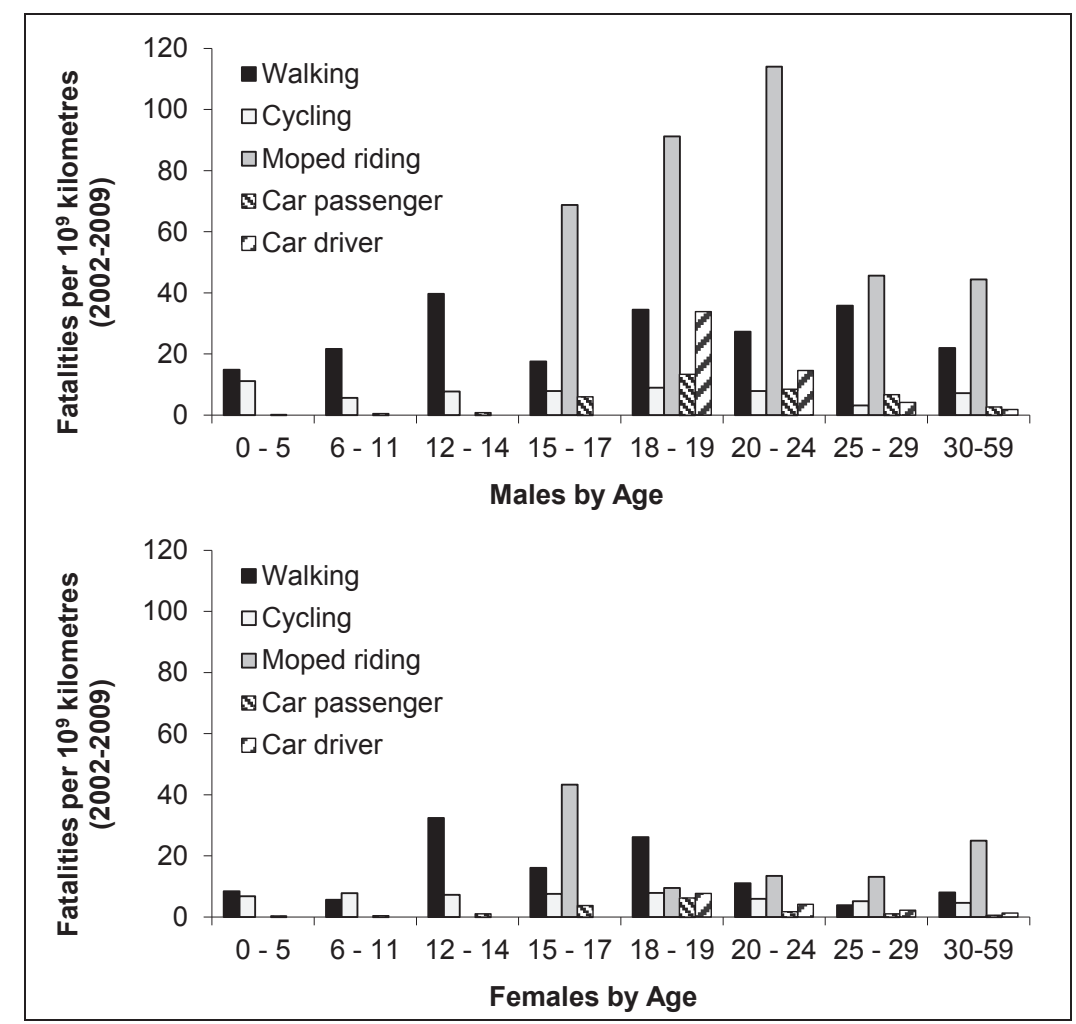

Figure 2.5. Involvement in fatal crashes per $10^{9}$ kilometres by gender, transport mode and age group. 'ALL' presents the average risk for all age groups ( 0 to $75+$ of age). (Data source CBSOVG, IenM-MON, years 2002-2009/ BRON/SWOV).

Regarding the influence of higher sensation seeking among males, it was expected that all three non-car traffic modes would be affected, showing higher risks for males than for females. Figure 2.5 shows that only among moped riders do males have a convincingly higher risk than females. No gender differences were observed in cycle risk in any of the age groups. For 
pedestrians, gender differences become apparent from age 18 onwards. Thus the expectation that the fatality risk of males would be higher than that of females (H5) was only confirmed for moped riders and pedestrians from age 18 , but not for cyclists.

\subsection{Discussion}

The results confirmed that in the Netherlands road mortality among young adolescents is higher than among children and that this rise is mainly the result of male and female adolescents travelling larger distances, becoming independent road users and users of riskier traffic modes, mainly bicycles and mopeds, while walking distances do not change. This shift requires further investigation in relation to trip conditions (e.g., time of day, day of week) and the attractiveness of alternative transport modes (e.g., being a passenger of a novice driver).

The results supported the hypothesis of higher road mortality among young males, but disaggregation of the data showed this to be primarily due to a high crash risk as moped riders, where factors such as inexperience and deliberate risk taking may play an additional role. In the age category 18 to 19 , the fatality risk of moped riding is about 3 times that of car drivers. In theory, this suggest that measures that encourage migration from car driving to moped riding, such as night-time and passenger restrictions, shown to be effective in reducing novice driver risks in early licensing countries (Vanlaar et al., 2009), may have detrimental effects in countries where moped riding is an attractive alternative to car driving (OECD-ECMT, 2006). In the Netherlands, this impact is still small as most youngsters use bicycles instead of mopeds. But in countries with a strong 'moped culture,' such as Italy and Greece, these impacts may be considerable. Indeed, in cities such as Rome and Athens, more road users are killed as moped and motorcycle riders than as car occupants (Shinar, 2012). Studies on the effects of measures on the modal split are needed to actually assess their effects on safety.

Compared to mopeds, cycling is relatively safe, but not compared to the low risk of car passengers, especially for the 10 to 14 year olds. For the 15 to 17 year olds, the risks of cycling do not change, but the risks of car passengers do. Their passenger risk increases, probably because of this age group now being more often passengers in a car with a novice driver at the wheel, while in the younger age group there is more often an experienced driver at the 
wheel (see an overview of the Dutch data on passenger risks and novice drivers: SWOV, 2012 ).

The study postulated effects on safety because of inexperience, and expected higher fatality rates per distance travelled for males compared to females. These expectations were not confirmed for cycling, as novel and unfamiliar cycle conditions did not result in higher fatality risk, and the risks of males and females did not differ, but were partially confirmed for mopeds. The unexpected finding for cycling may be related to early experience. In the Netherlands, on average children start cycling supervised by their caretakers from age 4 as part of their day-to-day trips (Van der Houwen et al., 2003). In this process they may develop skills that protect them from harm once they start cycling solo around age 8,5 in residential areas (Van der Houwen et al., 2003) and later around age 12 in city areas. This possible protective effect of early experience should be explored in order to enhance understanding of the interactive relationship between cycling competence and exposure to risk. The relevance of such a study is growing, because of recent trends that may decrease the levels of safe practice exactly at ages in which the child's brain is optimally 'wired' to learn new skills (Crone and Dahl, 2012). First, because of time pressure and perceived lack of safety, a growing group of parents prefers to transport their children by car rather than to accompany them on a bicycle (Van der Houwen et al., 2003). Second, because of the low status of cycling, children from non-western origins constituting $16 \%$ of the Dutch child population (CBS, 2009) prefer to use other means of transport (Harms, 2006). Not only would such a development affect cycling competence, it also has a negative impact on the health gains that are associated with active travel, and for cycling in particular (De Hartog et al., 2010)

The other finding that needs further exploration is the relatively low share of adolescent road fatalities in relation to the share of adolescents in the population. The study probably leads to an underestimate of the magnitude of the road safety problem because of this focus on road fatalities and the high physical resilience of young adolescents. A recent study of data from hospital discharges confirmed the 'high resilience' hypothesis, showing that for adolescents, the injury risk per distance travelled was the highest of all age groups, and about as high as that of the well-known high risk group of 75 and older (SWOV, 2009c), but that the proportion of seriously injured persons who died was much higher for the $75+$ age group $(20 \%)$ than for the age group 15 to 17 (3,5\%). However, little is known about the severity and 
long-term consequences of these road injuries among young adolescents. The national estimate that overall $4 \%$ of injuries will result in life long disabilities (Polinder et al., 2007), may not apply to this age group. Therefore, to assess the full impact of road crashes involving adolescents, further study is required into the long-term consequences of injuries. Most likely, the studied relationship between changing mobility patterns and road mortality is not unique to the Netherlands but may also apply to other late licensing European countries. Although the role of changing mobility patterns in these EU states could not be explored because of the absence of reliable data, the fatality data in the EU also shows fatality rates rising in early adolescence with higher rates for males (European Road Safety Observatory, 2010a, $2010 \mathrm{~b}$ ) and a high share (44\% ) of young male fatalities involving a motorized two-wheeler. Data from other European late licensing countries are thus suggestive of similar phenomena to be present, but more detailed comparisons among and between early and late licensing countries are needed to statistically test the generalizability of these results to other latelicensing countries and in addition, to assess the differential effects of licensing age on the mobility and safety of pre-license teens as well as that of teens at licensing age.

\subsection{Conclusion}

Given the goal of independent mobility in early adolescence, the present study examined changing mobility patterns with age and by gender and assessed the effects on road mortality and risk in an early licensing country. The study confirmed the importance of changes in mobility patterns for understanding the rising road mortality when youngsters enter into their teens. 



\title{
3. Theoretical perspectives, conceptual model and research questions
}

\begin{abstract}
The dissertation is set in the practical domain of road safety interventions, with a focus on road safety education (RSE). From this practical perspective, the study draws from a wide range of theoretical fields, such as safety theory, human factors, skill acquisition theory, and social, developmental and neuro-psychology. This chapter discusses the relevance of these perspectives for understanding adolescent road risk and the implications for effective road safety education. The chapter is concluded with a graphic presentation of a theoretical framework for the study of adolescent road risk and an overview of the research questions.
\end{abstract}

\subsection{Introduction}

While childhood is a relatively safe period, from age 10 onwards the frequency of road injuries and fatalities increases steadily, especially among young males. Inexperience, poor quality of the road system, and high exposure, such as the use of relatively risky transport modes and travel under more dangerous conditions, appear to contribute to this rise. This chapter reviews the scientific literature and aims to identify theoretical underpinnings of possible causes and effective countermeasures, the central question being: "Why do young adolescents behave in a risky manner in road traffic, and how can risky behaviour be prevented? Because a broad range of fundamental research fields are relevant for answering this question, and a thorough review of each of those fields is not feasible, this chapter is focussed on those theoretical perspectives that are relevant for the context, the research questions, and the approach of the studies conducted in the framework of this dissertation. The first domain, discussed in Section 3.2, is the science of how the traffic environment, in its broadest sense, affects the behaviour and safety of road users in general, and that of adolescents in particular. The second domain, discussed in Section 3.3, describes how humans control road hazards, and includes literature on topics such as skill acquisition, hazard awareness and perception. The third domain is the study of general theories of what motivates and deters adolescents from deliberately - behaving in a risky manner. This issue is discussed in Section 3.4. The fourth domain - Section 3.5 - deals with adolescent maturation and is more general in nature, and not specific to road safety. It aims to identify implications of findings on brain maturation for the understanding of 
adolescent road behaviour. The chapter is concluded in Section 3.6 with the research questions addressed in the dissertation and a conceptual model of the relationships among these questions.

\subsection{Theories on safe road systems}

For the understanding and prevention of road crashes and fatalities, two approaches are to be distinguished that fundamentally differ in their analysis of the nature of road risk and their approach to prevention strategies. The first, the individual approach, states that people crash because of their personal characteristics and decisions, resulting in unsafe road behaviour. The second, the safe system approach (OECD-ECMT, 2008), states that road users crash because of the user-unfriendly characteristics of the road system.

Two observations in road safety are central to both the individual perspective and the safe system approach (SSA), namely that human behaviour is directly or indirectly responsible for an estimated $96 \%$ of crashes (Sabey and Taylor, 1980), and that road crashes and injuries are not equally distributed in the road user population. Some road users have higher crash involvement than others (e.g.,Af Wåhlberg, 2009; Visser et al., 2007). Both approaches acknowledge this, but differ in their interpretation and implications. Whereas the individual approach aims to adapt road user performance to the demands of the road system, the safe system approach (SSA), in concurrence with Reason's theory on human error (1990), aims to understand how these errors are elicited by the design of the traffic system, in order to eliminate those conditions from the system. Haddon's theory on road safety, which is rooted in the epidemiology of infectious disease, is one of the earliest SSAs (Haddon, 1980a). His theory applies successful strategies from the control of 'disease' to the control of road injuries. Similar to more recent SSAs, it advocates a shift from an individual to a community-centred emphasis, integrating safety as part of the overall system. Haddon mentions the provision of purified milk and water, rather than relying on the individual's action of boiling milk and water before consumption, as an example of such a successful approach. He concludes: "It has been the consistent experience of public health agencies concerned with the reduction of other causes of morbidity and mortality that measures which do not require the continued, active cooperation of the public are much more efficacious than those which do" (Haddon, 1980a p. 416). Another inspiration for SSAs comes from human factors and aims to understand how individuals interact with systems, equipment and products. In his book "The design of 
everyday things", Norman (1988) applies concepts from human factors and describes compelling examples of poor product designs, showing how these designs lead people to make errors. Norman appeals to designers to ensure that errors are easy to detect, have minimal consequences and that their effects can be reversed. Similarly, the TRIPOD model, which is based on the so-called 'Swiss cheese model' (Wagenaar et al., 1990), has applied insights from human factors to the understanding of accident causation in a wide range of fields, such as the oil industry and the traffic system. Haddon's approach, Reason's model of human error, human factors, and operationalisations such as the TRIPOD model, have inspired later safe system approaches, such as 'sustainable safety' in the Netherlands (Wegman and Aarts, 2006), and 'vision zero' in Sweden (Tingvall and Haworth, 1999). See the recent OECD-ECMT report for a more detailed discussion on SSAs to road safety (2008).

For understanding adolescent road risk, SSA would primarily focus on hazards arising from the interaction of adolescents with the road system, and in terms of prevention would aim to eliminate those hazards that exceed adolescents' capacities. To test the relevance of the safe system approach, Chapter 8 uses this framework to assess the influence of the road system and the legal driver licensing age on the safety of young adolescents.

\subsection{The control of danger}

The control of danger is an inherent aspect of the task of moving safely in traffic. Because of high speeds, road users have to monitor continuously latent dangers and react to them. Drawing from cognitive psychology, skill acquisition theories, human factors and motivation theory, the strategies that road users apply to control these dangers have extensively been studied (see Cacciabue, 2007 for an overview). This section does not review these theories in detail, but only as related to the safety of young adolescents. For clarity, the theories are grouped into two categories: (a) task-competency and skill acquisition theories, and (b) theories of safety motivation. Task competency and skill acquisition theories are relevant for understanding whether adolescents may act in risky ways because of being inexperienced at the task. Theories of safety motivations are relevant for understanding whether adolescents may act in risky ways because they have strong motivation to be at risk; for instance because they enjoy the thrill. 


\subsubsection{Task competency and skill acquisition}

Task competency models use insights from cognitive psychology, ergonomics, and human factors to study the relationship between human capacities (e.g., memory, attention, perception) and the characteristics of the traffic task. These models define the traffic task as a dynamic decision task (DDT) that requires 'interdependent' decision-making in an environment that changes over time, either by previous actions of the decision maker or by events outside the control of the decision maker. Within this context, a road user reaches a decision by perceiving and selecting the relevant elements in the environment, by comprehending their meaning, and projecting their status in the near future' all within a limited amount of time and space (Endsley, 1995). Cyclists approaching an intersection to be crossed illustrate this process. Cyclists first need to perceive all relevant elements of the situation (e.g., what are the priority rules, how wide is the intersection, is a car approaching and at what speed?). This perception is followed by comprehension of the meaning (e.g., has the approaching car the right of way?), and projection of the status in the near future (given the speed of the car, the width of the intersection, and the cyclist's own speed and agility, is the available time sufficient to clear the intersection?). This effort demands integration of information from many different sources, and in heavy traffic, such decisions need to be made and carried out within a short time period of only seconds. The higher the information load and the shorter the time frame, the higher the workload, meaning that attention, memory and perception are easily overloaded (Grayson, 1981). Fortunately, the workload, is only partly determined by the traffic conditions, and is partly under the control of the individual road user. How a road user may reduce work load can again be illustrated by the example of the cyclist at the intersection. The cyclist may decide to select the shortest gap in the stream of cars, but may also wait for a longer gap. Whereas the first option may only be safe if every single one of the cyclist's assessments is correct, the second leaves room for incorrect assessments and may lead to safer outcomes. The car may go faster than estimated but because of the larger gap, the cyclist has still sufficient time to cross safely.

Task-competency models study how road users balance these task demands (what the task requires a road user to do) and task capabilities (what a road user is capable of doing), and postulate that danger arises when task demands exceed task capabilities. Examples of task-competency models include the model of subjective safety (Brown and Groeger, 1987), the task 
capability interface model (Fuller, 2005), the calibration model (see De Craen, 2010) and the zero risk theory (Summala, 1988). Although task-competency models were primarily developed and applied to study car driver behaviour and to understand the development of expertise in novice car drivers, these models are also valuable for understanding cycling performance, the task demands, and the acquisition of cycling skills. Unfortunately, studies on the development of cycling skills are relatively rare. An empirical study on cycling expertise among school aged children in the Netherlands showed that even in a country in which children start to cycle at a very early age (Van der Houwen et al., 2003), at age 12 basic skills such as balance, following a designated track and concentration on the task, have not yet reached expert levels (Brookhuis et al., 1987). These findings suggest that inexperience may contribute to risky decisions among young adolescents, and that interventions that accelerate the process of skill acquisition may be effective.

The development of such interventions requires - amongst other understanding - a thorough understanding of the process of skill acquisition. Studies into this process show that novices go through distinct stages of competence, progressing from knowledge based learning (knowing what to do) to skill based performance (knowing how to do it) (Anderson, 1982; Rasmussen, 1985). By extensive practice on the task, these routines become automated, which means that perceptions and actions no longer require conscious processing, and require little attention (Shriffrin and Schneider, 1977). Deliberate practice is essential for reaching 'expert' levels of performance (Ericsson et al., 2007). For traffic performance, in addition to the hours of deliberate practice to improve performance, a variety of traffic situations that differ in complexity adds to the achievement of expert levels. Complex situations, that are traffic situations with a high information load and short available decision time, require more practice than simple traffic situations with a low information load and long available decision times. Probably, such varied learning experience also helps one to learn to differentiate between those situations in which the trained routines apply and those in which they do not (Rothengatter, 1985). In Chapter 6 the taskcompetency models are used to assess the competency of young adolescents in negotiating a complex and potentially highly dangerous traffic situation, and the effects of road safety education) on the development of these skills.

\subsubsection{Safety motivation theories}

In contrast to task and competency models, motivational models assume that traffic participation is not just a task, and a road trip not just the result of a 
desire to go from $\mathrm{A}$ to $\mathrm{B}$, but an expression of numerous and frequently competing goals. These behaviour models have been used to understand all sorts of risky and health compromising behaviours, such as smoking, substance abuse, and unsafe sex.

The understanding of deliberate risk taking is central to these motivational models. Two theoretical perspectives are especially relevant for the discussion of deliberate risk taking among young adolescents. The first is that risk is not a negative characteristic, but also has positive connotations. Several authors (Näätänen and Summala, 1974; Wilde, 1982) postulate that road users pursue an optimal level of 'risk' and 'arousal'. While enjoying the excitement associated with risk taking, road users also aim to keep risk levels carefully within preferred boundaries. The second perspective is that of extra motives. Road travel is not just a task, but also a means to an end. Examples of such extra motives may be 'impressing peers', 'conforming to group norms', and 'tension release'. The role of extra motives in risk taking has been studied extensively for adolescent car drivers, but little is known about the influence of extra motives among young non-driving adolescent road users.

Both the theory on preferred levels of arousal and the theory on extra motives explain why after implementation safety countermeasures are frequently less effective than expected. The safety gains are partly lost because road users adapt their behaviour by taking extra risks (OECD, 1990). This finding has been demonstrated for many safety measures, such as safety belts (Janssen, 1994), airbags (Sagberg et al., 1997), helmet use (Kemler et al., 2009) and car drivers overtaking helmet-wearing cyclists (Walker, 2007).

\subsubsection{Implications for understanding unsafe acts}

The distinction between 'task-competency models' and 'safety motivation models' has implications for understanding risky acts, and for the design of prevention strategies. In the literature, many terms are used to refer to dangerous behaviours, often with detailed and refined classifications (e.g., Harré, 2000; Reason et al., 1990). Central to these classifications is the role of intention. Consistent with Reason's Generic Error Modelling System (GEMS)(1990), an unsafe act is defined as an 'error', if a person unintentionally deviates from the 'safe line of action'. For example, a red traffic light is overlooked, or the meaning of a traffic sign is misunderstood. These errors are elicited by factors such as inexperience, lack of competency, fatigue, or confusing traffic conditions. The task-competency models, discussed in the 
previous section, provide the theoretical framework for interpreting these errors. In contrast, intentional risky acts are deliberate transgressions of rules, procedures, and precautions. For instance, a cyclist sees the red traffic signal, but still decides to disobey it. Intentional risky acts originate from extra motives such as 'enjoying' risks (e.g., driving extremely fast on a motorway in the middle of the night) and impressing friends. Behaviour models discussed in the next section - provide the theoretical framework for understanding these dangerous decisions.

\subsection{Behaviour models of road risk in adolescence}

On motivation in general (Eccles and Wigfield, 2002) and on risk behaviour specifically, an abundance of behaviour models is available. In their handbook on health behaviour and health education, Glanz, Rimer \& Viswanath (2008) provide an overview of a large number of these models. This section limits the discussion to those models most frequently used in studies of the road safety of adolescents. To identify these highly used models, we examined the studies from one of the latest systematic reviews of risky road behaviour among young - 14 to 18 year old - car drivers (Strecher et al., 2007). After the exclusion of meta-analyses, narrative surveys and laboratory studies, 141 studies were available for further analysis. Table 3.1 shows that almost all studies (93\%) used one or more of the following models: health belief model (HBM), 31\%; the theory of planned behaviour/theory of reasoned action (TPB/TRA), 29\%; social cognitive theory (SCT), 27\% and problem behaviour theory (PBT), 9\%. These proportions did not differ among intervention studies, i.e., studies that assessed effects of an intervention, and prediction studies, i.e., studies that predicted risk behaviour from underlying behaviour determinants. In the remainder of this section first TPB/TRA and HBM will be discussed in more detail, followed by SCT and PBT. 


\begin{tabular}{lrrr}
\hline \multirow{2}{*}{ Models } & \multicolumn{3}{c}{ Study type } \\
\cline { 2 - 4 } & $\begin{array}{r}\text { Intervention } \\
\mathrm{n}=45\end{array}$ & $\begin{array}{r}\text { Prediction } \\
\mathrm{n}=96\end{array}$ & $\begin{array}{r}\text { All studies } \\
\mathrm{n}=141\end{array}$ \\
\hline Health belief model (HBM) & $33 \%$ & $29 \%$ & $31 \%$ \\
$\begin{array}{l}\text { Theory of reasoned action/Theory of } \\
\text { planned behaviour TRA/TPB }\end{array}$ & $27 \%$ & $32 \%$ & $29 \%$ \\
Social cognitive theory (SCT) & $36 \%$ & $21 \%$ & $27 \%$ \\
Problem behaviour theory (PBT) & $3 \%$ & $14 \%$ & $9 \%$ \\
Other theories $^{\text {a }}$ & $1 \%$ & $4 \%$ & $4 \%$ \\
\hline
\end{tabular}

Table 3.1. Frequency of behaviour models in studies of adolescent drivers, categorized by intervention and prediction studies based on the reported studies in the systematic review by Strecher et al (2007). Note: As models were also used in combination, the total frequency is larger than the total number of studies. a. 'Other theories' includes studies in which none of the above theories were used.

\subsubsection{Theory of Reasoned Action and Theory of Planned Behaviour (TRA/TPB), and Health Belief Model (HBM)}

TRA/TPB and HBM, both aim to predict behaviour and behaviour change from underlying behaviour determinants. Whereas TRA/TPB applies to all sorts of behaviour from buying a car to risk behaviour, HBM mainly applies to health-related behaviours. Here we concentrate on their use for predicting and explaining risk behaviour.

Central to TRA/TPB is the assumption that if people evaluate behaviour as positive (attitude), and assume that significant others want them to perform the behaviour (subjective norm), this deliberation results in a stronger motivation (intention) and a higher likelihood that they will perform the behaviour. TPB advances TRA by introducing the concept of perceived control over the opportunities, resources, and skills (Montano and Kasprzyk, 2008). Of all these relationships, behavioural intention is presumed to be the strongest predictor of actual behaviour, and has therefore frequently been used as an outcome criterion in evaluations of road safety interventions (Dragutinovic and Twisk, 2006).

Because the intention-behaviour relationship is central to the theory, and intention is frequently used in evaluation studies to assess the impact of an intervention, several reviews have assessed the actual strength of this relationship (e.g., Armitage and Conner, 2001; Webb and Sheeran, 2006). Based on a meta-analysis of 185 studies, mainly studies of correlations 
between intention and behaviour, Armitage \& Conner (2001) concluded that behavioural intention was a strong predictor of behaviour, accounting for $27 \%$ of the variance. However, correlation studies do not clarify the causality and the mechanisms in the relationship, nor do they provide information about the strength of a relationship after an intervention. To find an estimate of this strength, Webb \& Sheeran (2006) conducted a meta-analysis that only included studies that evaluated the effect of an intervention, and in addition met the following criteria: (a) random assignment of participants to treatment and control groups, (b) significant difference in intention scores between the treatment and control groups, and (c) follow-up of actual behaviour. The results confirmed the postulated mechanism of intentions changing behaviour, but compared to the Armitage \& Conner review, the strength of the relationship was considerably weaker. A medium-to-large change in intention resulted in only a small-to-medium change in behaviour. Therefore, the authors concluded that behaviour is not solely influenced by intention, but that the intention-behaviour relationship is mediated by other factors as well.

Unfortunately, the Webb \& Sheeran meta-analysis did not include studies on traffic behaviour, nor did it study the strength of the relationship specifically in an adolescent population. To the best of our knowledge such metaanalyses on the intention-behaviour relationship for road behaviour among adolescents are not available. However, some individual studies explicitly studied this relationship among adolescent road users. A prospective study on drink driving, for instance, showed that among a group of adolescents who had expressed a strong intention not to drink and drive, one year later about $40 \%$ reported having engaged in this risk behaviour (Gibbons et al., 2002). Further, a review of studies on health-compromising behaviour concluded that the strength of the intention-behaviour relationship was weaker in younger than in older age groups (Gerrard et al., 2008). The researchers pointed out, however, that this weak relationship could also be an artefact of the low variance in the extreme risk behaviours in the adolescent group.

Another aspect that potentially may weaken the relationship between behaviour and intention in traffic behaviour is the character of the traffic task itself. Traffic participation is a highly skilled task (Fuller, 2008), and road users with inadequate road skills may unintentionally engage in risky behaviour. This may specifically apply to adolescents. Because of being young, outgoing and novelty seeking, adolescents frequently travel in 
unfamiliar circumstances to unfamiliar places. These conditions are more demanding, and increase the likelihood of risky behaviours because of errors, miscalculations, distractions and the like.

To summarize, although intention predicts behaviour, in adolescence especially, behaviour may also be affected by many other factors. Potential factors are adolescents' psychological development (e.g., impulsiveness) and their inexperience. However, empirical studies are needed to test these relationships. Because the strength of the relationship between intention and behaviour remains unknown for adolescents, in this dissertation the effects of education programmes were assessed using self-reported behaviour as the outcome criterion, instead of intention (see Chapter 7).

The Health Belief Model (HBM) consists of the following preconditions for health behaviour and behaviour change: perceived susceptibility (persons perceive themselves to be susceptible to the illness or other harmful event); perceived severity; perceived barriers; cues to action; and self-efficacy (the belief that one can successfully perform the action required to produce the desired outcome) (Champion and Skinner, 2008). Thus in HBM, threat perception (perceived susceptibility and severity) and behavioural evaluation (perceived barriers, cues to action, and self-efficacy) are the two main components that motivate people to change their behaviour.

In a study on the relevance of HBM for adolescent risk behaviour, Reyna \& Farley (2006) reviewed the risk-related literature on adolescent beliefs regarding 'threat perception'. A similar study was reported by Fischhoff, Bruine de Bruin, Parker, Millstein \& Halpern-Felsher (2010). Although the results are mixed, in both studies the authors concluded that in contrast to popular beliefs, little evidence exists that adolescents feel invincible or that they underestimate the seriousness of events.

These findings have implications for countermeasures such as education. For example adolescents even overestimate their chances of dying (Fischhoff et al., 2010), yet based on models such as HBM, current education programmes frequently aim to modify 'threat perception' by informing youngsters about the risks they run and the serious consequences of road crashes. Moreover, since adolescent risk behaviour may not originate from underestimation of 'threats', programmes addressing this aspect may thus be less effective than often assumed. Within the framework of this dissertation, five education programmes were evaluated (Chapter 7). In line with HBM, two of these 
programmes aimed to change the perception of threat. The outcomes of these programmes were compared to those of programmes that were based on other approaches.

\subsubsection{Social cognitive theory (SCT) and problem behaviour theory (PBT)}

Whereas HBM and TRA/TPB focus on internal processes in relation to behaviour, social cognitive theory (SCT) and problem behaviour theory (PBT) emphasize the individual's interaction with and influence from the social environment.

Social cognitive theory (Bandura, 1989) is a 'social learning theory' that is based on five core concepts: observational learning/modelling, outcome expectations, self-efficacy, goal setting and self-regulation. Most of these concepts were also present in the previously discussed theories. Observational learning/modelling is an important element that seems unique for SCT. It refers to the phenomenon that people not only learn because of explicit instructions, but also by observing what others do. The theory positions actors as active agents in changing their circumstances. Because it is primarily a learning theory, it may accommodate most relevant factors in adolescent development, including transitions in terms of planning and control, the search for immediate gratification of needs, impulsiveness, and the adoption of new traffic roles.

Problem behaviour theory (PBT) also provides a framework for examining links between psychosocial characteristics, including personality and perceived social environment, and risky behaviour. The theory has frequently been applied to adolescent risk behaviour and specifically to risky driving (e.g., Bingham and Shope, 2004; Jessor, 1987; Jessor, 1992; Jessor et al., 1997). PBT recognizes three systems of variables: 'the behaviour system', 'the perceived environment system', and 'the personality system'. Regarding the behaviour system, Bingham and Shope (2004) describe PBT as classifying behaviour as conventional (i.e., socially prescribed/ encouraged) or problem behaviour (i.e., socially proscribed/ prohibited). The theory postulates that these problem behaviours tend to cluster in individuals, resulting in a 'problem behaviour syndrome'. The perceived-environment system includes factors such as social controls, models, and support systems (e.g., parents and friends). Finally, the personality system includes socio-cognitive variables such as values, expectations, beliefs, attitudes, and orientations toward self and society, thus resembling the elements and structure of TRA/TPB and HBM. 
PBT has particularly been applied to study adolescent risk behaviours, and several studies have used this theory and have showed that problem behaviour tends to cluster in individuals. However, to assess the relevance of this phenomenon of the co-occurrence of problem behaviour, the first question is how strong this connection is, and second, what proportion of youngsters is showing these clusters of problem behaviour? If the connection is strong and occurs in a large proportion of youngsters than prevention programs need to take this into account, whereas in the case of a weak relationship and a small proportion of youngsters than the urgency is far less. Some studies have demonstrated that problem behaviour and multi problem behaviour might even be rather seldom. Whereas adolescence is historically described as a troublesome period of deviance, mood swings, and high risk taking (Koops and Zuckerman, 2003), some recent empirical studies modify this image. For example, from a study on the prevalence of problem behaviour among Dutch adolescents (Junger et al., 2003), Westenberg (2008) concludes that a large majority acts 'perfectly normally, and that only $15 \%$ of youngsters report engaging in problem behaviour. Similar conclusions were reached in a study on happiness and well-being. A review of such studies even concluded, that the historical views of adolescence do not appear to apply to modern youth (Koops and Zuckerman, 2003).

The perceived environment, especially the family environment, can be a strong source of support for developing adolescents, especially if the family environment provides close relationships, adequate parenting skills, good communication, and positive role models. When these supports are lacking, or when parents engage in risky behaviours such as heavy drinking, the family environment may stimulate risk behaviour. By action and by example, parents shape the lives and the choices of their adolescent children (e.g., Parker and Benson, 2004; Resnick et al., 2004). For instance, adolescent car drivers and their parents hold very similar beliefs and exhibit similar driving styles (e.g., Bianchi and Summala, 2004; Ezinga et al., 2008; Taubman - BenAri et al., 2005), and youngsters whose fathers drink and drive also more frequently engage in that risk behaviour (Hjalmarsson and Lindquist, 2010). For young adolescents aged 10 to 17, however, little is known about these relationships.

In adolescence, the influence of parents decreases, while the influence of peers takes on continuously greater importance. This shift away from the family unit is an important component of the process of becoming an independent individual with adequate social skills, but also exposes the 
adolescent to high risks, sometimes as a result of - perceived - peer group pressure (see for a review Sumter et al., 2009). The negative influence of peer pressure has also been observed in risky road behaviour. For instance in simulated car driving, risky decisions increase in the presence of car passengers (Gardner and Steinberg, 2005), especially if the passenger is perceived as being attractive (Caird and White, 2009; Simons-Morton, 2009; White and Caird, 2009), or when the passenger is perceived as risk-accepting (Simons-Morton et al., 2014).

Inspired by SCT and PBT, this dissertation studied the co-occurrence of problem behaviours in young Dutch adolescents, and the relationship with the perceived presence of these behaviours in the adolescent's social environment (Chapter 5). Understanding these relationships can provide direction on prevention strategies. For youngsters who engage in several risky behaviours, prevention may be more effective by targeting the underlying risk-taking tendency, than by only focussing on one type of risky behaviour while ignoring the others. If the perceived social environment is a strong predictor of risk behaviour among young adolescents, interventions may be more successful by including the perceived social environment.

\subsection{Neuro-psychological theories}

Although the practical implications are still being explored (e.g., Paus, 2009), a review of adolescent risk behaviour is incomplete without a discussion of the recent findings on adolescent brain development. In the past, postmortem studies showed that in adolescence the structure of the brain is still changing. Only recently, it has become possible, by means of Magnetic Resonance Imaging (MRI) and functional MRI (fMRI), to observe the changes in the living brain unobtrusively and to study the effects of these changes on actual behaviour (Blakemore and Choudhury, 2006). The results from these MRI scans provided new insights into adolescent brain development. These findings, combined with results from laboratory studies on adolescent behaviour, indicate that 'typical adolescent behaviour' such as impulsiveness, risk taking, and sensation seeking may result from major structural changes in the adolescent brain. These structural changes involve two separate, but simultaneously developing processes in the brain that start around age 10: (a) structural changes in the brain cortex especially the pre-frontal cortex (PFC) and (b) heightened activation of the limbic system caused by puberty-related changes in hormonal activity. The changes in the brain cortex start with growth in grey matter (cortex), followed by a rise in the density and 
organisation of white matter, which serves as an isolating layer around the axons of the brain's neurons. This period of growth is followed by a period of 'synaptic pruning', resulting in a loss of grey matter (Giedd, 2008). Changes in both the grey and white matter, and the pruning of the nerve synapses, probably enhance the efficiency of information processing and cognitive control. The activation of the limbic system impacts brain systems related to emotions, motivations, and drives. Among other functions, these systems stimulate goal-directed behaviour, or to state it more plainly, determine 'how badly we want something'.

These two systems also play a role in adult behaviour and decision making, and are seen by some as the physiological base of the dual-processing model (Steinberg et al., 2008). Although detailed descriptions of the systems differ between authors, System 1 is described as the intuitive/socio-emotional system (limbic system) and System 2 is described as the reasoning and cognitive control system (cortex) (Gerrard et al., 2008; Gibbons et al., 2009; Kahneman, 2003a). In adolescence, these two systems change. But more importantly, they change at different paces.

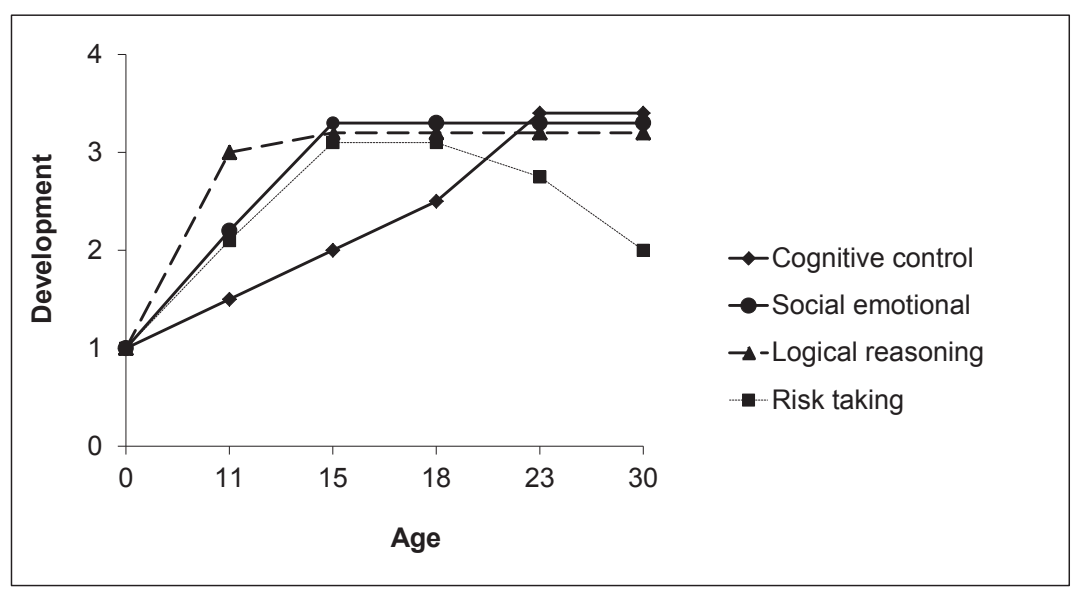

Figure 3.1. Schematic representation of the relevant developments in adolescence (Brijs et al., 2009) 
As illustrated in Figure 3.1, the socio-emotional system is characterized by an early and sharp activation (the limbic system), whereas the control functions located in the pre-frontal cortex develop much slower. In Steinberg's words, this difference in pace, results in a 'window of risky opportunities' (Steinberg, 2008). The limbic system is generating high emotions and high energy, while the control system is not able yet to channel and direct that energy 'wisely'. 'It is like turning on the engine of a car without a skilled driver at the wheel' (Steinberg quoted by Wallis (2008)). Even though the ability to think 'logically' has reached mature levels, this is not sufficient to deter adolescents from engaging in harmful activities in emotionally arousing (hot) conditions (Séguin et al., 2007).

Not surprisingly, these findings, which were generated under laboratory conditions, have also been generalized to understand the high crash rates in adolescence (e.g., Keating, 2007; Keating and Halpern-Felsher, 2008). Furthermore, the role of peers has been studied by observing the influence of passengers. Higher risk taking was found among young drivers when a peeraged passenger was present (Gardner and Steinberg, 2005), and when the passenger was perceived as sexually attractive (opposite sex pairs) (White and Caird, 2009), as 'cool' (same sex pairs) or as risk-accepting (SimonsMorton et al., 2014). Studies further confirm that driving decisions become more risky in emotionally arousing conditions.

This pattern of brain development and associated behaviour is not unique to humans, but has also been observed in primates and lower species such as rodents (Spear, 2000). This universal nature suggests that this pattern of brain development may not solely be dysfunctional, as could be concluded from the problems associated with it, but could have evolutionary advantages. Although hard to prove scientifically, several such advantages have been suggested. For instance, Spear (2000) postulates this pattern reduces the chance of inbreeding. In Spear's view, the growth of the grey matter, as well as the activation of the limbic systems would stimulate the acquisition of skills necessary for independence and survival away from parental caretakers, while the interaction with peers and exciting new experiences provide the setting to prepare for the 'great leap' in moving away from the natal family unit. Also Keating (2004) associates adolescent brain development with a high capacity for acquiring new skills, which is facilitated by challenges arising from interactions with novel physical and social environments. Not only are new skills acquired, but brain development also provides the adolescent with opportunities to recover from 
and to compensate for initial negative developments in early childhood. In line with these suggestions, Blakemore \& Choudhury (2006) speak of adolescence as a second 'sensitive' period in human development: the first, just after birth, with an initial high capacity for differentiating sensory inputs like sounds, facilitating language acquisition, and the second, in adolescence, with a high capacity for learning, facilitating skills vital for the adoption of adult roles. Therefore, adolescent brain development is not deterministic, reducing an adolescent's choices and activities, but instead is a result of a complex interaction between brain development and stimuli from the environment. Or as Johnson (2010) puts it in a reply to Males' thesis of research on adolescent brain development as being deterministic (Males, 2009), "Thus, for better or for worse, the brain comes to reflect its environment, which helps to explain the tremendous interindividual variability in trajectories of brain development in adolescence" (p.8).

Also, Paus (2009), in a review of studies into the brain development of adolescents, points to the conceptual complications of assuming a causal relationship between task performance and observed brain activity, as he states: "Quite often, we view developmental changes in brain structure as (biological) prerequisites of a particular cognitive ability. For example, the common logic assumes that cognitive/executive control of behaviour emerges in full only after the pre-frontal cortex reaches the adult-like level of structural maturity. But given the role of experience in shaping the brain, it might also be that high demands on cognitive control faced, for example, by young adolescents assuming adult roles due to family circumstances, may facilitate structural maturation of their pre-frontal cortex. This scenario, if proven correct, will move us away from the 'passive' view of brain development into one that emphasizes an active role of the individual and his/her environment in modulating the "biological" (e.g., hormonal) developmental processes" (p.110).

What are the implications of findings in this field for the present study? Clearly, within the scope of this dissertation, we cannot study the influence of biological maturation. Instead, the dissertation uses these insights to understand adolescent risk behaviour and in particular the question of how, in prevention strategies, to strike a balance between protection from harm and the provision of challenges to stimulate mental growth and development. 


\subsection{Conceptual model and research questions}

This chapter has presented an overview and discussion of the theoretical base relevant for the study of adolescent road risk and prevention strategies. The design of the studies and the analysis of the data in the studies presented in the remainder of the dissertation are, implicitly or explicitly, based on these theoretical underpinnings, which are discussed in more detail in the relevant chapters.

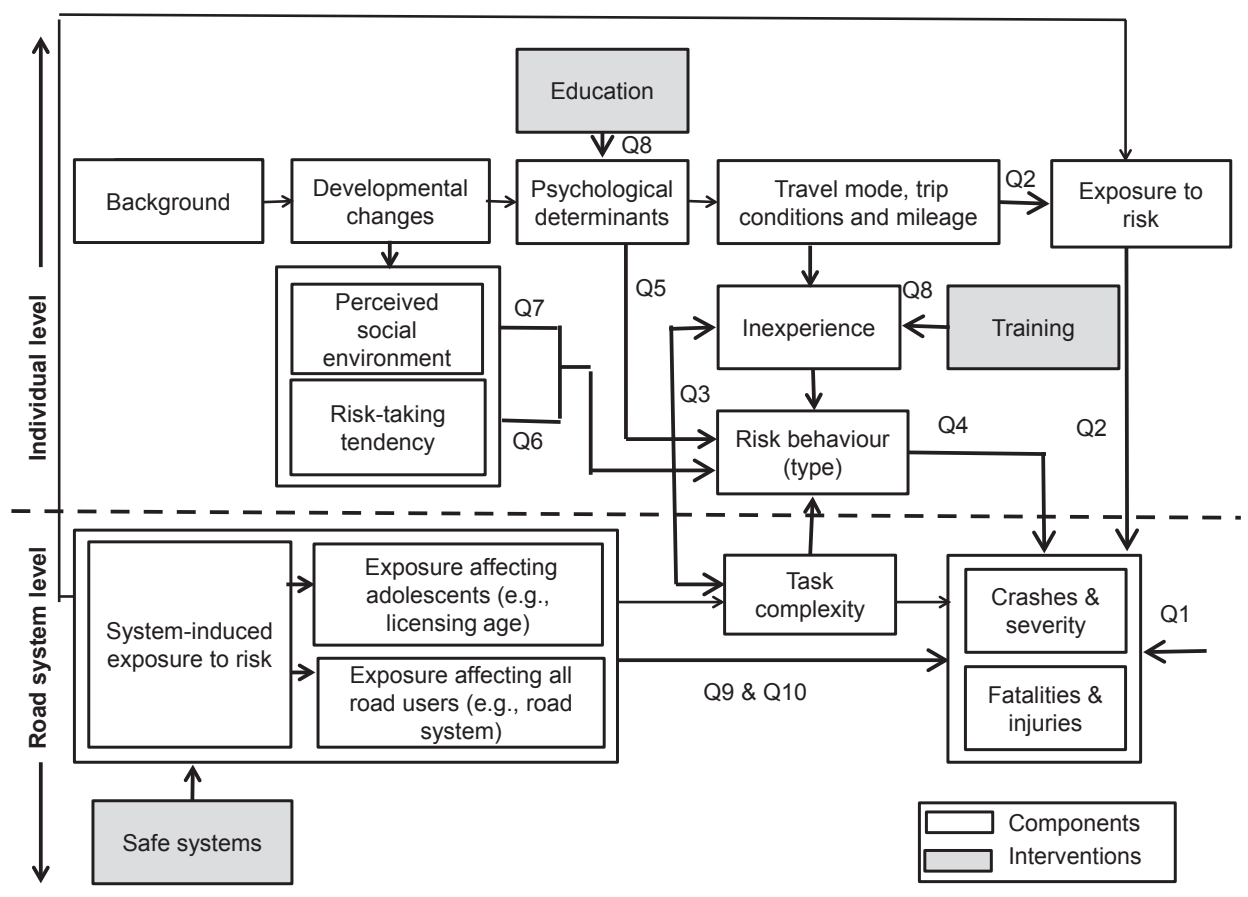

Figure 3.2. Conceptual framework of adolescent road risk composed of potentially contributing components and three interventions. Arrows in bold depict the relationships and numbered research questions addressed in the dissertation.

Figure 3.2 presents a conceptual model of the components and interventions addressed in the dissertation. Its structure is inspired by the Logic models on health behaviour and health behaviour change, as presented by Bartholomew et al. (2011). These health behaviour models, similar to our road risk model, consist of two levels: an individual level and a (road) system level. In the road risk model, the 'individual level' concerns the adolescent. It contains the more general characteristics such as maturation and risk-taking tendencies, and the perceived social environment, as well as 
the components that are specifically related to road safety, such as psychological determinants, road skills/inexperience, trip conditions, and exposure to risk.

The road system level concerns the traffic system as a whole, which entails the road infrastructure but also regulations such as legal alcohol levels, driver licensing age and vehicle requirements. The model shows that lack of safety - in terms of crashes, injuries and fatalities - is the result of chain of processes at both levels. At the individual level it is directly affected by changes in exposure and in risk behaviour. Changes in exposure result from two processes: changes in individual choices on how a person gets from A to $B$, and changes in the safety of the road system. Risk behaviour may originate from two traffic-related processes. From inexperience and poor road skills in relation to task complexity as was described by the taskcapacity models, and from psychological determinants such as poor knowledge, opinions and self-assessments. But there is probably also a relationship with adolescent maturation and brain development. In this context, this model focuses on the presence of a possible 'general risk-taking tendency' and the extent to which that tendency may also be related to traffic behaviour. In terms of general adolescent characteristics, the model also depicts the relationship between adolescent risk behaviour and the perceived social environment, especially the behaviours of friends, siblings, and parents.

In addition to these explored relationships, the dissertation reports on three intervention evaluation studies that were conducted. Two of these intervention studies targeted components at the individual level: 'Training' aimed to train skills necessary for safe behaviour in the vicinity of trucks, and education' aimed to change psychological determinants, such as beliefs and attitudes. The results of these evaluations are respectively reported in the Chapters 6 and 7. The third intervention concerned the effects of safe systems on adolescent mortality. Whereas the evaluation of the first two interventions was based on a study design in which the performance of an intervention group was compared to that of a control group, the 'safe system' evaluation was carried out by comparing mortality figures from countries with different levels of safe systems. The results are presented in Chapter 8.

The bold lines in Figure 3.3 depict the relationships addressed in the dissertation and also position the research questions, which are the following: 
Q1. What is the magnitude and nature of traffic mortality among young adolescents (10-17 years old) in a late-licensing country, such as the Netherlands? (Chapter 2)

Q2. To what extent do mobility patterns change in early adolescence and do these changes contribute to road mortality in this age group? (Chapter 2)

Q3. Are young adolescents sufficiently prepared to meet the task demands of complex traffic situations, such as dealing with blind spots? (Chapter 6)

Q4. What type of risky road behaviours do young adolescents engage in and are these predictive of crashes? (Chapter 4)

Q5. Are the psychological determinants of risk behaviour that are frequently targeted in RSE indeed predictive of risk behaviour? (Chapter 4)

Q6. Is risky road behaviour an expression of a more general tendency to behave in a risky manner in other domains, such as smoking and alcohol use, as well? (Chapter 5)

Q7. How strong is the relationship between adolescent risky behaviour and risky behaviour in their perceived social environment, especially the behaviour of parents, siblings and friends? (Chapter 5)

Q8. How effective are education programmes in changing risk behaviours? (Chapters 6 \& 7)

Q9. To what extent do safe road systems protect young adolescents from road harm? (Chapter 8 )

Q10. What is more beneficial for young adolescent safety - making a car driver license available for this age group, or licensing them at the later age of 18 , which restricts youngsters below the licensing age to the use of bicycles, mopeds, or to walking? (Chapter 8 ) 



\title{
4. The relationships among psychological determinants, risk behaviour, and road crashes: implications for RSE programmes ${ }^{7}$
}

\begin{abstract}
Road safety education (RSE) assumes that psychological determinants predict risk behaviour, and subsequently that risk behaviour predicts crash involvement. This study examined the validity of this assumption, by analysing these relationships in two age groups of teen cyclists and pedestrians: a younger age group (12 and 13 years old: $n=1372$ ) and an older age group (14 through 16 years old: $n=938$ ). A questionnaire was administered at school during regular class consisting of items on demographics, on risk behaviour based on the Generic Error Modelling System (GEMS), on psychological determinants targeted in RSE programmes, and on crash involvement. For both age groups, the results indicated that risk behaviour predicted crashes (young group $R^{2}=.05$; older group $R^{2}=.11$ ). Path analyses also confirmed that risk behaviour could be predicted from the psychological determinants, sharing respectively $44 \%$ of the variance in the younger age group and $34 \%$ in the older group. In conclusion, these results confirm the RSE assumption that psychological determinants are associated with a higher frequency of risk behaviours and that the latter are again associated with higher crash frequencies. Just as in earlier studies on adolescent risk behaviour, the GEMS based distinction between errors and violations was not confirmed, suggesting that this distinction - derived from studies on adult car drivers - may not apply to young adolescent cyclists and pedestrians.
\end{abstract}

\subsection{Introduction}

Road injuries are a prime cause of death among young adolescents. Much of this burden could be reduced if interventions were effective in preventing risk behaviour among these youngsters. Classroom-based road safety education (RSE) is one of the most commonly used interventions. But despite its popularity, little is known about its effectiveness (Dragutinovic and Twisk, 2006; SUPREME, 2007; Williams, 2007). Even the validity of the implicit assumptions about the relationships between the educational objectives - that is, what the RSE programme aims to achieve on the one hand, and risk behaviour and road crashes on the other - have seldom been empirically tested. To assess this relationship empirically, the present study

\footnotetext{
7 Submitted for publication as Twisk, D., Vlakveld, W., Commandeur, J., Shope, J. T., \& Kok, G., 2014. The relationships among psychological determinants, risk behaviour, and road crashes, and their implications for road safety education programmes. Journal of Transport Studies, Part F. (submitted 04-02-2014).
} 
examined the relationships between psychological determinants frequently targeted by RSE, risk behaviour and crashes among young adolescents of 12 to 16 years old. Note that the 'psychological determinants' investigated in this paper were not derived from earlier studies or theoretical models, but were based on their implicit use in education programmes. No systematic overview of these determinants is available yet, nor do RSE programme materials explicitly provide them. To overcome this, in this study psychological determinants were obtained based on the descriptions provided by professionals who were familiar with some frequently used RSE programmes. These descriptions indicated that RSE programmes for 12 to 13 year olds addressed one or more of the following psychological determinants: 'knowledge of traffic rules', 'opinions about traffic rules', 'carelessness', 'opinions about social behaviour', and 'hazard awareness'. RSE programmes for 14 to 16 year olds addressed 'opinions about traffic rules', 'attitudes on alcohol use in traffic', 'competencies in comparison to those of others' and 'feeling responsible for one's actions'.

Concerning the description and classification of risk behaviour, several models are available of which the Generic Error Modelling System (GEMS) is one of the most commonly used in road safety (Reason et al., 1990). GEMS provides evidence for two categories of risk behaviour - 'errors' and 'violations' - each governed by different psychological mechanisms, and each requiring different counteractive methods in RSE. Errors are unintentional deviations from safe practices and reflect inadequate skills (e.g., because of inexperience), or temporarily adverse states (e.g., because of fatigue). Violations, on the contrary, are deliberate deviations from safe practices (e.g., deliberately violating a red light), reflecting a person's safety motivation (e.g., a trade-off between risk and time lost). A recent metaanalysis on studies using the Driver Behaviour Questionnaire (DBQ) - a GEMS-based questionnaire - confirmed that for adult car drivers both violations and errors predicted crashes, with correlations of respectively .12 and .10 (De Winter and Dodou, 2010).

GEMS has also been used in studies on adolescent road behaviour. Table 4.1 presents an overview of the results of the four studies, showing that: (a) the expected 'violations' versus 'errors' factor structure was not found in some studies (Elliott and Baughan, 2004; Sullman and Mann, 2009), (b) the risk behaviour factors were highly intercorrelated (Feenstra et al., 2011; Steg and Van Brussel, 2009), and (c) in addition to 'errors' and 'violations' three other types of risk behaviour could be distinguished: 'dangerous play', 'lack of 
protective behaviour', and 'unsafe crossing' (Elliott and Baughan, 2004; Sullman and Mann, 2009). Further, only two studies investigated the association between risk behaviour types and crashes. The study among a large sample of Dutch cyclists found a positive association with crashes (Feenstra et al., 2011), whereas the study among Dutch moped riders did not find such an association, possibly due to a smaller sample size (Steg and Van Brussel, 2009). Thus, in these studies the factor structures as well as the association with crashes differ from those found in studies on car drivers. Several explanations have been offered for these differences such as the lower power in the studies, the way the items were formulated (e.g.,Steg and Van Brussel, 2009), or the specifics of the pedestrian and cyclist task (Elliott and Baughan, 2004). An additional explanation might the large age difference. In adolescence, thinking processes and social cognitions have been found to differ from those in adulthood, and also to undergo rapid changes when adolescence progresses towards adulthood (Blakemore et al., 2007; Blakemore and Choudhury, 2006; Spear, 2013). These features also affect the perception of the rationality and intentionality of behaviour in this period in life (Reyna and Farley, 2006). This may affect how risky behaviour is being perceived, either as an error or as a violation. Therefore the present study examined the role of errors and violations in two age groups: a younger group of 12 to 13 years old, and an older group of 14 to 16 years old.

\begin{tabular}{|c|c|c|c|c|c|c|}
\hline Study & $\begin{array}{l}\text { Road user } \\
\text { type (sample } \\
\text { size) }\end{array}$ & Age & $\begin{array}{l}\text { Factor } \\
\text { structure }\end{array}$ & $\begin{array}{l}\text { Explained } \\
\text { Variance } \\
\left(R^{2}\right)^{2}\end{array}$ & $\begin{array}{l}\text { Correlations } \\
\text { among } \\
\text { factors }\end{array}$ & $\begin{array}{l}\text { Relationship } \\
\text { with } \\
\text { crashes }\end{array}$ \\
\hline $\begin{array}{l}\text { Steg \& Van Brussel } \\
(2009) \\
\text { Netherlands }\end{array}$ & $\begin{array}{l}\text { Moped } \\
\text { riders } \\
(\mathrm{n}=146)\end{array}$ & $16-25$ & $\begin{array}{l}\text { - Errors } \\
\text { - Violations } \\
\text { - Lapses }\end{array}$ & $32 \%$ & $.39-.46$ & $\begin{array}{l}\text { Nagelkerke } \\
R^{2}=.05 \text { (n.s.) }\end{array}$ \\
\hline $\begin{array}{l}\text { Elliott \& Baughan } \\
\text { (2004) } \\
\text { United Kingdom }\end{array}$ & $\begin{array}{l}\text { Pedestrians } \\
\text { and } \\
\text { cyclists } \\
(\mathrm{n}=2433)\end{array}$ & $\begin{array}{l}11-12 \\
13-14 \\
15-16\end{array}$ & $\begin{array}{l}\text { - Dangerous play } \\
\text { - Lack of protective } \\
\text { behaviour } \\
\text { - Unsafe crossing }\end{array}$ & $34.6 \%$ & $\begin{array}{l}\text { Not } \\
\text { reported }\end{array}$ & $\begin{array}{l}\text { Not } \\
\text { investigated }\end{array}$ \\
\hline $\begin{array}{l}\text { Feenstra et al. } \\
(2011) \\
\text { Netherlands }\end{array}$ & $\begin{array}{l}\text { Cyclists } \\
(\mathrm{n}=1749)\end{array}$ & $13-18$ & $\begin{array}{l}\text { - Errors } \\
\text { - Violations } \\
\text { - Extreme } \\
\text { violations }\end{array}$ & $46 \%$ & $.56-.67$ & $\begin{array}{l}R^{2}=.04 \text { for } \\
\text { crashes and } R^{2} \\
=.15 \text { for near } \\
\text { misses } p<.01\end{array}$ \\
\hline $\begin{array}{l}\text { Sullman \& Mann } \\
(2009)^{1} \\
\text { New Zealand }\end{array}$ & $\begin{array}{l}\text { Pedestrians } \\
\text { and } \\
\text { cyclists } \\
(\mathrm{n}=944)\end{array}$ & $13-18$ & $\begin{array}{l}\text { - Dangerous play } \\
\text { - Lack of protective } \\
\text { behaviour } \\
\text { - Unsafe crossing }\end{array}$ & $32 \%$ & $\begin{array}{l}\text { Not } \\
\text { reported }\end{array}$ & $\begin{array}{l}\text { Not } \\
\text { investigated }\end{array}$ \\
\hline
\end{tabular}

Table 4.1 GEMS-based surveys for non-driving adolescent road risk behaviour. ${ }^{1}$ Replication of Elliott \& Baughan $2004{ }^{2}$ Part of the total variance explained by the factors in the 'Factor structure'. 
Also in adolescence a wider range of risk behaviour has been distinguished than in adulthood. Whereas GEMS primarily differentiates between errors and violations, two studies on adolescent risky road behaviour did not find this distinction but instead reported these three other factors: 'lack of protective behaviour', 'dangerous play' and 'unsafe crossing' (Elliott and Baughan, 2004; Sullman and Mann, 2009). Since the relationship of these additional factors with crashes is still unknown, the present study also endeavoured to assess the direct effects of lack of protective behaviour and dangerous play on road crashes.

The hypothetical model for this study is presented in Figure 4.1. It shows how the psychological determinants (e.g., knowledge of traffic rules) implicitly targeted by RSE affect four types of risk behaviour which in their turn influence crash risk. To test this hypothetical model for young adolescents, a questionnaire was developed and administered to Dutch cyclists and pedestrians of 12 to 16 years old. The following hypotheses were tested: (a) violations, errors, dangerous play and lack of protective behaviour are different types of risk behaviour (H1), (b) these risk behaviours are predictive of crashes $(\mathrm{H} 2)$, and (c) the psychological determinants frequently targeted in road safety education programmes predict risk behaviour and the effect of psychological determinants on crashes is therefore mediated by risk behaviour (H3). To assess the generalizability of the observed patterns, these hypotheses were tested in two age groups: the 12 to 13 year olds (the younger age group) and the 14 to 16 year olds (the older age group). 


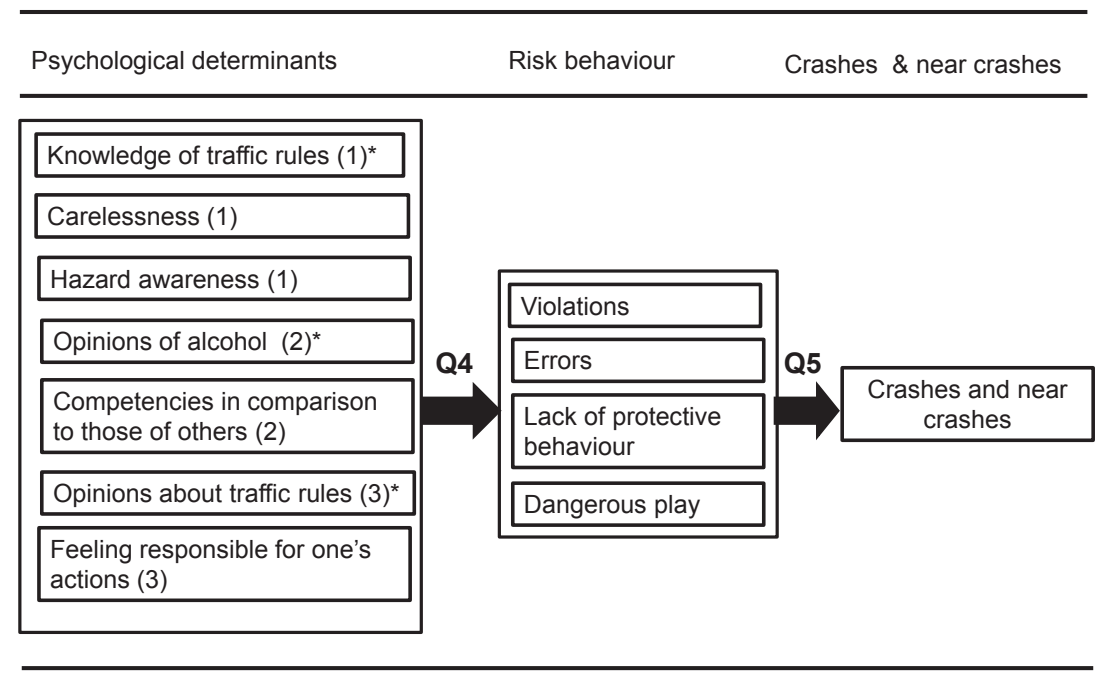

Figure 4.1. Hypothetical model of the presumed relationships on which RSE is based. 1 = younger age group, 2 = older age group, 3 = both age groups. The arrows depict the direction of the hypothesed relationships between psychological determinants, risk behaviour, and crashes and near crashes.

\subsection{Method}

\subsubsection{Sample and procedure}

The data for this study were obtained from a questionnaire used in the pre-test of an evaluation study of RSE programmes (reported in Twisk, Vlakveld, et al., 2014b). For this evaluation study, schools were recruited that used one of the evaluated education programmes on a regular basis - the intervention schools - and schools that were matched with the intervention schools in terms of level of education and geographical location, the reference schools. All schools were for secondary education, and included schools for higher secondary education, which prepares youngsters for university, and vocational education, which prepares youngsters for a specific job or function (e.g., carpentry or administration). Students from the intervention and reference schools completed the questionnaire in the pre-test phase of the evaluation study, during regular class at school. After completion, the questionnaires were handed in by the student in a self-sealed envelope. Participants were excluded from the analysis if information on 'bicycle use' was missing or if they reported not having cycled at all. This resulted in the removal from the analysis of 135 participants in the older 
age group. There were 1372 participants in the 12-13 years age group and 938 remaining participants in the $14-16$ years age group.

\subsubsection{Questionnaire}

The questionnaire - see Appendices A and B - consisted of five parts: (a) Demographics (D), (b) Exposure (E), (c) Risk Behaviour (RB), (d) Psychological Determinants (PD), and (e) Crash Frequency (CF). For RB, the Adolescent Road Behaviour Questionnaire (ARBQ) developed by Elliott \& Baughan (2004) was translated into Dutch and some items on pedestrian behaviour were replaced by items on cycling. Although the questionnaires were standardized in terms of topics, the RB items for the two age groups differed slightly to accommodate differences in mental and social maturation. The PD items were derived from previous studies: items on knowledge of traffic rules from Woldringh \& Katteler (2002), items on competencies in comparison to those of others from Adams-Guppy \& Guppy (1995), and items on hazard awareness from O'Brien, Rooney, Carey \& Fuller (2002). Where necessary, items were adapted to walking and cycling behaviour. For each subscale of the RB and PD items used in the questionnaire two example items are provided in Tables 4.3 and 4.4, respectively.

\subsubsection{Measures}

\section{Demographics (D) and Exposure (E)}

For the predictor variables on Demographics, information was obtained about the participants' gender, age, and the type of school that they attended: Vocational Secondary Education or Higher Secondary Education. Exposure was measured by means of a single item concerning the number of cycle trips per week.

\section{Types of Risk Behaviour (RB)}

Items were included to measure four types of risk behaviour: violations, errors (Reason et al., 1990), lack of protective behaviour, and dangerous play (Elliott and Baughan, 2004). Whereas errors were items referring to risky acts that were not intended to be risky, violations were intentional transgressions of a well-known rule. Dangerous play included all items referring to agerelated risk behaviours such as playing chicken or cycling so close together that handlebars almost touch. The RB section for the older age group contained such a small number of dangerous play items that this subscale had to be excluded from analysis. Lack of protective behaviour included 
intentional acts that lowered objective crash risk, but that were not based on a legal traffic rule, for instance 'crossing the road when cars have not stopped yet'. Responses to the items measuring risk behaviour consisted of six-point Likert scales (with categories ranging from 'never' $=1$ to 'always' $=6$ ). After recoding all items such that high scores always indicated risky behaviour, the internal consistency of each subscale was established using Cronbach's $\alpha$ (Cronbach, 1951).

\section{Psychological determinants (PD)}

For the PDs, the questionnaire contained different items for the two age groups. Therefore, separate data reduction procedures were carried out for each group, including reliability analysis per subscale, and descriptives of the non-missing items of subscales. For the younger age group, the PDs were: 'knowledge of traffic rules',' opinions about traffic rules', 'carelessness', 'opinions about social behaviour', and 'hazard awareness'. For the older age group, the PDs were: 'opinions about traffic rules', 'opinions of alcohol', 'competencies in comparison to those of others', and 'feeling responsible for one's actions'. After recoding all items such that high scores always indicated a 'risky' response, the internal consistency of each subscale was established using Cronbach's $\alpha$ (Cronbach, 1951).

\section{Crash Frequency (CF)}

In the younger age group, the CF variable was constructed by combining information from two items: a binary item on crash involvement (yes/no) followed by an item on the number of crashes. Negative responses to the binary item were coded as zero crashes. The questions were: 1 . Did you have an accident with your bicycle in the last year? Yes/no; 2. How many accidents did you have? Missing information on the binary item was coded as 'zero crashes', if the frequency item did not contain additional information. If, however, the frequency item contained information, that frequency was entered in the CF variable. In the older age group, CF was constructed summing the scores on three items: the frequency of material damage-only crashes, involvement in injury crashes, and the frequency of near-crashes. The questions were: 1 . Have you been in an accident in the last two years that only resulted in damage to your moped or bicycle? Yes/no; 2 . In the last two years, have you been in an accident that was so serious that you needed to see a doctor, or to go to a hospital? Yes/No; 3. How often did it happen that you almost had an accident, but that it did not happen? Very seldom, A few times a year, (almost) every month, (almost) every week. 


\subsubsection{Data analysis}

The following measures were used in the analysis:

- The mean score of all items on 'Risk behaviour' (RBTotal), and the four risk behaviour subscales ( $\mathrm{RB}_{1}$ to $\left.\mathrm{RB}_{4}\right)$;

- Psychological Determinants (PD) consisting of four subscales in the younger age group and three subscales in the older age group $\left(\mathrm{PD}_{1}, \ldots\right.$, $\mathrm{PD}_{3 /} \mathrm{PD}_{4}$ );

- $\quad$ Crashes/near miss frequency (CF);

- $\quad$ Exposure (E);

- Demographics (D) consisting of the variables: Gender, Age, and School type with categories Higher Secondary Education and Vocational Secondary Education.

For both age groups the following analyses were carried out. First, the validity of the RB subscales as predictors of crashes (CF) was assessed by means of a hierarchical multiple regression analysis with Crash Frequency (CF) as the dependent variable and the RB subscales as predictor variables, thereby controlling for Demographics (D) and Exposure (E), and entering the proximal variables $(\mathrm{RB})$ in the first block, the exposure variable (E) in the second block, and the most distal variables (D) in the last block: $C F=a+$ $\mathrm{b}_{1} \mathrm{RB}_{1}+\ldots . .+\mathrm{b}_{4} \mathrm{RB}_{4}+\mathrm{b}_{5} \mathrm{E}+\mathrm{b}_{6} \mathrm{D}_{1}+\ldots . .+\mathrm{b}_{9} \mathrm{D}_{4}$. The explained variance $\left(R^{2}\right)$ and the increment of the explained variance $\left(\Delta R^{2}\right)$ were used as indicators of the extent to which the predictors in the regression model contributed to the prediction of the dependent variable. The value of $\left(R^{2}\right)^{*}(100)$ represents the percentage of variance in the dependent variable that is explained by the predictors in the model. The value of $\left(\Delta R^{2}\right)^{*}(100)$ represents the additional percentage of variance that is explained by adding another set of predictors to the model. The standardised regression coefficient $(\beta)$ was used as an indicator of the degree to which each predictor affected the dependent variable, under the condition that the effects of all other predictors in the model are held constant. Under these conditions, the standardised regression coefficient represents the number of standard deviations $(S D)$ that the outcome variable changes as a result of one $S D$ change in the predictor variable. Possible multicollinearity between the predictors was assessed whereby variance inflation factor (VIF) values less than 5 were considered adequate (Field, 2009).

Second, to represent, estimate, and test the theoretical network of the linear relationships between the variables shown in Figure 1, path analyses were 
performed with AMOS for SPSS (Arbuckle, 2013). In contrast to regression analysis, in path analysis an observed variable can simultaneously be treated as an independent (exogenous) variable and as a dependent (endogenous) variable. Only the scales that were sufficiently internally consistent were included in the path analyses. For each age group, the path model was tested and a final model was developed in the following steps. First, to apply path analysis, respondents with one or more missing values had to be removed from the data set. The remaining data set was then randomly split into a calibration and a validation set. The calibration set was used to test the hypothetical model presented in Figure 1 and to develop the 'optimal' model with the best model fit. In the next step, this optimal model was validated on the validation data set. Several indices were used to assess model fit, and the following criteria were used to assess whether a satisfactory model had been found. The chi-square for the likelihood ratio test comparing a specific model and the saturated model had to be non-significant. The larger the $p$ value for this test, the better the fit (Bollen and Long, 1993). Further, the Goodness-offit index (Gfi) had to be larger than 0.90, the adjusted Goodness of fit index (agfi) had to be larger than 0.85, and the Root Mean Square Error of Approximation (rmsea) had to be smaller than 0.08 (Byrne, 2001). The best model was obtained by first trimming the hypothetical model applied to the calibration set, removing all statistically non-significant parameters, followed by iteratively freeing parameters as indicated by the modification indices, in order from largest to smallest index value, and thus continuing until further modifications only marginally improved the model fit.

\subsection{Results}

\subsubsection{Sample characteristics}

In Table 4.2, characteristics are presented of the 2310 participants. A comparison of the distribution by school type in the study sample and in the general population showed youngsters in Vocational Secondary Education to be underrepresented in the study. Only $40 \%$ in the younger age group and $21 \%$ in the older age group were enrolled in Vocational Secondary Education, whereas this percentage is about $50 \%$ in both groups in the general population. 


\begin{tabular}{lll}
\hline & $\begin{array}{l}\text { Young adolescents } \\
\text { Age 12-13 }\end{array}$ & $\begin{array}{l}\text { Older adolescents } \\
\text { Age 14-16 }\end{array}$ \\
\hline Sample size & 1372 & 938 \\
Gender (\% male) & $48 \%$ & $48 \%$ \\
\hline Age & 12 yrs. 73\% & 14 yrs. 24.5\% \\
& 13 yrs. 27\% & 15 yrs. 53.7\% \\
& & 16 yrs. 21.8\% \\
\hline Cycles almost every week & $99 \%$ & $92 \%$ \\
\hline Mean frequency of crashes (SD) & $0.95(1.74)$ & $4.45(1.60)^{*}$ \\
\hline School type $\quad$ Vocational Secondary Education & $40 \%$ & $21 \%$ \\
$\quad$ Higher Secondary Education & $48 \%$ & $79 \%$ \\
\hline
\end{tabular}

Table 4.2. Characteristics of the sample by age group. ${ }^{*}$ Includes crashes as well as near misses.

\subsubsection{Scale reliability of risk behaviour subtypes and psychological determinants}

For the risk behaviour subtypes, Table 4.3 presents two example items for each subscale and the results from the reliability analyses and mean scores and standard deviations by subscale and age group. High values indicate risky behaviour. Based on Kline's criterion (Kline, 1999) of a Cronbach's $\alpha$ larger than .70 indicating sufficient internal consistency, all risk behaviour subscales were internally consistent. 


\begin{tabular}{|c|c|c|c|c|}
\hline \multirow[b]{2}{*}{ Subscales } & \multicolumn{2}{|c|}{$\begin{array}{l}\text { Age group 12-13 } \\
n=1372\end{array}$} & \multicolumn{2}{|c|}{$\begin{array}{c}\text { Age group 14-16 } \\
n=938\end{array}$} \\
\hline & $\begin{array}{r}\text { Alpha } \\
\text { (\# items) }\end{array}$ & Mean $(S D)$ & $\begin{array}{r}\text { Alpha } \\
\text { (\#items) }\end{array}$ & Mean $(S D)$ \\
\hline $\begin{array}{l}\text { Errors ( } 1=\text { never, } 6=\text { always) } \\
\text { - As cyclist forgetting to } \\
\text { indicate when changing } \\
\text { directions } \\
\text { - } \quad \text { Needing to brake suddenly } \\
\text { because of having overlooked } \\
\text { an oncoming car }\end{array}$ & $.74(9)$ & $\begin{array}{r}1.94(.59) \\
n=1292\end{array}$ & $.78(11)$ & $\begin{array}{r}1.88(.55) \\
n=899\end{array}$ \\
\hline $\begin{array}{l}\text { Lack of protective behaviour } \\
\text { (1=always, } 6=\text { never) } \\
\text { - In darkness, only crossing the } \\
\text { street at the street light, } \\
\text { because of visibility for other } \\
\text { road users } \\
\text { - Cycling so close together that } \\
\text { handle bars almost touch }\end{array}$ & $.71(12)$ & $\begin{array}{r}3.31(.63) \\
\mathrm{n}=1297\end{array}$ & $.72(13)$ & $\begin{array}{r}2.63(.55) \\
\mathrm{n}=897\end{array}$ \\
\hline $\begin{array}{l}\text { Violations( } 1=\text { never, } 6=\text { always) } \\
\text { - Violating a red traffic light } \\
\text { - } \quad \text { As a cyclist having yourself } \\
\text { pulled by a moped rider }\end{array}$ & $.78(10)$ & $\begin{array}{r}1.81(.64) \\
\mathrm{n}=1324\end{array}$ & $.84(16)$ & $\begin{array}{r}1.87(.56) \\
\mathrm{n}=898\end{array}$ \\
\hline $\begin{array}{l}\text { Dangerous play (1=never, } 6=\text { always) } \\
\text { - } \quad \text { Roller blading between cars } \\
\text { - Forgetting to watch out } \\
\text { because of talking to friends }\end{array}$ & $.80(10)$ & $\begin{array}{r}2.10(.78) \\
\mathrm{n}=1313\end{array}$ & NA & NA \\
\hline All Items & $.91(41)$ & $\begin{array}{r}2.3(.55) \\
\mathrm{n}=1169\end{array}$ & $.91(40)$ & $\begin{array}{r}2.12(.51) \\
\mathrm{n}=848\end{array}$ \\
\hline
\end{tabular}

Table 4.3. Risk behaviour subscales with example items, and their reliability (Cronbach's Alpha) Note: Higher values indicate lower safety. Sample sizes vary since reliability analysis only includes cases without missing data.

Table 4.4 presents two example items of each psychological determinant, as well as the results from the reliability analyses of the items of each psychological determinant in the two age groups. For the younger age group, only 'Opinions about traffic rules' and 'Carelessness' satisfied Kline's criterion of Cronbach's $\alpha$ larger than .70 for internal consistency, whereas the reliability of 'Knowledge of traffic rules' was extremely low. 
- Schematic representations of traffic situations including a cyclist and $\mathrm{n}=1372^{1}$ other road users. The task was to select the correct cycle behaviour in that situation

Opinions about traffic rules ( 1 =totally disagree, 5=totally agree) (Woldringh \& $2.47(.69) \quad .74(6)$

Katteler, 2002)

- Traffic rules are often tedious

- I can decide for myself whether to obey the traffic rules or not

Carelessness ( $1=$ never $4=$ always )

\begin{tabular}{rr}
$2.34(.71)$ & $.73(5)$ \\
$\mathrm{n}=1316$ & \\
\hline $\begin{array}{r}2.62(.47) \\
\mathrm{n}=1291\end{array}$ & $.67(12)$
\end{tabular}

- If I have the right of way, I do not watch other traffic

- I do not take extra care in the vicinity of children

Feeling responsible for one's actions (1=totally disagree, 5=totally agree)

- I do not feel ashamed when acting dangerously
- If I only create danger for myself, then that is my own business

Hazard awareness (1=very dangerous, 3=not dangerous) (O'Brien et al., 2002) $1.72(.34) \quad .69(7)$
How dangerous is:

- Cycling in the dark without bicycle lights

- Being pulled by a lorry

\section{Age group 14-16 years $(\mathrm{n}=938)$}

\begin{tabular}{|c|c|c|}
\hline $\begin{array}{l}\text { Opinions about traffic rules ( } 1 \text { =totally disagree, } 5=\text { totally agree) } \\
\text { - I can decide for myself to adhere to traffic rules or not } \\
\text { - Traffic rules are not useful }\end{array}$ & $\begin{array}{r}2.73(.47) \\
\mathrm{n}=924\end{array}$ & $.56(5)$ \\
\hline $\begin{array}{l}\text { Opinions of alcohol ( } 1=\text { totally agree, } 5=\text { totally disagree) } \\
\text { - I disapprove of a cyclist being tipsy } \\
\text { - While partying one should be aware of how to get home safely }\end{array}$ & $\begin{array}{r}2.54(.82) \\
n=921\end{array}$ & $.77(4)$ \\
\hline $\begin{array}{l}\text { Competencies in comparison to those of others }(1=\text { much better, } 5=\mathrm{a} \text { lot worse) } \\
\text { (Adams-Guppy and Guppy, 1995) } \\
\text { - Hazard perception and anticipation in comparison to that of others } \\
\text { - Resistance to peer pressure in comparison to that of others }\end{array}$ & $\begin{array}{r}2.71(.65) \\
n=919\end{array}$ & $.70(4)$ \\
\hline $\begin{array}{l}\text { Feeling responsible for actions (1=totally agree, } 5=\text { totally disagree) } \\
\text { - To behave correctly in traffic is not just important for avoiding being } \\
\text { ticketed } \\
\text { - It is important for me not to get into dangerous situations because of my } \\
\text { own doing }\end{array}$ & $\begin{array}{r}2.57(.50) \\
n=868\end{array}$ & $.74(9)$ \\
\hline
\end{tabular}

Table 4.4. Psychological determinant subscales with example items, and their reliability (Cronbach's Alpha). Note: Higher values indicate lower safety. Sample sizes vary since a reliability analysis only includes cases without missing data.

For the older age group, all scales were sufficiently reliable with the exception of 'Opinions about traffic rules'. Because of their lack of internal consistency, 'Knowledge about traffic rules' for the younger age group and 'Opinions about traffic rules' for the older age group were excluded from 
further analyses. For the scales with sufficient internal consistency, the average score on the non-missing items was computed for each participant and used in the analyses.

The bivariate correlations between all the measures (the risk behaviour subscales, the psychological determinants, bicycle use (exposure), age, gender, school type, and crash frequency) are presented in Table 4.5, for each age group separately. Since these correlations only include participants without any missing values on all the measures at hand, there are $n=1131$ respondents in the younger age group and $n=901$ respondents in the older age group. Thus in the younger age group 241 participants were removed and from the older age group 37 participants. 


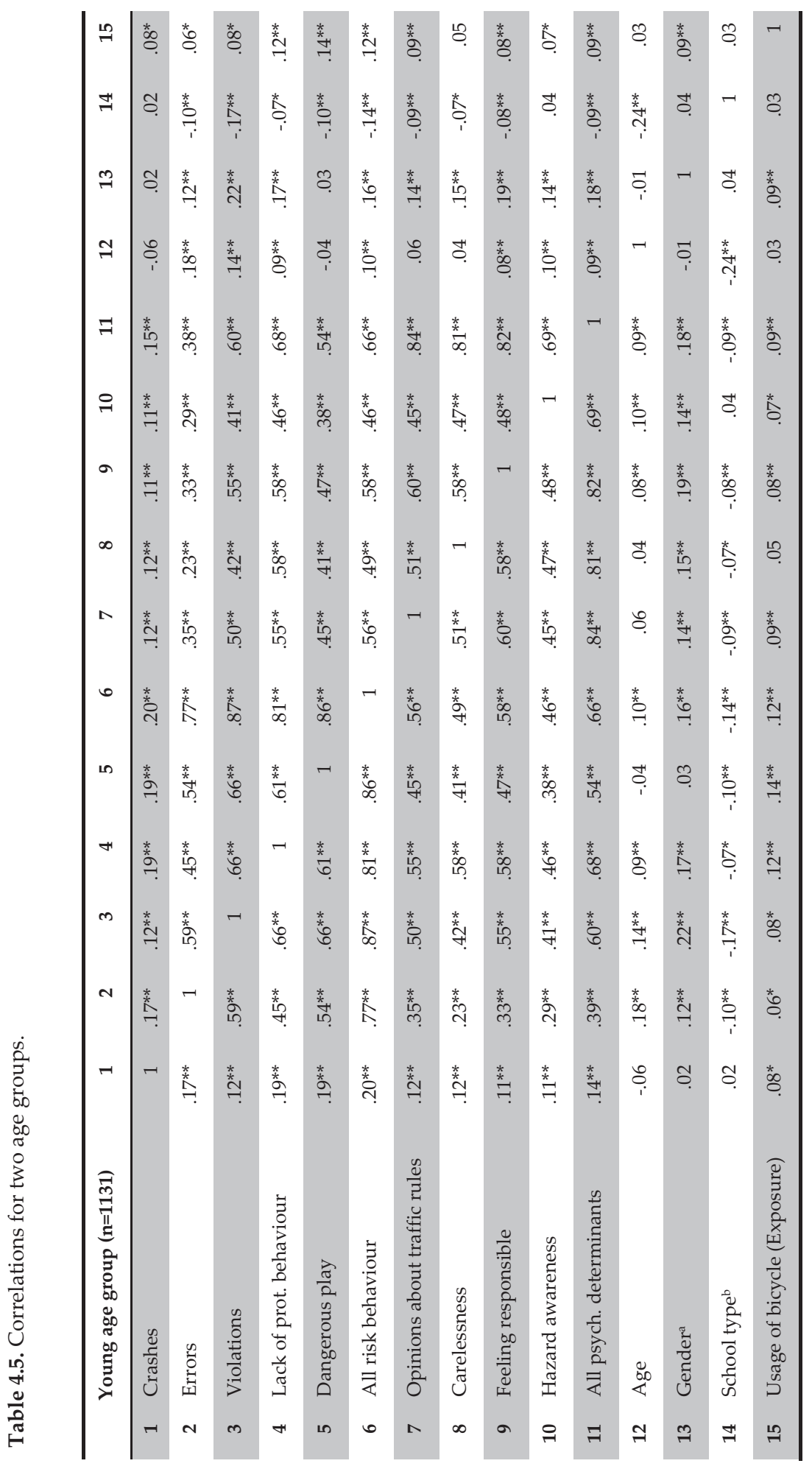




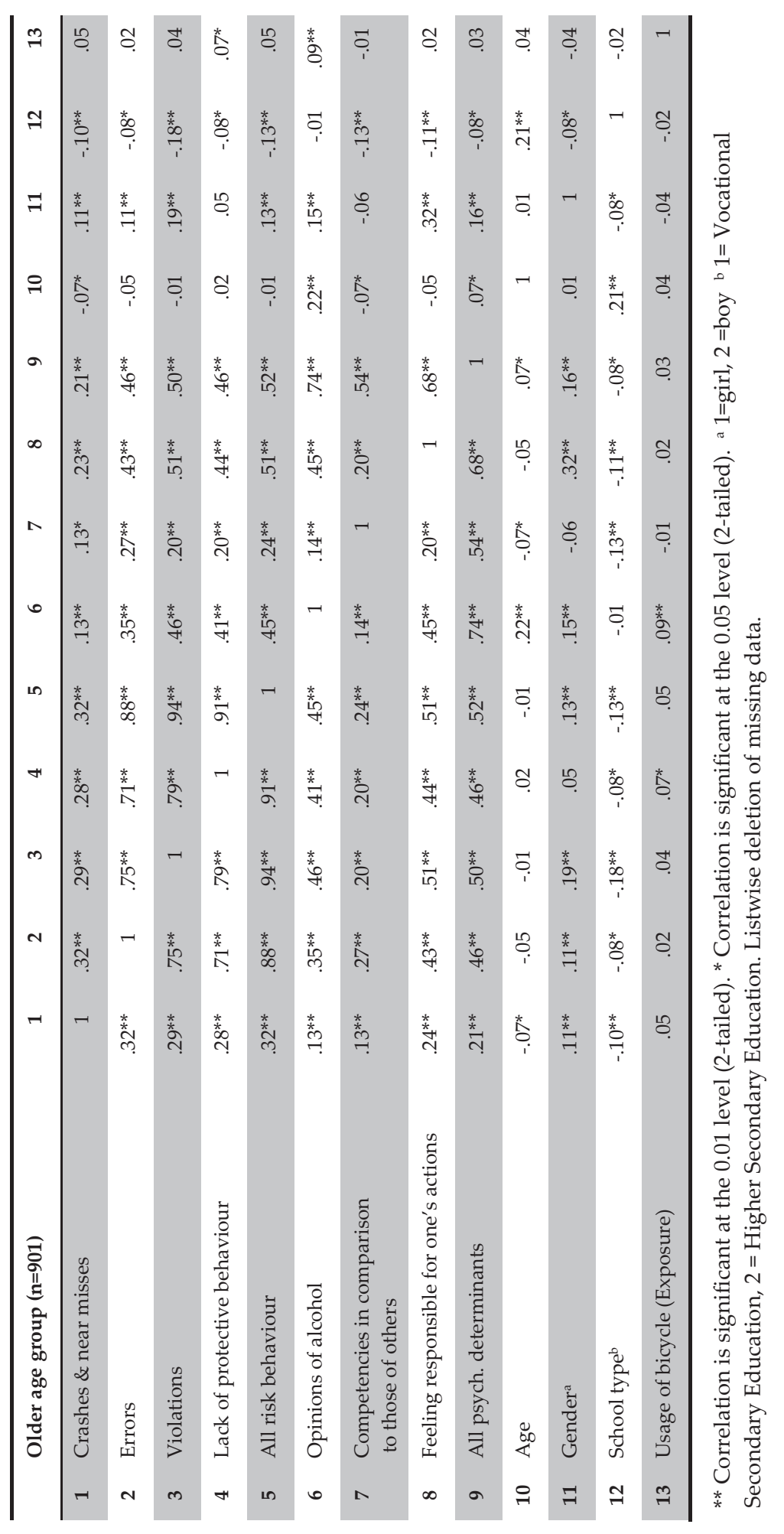




\subsubsection{Risk behaviour ( $R B)$ as a predictor of crashes}

The crash frequency variable for the younger age group was not normally distributed (skewness $=2.97, \mathrm{SD}=.07$; kurtosis $=11.13, S D=.13$ ), thereby violating one of the assumptions of regression analysis. For the older age group, the skewness of the crash frequency variable was acceptable $(1.2, S D=$ .08 ), but not the kurtosis $(1.02, S D=.16$ ). In SPSS (that we used for all analyses) values of skewness and kurtosis close to zero indicate normality. The values for skewness and kurtosis clearly indicate non-normality of crash frequency in the two age groups, and especially in the young group. However, as mentioned in the classic Tabachnick and Fidell (2007) book, a significant result for the deviation of skewness is not a problem in samples larger than 100, while the same applies to kurtosis in samples larger than 200.

\begin{tabular}{|c|c|c|c|c|c|c|c|c|c|}
\hline & \multirow[b]{2}{*}{$\begin{array}{l}\text { Step/ } \\
\text { Variable }\end{array}$} & \multicolumn{4}{|c|}{ Age group $12-13(n=1162)$} & \multicolumn{4}{|c|}{ Age group 14-16 $(n=915)$} \\
\hline & & $r$ & $\begin{array}{l}\text { Step } 1 \\
(p)\end{array}$ & $\begin{array}{c}\text { Step } 2 \\
(p)\end{array}$ & $\begin{array}{c}\text { Step } 3 \\
(p)\end{array}$ & $r$ & $\begin{array}{l}\text { Step } 1 \\
(p)\end{array}$ & $\begin{array}{c}\text { Step } 2 \\
(p)\end{array}$ & $\begin{array}{c}\text { Step } 3 \\
(p)\end{array}$ \\
\hline \multirow[t]{4}{*}{1.} & Errors & .17 & $\begin{array}{r}.11 \\
(.004)\end{array}$ & $\begin{array}{r}.11 \\
(.004)\end{array}$ & $\begin{array}{r}.12 \\
(.001)\end{array}$ & .32 & $\begin{array}{r}.20 \\
(.00)\end{array}$ & $\begin{array}{r}.20 \\
(.00)\end{array}$ & $\begin{array}{r}.20 \\
(.00)\end{array}$ \\
\hline & $\begin{array}{l}\text { Dangerous } \\
\text { play }\end{array}$ & .19 & $\begin{array}{r}.13 \\
(.002)\end{array}$ & $\begin{array}{r}\mathbf{. 1 2} \\
(.003)\end{array}$ & $\begin{array}{r}.10 \\
(.02)\end{array}$ & NA & NA & NA & NA \\
\hline & Violations & .12 & $\begin{array}{r}.11 \\
(.013) \\
\end{array}$ & $\begin{array}{r}-.11 \\
(.015) \\
\end{array}$ & $\begin{array}{r}.09 \\
(.04) \\
\end{array}$ & .29 & $\begin{array}{r}.09 \\
(.12) \\
\end{array}$ & $\begin{array}{r}.09 \\
(.12) \\
\end{array}$ & $\begin{array}{r}.04 \\
(.49) \\
\end{array}$ \\
\hline & $\begin{array}{l}\text { Lack of } \\
\text { protective } \\
\text { behaviour }\end{array}$ & .19 & $\begin{array}{r}.13 \\
(.001)\end{array}$ & $\begin{array}{r}.13 \\
(.001)\end{array}$ & $\begin{array}{r}.13 \\
(.001)\end{array}$ & .28 & $\begin{array}{r}.07 \\
(.16)\end{array}$ & $\begin{array}{r}.07 \\
(.20)\end{array}$ & $\begin{array}{r}.10 \\
(.07)\end{array}$ \\
\hline 2. & Exposure & .08 & & $\begin{array}{r}.05 \\
(.086) \\
\end{array}$ & $\begin{array}{r}.05 \\
(.075) \\
\end{array}$ & .05 & & $\begin{array}{r}.04 \\
(.22) \\
\end{array}$ & $\begin{array}{r}.04 \\
(.18) \\
\end{array}$ \\
\hline \multirow[t]{3}{*}{3.} & Age & -.06 & & & $\begin{array}{r}-.07 \\
(.02) \\
\end{array}$ & -.07 & & & $\begin{array}{r}-.06 \\
(.08) \\
\end{array}$ \\
\hline & Gender & .03 & & & $\begin{array}{r}.00 \\
(.91) \\
\end{array}$ & .11 & & & $\begin{array}{r}.07 \\
(.02) \\
\end{array}$ \\
\hline & School type & .02 & & & $\begin{array}{r}.02 \\
(.54)\end{array}$ & -.11 & & & $\begin{array}{l}-.06 \\
(.09)\end{array}$ \\
\hline$\Delta R^{2}$ & & & & .01 & --- & & & .00 & .01 \\
\hline$R^{2}$ & & & .05 & .06 & .06 & & .11 & .11 & .12 \\
\hline
\end{tabular}

Table 4.6. Correlations $(r)$ and hierarchical multiple regression analysis results for predicting crashes/near crashes in the two age groups: additional explained variance $\left(\Delta R^{2}\right)$ and standardized regression coefficients $(\beta) . \beta$ values in bold are significant $(p<.05)$

Hierarchical multiple regression on the prediction of crashes, see Table 4.6, show that the combination of risk behaviours explains $5 \%$ of the variance in crashes in the younger age group $\left(R^{2}=.05\right)$ and $11 \%$ in the older age group 
$\left(R^{2}=.11\right)$. For both groups, adding exposure in step 2 and the demographic variables in step 3 added little to the prediction $\left(\Delta R^{2}=.01\right)$. In the final model (step 3) several risk behaviour subtypes emerged as significant predictors in the young group: errors $(\beta=.12)$, dangerous play $(\beta=.10)$, lack of protective behaviour $(\beta=.13)$, violations $(\beta=-.09)$, together with age $(\beta=-.07)$. In the older age group only errors $(\beta=.20)$ and gender $(\beta=.07)$ were significant.

The standardized regression coefficients $(\beta)$ serve as indicators of the extent in which each predictor affects crash frequency, under the condition that the effects of all other predictors are kept constant. Further, as these coefficients are standardized, the values are comparable across predictors. As $\beta$ quantifies the effect, the $\beta$ of .20 for errors in the older age group, for example, entails that an increase of one standard deviation (SD) in errors is associated with an increase of .20 SD in crash frequency. In all analyses, the Variance Inflation Factor (VIF) statistics for multicollinearity of the predictors were satisfactory, the highest value being VIF $=3.53$ for 'violations' in step 3 of the older age group.

\subsubsection{The effects of Psychological Determinants (PD) on risk behaviour and crashes (CF)}

Path analysis in AMOS SPSS was applied to test the hypothetical model displayed in Figure 1, splitting the data set in a calibration and test set. For both age groups, the test on the calibration set - including all the variables of the hypothetical model - showed insufficient fit (see Section 2.4 for the criteria). Sufficiently fitting path models could only be obtained by replacing the four separate risk behaviour subtypes - errors, violations, dangerous play, and lack of protective behaviour - with the combined risk behaviour score. Figures 2 and 3 present the final optimal models fitted on the data sets of the younger and older age groups, respectively. The values above the arrows are the standardized path coefficients which can be compared across the relationships. Standardized path coefficients with absolute values less than 0.10 are indicative of a small effect. Values around 0.30 indicate a medium effect, and values larger than 0.50 are indicative of a large effect.

In the younger age group, most effects are small, with the exception of feeling responsible for one's actions, which has a medium sized effect $(\beta=$ .29). The four PDs explain $44 \%$ of the variance in risk behaviour $\left(R^{2}=.44\right)$. Age is a mediating variable between hazard awareness and crash frequency. The other demographic variables - gender and school type - did not contribute to the fit of the model. In total, $5 \%$ of the variance in crash 
frequency is explained by a combination of age and risk behaviour $\left(R^{2}=.05\right)$. There is no direct effect of the psychological determinants on crash frequency. All are indirect effects mediated by risk behaviour, with the exception of hazard awareness, which is also mediated by age.

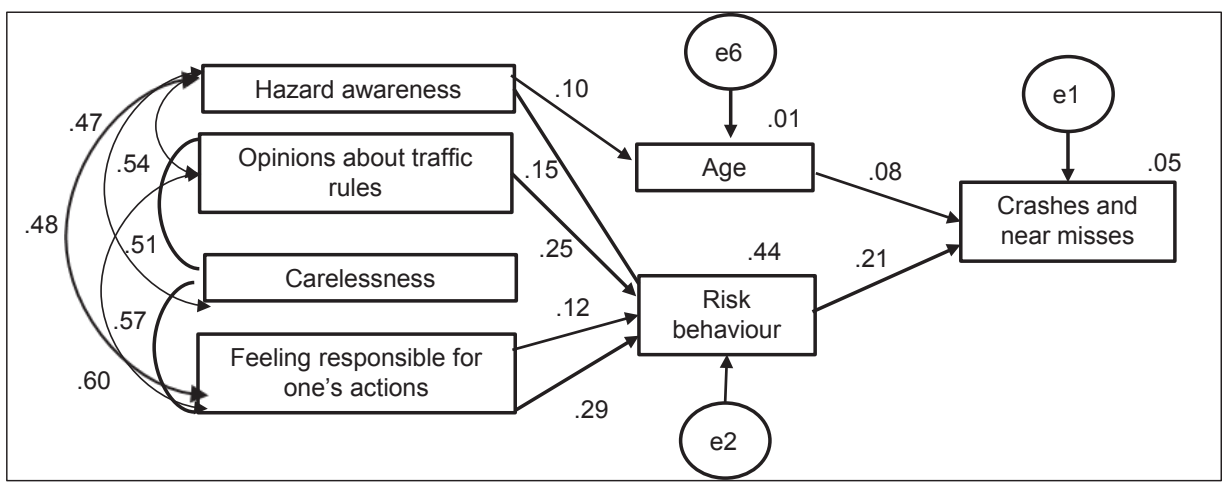

Figure 4.2. Final model for the younger age group $(n=1131)$ Standardized estimates: Chisquare $=8.230 \mathrm{df}=8 P=.41 \mathrm{Gfi}=.998$ agfi $=.993 \mathrm{rmsea}=.005$ pclose $=.998$.

The four remaining PDs explain $44 \%$ of the variance in 'Risk behaviour'. 'Age' is a mediating variable between 'Hazard awareness' and 'Crash frequency'. The other demographic variables - 'Gender' and 'School type' - did not contribute to the fit of the model. In total, $5 \%$ of the variance in 'Crash frequency' is explained by a combination of 'Age' and 'Risk behaviour'. There is no direct effect of the Psychological Determinants on 'Crash Frequency'. All are indirect effects mediated by 'Risk behaviour', with the exception of 'Hazard awareness' which is also mediated by 'Age'.

For the older age group, the final model presented in Figure 4.3 shows that $11 \%$ of the variance in 'Crashes and near crashes' was explained in the model, and $34 \%$ of the variance in 'Risk behaviour'. With the exception of 'Feeling responsible for one's actions', all effects of the Psychological Determinants are indirect, and mediated by 'Risk behaviour'. 


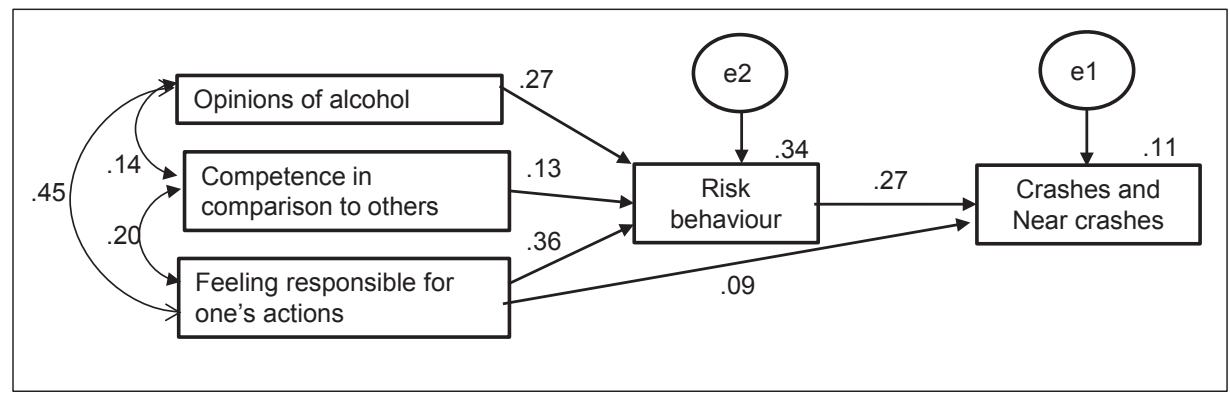

Figure 4.3. Final model for the older age group ( $n=901)$ Standardized estimates: Chisquare=3.917 $d f=2 P=.14 \mathrm{Gfi}=.998$ agfi $=.987$ rmsea $=.033$ pclose $=.655$.

For 'Feeling responsible for one's actions', the direct effect on 'Crashes and near crashes' is .09 while the indirect effect is $(.36)^{*}(.27)=0.10$. In terms of the magnitude of the effects, the standardized path coefficients are indicative of a medium direct effect on 'Risk behaviour' for 'Opinions about alcohol', and 'Feeling responsible for one's actions', and of a small direct effect for 'Competencies in comparison to those of others'. Further, there was a medium direct effect on 'Crashes and near crashes' for 'Risk behaviour', and a small direct effect for 'Feeling responsible for one's actions'.

\subsection{Discussion}

\subsubsection{Summary of results}

This study empirically tested the implicit assumptions of RSE concerning psychological determinants being predictive of risk behaviour, and subsequently risk behaviour being predictive of crashes. The results from the survey among young adolescents of 12 to 16 years old confirmed that selfreported risk behaviour predicted crashes, in both age groups, but the risk behaviour sub types - errors, violations, dangerous play, and lack of protective behaviour were highly correlated, which is suggestive of a common underlying factor. For the young age group, errors, dangerous play and lack of protective behaviour were all associated with increased crash involvement. However, the role of violations was hard to interpret because of a positive zero order effect, but a negative effect when combined with the other risk behaviour types. In the older age group only errors predicted crashes, whereas violations and lack of protective behaviour did not. 
Concerning the behaviour determinants knowledge about traffic rules in the young group and opinions about traffic rules in the older age group had to be excluded from further analyses because of the scale reliability being too low. In concurrence with the assumptions of RSE, in both age groups the remaining psychological determinants did predict risk behaviour, but these patterns did not differ for the different risk behaviour subtypes. In the younger group hazard awareness, opinions about traffic rules, carelessness, and feeling responsible for ones actions has a small to medium effect on risk behaviour. In the older age group, opinions about alcohol, competencies in comparison to those of others, and feeling responsible for one's actions predicted risk behaviour.

Further, the implicit assumption of RSE programmes that risk behaviour mediates the relationship between psychological determinants and crashes was confirmed. There were two additional effects. In the younger age group the effect of hazard awareness was mediated by age, and in the older age group feeling responsible for one's actions also had a direct effect on crashes. However, the different risk behaviour subtypes were not substantiated in the path analyses.

\subsubsection{Risk behaviour predicts crashes}

The finding that the different risk behaviour subtypes do not correspond with those found among mature car drivers is in line with the results obtained in earlier studies (Elliott and Baughan, 2004; Steg and Van Brussel, 2009; Sullman and Mann, 2009). The present study was not set up to test possible explanations, but confirmed the complex relationship of errors and violations with crashes. In contrast to expectations, in both age groups, violations did not play a role in the prediction of crashes, whereas errors did. This unexpected finding was mainly due to the fact that violations were even more strongly associated with the other risk behaviour types than errors were. Dangerous play, lack of protective behaviour, and violations all have in common that they reflect a more or less intentional action, whereas errors reflect an unintentional deviation from safe practices. This implicit dichotomy may contribute to the described differences between adults and young adolescents on the intentionality of behaviours. Adults frequently perceive their behaviour as conscious and intentional, while in fact it is automatic, with rationalisations after the fact rather than preceding it. Decision making among adolescents is more often a result of conscious deliberations in combination with impulsiveness (Blakemore et al., 2007; Blakemore and Frith, 2005; Reyna and Farley, 2006). The fact that young 
adolescents are slower than adults in deciding whether an action would be 'unwise' or 'dangerous' (Reyna and Farley, 2006), also in traffic (Feenstra et al., 2012), has been thought to be a result from that. For the development of questionnaires like the one used in the present study, as well as for the development of RSE programmes, the current models based on adult risk behaviour, such as Reason et al. (1990)'s Generic Error Modelling System (GEMS) may be inappropriate. A better understanding is needed of how adolescents interpret the origins of their actions, especially in relation to the role of intentionality.

Aside from a focus on risk behaviour, this study also assessed the influences of lack of protective behaviour. These behaviours are not motivated by traffic rules, but by a person's awareness of hazards. The results from the present study show lack of protective behaviour to be as strongly associated with crashes as risk behaviour. Moreover, since both age groups of youngsters seldom display protective behaviour, RSE programmes also need to find ways to stimulate these protective behaviours, rather than solely focus on risk behaviour. For example, the use of music players and mobile phones by cyclists and pedestrians is not forbidden by law, but safety would benefit if cyclists did not use them, as they deteriorate cycling performance (De Waard et al., 2010) and increase crash risk (Goldenbeld et al., 2012).

\subsubsection{Psychological determinants predictive of risky cycling behaviour}

Although most RSE programmes are not based on a thorough analysis of the possible relationships between psychological determinants and risk behaviour, most of those determinants targeted in RSE programmes were strongly associated with risk behaviour. Some of the 'hobbyhorses' of RSE programmes could not be tested because of internally inconsistent scales. This was the case for 'Knowledge about traffic rules' for example. The relevance of other 'hobbyhorses' was found to apply only to one age group; 'Opinions about traffic rules' for example, only had an effect in the younger age group. This conclusion needs to be treated with caution, though, since for the older age group the scale for 'Opinions about traffic rules' was not sufficiently reliable for inclusion in the analysis.

The influences of the factors Age, Gender and School type were all very small. The fact that the largest influences came from risk behaviour and risky psychological determinants means that there is no reason to especially target those subgroups of adolescents with a slightly higher crash risk, but rather to 
focus on all adolescents, regardless of age, gender and school type, who report engaging in risk behaviour and/or score high on risky psychological determinants.

\subsubsection{Study limitations}

To guide the interpretation of these findings several limitations need to be considered. The first limitation is the likelihood of Common Method Variance (CMV) (see Af Wåhlberg et al., 2010 for a thorough discussion on this topic). CMV is the variance attributable to measurement method, rather than to the constructs of interest. CMV may occur when all measures of behaviour, antecedents, and crashes are based on self-report and included in the same questionnaire, as is the case in the present study. Several psychological processes contribute to the occurrence of CMV, but 'consistency motives' and 'illusionary correlations' are the most relevant here. Podsakoff et al. (2003) describe consistency motives as 'the tendency of respondents to maintain consistency to similar questions and to organize information in a consistent way'. It is 'particularly problematic in those situations in which respondents are asked to provide retrospective accounts of their attitudes, perceptions and behaviours' (p. 881). Illusionary correlations result from the fact that '...raters often appear to possess assumptions concerning the co-occurrence of related items' (Berman and Kennyn (1976) quoted in Podsakoff et al. (2003 p. 881), such as the relationship between traffic crashes and aberrant behaviour. As discussed, this may also explain our findings on violations and errors. If a violation resulted in a crash, youngsters may well interpret the violation as being an error, since the road user would only have meant to violate the rules in situations where it was perceived to be safe to do so.

In addition to these psychological processes, the nature of the traffic task may also add to CMV. As most traffic behaviours are automatic and therefore escape conscious monitoring, events are stored as implicit memories that are not easily recalled. In the absence of direct feedback, road users may not become aware of the errors they make. Thus, not only will recall of risky behaviours be incomplete, it also will be biased towards actions under conscious control, such as intentional violations (Bradburn et al., 1987). Recall is not only imperfect for risk behaviours, it also is for crashes over a period of 10 years (Maycock et al., 1991). Thus, self-reported events may 'not reflect the actual covariation that exists between these events' (Podsakoff et al., 2003, p. 881). 
Another limitation concerns the correlational design of the present study. Such designs do not allow conclusions to be drawn about causality in the relationships, even though the present study frequently suggests that risky psychological determinants contribute to risk behaviour. Only in studies where the psychological determinant is manipulated experimentally can conclusions be drawn about the causality of the relationship.

\subsubsection{Conclusions}

This study shows that self-reported violations and errors known to predict crashes among adult car drivers may differ in the extent in which they predict crashes among young adolescent cyclists and pedestrians. In the latter group, only errors, dangerous play and lack of protective behaviours predicted crashes, whereas violations did not. To increase the robustness of this finding and to facilitate its use in RSE programmes, further research is needed into the ways in which adolescents classify their risky behaviours in terms of intentionality. As for the psychological determinants, the study shows that most of those addressed in RSE, but not all, are indeed predictors of risk behaviours. These findings in combination with further research could provide the underpinnings for evidence-based RSE programmes. 



\title{
5. The co-occurrence of problem behaviours in early adolescence, and the influence of the perceived social environment: Implications for interventions
}

\begin{abstract}
Problem behaviour theory (PBT) suggests that risky road behaviour in young adolescence is best understood as an expression of a tendency to engage in risky activities: a general risk tendency. Furthermore, the incidence of risk behaviour would be higher in adolescents who perceive their parents and peers (the perceived social environment) as engaging in these behaviours. Although such associations might have implications for the design of intervention strategies, little is known about these patterns among young Dutch adolescents. Objectives: This study examined (a) the co-occurrence of the risk behaviours, smoking, drinking, and gambling (General Risk Behaviours (GRB)) among Dutch adolescents and their association with Traffic-related Risk Behaviours (TRB), and (b) the relationships between adolescent risk behaviour and that in the perceived social environment (parents, siblings, and peers).
\end{abstract}

Method: Data from the 'Health Behaviour in School-aged Children' (HBSC) survey, conducted in 1991-1992 among 5360 Dutch adolescents (mean age 13.5; SD = 1.8) were reanalysed. As an exception, this version of the HBSC also contained questions on road behaviour.

Results: Regarding the co-occurrence of risk behaviour, the hierarchical regression with TRB as the dependent variable and GRB (smoking, drinking, and gambling) as the predictor showed that in addition to demographic characteristics, GRB significantly predicted TRB, sharing $7 \%$ of the variance. Regarding the influence of the perceived social environment, the hierarchical regression showed strong relationships for the GRB behaviours 'smoking', 'drinking' and 'gambling' among the adolescents and the presence of these behaviours in their perceived social environment, with the strongest relationships for these risk behaviours among peers. For adolescent TRB, the relationship with drunk driving by peers was low, whereas the association with drunk driving by parents was stronger. Partly, this relationship resulted from youngsters reporting having ridden as a passenger of a parent driver who had been drinking, and friends probably being too young to hold a driver license.

Conclusions: The analyses showed clear evidence for the co-occurrence of risk behaviours, as well as an association between risk behaviour and the perceived social environment. For TRB, parental behaviour predicted adolescent risk behaviour, whereas for GRB, peer behaviour was the strongest predictor.

\subsection{Introduction}

This chapter provides a study of multiple risk behaviours among adolescents, and their relationship with risk behaviours in the adolescents' 
social environment. The results from this study only serve as an illustration, because the data were obtained in 1991-1992 and may thus be outdated. Unfortunately, it is the only database to date in the Netherlands in which these risk patterns in relation to risky road behaviour can be studied. A recent inventory showed that even today the majority of studies in the Netherlands focus on single risk behaviours, such as smoking, petty crime, or risky road behaviour (Twisk and Stelling, 2014).

Adolescence is a period of great personal and physical growth that is characterized by many changes, such as a sharp increase in a wide range of risk behaviours, a growing importance of peers, and a decrease in parental supervision (Lerner and Steinberg, 2004). The sharp rise in different types of risk behaviour may suggest an underlying risk tendency that feeds these behaviours and that may result in youngsters engaging in multiple risk behaviours. The co-occurrence of such risk behaviours has extensively been studied, but primarily among adolescent car drivers (ages 17 to 24) (e.g., Bingham and Shope, 2004; Jessor, 1987; Jessor, 1992; Jessor et al., 1997; Junger et al., 1994), and to date not among young adolescents (10 to 17 years of age) in their roles as passengers, moped riders or cyclists. A related question is whether the incidence of adolescent risk behaviours is not only a characteristic of this specific phase in life, but whether it is also related to the incidence of risk behaviours in the adolescent's social environment.

These relationships are of great importance because they have implications for interventions. If risky road behaviour is strongly related to other risk behaviours, it could be more effective to target this underlying tendency, rather than targeting each risk behaviour in isolation. If risk behaviour is strongly related to the adolescent's social environment, then interventions should also take the influence of the social environment into account.

To contribute to the understanding of the co-occurrence of risk behaviours and the influence of the social environment in the Netherlands, the present study examined the co-occurrence of the risk behaviours, smoking, drinking, gambling and risky road behaviour among young Dutch adolescents and the relationship of these risk behaviours to risk behaviours in the adolescents' social environment (i.e., parents, siblings, and peers). To this end, data from the large-scale survey 'Health Behaviour in School-aged Children' (HBSC) on risk and health-compromising behaviour were reanalysed to provide answers to the following research questions: (a) Do the risk behaviours, 'drinking', 'smoking', 'gambling', and 'risky road behaviour' co-occur in early 
adolescence? And (b) to what extent is adolescent risk behaviour related to risk behaviour in their perceived social environment (parents, siblings, and peers)?

\subsection{Theoretical framework}

The study's theoretical framework is based on problem behaviour theory (PBT) (Jessor, 1992) and social cognitive theory (SCT) (Bandura, 1989). PBT is specifically designed to study the incidence of problem (i.e., risk) behaviours, their co-occurrence, and the influence of the social environment. The theory postulates that the activities of three systems influence problem behaviour: the 'behaviour system', 'the perceived environment', and the 'personality system'. The present study concerns the first two systems. The behaviour system classifies behaviour as conventional (i.e., socially prescribed/ encouraged) or problem behaviour (i.e., socially proscribed/ prohibited) (Bingham and Shope, 2004). The perceived environment system includes influences from the social environment (i.e., parents, friends, and relevant others) in terms of examples set, control exerted and support provided. The treatment of this system in PBT relies heavily on the concept of 'modelling' as used in SCT. Modelling refers to the phenomenon that people learn by imitating other people's actions. The phenomenon may account for the association between parental risk behaviour and that in adolescents, as was shown for risk behaviours such as alcohol use (Latendresse et al., 2008), smoking (Hampson et al., 2007; Morgan and Grube, 1989), driving style (Beck and Lockhart, 1992; Bianchi and Summala, 2004; Taubman - Ben-Ari et al., 2005) and drink-driving (Hjalmarsson and Lindquist, 2010).

Examples of influence from the perceived environment come from studies on peer pressure in adolescence (see for a review Sumter et al., 2009), showing that peer pressure, in combination with low confidence, increases risk behaviour. Several studies have addressed peer pressure in risky car driving and have shown that in a simulated car trip, the number of risky driving decisions increases in the presence of peer passengers, especially if the passenger is perceived as sexually attractive or 'cool' (Caird and White, 2009; Gardner and Steinberg, 2005; Simons-Morton, 2009; White and Caird, 2009), or as risk-accepting (Simons-Morton et al., 2014). These findings serve as an illustration of the relevance of the perceived social environment for the understanding of risky road behaviour. 


\subsection{Method}

\subsubsection{Instrument: the HBSC survey questionnaire}

Every four years, the HBSC survey, consisting of pre-set questions for young adolescents, is conducted in a large number of countries to monitor health risk behaviours such as smoking, drinking, gambling and unhealthy diets (see Dorsselaer et al., 2007 for a more detailed description). The standard HBSC survey does not contain items on traffic behaviour, but as an exception, the Dutch HBSC 1991-1992 version included several items on traffic behaviours. As previously mentioned, this version has resulted in the only database to date in the Netherlands that contains sufficient observations and items to allow a study of both the co-occurrence of risky road behaviours and other types of risk behaviour, and of the influence of the perceived social environment. Moreover, because the questionnaire was administered during class in school, the response rates are presumably high, which adds to the quality of the data. Unfortunately, this survey was conducted more than two decades ago and undoubtedly, these data do not reflect the current incidence of unsafe behaviour. Since then, the world has changed and adolescents have changed with it. However, both the co-occurrence of risk behaviours and the strong influence of the social environment are phenomena that are still considered today to be typical characteristics of adolescence (Lerner and Steinberg, 2004). Therefore, the HBSC 1991-1992 survey data may still provide information relevant for the understanding of present-day adolescent risk behaviour.

The 1991-92 HBSC survey, consisting of 168 pre-categorised items, was administered during class to a representative sample of schoolchildren in the Netherlands. In addition to items on demographics, the survey included items on tobacco use, alcohol consumption, gambling, perceptions of personal health and well-being, physical ailments, mental health, diet, perception of family relations and support, as well as bullying and school achievements. For tobacco use, alcohol consumption, gambling, and risky road behaviour, the HBSC survey contained both items on the behaviour of the adolescent and on that of parents, siblings and friends. The three items on the adolescent's traffic-related risk behaviour (TRB) referred to: 'Cycling or moped riding while under the influence of alcohol'; 'Riding as a passenger of a driver who had been drinking' and 'Not always wearing a seatbelt as a car passenger'. For risky road behaviour among parents, siblings and peers, only one item was available, namely 'Driving while intoxicated'. Whereas later 
versions of the HBSC survey also included items on injuries, the 1991-92 version did not. Table 5.1 shows the HBSC survey items used in the analyses. Whereas in the survey items regarding siblings, a differentiation was made between eldest sister and eldest brother, and for best friends, best male friend and best female friend, for the purpose of this analysis we did not use this differentiation but grouped these respectively as siblings and friends.

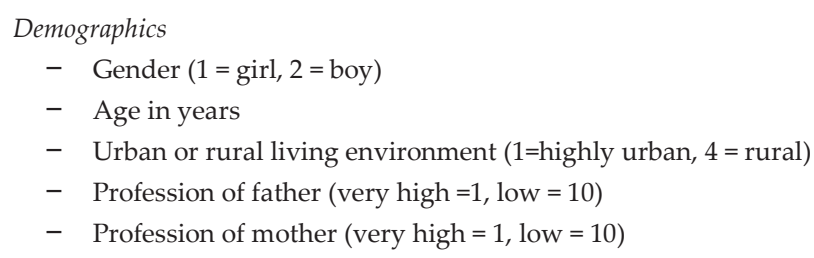

Adolescent risk behaviour

General Risk Behaviours adolescent (GRB)

- How much do you smoke in a week? (Number of cigarettes)

- Have you ever been drunk in the last 2 months? (Number of times)

- How often do you gamble? (1= never, $8=$ =very day)

Traffic-related Risk Behaviours adolescent (TRB)

- How often do you wear your seat belt? (1 = always, 4 = never)

- Have you ridden as a passenger with a driver (parents/ siblings/ friends) who had been drinking? For each driver type, (1= no, 2 = yes).

- When you were drunk, how did you get home? $(1=$ it did not happen, 2 = walk, passenger, public transport; 3 = on a bicycle or moped)

Risk behaviours in the perceived social environment

General risk behaviours (GRB)

- Do your parents/brother/sister/friends drink alcohol? For each group ( $1=$ never, $4=$ daily)

- Do your parents/brother/sister/friends smoke? For each group ( $1=$ no, 2 = yes)

- Do your parents/brother/sister/friends gamble? For each group ( $1=$ no, 2 = yes)

Traffic-related Risk behaviours (TRB)

- Do your parents/brother/sister/friends drive after drinking ( $1=$ no, 2 = yes)

Table 5.1. HBSC survey items used in the analyses.

\subsubsection{Sample}

The questionnaire was completed by 5360 youngsters, of whom $42 \%$ were female. The response rate was not available and could not be obtained so many years after data collection. Mean age was 13.5 years $(S D=1.8)$. The age 
distribution was as follows: $11-12$ years, $31 \% ; 13-17,67 \%$; and $2 \%$ were older than 17 . In terms of schooling, 30\% attended primary school, and $70 \%$ were in secondary education. About half (45\%) the sample came from urban areas (middle large and large towns) and the other half (55\%) from rural areas.

\subsubsection{Measures}

Reverse-phrased items were recoded such that low scores indicated safe/healthy/positive behaviours. Where the risk behaviour response was not present, missing values were replaced with a score indicating an absence of the problem behaviour, resulting in a conservative estimate of the prevalence of the specific risk behaviour.

Table 5.2 shows the distribution of risk behaviours in the sample by gender. All risk behaviours were reported sufficiently frequently for further use in the analyses. With the exception of riding with a driver who had been drinking, the incidence of risk behaviours was higher among boys than among girls. Among girls, 58\% had engaged at least once in any of the Traffic-related Risk Behaviours (TRB), and 37\% in any of the other General Risk Behaviours (GRB). Among boys, these percentages were higher, respectively 62 and $53 \%$.

\begin{tabular}{lcc}
\hline Risk Behaviours among adolescents & $\begin{array}{c}\text { Girls } \\
\mathrm{n}=2260\end{array}$ & $\begin{array}{c}\text { Boys } \\
\mathrm{n}=3100\end{array}$ \\
& $\%$ & $\%$ \\
\hline Has engaged at least once in any of the Traffic-related Risk Behaviours (TRB) & 58 & 62 \\
Drunk on cycle or moped & 3 & 9 \\
Passenger of a drinking driver & 20 & 20 \\
Not wearing seat belts & 48 & 53 \\
Has engaged in one of the General (non-traffic) Risk Behaviour (GRB) & 37 & 53 \\
Been drunk in the last two month s & 10 & 15 \\
Gambles & 25 & 45 \\
Uses tobacco & 17 & 18 \\
\hline
\end{tabular}

Table 5.2. The presence of risk behaviour by gender and risk type.

For the GRBs 'smoking', 'gambling' and 'drinking', the questionnaire contained equivalent questions for adolescent risk behaviour, and for the risk behaviour exhibited by parents, siblings and friends. This feature enabled a direct comparison between the adolescent risk behaviour and the presence of 
risk behaviour in the perceived social environment. Unfortunately for traffic behaviour, this was not the case. Whereas adolescent road risk behaviour was assessed using three traffic items, the presence of road risk behaviour in the social environment was measured by one single item, 'Driving under the influence of alcohol'. Moreover, this item did not correspond directly with any items on adolescent behaviour. Therefore, a composite score for adolescent TRB was constructed. However, the items of the TRB total did not reflect a single scale because the reliability was low $(\alpha=.09)$ and did not meet Kline's criterion of a Cronbach's $\alpha$ larger than .70. for a scale to be internally consistent (Kline, 1999). Therefore, the sum of scores on the TRB total was only used as an index - not a scale - of the 'total level of risk'. High totals indicated unsafe behaviour $(\min =5, \max =13$ ), because of each item of the index being associated with an objectively higher crash risk.

\subsubsection{Data analyses}

Correlation analyses were used to examine the strength of the associations among the individual risk factors contained in the multiple risk behaviour scores for GRB and TRB.

The association between risk behaviours in the perceived social environment and risk behaviours among adolescents was analysed using hierarchical regression. Separate hierarchical regressions were carried out for each risk behaviour type as the dependent variable (i.e., drinking, smoking, gambling, and $T R B_{\text {total }}$. In all four of these regressions, the first step contained the demographic variables as predictors (see Table 5.1. for an overview of these variables), the second step the parental risk behaviours (fathers and mothers), the third step the risk behaviours of siblings (eldest brother and eldest sister), and the fourth that of friends (best male friend and best female friend). The order of these steps reflected the relevance of the different groups in the maturation process of an individual (Jessor, 1992).

To examine the extent to which GRB - drinking, smoking and gambling predicted TRB total, a hierarchical regression was performed with adolescent $\mathrm{TRB}_{\text {total }}$ as the dependent variable and demographic variables as predictors in the first step, and adolescent GRB in the second step.

To examine the relationship between adolescent alcohol use in traffic and that of parents, siblings, and friends, odd ratios were calculated by means of Log Linear regressions, with 'riding home on a bicycle or moped while drunk' as the dependent variable and drink-driving by parents, older 
siblings and friends as predictors. In these analyses we differentiated between eldest brother and sister, and between best male and female friend. Separate analyses were carried out for male and female adolescents.

\section{4. $\quad$ Results}

\subsubsection{Co-occurrence of risk behaviours}

Table 5.3. shows the correlations among the risk behaviours. All were statistically significant $(p<.01)$, but the strength of the associations was low: correlations ranged from $0.4 \%$ to $35 \%$. 'Cycling and moped riding under the influence of alcohol' had the highest correlations with 'Smoking' (.27), 'Gambling' (.21), and 'Drinking' (.35), and the lowest with the 'Use of safety belts'(.09) and 'Riding as a passenger of a driver who had been drinking' (.04).

The strength of the relationship between the GRB and TRBtotal was tested by a two-step hierarchical regression analysis, with the demographic predictors in the first step, and the GRB behaviours smoking gambling, drinking in the second. The demographic variables explained only $2 \%$ of the variance in TRB total. Adding the GRB variables to the model explained an additional variance of $7 \%\left(\Delta R^{2}=.07\right)$ in TRB total.

\begin{tabular}{lccccc}
\hline & 2 & 3 & 4 & 5 & 6 \\
\hline 1. Cycling and moped riding with alcohol & $.09^{* *}$ & $.04^{* *}$ & $.21^{* *}$ & $.27^{* *}$ & $.35^{* *}$ \\
2. How often use safety belts & - & $.09^{* *}$ & $.10^{* *}$ & $.08^{* *}$ & $.09^{* * *}$ \\
3. Riding with a drinking driver (all) & & - & $.11^{* *}$ & $.07^{* *}$ & $.08^{* *}$ \\
4. How often gamble & & & - & $.24^{* *}$ & $.29^{* *}$ \\
5. How much smoking per week & & & & - & $.33^{* *}$ \\
6. How often drunk in the last two months & & & & & - \\
\hline
\end{tabular}

Table 5.3. Correlation matrix of risk behaviours among adolescents. ${ }^{* *} p<.01$

\subsubsection{Influence of the perceived social environment}

To examine the influence of the perceived social environment on each risk behaviour, a separate hierarchical regression was carried out. In Figure 5.1, the outcomes are graphically presented. For each variable, the results are expressed as the additional explained variance in percentages (values of $\Delta R^{2}$ * 
100) to the (block of) variables entered in the previous steps. Note that the values do not represent the standardized Beta values.

\section{Predicting adolescent TRB total from drink-driving in the perceived social environment}

The hierarchical regression with $\mathrm{TRB}_{\text {total }}$ as the dependent variable and Driving while under the influence (DWI) by parents, siblings and friends as predictors showed that these behaviours of parents, siblings, and friends explained $9 \%$ of the variance in adolescent TRB total. Parental DWI had the

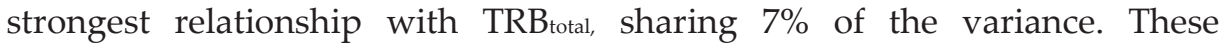
relationships for siblings and friends were weak, explaining respectively $0.4 \%$ and $0.1 \%$ of the variance. No information was available on the proportion of siblings and friends in possession of a driving license. A low proportion of license holders may provide an alternative explanation for these weak relationships.

When youngsters reported having accepted rides from drivers who according to their perception had been drinking $(n=1090)$, the majority of these drivers were their own parents ( $n=967)$.

\section{Predicting adolescent GRB from the perceived social environment}

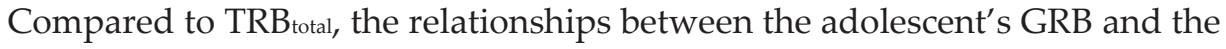
perceived GRB in the social environment were stronger, explaining $6.5 \%$ of the variance in drinking, 15\% in gambling, and 12\% in smoking.

Of all these predictors, the risk behaviour of friends was the best predictor of adolescent risk behaviour. For alcohol use, drinking friends explained $6 \%$ of the variance of drinking adolescents, whereas drinking parents explained $0 \%$ and drinking siblings $0.5 \%$. This was also the case for smoking. Smoking by parents and siblings only explained respectively $1 \%$ and $2 \%$ of the variance in adolescent smoking, but smoking by friends explained $9 \%$ of the variance. For gambling, the patterns differed from those for drinking and smoking. Although for gambling the relationship with friends' behaviour was still strong (6\%), the relationships with parents' and siblings' gambling behaviour were approximately equally strong, explaining respectively 5 and $4 \%$ of the variance.

\subsubsection{Drunk driving and riding in more detail}

Table 5.4 presents the results of a logistic regression on the odds of riding home on a bicycle or moped while drunk. In these analyses, siblings and 
friends were differentiated by gender. The regression shows that the odds for this type of risky road behaviour are significantly lower if a boy's father, oldest sister, and best male friend do not drink and drive. For girls, none of these odds ratios was significant.

\begin{tabular}{lrrrrrrrrr}
\hline \multirow{2}{*}{$\begin{array}{l}\text { No DWI in perceived social } \\
\text { environment }\end{array}$} & B & S.E. & Wald & df & Sig. $\begin{array}{l}\text { Odds } \\
\text { Ratio }\end{array}$ & \multicolumn{2}{c}{$95 \%$ C.I } \\
\hline Father & & & & & & & Lower & Upper \\
Mother & -.354 & .161 & 4.821 & 1 & .03 & .70 & .51 & .96 \\
Eldest brother & .026 & .312 & .007 & 1 & .93 & 1.03 & .56 & 1.89 \\
Eldest sister & -.514 & .461 & 1.243 & 1 & .27 & .60 & .24 & 1.48 \\
Best male friend & -1.461 & .727 & 4.031 & 1 & .05 & .23 & .05 & .97 \\
Best female friend & -1.491 & .359 & 17.228 & 1 & .00 & .23 & .11 & .46 \\
Constant & -1.201 & .747 & 2.583 & 1 & .11 & .30 & .07 & 1.30 \\
\hline
\end{tabular}

Table 5.4. The odds ratios for boys of riding home drunk on moped or bicycle. $p<.05$. An odds ratio lower than 1 indicates the odds of a young male were lower if there was no DWI by this other person in the perceived social environment. 

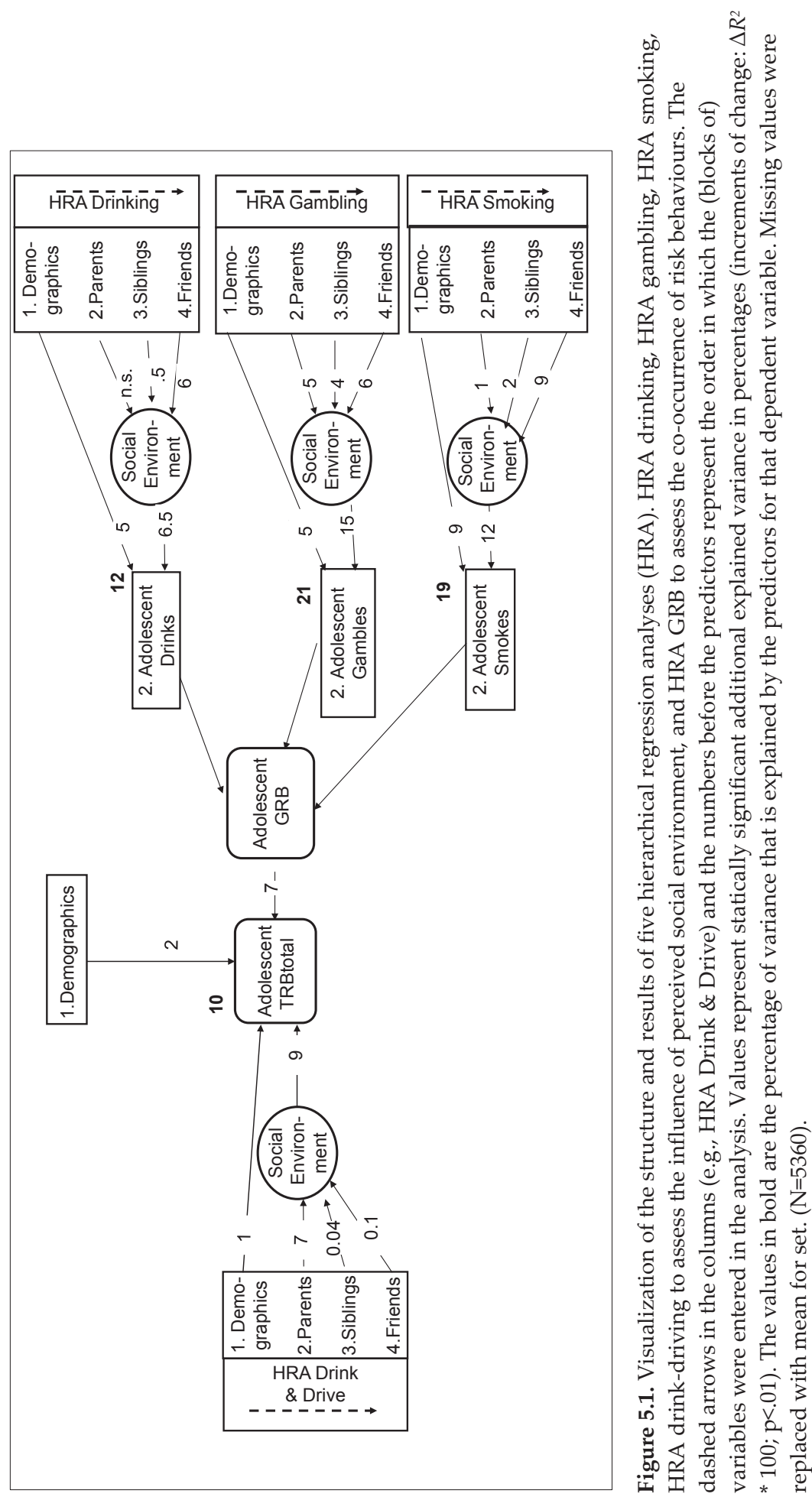


\subsection{Discussion}

Guided by two of the components of Problem Behaviour Theory (problem behaviour and perceived social environment) and by Social Cognitive Theory, this study aimed to identify the co-occurrence of risk behaviours and to assess the influence of the perceived social environment on risk behaviour among young Dutch adolescents, ages 11 to 17. Existing data from a largescale survey on the health and risk behaviours of young adolescents were reanalysed with respect to the relationship between General Risk Behaviours (GRB): Smoking, Gambling, and Drinking, and Traffic-related Risk Behaviours (TRB): Seat belt use, Riding with a driver who has been drinking, and Riding a bicycle or moped while drunk. The study confirms earlier findings that risk behaviour tends to co-occur among young adolescents. The strength of this relationship, however, differs by risk behaviour. Riding a bicycle/moped when drunk, gambling, frequency of being drunk and smoking were all correlated, and are presumably an expression of an underlying risk-taking tendency. The present study did not assess the extent to which these risk behaviours are associated with injuries. Elsewhere, several studies have studied this relationship and have shown that, for instance, engagement in multiple delinquent and illegal behaviours was found to increase the likelihood (about five times) of reports of medical treatment and injuries (1.8 times) in the past three months (Buckley et al., 2012). Similarly, Picket et al. (2002) used the HBSC survey data for 12 countries and showed that the more individuals engaged in multiple health risk behaviours such as smoking, excess drinking, and non-use of safety belts, the higher their odds of having sustained severe injuries. Looze et al. (2011) used the data from the 2005-2006 HBSC survey to show a cumulative effect of early onset of multiple risk behaviours on medically treated injuries at age 15. These studies illustrate that multiple risk behaviours do increase the likelihood of injuries.

Regarding the influence of the perceived social environment, the study showed mixed results. For adolescent smoking, drinking, and gambling, risk behaviour among peers was the strongest predictor, stronger than the risk behaviours of parents and siblings. In contrast, for adolescent Traffic-related risk Behaviour (TRB), parental drink-driving was the strongest predictor, stronger than drink-driving among siblings or friends. This strong relationship with parental drink-driving is mainly due to youngsters reporting having been passengers of drinking parents. Note that this - in 
contrast to the other TRB behaviours - may not be an intentional risky act on the part of the adolescent. It may be an almost inevitable consequence of the adolescent's dependency for transportation on others, particularly parents. To safeguard one's safety in such situations is complicated, and requires not only advanced social skills, but also the availability of alternative means of transportation.

\subsubsection{Strengths and weaknesses of the study}

Strengths of the study were the large sample size, the inclusion of a wide range of risk behaviours, and the additional information on the risk behaviours of parents, siblings, and friends. That the data were gathered more than two decades ago weakens its relevance, but does not weaken its insights into the psychological mechanisms underlying risk behaviour. Current literature still reports the co-occurrence of risk behaviours and the influence of the social environment as a feature of modern adolescence. More recently, a similar study was carried out on the co-occurrence of problem behaviours among adolescents in the Netherlands (Nieuwenhuijzen et al., 2009). This study examined the relationships among health-compromising behaviours, illegal drug use, unprotected sex, delinquency, and the violations of traffic lights as an indicator of risky road behaviour. For the 1215 year olds, the Nieuwenhuijzen study reported a broad cluster of 'delinquency' behaviour that included traffic light violations. The second cluster contained health-compromising behaviours, such as alcohol use, smoking and drug abuse. These patterns of co-occurrence are similar to our study. Even with a weaker operationalisation of risky road behaviour - only red light violations - these findings provide further support for the conclusion that youngsters who behave in a risky manner on the road, also may engage in other types of risk behaviours, and vice versa.

Still, also our study suffered from too few items on risky road behaviour among young adolescents, and even fewer items on risky road behaviour among parents, siblings, and friends. The items did not sample a sufficiently broad range of potentially risky behaviours and therefore did not provide a complete overview of risk behaviours. Those behaviours that were included, however, have been shown to increase crash risk and/or injury. 


\subsubsection{Implications of the findings}

Both the strong relationships among problem behaviours and the associations with the presence of problem behaviour in the adolescent's perceived social environment have some implications for the design and applications of prevention strategies. These strategies need not solely focus on road risk, but should address the determinants of risk behaviour in general, as well as specifically concentrate on the risk behaviours of friends as an important determinant of their own behaviour. Whether adolescent risk behaviour is a result of the influence of friends, or whether adolescents prefer friends who favour the same 'scene' cannot be concluded from these findings. However, that ' friends ' matter in adolescence and adolescent road risk has already widely been documented (Brown, 2004; Gardner and Steinberg, 2005; Steinberg and Monahan, 2007). Despite these clear relationships, the implications of these findings should not be taken too far. First, the general risk tendency and influence of peers are just one aspect of the problem, sharing only a small proportion of the variance in risk behaviour. Second, the road behaviours studied are well defined and do not require advanced skills. It is not complicated to use a safety belt, to ride sober, or to refuse a ride from a drunk driver. It is the social context that complicates the considerations for decisions regarding these behaviours. What these complications are and how these can be resolved needs to be studied first before interventions can be successful. Third, the study addressed a small selection of road risk behaviours that are directly under the control of a person. This is in contrast to crossing a street (which is shown to be a highly dangerous activity for cyclists), which requires complex skills such as the assessment of speeds and distance, and the intentions of other road users. Those behaviours and their determinants differ from the ones studied herein.

\subsection{Conclusions}

The results show evidence of the co-occurrence of risk behaviours, as well as an association between an adolescent's risk behaviour and risk behaviour in the perceived social environment. However, the co-occurrence is not strong enough to recommend redirecting intervention strategies. The results for the relationship with the perceived social environment, however, may have implications for the scope of intervention strategies. Similar to other studies, for smoking, gambling, and drinking, the results from our study confirm the strong relationships between behaviour of adolescents and that of their 
friends. However, for traffic-related risk behaviour, parental behaviour was the strongest predictor. Youngsters who had accepted rides from drunk drivers often reported those drivers to have been their own parents. Thus, intervention strategies not only should address peer pressure, but should broaden their scope to include parental influence as well. 



\title{
6. Inexperience and risky decisions of young adolescents in interactions with trucks, and the effects of competency versus awareness education $^{8}$
}

\begin{abstract}
Road injuries are a prime cause of death in early adolescence. Often Road Safety Education (RSE) is used to target risky road behaviour in this age group. These RSE programmes are frequently based on the assumption that deliberate risk taking rather than lack of competency underlies risk behaviour. This study tested the competency of 10 to 13 year olds, by examining their decisions - as pedestrians and cyclists - in dealing with blind spot areas around trucks. Also, the effects of an Awareness programme and a Competency programme on these decisions were evaluated.

Method: Table-top models were used, representing seven scenarios that differed in complexity: one basic scenario to test the identification of blind spot areas, and 6 traffic scenarios to test behaviour in traffic situations of low or high task complexity. Using a quasiexperimental design (pre-test and post-test reference group design without randomization), the programme effects were assessed by requiring participants $(n=62)$ to show, for each table-top traffic scenario, how they would act if they were in that traffic situation.

Results: On the basic scenario, at pre-test $42 \%$ of the youngsters identified all blind spots correctly, but only $27 \%$ showed safe behaviour in simple scenarios and $5 \%$ in complex scenarios. The competency programme yielded improved performance on the basic scenario but not on the traffic scenarios, whereas the awareness programme did not result in any improvements. The correlation between improvements on the basic scenarios and the traffic scenarios was not significant.

Conclusions: Young adolescents have not yet mastered the necessary skills for safe performance in simple and complex traffic situations, thus underlining the need for effective prevention programmes. RSE may improve the understanding of blind spot areas but this does not 'automatically' transfer to performance in traffic situations. Implications for the design of RSE are discussed.
\end{abstract}

\subsection{Introduction}

Road safety education (RSE) programmes are widely used with the goal of changing behaviour among young adolescents, so that injuries and fatalities are prevented. However, little is known regarding whether these programmes

${ }^{8}$ This chapter was published as the following article: Twisk, D., Vlakveld, W., Mesken, J., Shope, J.T. Kok, G, 2013. Inexperience and risky decisions of young adolescents in interactions with lorries, and the effects of competency versus awareness education. Accident Analysis \& Prevention $55,219-225$. 
address the relevant determinants of risk behaviour, achieve their objectives, and actually change behaviour (Dragutinovic and Twisk, 2006; SUPREME, 2007; Williams, 2007). For example, blind spot programmes have become increasingly popular to educate and train young cyclists and pedestrians, now that the additional mirrors on trucks - compulsory in the EU since 2003 - and other technical systems that seek to improve truck drivers' view, have only led to a temporary reduction in fatalities (Schoon et al., 2008). Of all fatal crashes between cyclists and trucks in the period 1997 and 2006, 45\% happen because of cyclists being in the driver's blind spot. Of those blind spot fatal crashes, $28 \%$ involves a cyclist in the age category 0 to 17 (Schoon et al., 2008). To date little is known about the antecedents of these risky decisions. Is it that youngsters foster safety compromising attitudes and beliefs, resulting in 'carelessness' and deliberate ignoring of these risks? Or is it that these youngsters lack the necessary skills to deal with these potential risks, and just do not know what to do? Whereas education programmes for children are implicitly based on the assumption that they are still inexperienced road users, those for young adolescents tend to focus on attitudes and beliefs as the main determinants of risky behaviour (Dragutinovic and Twisk, 2006). The latter focus is supported by results from epidemiologic studies showing a strong rise in all sorts of risky behaviours in this age group, such as smoking, alcohol use, and petty crime (Dorsselaer et al., 2007; Ezinga et al., 2008; Junger et al., 2003; Kumpula and Paavola, 2008), and by results from studies on the psychological determinants suggesting that youngsters are well aware of risks (e.g., Reyna and Farley, 2006; Steinberg, 2008) but still behave in a risky manner because of strong desires for novel and exciting experiences, high desire for peer approval, and low impulse control (Dahl, 2004).

In contrast, studies on expertise development, however, support the possible role of inexperience as a determinant of risk behaviour, pointing to the slow acquisition of new skills (Anderson, 1982) and the necessity of deliberate practice (Ericsson, 2005). Also, several behaviour models point to the importance of expertise, in that skills are a restricting factor for attitudes/beliefs to influence road behaviour (e.g., Fuller, 2008). That is, despite a positive safety motivation youngsters may still behave risky because of poor skills. Although this distinction between 'attitudes/beliefs' and 'inexperience' is of utmost importance for the design of RSE programmes (Bartholomew et al., 2011), until now this information has not been available. Therefore, the present study examined the initial proficiency of 10 to 13 year old adolescents in simple and complex blind spot situations, and evaluated and compared the effects of two types of blind spot education 
programmes: a programme aimed at raising proficiency and a programme aimed at increasing risk awareness. The study focussed on blind spot situations because of the complex psychological mechanisms involved, the high incidence of this type of situation in road traffic, and the serious consequences of such a crash.

With respect to the competency of young adolescents - before the intervention - the following hypotheses were formulated. Because blind spot scenarios require the recognition of situations in which truck drivers can easily make errors, and the processing of information that may contain contradictory cues and distractors (Endsley, 1995; Fuller, 2008), road users need to possess abilities such as 'empathy', 'perspective-taking', and 'selective and focussed attention'. These abilities, however, are not yet fully developed in early adolescence, partly because of the immaturity of the adolescent brain (Blakemore and Choudhury, 2006; Keating, 2007). It is therefore expected that youngsters will frequently make risky decisions in blind spot situations (H1). The development of these skills may be accelerated by practice on the task (Crone and Dahl, 2012; Johnson et al., 2010; Keating, 2007), whereby the simple tasks require less practice than the more complex ones (Anderson, 1982; Ericsson, 2005; Shriffrin and Schneider, 1977). Young adolescents in the Netherlands have had little practical experience with these blind spot situations. It is therefore expected that risky decisions will be made more frequently in complex traffic situations containing contradictory cues and distractors than in simple ones (H2).

In the evaluation study, two blind spot programmes were assessed. The Awareness programme addressed carelessness, not only in blind spot scenarios, but also in other traffic situations. The Competency programme solely addressed blind spot hazards and used a condensed message of only four rules: (a) Do not cross the street right in front or right behind a truck; (b) At signalized intersections, always wait behind the stop line; (c) When approaching an intersection, stay behind the truck; and (d) Make sure the truck driver sees you. Besides these differences, the programmes were very similar. Both were comprised of a half-day of instruction, whereby a real truck was placed in the schoolyard. The limitations in the truck driver's field of view were demonstrated and information on safe behaviour was provided. Participants could climb into the driver's seat and see for themselves where the blind spots were located. Blind spots were further illustrated through graphic representations and videos. Practical training in real-world situations was not included in either of the programmes. Both 
programmes visited schools on request, the costs were often covered by subsidies from local governments, and instructors were volunteers, frequently retired truck drivers.

This study further tested the validity of the presumed didactic mechanisms. Both programmes implicitly assumed a successful 'far' transfer of learning (Barnett and Ceci, 2002), meaning that the mere provision of instruction and demonstration were expected to yield better performance in actual traffic situations. The present study hypothesized that if demonstrations of blind spots and instructions were sufficient for improving actual behaviour in traffic, improvements in the 'identification of blind zones' should be associated with improved performance in simple and complex traffic scenarios (H3). The evaluation was conducted in a field setting in schools that already used the programmes on a regular basis. Performance was assessed by means of table-top models representing traffic situations. The field setting was chosen because of the study's aim to inform policy makers, teachers and educators about the 'net' effect of the programmes in use. The table-top model was used for two reasons: first, because exposing adolescents to real traffic situations would be too dangerous and second, because the evaluation study required rigorous control over task complexity.

Even though these RSE programmes were intended to improve road safety and thus reduce injury rates, the evaluation study only used 'road decisions' as a success criterion. Because crashes are rare, an evaluation study aiming to demonstrate effects on crashes and fatalities, would have required sample sizes of thousands of participants and extremely long observation periods (Hauer, 2008). Still, based on the assumptions that competency is a precondition for safe decisions and safe decisions reduce crash risk, this study uses 'change in the number of safe decisions' as an indicator of the potential impact these programmes may have on road safety.

\subsection{Method}

\subsubsection{Participants}

Four primary schools in the Netherlands participated in the study: two intervention and two reference schools. The intervention schools were those that came first in the programme's 'tour scheme'. These schools were matched in terms of geographical location with two reference schools that used neither of the programmes. No other criteria were used for matching. 
All participants $(n=63)$ of the last two grades of these four primary schools participated in the study and completed both the pre- and the post-test as part of their regular school day. They were between 10 and 13 years of age. In the intervention group, $49 \%$ of the participants were boys. In the reference group, this proportion was $51 \%$.

\subsubsection{Design}

A quasi-experimental approach with a non-equivalent control group design (Cook and Campbell, 1979) and a Split Plot Factorial (SPF) design (Jones, 2009) was employed. Identical task scenarios were used for pre- and posttest. The pre-test was administered just before the programme and the posttest about one month later.

\subsubsection{Task scenarios}

Seven table-top models of traffic scenarios were employed to assess performance. These table-top models were approximately 1 by 2 metres in size; each depicting a schematic road layout in 2-D and containing scaled movable models in 3-D of cars, trucks, pedestrians, and cyclists. Participants were instructed that the pedestrians and cyclist models represented 'themselves' and were asked to indicate on the table-top model where they would wait or where they would cross in that given traffic situation. These tasks did not require a correct assessment of speed or distance.

Three complexity levels were used: One basic scenario. Using a scaled model of a lorry, participants were required to indicate locations at which the lorry driver would or would not be able to see them.

Three simple traffic scenarios. In these scenarios no distractors were present and safe behaviour only required the application of a single 'rule'.

Three complex traffic scenarios. These scenarios were complex because of additional features that complicated the decision process, such as the presence of distractors, extra information, or conflicting rules.

Figure 6.1 shows examples of the scenarios with two levels of complexity. A complete overview of the scenarios are presented in Appendix C. The order in which scenarios were presented was the same for all participants, and did not differ between pre- and post-test. The first, third, and fourth scenarios were simple while the second, fifth, and seventh scenarios were complex. The sixth scenario was the basic scenario. 

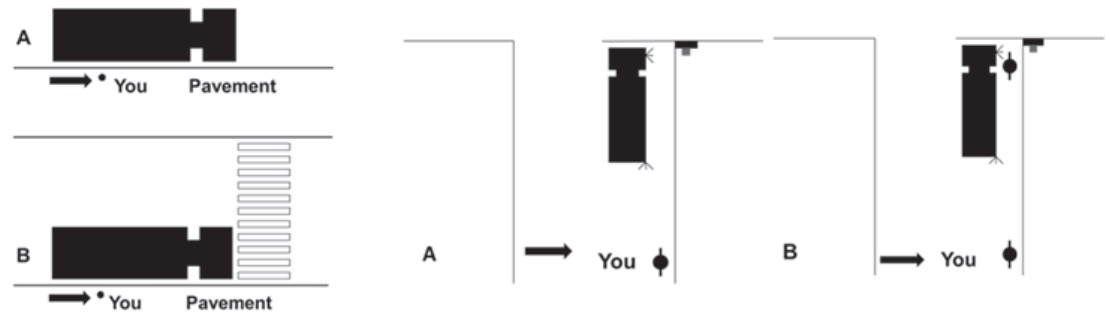

Figure 6.1. Schematic examples of simple (A) and complex (B) scenarios. The scenario on the right invites participants to apply the rule, "On approaching an intersection with a truck waiting at a red light, always wait behind the truck". The arrow highlights the position of the model representing the participant. In the B condition, complexity is added by positioning another cyclist in the blind spot, as distractor. The scenario on the left represents a truck parked at the curb with the engine running. It invites participants to apply the rule, "Do not cross a street right in front of a lorry". The B condition adds complexity by showing a pedestrian crossing.

\subsubsection{Procedure}

At the intervention schools, the programme was carried out as usual, with the exception that participants, instructors and school staff were informed about the purpose of the evaluation. The control schools did not receive an intervention. No information was collected on the actual delivery of the programmes, but feedback from the organizers of the programs pointed out that there had been no abnormalities. To test performance, a research assistant met with each participant individually in a room in the participant's school, and described the main characteristics of each scenario. Participants were then instructed to demonstrate on the table-top by moving a model piece representing them, how they would act in that scenario as a cyclist or pedestrian. For example, the instruction for the intersection scenario shown in Figure 6.1 read: "You approach this intersection on your bicycle. The traffic light is red. A lorry is waiting at the stop line and its turn signals show that it plans to turn right once the light is green. You want to go straight. Please position your bicycle where you would wait while the traffic light is red". If participants waited behind the lorry, they were awarded one point. If they positioned the bicycle between the lorry and the pavement, no point was awarded. No feedback was given on the correctness of the decision, and no incentive was provided. 


\subsubsection{Measures}

The following measures were used in the analyses: (a) performance by complexity, calculated as the sum of scores on the scenarios within each complexity level; (b) gain scores, calculated as the difference between the performance on the pre- and post-test for each participant; (c) mastery, calculated as the proportion of participants that received the highest possible score within a complexity level.

\subsubsection{Data analyses}

Initial competency levels were assessed using Mixed design ANOVA with task complexity as a within-subject variable and gender and grade as between-subject variables. The effects of the programmes were assessed using Mixed design ANOVA with pre-test and post-test as within-subject variables and experimental group as a between-subject variable.

\subsection{Results}

\subsubsection{Initial (baseline) proficiency}

The total mean and mastery scores at baseline, shown in Table 6.1, indicate that about $67 \%$ of the participants correctly identified all blind spots, but only $43 \%$ made safe decisions in all simple scenarios and $3 \%$ in all complex scenarios. This finding supports the hypothesis that young adolescents frequently make risky decisions in blind spot situations (H1). Regarding the influence of task complexity on performance (H2), Table 6.1 shows that performance deteriorated with increasing task complexity, resulting in lower mean scores for the complex scenarios $(M=1.2)$ than for the simple scenarios $(M=2.2)$. Inspection showed that the data did not meet the 'normality' and 'homogeneity' assumptions. However, as discussed by Field (2009, p. 360), in studies such as these, where group sizes are equal, the F-statistic can be quite robust to violations of normality and homogeneity. The mixed design ANOVA, with task complexity as the within-subject variable and gender and grade as between-subject variables, showed the main effect of complexity to be statistically significant $(F(1,57)=64.64 ; p<.001$, with a medium effect size partial $\left.\eta^{2}=0.53\right)$. No interactions were present for gender $(F(1,57)=1.74 ; p<$ $.19)$ and grade $(F(1,57)=0.34 ; p<.58)$. The correlation between the basic and complex traffic scenarios was weak and not significant $(r=15.2 p<.23 . n=$ 63), which does not support $\mathrm{H} 3$ that expected a strong relationship between the correct identification of blind spots and safe behaviour in traffic scenarios. 


\begin{tabular}{lcccc}
\hline $\begin{array}{l}\text { Scenarios by } \\
\text { complexity level }\end{array}$ & $\begin{array}{c}\text { Min-Max } \\
\text { score }\end{array}$ & $\begin{array}{c}\text { Mean at } \\
\text { baseline }\end{array}$ & SD & $\begin{array}{c}\text { Mastery } \\
\text { (all items correct) }\end{array}$ \\
\hline Basic & $0-6$ & 5.4 & 1.9 & $42(67 \%)$ \\
Simple & $0-3$ & 2.2 & .78 & $27(43 \%)$ \\
Complex & $0-3$ & 1.2 & .78 & $3(5 \%)$ \\
Total & $0-12$ & 8.9 & 1.9 & $0(0 \%)$ \\
\hline
\end{tabular}

Table 6.1. Performance at baseline by complexity ( $N=63$, all schools both programmes).

Mastery was affected by task complexity, with the highest proportion of participants with correct responses on simple traffic scenarios $(43 \%)$ and the lowest on the complex traffic scenarios (5\%). This finding provides support for $\mathrm{H} 2$ that expected task performance to deteriorate with task complexity, and that therefore, lack of competency is likely to be one of the determinants of risk behaviour

\subsubsection{Effects of the education programmes}

\section{Ceiling effects and non-equivalence of experimental groups}

Potential effects of the programmes could have been obscured by two phenomena: (a) a ceiling effect, where performance scores at pre-test would be close to the maximum score; and (b) non-equivalence of groups where scores of the reference and intervention group would differ at pre-test. In terms of the former, a comparison of the pre-test performance scores with the maximum attainable score showed that for the basic scenario, mean scores were close to maximum but still left some room for improvement, and that for simple and complex scenarios, mean scores were well below the maximum score (see Table 6.1). Programme effects were thus not impacted by ceiling effects. Regarding the equivalence of groups, analyses showed that for both programmes the intervention and reference groups did not differ at pre-test.

Between the programmes, however, scores of the intervention group differed at pre-test (see Table 6.2). A mixed design ANOVA with complexity as the within-subject factor and programme as the between-subject factor showed a significant main effect of programme $\left(F(1,61)=7.98, p=.04\right.$; partial $\left.\eta^{2}=.12\right)$, a main effect of complexity $\left(F(1,61)=95.89, p<.001\right.$ partial $\left.\eta^{2} .61\right)$, but no interactions between programme and complexity, indicating that compared to the Competency programme, participants in the Awareness programme performed better at pre-test on all three types of scenarios. Unfortunately, we did not gather background information on the schools and could therefore 
not clarify why the 'competency' schools had lower pre-test scores than the 'awareness' schools. The difference on the pre-test between the programmes was not considered problematic because the evaluation sought to compare the experimental groups within programmes rather than between programmes. Furthermore, the pre-test score for the better performing Awareness programmes still left sufficient room for improvement in all three complexity conditions.

\begin{tabular}{|c|c|c|c|c|c|c|c|c|c|c|}
\hline \multirow{2}{*}{\multicolumn{2}{|c|}{ Education programme }} & & \multicolumn{4}{|c|}{$\begin{array}{l}\text { Pre-test by complexity } \\
\text { (maximum scores) }\end{array}$} & \multicolumn{4}{|c|}{$\begin{array}{l}\text { Post-test by complexity } \\
\text { (maximum scores) }\end{array}$} \\
\hline & & & $\begin{array}{c}\mathrm{T} \\
(12) \\
\end{array}$ & $\begin{array}{c}B \\
(6)\end{array}$ & $\begin{array}{c}S \\
(3)\end{array}$ & $\begin{array}{c}C \\
(3) \\
\end{array}$ & $\begin{array}{c}\mathrm{T} \\
(12) \\
\end{array}$ & $\begin{array}{l}\text { B } \\
(6) \\
\end{array}$ & $\begin{array}{c}S \\
(3)\end{array}$ & $\begin{array}{l}\mathrm{C} \\
(3) \\
\end{array}$ \\
\hline \multirow{4}{*}{ Comp } & Intervention & $M$ & 8.2 & 5.2 & 2.0 & 1.0 & 9.5 & 5.8 & 2.2 & 1.5 \\
\hline & $n=19$ & $(S D)$ & 2.5 & $(1.8)$ & $(.9)$ & (.7) & (1.8) & $(0.7)$ & (.9) & (.9) \\
\hline & Reference & $M$ & 8.7 & 5.6 & 2.1 & 1.0 & 8.5 & 5.2 & 2.3 & 1.0 \\
\hline & $n=20$ & $(S D)$ & $(1.4)$ & $(0.7)$ & $(.8)$ & $(.7)$ & $(1.8)$ & $(1.2)$ & $(.8)$ & $(.8)$ \\
\hline \multirow{4}{*}{ Aware } & Intervention & $M$ & 9.5 & 5.5 & 2.4 & 1.6 & 9.7 & 5.7 & 2.6 & 1.4 \\
\hline & $n=12$ & $(S D)$ & (1.4) & $(0.8)$ & $(.7)$ & $(.8)$ & (1.1) & $(0.5)$ & (.5) & $(.5)$ \\
\hline & Reference & $M$ & 9.6 & 5.6 & 2.6 & 1.4 & 9.3 & 5.6 & 2.3 & 1.3 \\
\hline & $n=12$ & $(S D)$ & $(1.2)$ & $(0.5)$ & (.5) & $(.8)$ & (1.5) & $(0.8)$ & $(.8)$ & $(.7)$ \\
\hline
\end{tabular}

Table 6.2. Pre- and post-test means by complexity level, education programme, and experimental group $/$ comp $=$ competency programme, Aware $=$ Awareness raising programme. $\mathrm{T}=$ total; $\mathrm{B}=\mathrm{Basic} ; \mathrm{S}=$ simple; $\mathrm{C}=$ complex.

\section{Effects by complexity level}

For each programme separately, the effects of the task performance for the three complexity levels were assessed. To that end, the improvements relative to the reference group were tested by means of mixed ANOVAs, with 'time' - pre-test and post-test - within-subject and 'intervention' intervention group and reference group - as between-subject variables. The interactions between time and intervention conditions, summarized in Table 6.3, confirmed that the Competency programme yielded significant improvements on the basic and the total scores $(p<.05)$, but not on the simple and complex scenarios. The Awareness programme, however, did not yield significant improvements on any of the complexity levels. 


\begin{tabular}{lccccccccc}
\hline & \multicolumn{3}{c}{ Competency programme } & & \multicolumn{4}{c}{ Awareness programme } \\
\cline { 2 - 4 } \cline { 8 - 10 } Scenarios & $D f$ & $F$ & $\eta_{P}^{2}$ & $P$ & & $D f$ & $F$ & $\eta_{P}^{2}$ & $P$ \\
\hline Basic & $1 ; 37$ & 4.84 & .01 & .03 & & $1 ; 22$ & 0.23 & .63 \\
Simple & $1 ; 37$ & 0.12 & & .73 & & $1 ; 22$ & 1.15 & .30 \\
Complex & $1 ; 37$ & 2.82 & & .10 & & $1 ; 22$ & 0.05 & .83 \\
Total & $1 ; 37$ & 7.93 & .12 & .03 & & $1 ; 22$ & 0.04 & \\
\hline
\end{tabular}

Table 6.3. Analysis of variance: Interactions between intervention and time by scenario type Note: Summary table of the interactions between time and intervention based on separate ANOVAs for each programme and complexity level with test (pre- and post-test scores) as the within-subject measure (time) and intervention group (reference versus intervention) as the grouping factor.

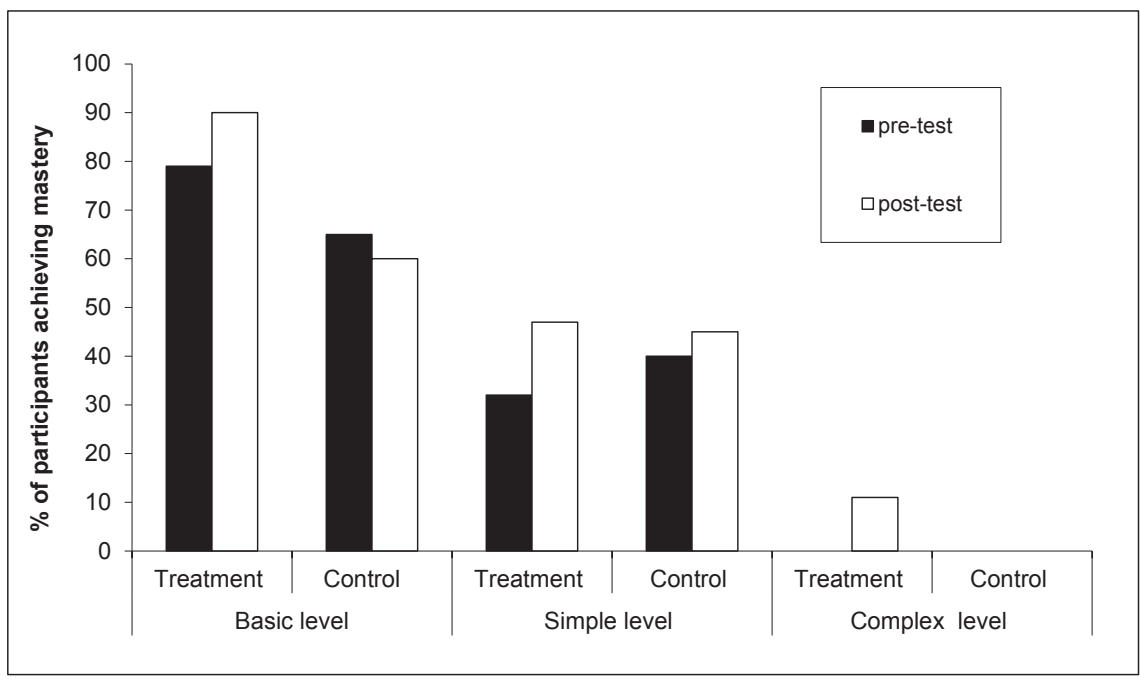

Figure 6.2. Proportion of participants exhibiting mastery (1 point on each scenario within a complexity level) at pre- and post-test for Competency programme by scenario complexity and experimental group.

\section{Transfer and mastery}

Because only the Competency programme yielded significant improvements, detailed analyses of the degree to which improvements on the basic scenarios were transferred to traffic scenarios were only conducted for that programme. Kendall's tau on the gain scores did not result in significant correlations between improvements on the basic scenario and the combined scores on the simple and complex scenarios. Therefore, H3 stating that improvement on the basic scenarios is associated with performance improvement on traffic scenarios was not confirmed. 
Mastery improved in the Competency programme's intervention group for all complexity levels while only minor changes in mastery were found in the reference group (Figure 6.2). Among participants in the intervention group, $90 \%$ received the maximum score on the basic scenario at post-test. Success rates fell rapidly on the traffic scenarios. On the simple scenarios, only $47 \%$ of the intervention group dealt appropriately with each scenario. For the complex scenarios, this percentage was a mere $11 \%$.

\subsection{Discussion}

\subsubsection{Summary of results}

The objectives of this study were to: (a) assess the initial performance of how young adolescents interact with trucks at varying levels of task complexity, (b) evaluate the effects of two road safety education (RSE) programmes on performance in traffic scenarios, and (c) assess the expected impact of the programmes on road safety. Because only the Competency programme yielded improved performance, objective c was only assessed for that programme.

The results from the study support the hypothesis that young adolescents in blind spot situations make decisions that increase their risk of being overlooked by the driver. About a third of participants did not correctly identify all blind spot locations. Performance deteriorated further in traffic scenarios in which this knowledge needed to be applied - only one out of two participants made safe decisions in all simple scenarios and only one out of twenty did so in all complex scenarios. This difference by scenario complexity supports the hypothesis that lack of skills, rather than unsafe attitudes/beliefs, underlies these risky decisions.

The programmes' didactic assumptions that unsafe behaviour results from poor identification of blind spot locations and that unsafe behaviour can be improved by training on blind spot identification were not supported by the findings, as the correct identification of blind spots did not predict the safety of their decisions in the traffic scenarios, and improved blind spot identification after the Competency programme did not lead to improved behaviour in traffic scenarios. Based on the assumption that correct performance on the traffic scenarios is a precondition for safe behaviour in actual traffic situations, it is unlikely that the competency programme will have a positive impact on road safety. 


\subsubsection{Strengths and weaknesses of the study}

Three characteristics of the study may have affected the generalizability of the results for road safety: a) the use of table-top models, b) the absence of an experimental condition in which the factor 'deliberate risk taking' was manipulated, and c) the field setting.

The table-top models enabled the manipulation of scenario complexity, eliminated interference from other sources, provided participants with sufficient time to complete the task, and prevented exposure to hazardous conditions. Despite these advantages, one could debate the degree to which these table-top models were adequate representations of real traffic situations. Although the external validity of the method could not be assessed for safety reasons, the finding that complex scenarios yielded a higher number of incorrect responses than simple scenarios indicates that the experimental conditions of task complexity were adequately manipulated. The greatest threat to external validity, however, is the absence of dynamic features and time pressure that is characteristic to modern traffic. Most likely, this absence has led to an overestimation of the competency of young adolescents in actual traffic, which implies that the poor performances on the table top may serve merely as an indicator of an even greater problem.

The experimental manipulation in this study was adequate for the assessment of proficiency, but less suitable for assessing the influence of safety-compromising attitudes - doing so would have called for a separate manipulation of motivation and drives, such as the introduction of peer pressure (Gardner and Steinberg, 2005), frustration, or immediate rewards for risk behaviours (Reyna and Rivers, 2008). Based on the present study, it cannot be ruled out that in addition to lack of competency, deliberate risktaking may also play a role in risky behaviour in blind spot situations.

The field setting did not allow the random assignment of schools to conditions. Moreover, only four schools participated in the study. These facts weaken the conclusions regarding the magnitude of the effects, and limit the generalisability of the results. However, the results on the initial levels of competency - before the intervention - do not suffer from these limitations, and are still indicative of the high frequency of risky decisions made by this age group, that very likely result from poor skills. 


\subsubsection{Implications for Road Safety Education}

If anything, the present study has pointed out the role of lack of competency in adolescent risk behaviour and the inadequacy of current programmes to enhance competency levels enough to expect road safety benefits. Also, it is unlikely that these skills can be easily and safely acquired in real traffic because of the absence of consistent feedback, the rarity of high-risk events, and the severity of the consequences of incorrect decisions. Evidence-based RSE programmes may contribute to the acquisition of these skills, but require rigorous testing with respect to determinants of unsafe actions, training methods, and stages in the acquisition of skills that take into account the cognitive and social development of young adolescents (Bartholomew et al., 2011; Dreyfus and Dreyfus, 1980). Most likely, such programme development will show that just a half-day training will never be sufficient to ensure mastery of all possible scenarios in real traffic. More is therefore to be expected from extending the learning process so that it is not limited only to school-based programmes (Speelman and Kirsner, 2005; Twisk and Kuiken, 2006). This goal could be achieved by including additional support from computer-based tailored and interactive programmes that provide consistent feedback on performance and guide students through the different stages of the learning process (see Vlakveld, 2011 for an overview of mechanismes of simulation in training hazard perception skills), and by caretakers providing supervised training in real traffic. Simulation has been shown to be effective in hazard perception training of young drivers (Vlakveld et al., 2011), while supervised driving has been shown to improve road safety of novice drivers in the USA (Shope, 2007; Vanlaar et al., 2009) and the European Union (Twisk and Stacey, 2007).

One aspect that needs further exploration as part of the development of interventions is the possible role of cognitive immaturity, as this may affect what can be achieved by training. Recent studies on adolescent brain development show that some executive functions that are essential for safe traffic behaviour may be affected by structural changes in the prefrontal cortex (Blakemore and Choudhury, 2006, p. 307; Giedd, 2008). This development, however, does not fully limit the potential effects of RSE programmes, as these structural changes are also found to enhance the brain's capacity for acquiring new skills (Johnson et al., 2010; Keating and Halpern-Felsher, 2008), to increase the brain's sensitivity for experiential input (Blakemore and Choudhury, 2006 p. 307), and to direct attention and motivation depending on the social context (e.g., peer appraisal) (Crone and 
Dahl, 2012). Further exploration of the learning capacities of young adolescents may help in developing intervention programmes that are able to strike a balance between risk exposure and experiential learning, and that yield robust traffic skills that are not affected by interfering factors typical of young adolescents (Dahl, 2004), such as distractions, impulsivity, sensationseeking, peer pressure, and absentmindedness.

\section{Acknowledgements}

The KPVV, TLN, and the Frysian Organisation of Lorry drivers facilitated this study. 


\title{
7. Five road safety education programmes for young adolescents: a multi-programme evaluation in a field setting ${ }^{9}$
}

\begin{abstract}
A practical approach was developed to assess and compare the effects of five short road safety education (RSE) programmes for young adolescents that does not rely on injury or crash data but uses self-reported behaviour.

Method: Questionnaires were administered just before and about one month after participation in the RSE programmes, both to youngsters who had participated in a RSE programme, the intervention group, and to a comparable reference group of youngsters who had not, the reference group. For each RSE programme, the answers to the questionnaires in the pre- and post-test were checked for internal consistency and then condensed into a single safety score using categorical principal components analysis. Next, an analysis of covariance was performed on the obtained safety scores in order to compare the post-test scores of the intervention and reference groups, corrected for their corresponding pre-test scores.

Results: Three out of five RSE programmes resulted in significantly improved self-reported safety behaviour. However, the proportions of participants that changed their behaviour relative to the reference group were small, ranging from $3 \%$ to $20 \%$. Comparisons among programme types showed cognitive approaches not to differ in effect from programmes that used fear-appeal approaches.

Conclusions: The method used provides a practical tool to assess and compare the effects of different education programmes on self-reported behaviour, showing that only three out five RSE programmes led to the anticipated change in behaviour.
\end{abstract}

\subsection{Introduction}

Road Safety Education (RSE) programmes are frequently funded and implemented without evidence of their actual effects (Dragutinovic and Twisk, 2006; Williams, 2007). Because of a growing interest in evidence-based policy (OECD-ECMT, 2008), road safety outcome measures are now being requested as evidence of RSE effects (or lack thereof) on road casualties. These demands, however, raise some difficult methodological issues, such as whether road casualty reduction could serve as the only outcome criterion, and whether effects from different types of RSE programmes can be compared in terms of their relative effectiveness. This study aims to

\footnotetext{
9 This chapter was first published in Accident Analysis \& Prevention: Twisk, D., Vlakveld, W., Commandeur, J.J.F., Shope, J.T., Kok, G., 2014. Five road safety education programmes for young adolescents: a multi-programme evaluation. Accident Analysis \& Prevention, 66, 55-61.
} 
contribute to the evidence base of the effects of RSE by achieving the following objectives: a) develop a feasible and practical method for evaluating RSE programmes that would also permit comparison among programmes, and b) apply this method to assess and compare the effects of several education programmes for young adolescent cyclists and pedestrians. For objective (a) the study explores the possibility of using 'casualties' as an outcome criterion, assesses the strengths and weaknesses of 'road behaviour' and 'behaviour intentions' as surrogate measures, and evaluates the reliability of self-reported and observed behaviour. For objective (b) the evaluation method developed under (a) was used to evaluate and compare the effects of five school-based RSE programmes for adolescents 11 to 17 years of age. These programmes were similar in their aims to stimulate safe cyclist and pedestrian behaviour, but differed in their didactic content and delivery.

\subsubsection{Issues regarding the evaluation of RSE programmes}

\section{Crash-related outcome and the need for surrogate measures}

Several characteristics of crashes in combination with the objectives of RSE, weaken their usefulness as outcome criteria in evaluations (see also Hauer, 2008 for a discussion on this topic). First, the relationship between risk behaviour and crashes is asymmetrical. Although about $95 \%$ of crashes can be attributed to risky behaviours or human failure (Sabey and Taylor, 1980), only an extremely small proportion of risky behaviour actually results in a crash. Therefore crashes and injuries remain rare events in the population of road users. For sufficient statistical power to demonstrate an effect on crashrelated outcomes, a study would require that large numbers of participants (hundreds of thousands) be included in an education programme and that their crash and injury records be monitored over a long period of time (years) (Hauer, 2008). Given the emotional and economic burden of injury and death, and the scarce financial resources available for interventions, it is neither ethical nor practical (Chalmers, 2003) to expose a large number of road users to programmes of unknown quality, just for the purpose of evaluation. Thus, surrogate outcome criteria are needed that are still predictive of crashes, but that are reliable, easily obtainable, and available in a short period of time.

The theoretical basis for such a surrogate criterion may be found in two fields. In the field of road safety, it is the use of Safety Performance Indicators (SPIs) as predictors of crashes (ETSC, 2001; OECD-ECMT, 2008). In the field of social sciences, it is the use of behaviour models (BMs) to predict 
behaviour from underlying psychological determinants (Bartholomew et al., 2011; Glanz, Rimer, et al., 2008). The relationship with RSE is as follows. RSE aims to modify risk behaviour that is known to increase crash risk (SPI), for instance drink-driving. This goal is achieved by changing one or more of the underlying psychological determinants, for instance the 'attitudes about drink-driving'.

\section{Safety Performance Indicators and predictors of risk behaviour as surrogate measures}

SPIs are variables that are causally related to crash-related outcomes, either as an empirically tested relationship or as a logical relationship (ETSC, 2001). For empirically-tested SPIs, the extent to which risk behaviour increases crash risk is known, and therefore the effect of the intervention can be quantified in terms of crash-related outcomes. For logical SPIs, this is not the case, so it can only be inferred that the risk behaviour will increase crash risk. Unfortunately, 'empirical' SPIs are mainly available for 'car driving' and not yet for other travel modes such as cycling, walking or moped riding (Hakkert and Gitelman, 2007). Thus, evaluation studies for these travel modes can only make use of logical SPIs.

Similarly, behaviour models (BMs) are used to assess expected effects on (road) behaviour. BMs, such as the Health Belief Model or the Theory of Planned Behaviour, provide theories regarding how behaviour can be predicted from underlying psychological determinants (see Glanz, Rimer, et al., 2008 for an overview). If it were possible to predict behavioural change from changes in underlying determinants, variables from a particular BM could be used as outcome criteria in evaluation studies of RSE. Of all determinants, behavioural intention is the strongest determinant of behaviour (e.g., Glanz, Rimer, et al., 2008). Intention mediates the influence of other predictors, such as attitudes and knowledge, on behaviour and indicates "...how hard one is prepared to try, or how much effort one will exert, in order to achieve desired outcomes" (Webb and Sheeran, 2006 p. 249). To assess the actual strength of the intention-behaviour relationship after an intervention, Webb and Sheeran (2006) conducted a meta-analysis of randomized controlled trials, and concluded that a large change in intention only resulted in a medium-to-small change in behaviour. This finding confirmed again the intention-behaviour gap, but further analyses also showed the conditions under which this gap was greatest, namely: (a) when participants lacked control over the behaviour, (b) when the behaviour was performed in a social context, for instance smoking and drinking with friends, 
and (c) when the intention involved behaviour that had become a habit. Although these conclusions were not differentiated by age group, some of these characteristics may have an even greater impact on young adolescents. Lack of control especially may play a stronger role among adolescents than among adults, because of adolescents' greater impulsiveness (e.g., Gerrard et al., 2008; Gibbons et al., 2009; Gibbons et al., 2002; Reyna and Farley, 2006), their still-developing cognitive and executive skills (e.g., Blakemore et al., 2007; Blakemore and Choudhury, 2006), and their inexperience as road users (Twisk and Stacey, 2007; Vlakveld, 2011). In addition, the influence of the social context may differ between adolescents and adults, because of peer pressure that leads to adolescents taking greater risks in the presence of peers than when being on their own (e.g., Brown, 2004; Gardner and Steinberg, 2005; Sumter et al., 2009). Hence, in studies of young adolescents, changes in behaviour intentions may be a less reliable proxy for actual behaviour changes than for adults. Behaviour change, rather than change in intention, is thus the preferred criterion for evaluation studies involving this age group.

\section{Observation of behaviour versus self-report}

For the measurement of behaviour, two methods are at a researcher's disposal: observations of road behaviour and self-reports by means of questionnaires and diaries. Observations generate rich and reliable data but, because of the high financial costs, often include a relatively small and/or unrepresentative sample of participants, and are restricted to only a few behaviours and traffic situations. Self-report surveys, on the other hand, are less costly and therefore can include large numbers of participants, and focus on a wide range of behaviours and situations. This feature improves the generalisability of the data, but the accuracy of the reports may be questioned (Af Wåhlberg, 2009). It is beyond the scope of this article to provide a full account of all the evidence, but from these general characteristics of the two methods, one could conclude that when road behaviour strongly varies among subgroups (age, gender, social economic status), trip circumstances (e.g., trips to school versus trips to a party), and social situations (e.g., the presence of friends), self-reports may provide a more complete picture than observation. To study the validity of such selfreports among young adolescents, Elliott \& Baughan (2004) reviewed the literature and concluded, based on the few studies that had actually assessed the strength of the relationship, that 'there is little reason to assume that selfreported behaviour will not serve as a good proxy for more objectively measured behaviour'. Further, Twisk et al. ( forthcoming) analysed the relationship between self-reported risk behaviour and self-reported crash 
involvement among young adolescent cyclists and pedestrians, and found that self-reported risk behaviour explained $6 \%$ to $11 \%$ of the variance in selfreported crash involvement. Given the low frequency of crashes and the asymmetrical relationship with risk behaviour (Hauer, 2008), this predictive power is rather strong, and supports the validity of self-reported risk behaviours as surrogate criteria for RSE programme outcomes, especially for those risk behaviours that strongly vary by subpopulations and by contextual factors such as the presence of peers and trip conditions. In contrast, if an RSE programme focuses on specific competencies and skills, such as road crossing (Duperrex et al., 2009) or interactions with trucks (Twisk, Vlakveld, Mesken, et al., 2013), observation of small samples of participants performing strictly defined tasks may provide reliable estimates of skill acquisition.

\section{Design of study, recruitment of programmes and programme types}

Five RSE programmes were evaluated in their field settings. All five programmes aimed to improve safe behaviour by raising risk awareness rather than by improving road competence. Self-reported behaviour was thus the preferred method to assess the effects. In the present study, a quasiexperimental design was used (see Cook and Campbell, 1979, for example), which involved a comparison between pre- and post-test scores of an intervention group and a reference group. A quasi-experimental design differs from a 'true' experiment in the sense that the participants are not randomly assigned to one of the experimental conditions.

The RSE programmes were selected for evaluation if the following qualitative criteria were met: the programme (a) addresses risk behaviour, (b) is well established in the field, meaning that the programme has been delivered on a regular basis and (c) policy makers fund the programme because of its assumed effectiveness. This information was obtained by a short questionnaire among policy makers and education professionals. All programmes were classroom-based but differed in duration from a few hours to a full day.

The programmes also differed in approach and delivery. Three 'cognitive' programmes aimed to deter youngsters from taking risks by improving their understanding and insight through information and demonstrations of the safety-critical features, such as braking/stopping distances, limitations in visual perception and reaction times, and the vulnerability of the human body. These programmes assumed that information and personal experiences 
were sufficient to generate behavioural change. Two 'fear-appeal' programmes aimed to deter youngsters from taking risks by eliciting fear and informing them about the negative and often gruesome consequences of risk behaviour. These programmes used videos of crashes and personal accounts of road victims and assumed that the generated fear and anticipated regret were sufficient for behavioural change. Fear-appeal programmes are popular with policy makers, but are often less effective than commonly expected. For instance, studies of the effect of fear appeal in health related programmes showed that fear-appeal programmes are only effective when a person feels sufficiently competent to deflect the risk (efficacy) (Peters et al., 2012). The effects of fear appeal in road safety may differ from those in health prevention, since the perceived threats may - theoretically - be neutralized by the actor's perceived 'superior' road skills, his perceived efficacy. For instance, accepting small gaps between cars to cross a road, may not feel risky, if youngsters are convinced of their superior skills in judging speeds of oncoming traffic, and their fast reflexes. Thus, testimonies from injured road users may be impressive but will still not be seen to apply to them. Cognitive programmes, however, may be informative, but may not be successful in drawing the attention of the young adolescent. These programmes may solely address logical reasoning without leaving a long lasting mark. According to Damasio's Somatic Marker Hypothesis emotions play a critical role in creating such a mark, which then contributes to the ability to make fast decisions in complex and uncertain situations (Damasio et al., 1996). To test these potential effects, the present study compares cognitive and fear-appeal programmes on self-reported risk behaviour among young adolescents.

\section{2. $\quad$ Method}

\subsubsection{Interventions}

The three cognitive programmes were:

1. Traffic Market (age group 12-13). This programme was a one-day course that, by means of practical exercises, aimed to raise awareness of risky behaviour, to improve understanding of hazards, to stimulate empathy and the ability to "put oneself in another person's shoes." Examples of the practical exercises are "observing the conspicuity of cyclists in the dark, with and without bicycle light', 'experiencing the influence of alcohol on stability by wearing special 'alcohol goggles', and 'watching a traffic situation from another person's perspective', for instance by observing for oneself what a lorry driver can and cannot see. 
2. Traffic education for young adolescents (age group 12-13). This programme consisted of three lessons of 50 minutes each. Targeting pupils who had just started secondary school, it aimed to improve risk awareness and behavioural intentions with the aid of interactive materials (e.g., a traffic quiz) and videos. In addition, it contained a 'music player' test to raise awareness of the risks of listening to music when on the road, and a test of the technical status of the bicycles, including safety features such as working brakes and bicycle lights.

3. Driver instructors in school (age group 12-13). This programme consisted of two lessons of 50 minutes each. From the perspective of car drivers, driver instructors educated youngsters in their first years of secondary school about dangerous cycling behaviour. The driver instructors had received special training for delivering the programmes for this age group.

The two fear-appeal programmes were:

4. Traffic informers (age group 15-25). In this half-day programme, youngsters who had sustained injuries in a road crash and still suffered the consequences in terms of visible injuries and disabilities, spoke about their crashes and how the injuries affected their lives. After the session, each participant was asked to write a reaction. In addition, by riding in a wheelchair and moving around an obstacle course blindfolded, youngsters experienced for themselves the detrimental effects of physical handicaps on simple daily life activities.

5. Victim Aid (age group 15-18). This half-day programme focussed on the long term and far-reaching consequences of unsafe behaviour. The coordinator of the local Victim Aid organisation gave an introduction, and further supported that message with pictures from crashes, emotionally-loaded videos, and testimonies from victims and their relatives. No practical exercises were involved in this programme.

\subsubsection{Participants}

For the intervention group, schools were recruited that used one of the education programmes on a regular basis. Based on the characteristics of the intervention schools (their level of education and geographical location), comparable reference schools were selected that did not use the education programmes. All schools were for secondary education, and included higher secondary education, which prepares youngsters for university, and vocational education, which prepares youngsters for a specific job or function (e.g., carpentry or administration). 


\subsubsection{Design and procedure}

In the pre- and the post-test the same questionnaire (see Section 7.2.4) was administered during class. In the intervention group, the questionnaire was administered just before the RSE programme and again about one month later. Similarly, in the reference group about a month elapsed between the administration of the pre- and post-test questionnaires. In a previous pilot study, the questionnaires had been tested for comprehensibility and variance in responses among young adolescents, and revised accordingly. Participants were informed about the purpose of the study and the instructions emphasized that their answers would be treated confidentially and only used for the purpose of the present study. Participants were asked to report only the first three letters of their surname, thus further protecting their anonymity. These three letters, together with age and gender, were used to link the pre- and post-test records of the participants. On average, the questionnaire took about 20 minutes to complete.

Table 7.1 presents the sample sizes in each programme and experimental condition, the mean age in each group, and the proportion of participants for which the pre-test results could be successfully linked with those from the post-test. A number of participants could not be linked as a result of bad handwriting, drop-out, or the school's schedule, and because of the constitution of classes changing, depending on the time of day and day of the week. Although some programmes also targeted an older age group, the present evaluation only included youngsters 12 to 17 years old. The cognitive programme focussed on the 12 to 13 year old group, whereas the fear-appeal programmes focussed on a slightly older age group $15^{+}$(see Table 7.1.).

\begin{tabular}{llrrr}
\hline Approach & Name of programme & $\begin{array}{r}\text { Mean } \\
\text { Age }(S D)\end{array}$ & $\begin{array}{r}\text { Intervention } \\
\mathrm{N}(\% \text { linked })^{\mathrm{a}}\end{array}$ & $\begin{array}{r}\text { Reference } \\
\mathrm{N}(\% \text { linked) }\end{array}$ \\
\hline \multirow{3}{*}{ Cognitive } & $\begin{array}{l}\text { 1.Traffic Market } \\
\text { 2.Traffic education for }\end{array}$ & $12.3(.76)$ & $254(84 \%)$ & $74(33 \%)$ \\
& $\begin{array}{l}\text { adolescents } \\
\text { 3.Driver instructor in school }\end{array}$ & $13.6(.66)$ & $240(36 \%)$ & $155(73 \%)$ \\
\hline \multirow{2}{*}{ Fear-based } & 4.Traffic informers & $15.1(.77)$ & $359(65 \%)$ & $76(24 \%)$ \\
& 5.Victim Aid & $15.2(.98)$ & $175(58 \%)$ & $255(73 \%)$ \\
\hline
\end{tabular}

Table 7.1. Overview of programmes, mean age, and sample size of intervention and reference groups a Proportion of pre-test questionnaires successfully linked to post-test questionnaires. 


\subsubsection{The questionnaire}

The questionnaire contained items on behaviour determinants such as risk awareness and opinions about traffic rules, risky road behaviour such as violating traffic lights, and demographics such as gender, age, and school type. In the present study, only the responses on the items concerning selfreported road behaviour were used to assess the effects of the RSE programmes. The items were derived from Elliott \& Baughan's Adolescent Road User Behaviour Questionnaire (ARBQ) (Elliott and Baughan, 2004). Based on earlier studies on aberrant driving behaviour (Parker et al., 1992; Reason et al., 1990), the ARBQ addresses four types of road behaviour: 'intentional violations', 'unintentional errors', 'play', and 'protective behaviours'. Participants rated, on 6-point Likert scales ranging from 'never' to 'always', the frequency with which they engaged in each of 28 listed behaviours. To adapt the ARBQ to the Dutch traffic situation, a number of items on pedestrian behaviour were replaced by items on cycling behaviour. This adapted Dutch version is referred to as the ARBQ-BC. A few representative items of the ARBQ-BC are presented in Table 7.2. The complete questionnaires are presented in Appendices A and B.

How often do you......1= never, $6=$ always

- Forget to indicate changing direction when you cycle

- Need to brake suddenly because of having overlooked an oncoming car

- Cycle so close together that handle bars almost touch

- Cross the street only at locations where the light is good

- Forget to watch the traffic because of being on the phone

- Wear a helmet as a moped passenger

- Violate a red traffic light

Table 7.2. Sample items of ARBQ-BC, adapted and translated from Dutch, and derived from the ARBQ questionnaire (Elliott and Baughan, 2004).

\subsubsection{Data analysis}

Participants whose records could not be linked successfully (see Section 7.2.3) were excluded from all further analyses. For the remaining 1,874 participants it was investigated whether their responses on the 28 items of the ARBQ-BC in the pre- and the post-test could be reduced to a number of internally consistent subscales. A Categorical Principal Component Analysis (CATPCA, see Meulman and Heiser, 1999) of the scores on the 6-point Likert scales treated as ordinal variables showed that the first two principal 
components explained 26 and $11 \%$ of the variance in the data, respectively. All 28 variables had positive loadings on the first principal component, meaning that this component can be interpreted as a general 'safe behaviour' factor. Although the second principal component had an eigenvalue larger than one and also met Kaiser's criterion (Kaiser, 1960), the loadings of the 28 items of the ARBQ-BC on this second component did not display an interpretable pattern in terms of the earlier mentioned behaviour types 'intentional violations', 'unintentional errors', 'play', and 'protective behaviours'. Therefore, only the participants' object scores on the first principal component were retained and used as a criterion variable in the evaluation of the effects of the individual programmes.

Separate inspection of the obtained quantifications of the participants in terms of safe behaviour showed that the intervention and the reference group of each programme differed on the pre-test, indicating that the two groups were not equivalent in terms of safe behaviour. To statistically control for these initial differences, each programme was therefore evaluated with an ANalysis of COVAriance (ANCOVA) of the post-test scores using the pretest scores as covariates and experimental condition as a between-subjects factor. This was done separately for participants in higher secondary education schools and in vocational education schools. The ANCOVA assumptions of homogeneity of regression slopes in the groups and of independence of the covariate and treatment effects (see Field, 2009, p. 397 ) were tested. In order to be able to compare across programmes, the effect size $\eta^{2}$ was used to calculate the percentage of youngsters in the intervention group who changed their behaviour relative to the reference group. For this purpose, a Binomial Effect-Size Display (BESD) table was constructed for each programme (see Rosnow \& Rosenthal (2005) and Randolph \& Edmondson (2005) for details, and a discussion of its practical applications).

\section{3. $\quad$ Results}

\subsubsection{The effects of individual RSE programmes}

The results of the ANCOVA's are presented in Table 7.3 and the estimated means (i.e., the mean safe behaviour scores at post-test corrected for the scores at pre-test) are given in Table 7.4. With the exception of the RSE programmes 'Traffic education for young adolescents' and Traffic Informers', these results indicate that the intervention group reported safer behaviour than the reference group at post-test in the remaining programmes. 
However, the effect of 'Traffic Market' differed by school type and was only significant in vocational education schools. Based on Cohen's reported criteria (small effect $\eta^{2}=.01$, medium effect $\eta^{2}=.0588$ and large effect $\eta^{2}=$ .1379), the effect sizes are small (Cohen, 1988 p. 285-288). Only for the 'Traffic Market' programme in vocational education schools did the results reach a medium effect size of $\eta^{2}=.06$. The ANCOVA assumption of the independence of treatment effect and covariate was not satisfied for two RSE programmes: 'Traffic education for young adolescents' and 'Traffic Informers' (see Table 7.3). However, additional analyses on these two programmes using repeated measures ANOVA did not change the significance level. The ANCOVA assumption of the homogeneity of regression slopes was tested according to the procedure described by Field (2009) and was satisfied for all RSE programmes, with the exception of 'Victim Aid' in higher secondary education schools. However, repeated measures ANOVA again yielded similar results: $(F(1,261)=5.81, p=.02$, and an effect size of $\eta^{2}=.02$ ).

\begin{tabular}{llrrrr}
\hline Programmes & School type & $F$ & $d f$ & $p$ & $\begin{array}{r}\text { Effect } \\
\text { size }\left(\eta^{2}\right)\end{array}$ \\
\hline Traffic Market & Vocational & 9.18 & 1,146 & .01 & .06 \\
& Higher & .67 & 1,149 & .42 & \\
\hline Education of young adolescents & Vocational & .04 & 1,225 & $.84^{\mathrm{a}}$ & \\
& Higher (NA) & & & & \\
\hline Driving instructors in school & Vocational (NA) & & & & \\
& Higher & 4.21 & 1,190 & .04 & .02 \\
\hline Traffic Informers & Vocational (NA) & & & & \\
& Higher & 1.16 & 1,417 & $.28^{\mathrm{a}}$ & \\
\hline Victims Aid & Vocational & 4.01 & 1,117 & .05 & .03 \\
& Higher & 5.47 & 1,261 & $.022^{\mathrm{b}}$ & .02 \\
\hline
\end{tabular}

Table 7.3. ANCOVA results by programme and school type, with pre-test as covariate and post-test as dependent variable, including $F$ value, significance level and effect size (Cohen, 1988). a. Independence assumption not satisfied; b. Homogeneity assumption not satisfied. 


\begin{tabular}{llrrrr}
\hline Programmes & School type & \multicolumn{2}{c}{ Treatment group } & \multicolumn{2}{c}{ Reference group } \\
\cline { 2 - 6 } & & Mean & SE & Mean & $S E$ \\
\hline Traffic Market & Vocational & -.17 & 09 & .19 & .10 \\
& Higher & -.20 & .06 & -.08 & .13 \\
\hline Education for young adolescents & Vocational & .20 & .09 & .23 & 06 \\
& Higher & & & & \\
\hline Driving instructors in school & Vocational $^{*}$ & & & & \\
& Higher & -.01 & .07 & .20 & .08 \\
\hline Traffic Informers & Vocational $^{*}$ & & & & \\
& Higher & -.14 & .04 & -.03 & .09 \\
\hline Victims Aid & Vocational & .40 & .14 & .78 & .13 \\
& Higher & .01 & .07 & .20 & .05 \\
\hline
\end{tabular}

Table 7.4. Estimated means of the scores on 'safe behaviour' Note. Safe behaviour has negative values; unsafe behaviour has positive values. ${ }^{*}$ Not sufficient numbers of participants in reference and/or intervention group.

\subsubsection{Comparison among RSE programmes}

The effect sizes of the $F$-tests were used to compare RSE programme effects. To this end, for each programme, a BESD table was constructed to calculate the percentage of participants who reported having changed their behaviour relative to the reference group (Randolph and Edmondson, 2005). The higher that percentage, the more effective the programme is. As an illustration, Table 7.5 presents the complete BESD table for the programme 'Victim Aid' in vocational education schools where the effect size was $\eta^{2}=0.03$ (see Table 7.3). Table 7.5 shows that a higher percentage of students in the intervention group $(58.6 \%)$ reported changing their behaviour in the desired direction than in the reference group (41.4\%). This difference results in a net effect of $17.2 \%$ (58.6 minus 41.4$)$.

\begin{tabular}{lccc}
\hline Group & Positive effect & No effect & Total \\
\hline Intervention & $58.6^{\mathrm{a}}$ & $41.4^{\mathrm{b}}$ & 100 \\
Reference & $41.4^{\mathrm{b}}$ & $58.6^{\mathrm{a}}$ & 100 \\
Total & 100 & 100 & 100 \\
\hline
\end{tabular}

Table 7.5. Example of BESD table for Victim Aid programme/ vocational education (\%) Note: ${ }^{\mathrm{a}} 100^{*}(.500+\eta / 2)$ and ${ }^{\mathrm{b}} 100^{*}(.500-\eta / 2)$. 
The relative percentages for the five programmes are presented in Table 7.6 in two categories: cognitive and fear-appeal programmes. On average, 10.2\% of the intervention group participants improved their behaviour relative to the reference group participants.

\begin{tabular}{lrr}
\hline Programme Improvement & Per programme type & Per programme \\
& $\%$ & $\%$ \\
\hline All Cognitive programmes & 10 & 17.2 \\
Traffic Market & & $8.3^{*}$ \\
Traffic education for young adolescents & & 14.1 \\
$\quad$ Driving instructors in school & 14.4 & $3.2^{*}$ \\
\hline All Emotion/fear-appeal programmes & & 20.0 \\
$\quad$ Traffic informers & & \\
$\quad$ Victim Aid & 10.2 & \\
\hline All Programmes & &
\end{tabular}

* Not statistically significant $p<.05$

Table 7.6. Comparison of programmes by type: the percentage of participants who improved in the intervention group relative to the reference group (irrespective of school type).

A comparison of the programme types showed that the fear-appeal programmes yielded a slightly higher percentage of participants $(14.4 \%)$ improving their behaviour than did the cognitive programmes (10\%). For both school types, this difference was not statistically significant (approach * condition: vocational school type; $F(1,562)=1.96, p=.16$; for the higher school type $F(1,1156)=.68, p=.41)$.

\subsubsection{Effects by gender and school type}

An ANCOVA of all participants with gender, school type, RSE programme, and programme type as grouping variables showed a main effect for gender $(F(1,1802)=11.68, p=.001)$, with boys reporting riskier behaviour than girls. The interaction between gender and programme, as well as the interaction between gender and programme type (fear-appeal versus cognitive programmes), were not significant, indicating that effects of the programmes did not differ for boys and girls. Also the interactions between programme type and school type were not significant. 


\subsection{Discussion}

This study had two related objectives: (a) develop a 'feasible and practical' method for evaluating RSE that would also permit a comparison among programmes, and (b) apply the method to assess and compare the effects of five education programmes for young adolescents. First, the effects of the programmes are discussed, followed by a discussion of the evaluation method.

\subsubsection{The effects of the programmes}

Five programmes were included in the evaluation. Three of those resulted in statistically significant but small improvements in self-reported safe behaviour. Relative to the reference participants, between $3 \%$ and $20 \%$ of the programme participants changed their behaviour in the desired direction. The different didactic approaches enabled a comparison of the effects of 'cognitive' and 'fear-appeal' programmes.

Contrary to popular belief, the present evaluation study shows fear-appeal programmes not to be more effective than cognitive programmes. This finding concurs with earlier reports from review studies and meta-analyses (Ruiter et al., 2001; SWOV, 2009a; Van Vlierden, 2006; Witte and Allen, 2000) that showed that fear-evoking programmes may be less effective than often assumed, and even may lead to resistance, as was the case for 'speeders' in response to a fear-appeal campaign on speeding (Goldenbeld et al., 2008). In a review of RSE for adolescents, Williams (2007) also refers to these downsides where he states: "Adolescents are particularly likely to react to severe threats by discounting the likelihood of the negative outcome occurring to them, inoculating themselves, and high risk youth are most likely to reject such messages. Moreover, risk communication to young people is difficult because risk has attractions for them and they tend to assess risk in terms of opportunity for gains rather than opportunities for loss" (p.6). Given the possible drawbacks of fear-appeal programmes, the fine balance between acceptance and rejection of the message, and the minor differences shown in this study between the effects of cognitive and fearevoking programmes, the use of cognitive programmes in classroom settings is to be preferred.

The evaluation study shows the impacts of all five programmes to be small. Practitioners' expectations of the effects were higher than those actually found in the evaluation. However, given the complexities of behaviour 
change (Bartholomew et al., 2011; Dragutinovic and Twisk, 2006; Glanz, Stryker, et al., 2008), these expectations may have been too high for any RSE programme. Still, the study also revealed large differences - a factor six - in the effects among the programmes. Such a large difference between the weakest and the strongest programme also illustrates the variation in the quality of the programmes, and the scope for improvements. These findings underscore the need for evidence-based interventions that are developed using thorough evaluation studies. Such standard practice would also resolve the ethical dilemma in which prevention workers find themselves when they intervene in the lives of others for their benefit but often without their explicit consent, thereby using programmes of unknown quality. As shown here, some of these programmes did not live up to expectations. In theory, ineffective programmes that are not recognized as such may do more harm than good by creating a false sense of safety, overconfidence, denial, or rejection (Chalmers, 2003).

\subsubsection{Limitations and strengths of the evaluation method}

The second objective of the study was to develop a feasible and practical method for evaluating education programmes that would also permit comparison among programmes. As shown in the previous section, the approach enables a comparison among effects of programmes. But several limitations in the study may be reason for concern, namely: the low percentage of linked questionnaires in the pre- and post-test in some groups, the differences among cognitive programmes possibly confounded by age group, a possible Hawthorne effect, no random assignment to the experimental conditions, and no separate analyses for cyclist and pedestrian behaviour.

First, the low percentage of linked questionnaires was not due to the technical linkage process itself, but to different individuals participating in the pre- and post-test and to youngsters, deliberately or not, providing inaccurate information. It is not possible to rule out that this less-thandesired linkage may have affected the results. Therefore, more effort and better protocols are needed to assure that higher linkage percentages are achieved in the future. Second, with respect to the differences in effect between fear-appeal and cognitive approaches, it cannot be ruled out that the age of the participants may have affected the observed results. The fearappeal programmes were mainly administered to a slightly older age groups, than the cognitive programmes. The third limitation concerns the fact that the observed changes may have resulted from the field experiment itself, rather than from the intervention. The intervention groups were informed 
about the expectation that the intervention would change their behaviour. As has been demonstrated in several studies, information of this type along with the participants' awareness of taking part in an experiment may have caused a change toward safer road behaviour (Adair et al., 1989). This effect, also known as the Hawthorne effect, may have caused an overestimation of the magnitude of the behaviour change. Thus, the small effects of the programmes may have even been smaller, if we had controlled for the occurrence of these Hawthorne effects, for instance by the inclusion of additional reference groups or an additional but irrelevant intervention. The fourth limitation, concerning the pooling of risky cyclist and pedestrian behaviour, may have obscured possible differences in risk behaviours.

Aside of these limitations, several strengths were associated with the developed evaluation method, namely the quasi-experimental design, the differentiation between different types of risk behaviour, and the use of BESD tables to communicate the results. While a quasi-experimental design without random assignment is less than ideal, it is often the only feasible approach and does have some advantages. Programmes are evaluated in their natural setting and participants are tested in classrooms instead of laboratory conditions, resulting in high response rates and low selfrecruitment bias. Intervention and reference schools may not be comparable, as schools that run certain programmes may differ in safety culture and other aspects. However, as shown in the present study, these differences can be statistically controlled for if pre-test scores are available.

Further, this study used Reason et al. (1990) theoretical framework on risky behaviours to assess adolescent risk behaviour on the road. As for the different risk types - 'intentional violations', 'unintentional errors', 'play', and 'protective behaviours' - we did not find the expected factor structure. This, however, is not unique and could point at a structurally different attribution process for this age group, since several studies that also used Reason et al. (1990)'s violation dichotomy also failed to replicate the expected factor structure for road user behaviour in early adolescence (e.g., Elliott and Baughan, 2004; Sullman and Mann, 2009). Moreover, those studies that reported correlations among the different risk types showed these to be very high (Feenstra et al., 2011; Steg and Van Brussel, 2009), suggesting that individuals who commit violations are also the ones who score high on errors. Therefore, further study is needed of the possible differences between adult and adolescent interpretations of risky behaviour and associated attributions. 
The BESD tables were used to translate the findings into a measure that is easy to understand by practitioners who may not have a scientific background, but do have a desire to understand the results of their efforts. The BESD table made it possible to compare the outcome results of the programmes, was intuitively understandable, clarified the implications of effect sizes, and helped to convey the results to a non-scientific audience (Randolph and Edmondson, 2005).

\subsection{Conclusions}

This study evaluated the effects of five short RSE programmes using a common methodology. It showed that three out of five programmes resulted in self-reported behaviour changes, but the magnitude of these changes was relatively small. In contrast to popular belief, cognitive programmes were found to be as effective as fear-evoking programmes. The programmes were equally effective for boys and girls, and for students from different school types. The methodology developed for the evaluation of these programmes is practical, can be used in field settings, is relatively inexpensive, is theorybased, and appears to be of sufficient quality to result in reliable outcomes. Studies of this type may help professionals in the field to improve the impact of the RSE programmes currently in use. 



\title{
8. Quantifying the influence of safe road systems and legal licensing age on road mortality among pre-license adolescents ${ }^{10}$
}

\begin{abstract}
The role of risk behaviour (sometimes deliberate and sometimes from inexperience or other non-deliberate causes) in adolescent road mortality is well documented. However, little is known about the extent to which the 'road system' itself may also have an impact on younger adolescents' road mortality. This, by providing a safe or unsafe road environment for all road users (System-induced Exposure) and by allowing access to high-risk vehicles at a young or older age through the legal licensing age. This study seeks to explore these relationships by analysing the extent to which the road mortality of 10 to 17 year olds in various jurisdictions can be predicted from the System-induced Exposure (SE) in a jurisdiction and from its legal licensing age to drive motor vehicles.

Method: SE was operationalized as road fatalities per $10^{5}$ inhabitants/all ages together, but excluding the 10 to 17 year olds. Data on road fatalities during the years 2001 through 2008 were obtained from the OECD International Road Traffic Accident Database (IRTAD) and from the US NHTSA's Fatality Analysis Reporting System (FARS) database for 29 early and 10 late licensing jurisdictions. Linear mixed models were fitted with annual 'Adolescent road mortality per capita' for 2001 through 2008 as the dependent variable, and time-dependent 'SE' and time-independent 'Licensing system' as predictor variables. To control for different levels of motorisation, the time-dependent variable 'Annual per capita vehicle distance travelled' was used as a covariate. Licensing system of a jurisdiction was entered as a categorical predictor with late licensing countries as a baseline group.

Results and conclusions: The study found support for the protective effects of SE on adolescent safety. If SE increased by one unit, the mortality rate of 10 to 17 year olds increased by 0.487 units. No support was found for a protective effect of late licensing for this age group. Thus, compared to young adolescents who are allowed to drive motor vehicles in early licensing jurisdictions, late licensing does not provide extra protection for pre-license adolescents. This finding is probably the result of the high risks associated with alternative transport modes, such as moped riding and bicycling. Also, the fact that the study only included risks to young adolescents themselves and did not include the risks they might pose to other road users and passengers may have contributed to this finding, because such risks are greater when driving a motor vehicle than riding a moped or a bicycle.
\end{abstract}

10 This chapter was submitted in a modified version for publication as: Twisk, D., Commandeur, J.J.F., Bos, N., Shope, J.T., Kok, G., Quantifying the influence of safe road systems and legal licensing age on road mortality among pre-license adolescents. Accident Analysis and Prevention. (submitted 20-07-2014) 


\subsection{Introduction}

Road injuries worldwide are a leading cause of death among young adolescents 10 to 17 years old (Sleet et al., 2010). Three characteristics of adolescent development have been noted across jurisdictions as associated with adolescent road risk: a) increasing novelty seeking, b) increasing risk taking, and c) changing orientation in social affiliations from the family unit toward peer-interactions (Johnson et al., 2009; Keating and Halpern-Felsher, 2008). Because of these characteristics, interventions have been implemented that aim to reduce risk behaviour by addressing factors such as deliberate risk taking, inexperience and peer pressure (Dragutinovic and Twisk, 2006; SUPREME, 2007; Twisk, Vlakveld, et al., 2014b). Recent findings from brain research, however, have suggested that adolescent risk behaviour also results from structural changes in the adolescent brain (Boyer, 2006; Glendon and Bryan, 2011). Hence, risk behaviour may be hard to ameliorate by interventions such as education and publicity campaigns (Reyna and Farley, 2006). Moreover, there is still the question of how to approach risk behaviour. Although risk behaviour may be dangerous, it is probably also vital for the acquisition of skills necessary for the preparation of adult roles. Therefore, several researchers have cautioned against interventions that merely discourage the exploration of new behaviours and environments (Crone and Dahl, 2012; Johnson et al., 2009; Keating and Halpern-Felsher, 2008; Paus, 2009), and advise creating instead a social and physical environment that helps adolescents "...to learn about themselves and their environments and to explore adult behaviours, many of which are key to successful maturation" (Johnson et al., 2010, p. 9).

Such an approach to adolescent risk behaviour can be considered as an aspect of Safe System Approaches (SSA) and System Theory (Larsson et al., 2010; Salmon et al., 2010; Salmon et al., 2012) to the prevention of road casualties (OECD-ECMT, 2008). In keeping with earlier successful approaches in the field of injury control (Haddon, 1980a; Wagenaar and Reason, 1990; Wegman and Aarts, 2006), SSAs aim to create safe road systems, consisting of road infrastructure, legislation, and vehicles, such that safety is incorporated into the design of the system and not solely dependent on the decisions of individual road users. Or as Peden and colleagues state: A 'safe traffic system is one that accommodates and compensates for human vulnerability and fallibility' (Peden et al., 2004, p. 157). Thus, adolescents may benefit from these safe road systems that mitigate the most serious consequences of their occasional risky behaviour. SSA systems differ however in approach. For 
instance Vision Zero in Sweden is primarily based on the introduction of safe interaction and shared responsibility, whereas Sustainable Safety in the Netherlands centres around the application of Reason's Swiss cheese model (Reason, 1990; Reason et al., 1990; Wagenaar et al., 1990) of Generic Error Modelling Systems (GEMS) to road safety. This application not only incorporates the direct interactions between road users, but primarily focuses on the predisposing conditions such as legislation, road network and vehicle design (Wegman and Aarts, 2006, p. 29). Similar to Sustainable Safety, System Theory analyses the socio-technical complex system of interacting individual components as a whole (Salmon et al., 2012). It differs from Sustainable Safety in that it explicitly analyses the processes that lead to complex systems to fail. An example of this emphasis is the concept of 'Drift into failure' which addresses the slow and incremental movement of systems operations '... towards the edge of their safety envelope '(Dekker, 2005, p. 2).

This study uses aspects from System Theory to assess the potential influence of the road system on adolescent road mortality, which to date has not yet been quantified. In that context, the study assesses two factors relevant for or indicative of a SSA: a) System-induced Exposure to risk (SE), which potentially affects all road users, including adolescents, and b) the additional effect of licensing age, which mainly affects adolescents.

A wide range of measures are known to reduce SE and enhance road safety. Examples of such measures are low alcohol limits, low speed limits, crashworthy cars, and safe roads with forgiving roadsides. The combination of these measures has been shown to drive road mortality rates down (OECDECMT, 2008). Therefore, the overall road mortality rate (road fatalities per 100,000 inhabitants) can be regarded as a proxy for the level of SE in a country.

Late licensing has shown to be beneficial for the safety of novice drivers. Jurisdictions that license late - at age 18 and older - have better safety records for novice drivers than jurisdictions that license early, around age 14 to 17 (see OECD-ECMT, 2006 for an overview). Measures that affect the mobility patterns of high-risk groups may have a great impact on safety, as was for instance shown in a study of the safety effect of the free public transport pass for students and the economic recession in the Netherlands in the early 1990s (Twisk, 2000). This combination of events led to a strong drop in car ownership and car driving in those years among young males. The concurrent $50 \%$ drop in fatalities among young male drivers was most likely a direct result of those changes in mobility. 
To date, most studies have addressed the mobility and safety of car-driving adolescents. Little is known, however, about the effects of the restriction on car mobility on the safety of pre-license adolescents in late-licensing jurisdictions, the under-eighteen year olds. Although this age group is not yet exposed to the high risk of driving, because of their changing interests and leisure preferences, their mobility patterns change. Twisk, Bos, Shope and Kok (2013) compared mobility patterns of childhood and early adolescence in the Netherlands, a late-licensing country, and showed that from age 12 onward, mobility patterns changed from youngsters being primarily transported as passengers in cars to youngsters primarily getting around on bicycles and mopeds. At age 16, almost as many kilometres are travelled on a bicycle as in a car. Because a kilometre travelled by bicycle is about 2.5 times and on a moped even 6 times more dangerous than a kilometre travelled by car, this change in mobility patterns was shown to contribute to the rising number of road fatalities from age 10 onward. However, that purely descriptive study did not answer the question whether, similar to novice drivers, young adolescents would be better off in a late-licensing-country than in an early-licensing country.

This study sought to examine these relationships by comparing the road mortality of 10 through 17 year olds in jurisdictions with different levels of System-induced Exposure (SE) and different driver licensing ages. In order to study the latter relationship, jurisdictions were grouped into two categories: late- and early-licensing jurisdictions. Because jurisdictions self-regulate road policy, resulting in differences among jurisdictions on road design, enforcement strategies, education programmes, and licensing age (e.g., Eksler et al., 2008; Lynam et al., 2002), comparisons among jurisdictions with different levels of SE and different legal licensing ages may reveal whether these factors are predictive of road mortality among 10-17 year old adolescents. The hypothesis was tested that road systems with low SE protect adolescents significantly better than systems with high SE (H1). The study further assessed the additional influence of legal driver licensing age, by comparing young adolescent road mortality in jurisdictions with early and late licensing, irrespective of transport mode, at the same time controlling for the influence of level of motorization and of SE. Further, the research question was addressed whether road mortality rates of 10 to 17 year olds are lower in late-licensing jurisdictions than in jurisdictions that license early. 


\subsection{Method}

\subsubsection{Measures}

Annual System-induced Exposure (SE). In contrast to exposure to hazards such as chemicals, exposure to road risk cannot be measured objectively, but is commonly operationalized as 'fatalities per distance travelled' or 'the number of fatalities per capita' (Braimaister et al., 2002). The first rate is more precise as it also takes into account the extent to which the road system is used. This kind of data, however, is only available for a small number of countries, especially when it comes to stratification by age group. Data for the second rate is available for many countries over a long period of time, and the number of fatalities per capita has frequently been used as an indicator for safety performance for comparisons among countries, for instance in the SUNflower studies (Wegman et al., 2006) and the PIN studies (ETSC, 2009). Therefore, the present study operationalized SE as the number of road fatalities per 100,000 population in a jurisdiction per year, while excluding the age group under study, the 10 to 17 year olds, both in the number of fatalities and in the population numbers.

Average System-induced Exposure (SE) was calculated as the total of number of fatalities in a jurisdiction (excluding the 10 to 17 year olds) over the period 2001 through 2008 divided by the total population size (excluding the 10 to 17 year olds) in that period, multiplied by 100,000.

Annual young adolescent road mortality was operationalized as the number of road fatalities among 10 to 17 year olds per 100,000 population of that age group in a jurisdiction by year.

Average young adolescent road mortality was calculated as the total number of road fatalities among the 10 to 17 year olds over the period 2001 through 2008 divided by the total population of 10 to 17 year olds in that period, multiplied by 100,000 .

Annual per capita vehicle distance travelled was operationalized as the total motor vehicle distance travelled per capita per year. Since these data were missing for the years 2001 and 2002 in all US states, for each state a linear regression of the non-missing data on time was performed, and the extrapolated values from this regression analysis were imputed for the missing first two years. 


\subsubsection{Jurisdictions and legal driver licensing age}

\begin{tabular}{|c|c|c|c|}
\hline & $\begin{array}{l}\text { Learner stage } \\
\text { age }\end{array}$ & $\begin{array}{l}\text { Intermediate stage } \\
\text { Age (years) \& restrictions }\end{array}$ & $\begin{array}{l}\text { Full license } \\
\text { Age (years) }\end{array}$ \\
\hline Alabama & 15 & 16 \& passenger and night & 17 \\
\hline Arizona & $15+7 \mathrm{~m}$ & No intermediate license stage & 16 \\
\hline California & $15+6 m$ & 16 \& passenger and night & 17 \\
\hline Colorado & $\begin{array}{l}15 \text { with ed }{ }^{1} . \\
16 \text { without ed }\end{array}$ & $16 \&$ passenger and night & 17 \\
\hline Florida & 15 & $16 \&$ passenger & 18 \\
\hline Georgia & 15 & 16 \& passenger and night & 18 \\
\hline Illinois & 15 & 16 \& passenger and night & 17 \\
\hline Indiana & 15 & $16+1 \mathrm{~m} \&$ passenger and night & 18 \\
\hline Kentucky & 16 & 16 \& passenger and night & 17 \\
\hline Louisiana & 15 & 16 \& night restriction & 17 \\
\hline Maryland & $15+9 m$ & $16+3 m \&$ passenger and night & $17+9 m$ \\
\hline Massachusetts & 16 & $16+6 m \&$ passenger and night & 18 \\
\hline Michigan & $14+9 m$ & 16 \& night & 17 \\
\hline Minnesota & 15 & $16 \&$ no restrictions & 17 \\
\hline Missouri & 15 & $16 \&$ passenger and night & 18 \\
\hline New Jersey & 16 & $17 \&$ passenger and night & 18 \\
\hline New York & 16 & $16+6 m \&$ passenger and night & 18 without ed. \\
\hline North Carolina & 15 & $16 \&$ passenger and night restriction & $16+9 m$ \\
\hline Ohio & $16+6 m$ & $16 \&$ passenger and night restriction & 17 \\
\hline Pennsylvania & 16 & $16+6 m \&$ night restriction & 18 without ed. \\
\hline South Carolina & 15 & $\begin{array}{l}15+6 m \& \text { passenger \& night } \\
\text { restriction }\end{array}$ & $16+6 m$ \\
\hline Tennessee & 15 & $16 \&$ passenger and night restriction & 17 \\
\hline Texas & 15 & $\begin{array}{l}16 \& \text { night curfew and passenger } \\
\text { restriction }\end{array}$ & $16+6 \mathrm{~m}$ \\
\hline Virginia & $15+6 \mathrm{~m}$ & $\begin{array}{l}16+3 \mathrm{~m} \& \text { passenger and night } \\
\text { restriction }\end{array}$ & 18 \\
\hline Washington & 15 & $16 \&$ passenger and night restriction & 17 \\
\hline Wisconsin & 15 & $16 \&$ passenger and night restriction & $16+6 \mathrm{~m}$ \\
\hline
\end{tabular}

Table 8.1. Overview of ages, GDL stages and restriction for the US states (Baker et al., 2007) $1=$ education. 
To assess the effect of SE and driver licensing age, the SE data for 10 latelicensing (18 years and older) European countries (Austria, Belgium, Czech Republic, Denmark, Finland, France, Germany, Netherlands, Norway, and Switzerland) and 29 early-licensing countries and states that license for solo driving - albeit several with restrictions - between 15 and 17 years old (New Zealand, Canada, Australia, Alabama, Arizona, California, Colorado, Florida, Georgia, Illinois, Indiana, Kentucky, Louisiana, Massachusetts, Maryland, Michigan, Minnesota, Missouri, North Carolina, New Jersey, New York, Ohio, Pennsylvania, South Carolina, Tennessee, Texas, Virginia, Washington, and Wisconsin) were used in the analysis. Selection of countries and states was based on population size ( $>4$ million inhabitants) and availability of data in the IRTAD database or from FARS and the Population Reference Bureau (2011), for the individual US states. Because most states in the US have implemented a graduated driving license system (GDL), novice drivers go through three progressive stages from supervised driving (the learner stage) through unsupervised driving, but with restrictions during the intermediate stage, often on carriage of same-aged passengers and night time driving, to full licensure. Table 8.1 presents for the 25 states the characteristics of the GDL system as documented by Baker et al. (2007), showing that in most states youngsters in the period under study were allowed to drive unsupervised (the intermediate stage) around age 16, with the exceptions of New Jersey and South Carolina. The present study did not take into account that states may have changed the details of their systems in the study period and how this may have affected safety levels. In Australia, licensing age for solo driving, with a restricted license varied by state during our study period. With the exception of Victoria, all licensed at ages below 18 (OECD-ECMT, 2006, pp. 255-257).

\subsubsection{Databases}

For the European countries and for Canada, Australia, and New Zealand, yearly fatality (by age group), mobility, and population data (by age group) were obtained from the International Road Traffic and Accident Database (IRTAD, 2013) for the period 2001 through 2008. For the USA, population data were obtained from the Population Reference Bureau (2011), the data on motor vehicle travel from the Traffic Volume Trends of the Federal Highway Administration (FHWA), and the data on road fatalities from the NHTSA's Fatality Analysis Reporting System (FARS) database (NHTSA, 2013). The IRTAD database contains information on road fatalities from all member states of the Organisation for Economic Co-operation and Development $(\mathrm{OECD})$, which include both European and non-European countries. The 
USA is also available in this database, however not at the state level. A fatal traffic crash in the IRTAD database is defined as a crash that involves at least one vehicle (motorized or non-motorized) traveling on a public road in which at least one person is fatally injured and has died within 30 days of the crash. FARS is a database of fatal traffic crashes within the USA. that involve a crash with a motor vehicle traveling on a public road in which at least one person is fatally injured and has died within 30 days of the crash (Eurostat, 2009). Thus, IRTAD and FARS differ slightly on the definition of a road crash, with the consequence that compared to FARS, IRTAD includes an additional category, namely fatalities resulting from single bicycle crashes, crashes among bicyclists, and pedestrian-bicycle crashes. This has most likely little impact on the present study, as the number of fatalities in this additional IRTAD category is extremely low. In the Netherlands for instance, where a high proportion of travel occurs by bicycle, only 5.5\% of all road fatalities results from crashes without motorized traffic. Note that fatalities among cyclists and pedestrians involved in a crash with a motorized vehicle are included in both databases. Also note that mopeds are defined as a motor vehicle in both databases.

\subsubsection{Statistical analysis}

Linear mixed models (see, for example Stroup, 2013; Twisk, 2013) were fitted to the 10 through 17 year old adolescent age group with the annual 'Adolescent road mortality per capita' in 2001 through 2008 for 39 jurisdictions as the dependent variable (thus consisting of a total of $39 \times 8=$ 312 observations), and time-dependent 'SE' and time-independent 'Licensing system' as predictor variables. To control for different levels of motorisation in the 39 countries and states involved in the analysis, the time-dependent variable 'Annual per capita vehicle distance travelled' was used as a covariate. Licensing system of a country was entered as a categorical predictor with late-licensing countries as a baseline group (late being coded as 0 , and early being coded as 1 ).

Linear mixed models can be conceived of as generalizations of and improvements on repeated measures analysis of variance models. The latter models assume the residuals to satisfy a rather restrictive and often unrealistic residual compound symmetry variance structure, and are also very wasteful when 'subjects' (i.e., countries and states in the present case) happen to have missing data on one or more occasions because these 'subjects' then need to be completely removed from the analysis. Linear mixed models, on the other hand, not only can handle missing observations 
in the dependent variable but also allow the application of less restrictive residual covariance structures in order to handle the serial correlation present in repeated measures data.

In order to appropriately handle the serial correlation in the observations arising from the eight repeated measurements in the 39 countries and states, the following residual covariance structures were investigated with the SPSS procedure MIXED (IBM, 2012): compound symmetry, autoregressive of order 1, Toeplitz, and unstructured. The best fitting, most parsimonious model was identified by means of the Akaike information criterion where smaller values indicate a more parsimonious fit. For further details on linear mixed models we refer to Twisk (2013) and Stroup (2013).

\subsection{Results}

Figure 8.1 presents for the period 2001 through 2008 for the 39 jurisdictions the values for SE (all road fatalities per 100,000 excluding the 10 to 17 year olds), projecting on the x-axis, and adolescent mortality (road fatalities among 10 to 17 year olds per 100,000 population), projecting on the y-axis. Table 8.3 presents an overview of the country codes used in Figure 8.1. The figure shows that in all 39 countries and states, adolescent mortality was lower than that of the general population. But adolescent mortality was still positively associated with SE, with the Pearson product-moment correlation $\left(r_{s}=.80\right)$ showing that $64 \%$ of the variance was shared between the two variables.

\begin{tabular}{lrrrrr}
\hline Parameter & Estimate & Std. Error & $\mathrm{df}$ & $\mathrm{t}$ & $\mathrm{Sig}$. \\
\hline - Intercept & -1.540 & 1.046 & 44.575 & -1.473 & 0.148 \\
- Early licensing system $=1$ & -0.211 & 0.650 & 41.298 & 0.325 & 0.747 \\
- Late licensing system $=0$ & $0 \mathrm{a}$ & 0 &. &. & . \\
- Per capita vehicle distance & 0.216 & 0.083 & 53.903 & 2.609 & 0.012 \\
$\quad$ travelled & & & & & \\
- System-induced exposure & 0.487 & 0.044 & 73.652 & 11.148 & 0.000 \\
\hline
\end{tabular}

Table 8.2. Estimates of fixed effects in linear mixed model applied to age specific mortality of $10-17$ year olds with Toeplitz residual covariance structure. a. This parameter is set to zero. 
The values of the Akaike information criterion for the compound symmetry, autoregressive of order 1, Toeplitz, and unstructured residual covariance structures were 1173.019, 1165.618, 1144.167, and 1152.193, respectively. Of the residual covariance structures investigated with linear mixed models, it was therefore found that a Toeplitz structure yielded the best fitting and most parsimonious model. The results for this model are presented in Table 8.2. For the 10 to 17 year old adolescents, we find that SE is a significant predictor of their age-specific mortality. The positive value of 0.487 for the corresponding parameter estimate indicates that - after correction for the different levels of motorisation in the 39 countries and states - a decrease of one unit in the number of road fatalities per 100,000 population (i.e., a decrease of one unit in its general road safety) is associated with a decrease of 0.487 units in the mortality of 10 to 17 year old adolescents. However, the difference in mortality in the late and early-licensing countries and states is not found to be significant.

\begin{tabular}{llllll|ll}
\hline \multicolumn{2}{l}{ Country/State Code Early License } & & & & \multicolumn{2}{l}{ Country Code Late licence } \\
\hline Alabama & AL & Kentucky & KY & New Zealand & NZ & Austria & AT \\
Australia & AU & Louisiana & LA & Ohio & OH & Belgium & BE \\
Arizona & AZ & Massachusetts & MA & Pennsylvania & PA & Czech Republic & CZ \\
\hline California & CA & Maryland & MD & $\begin{array}{l}\text { South } \\
\text { Carolina }\end{array}$ & SC & Denmark & DK \\
Canada & CAN & Michigan & MI & Tennessee & TN & Finland & FI \\
\hline Colorado & CO & Minnesota & MN & Texas & TX & France & FR \\
Florida & FL & Missouri & MO & Virginia & VA & Germany & DE \\
\hline Georgia & GA & North Carolina & NC & Washington & WA & Netherlands & NL \\
Illinois & IL & New Jersey & NJ & Wisconsin & WI & Norway & NO \\
\hline Indiana & IN & New York & NY & & & Switzerland & CH \\
\hline
\end{tabular}

Table 8.3. Overview of country codes used in Figure 8.1. 


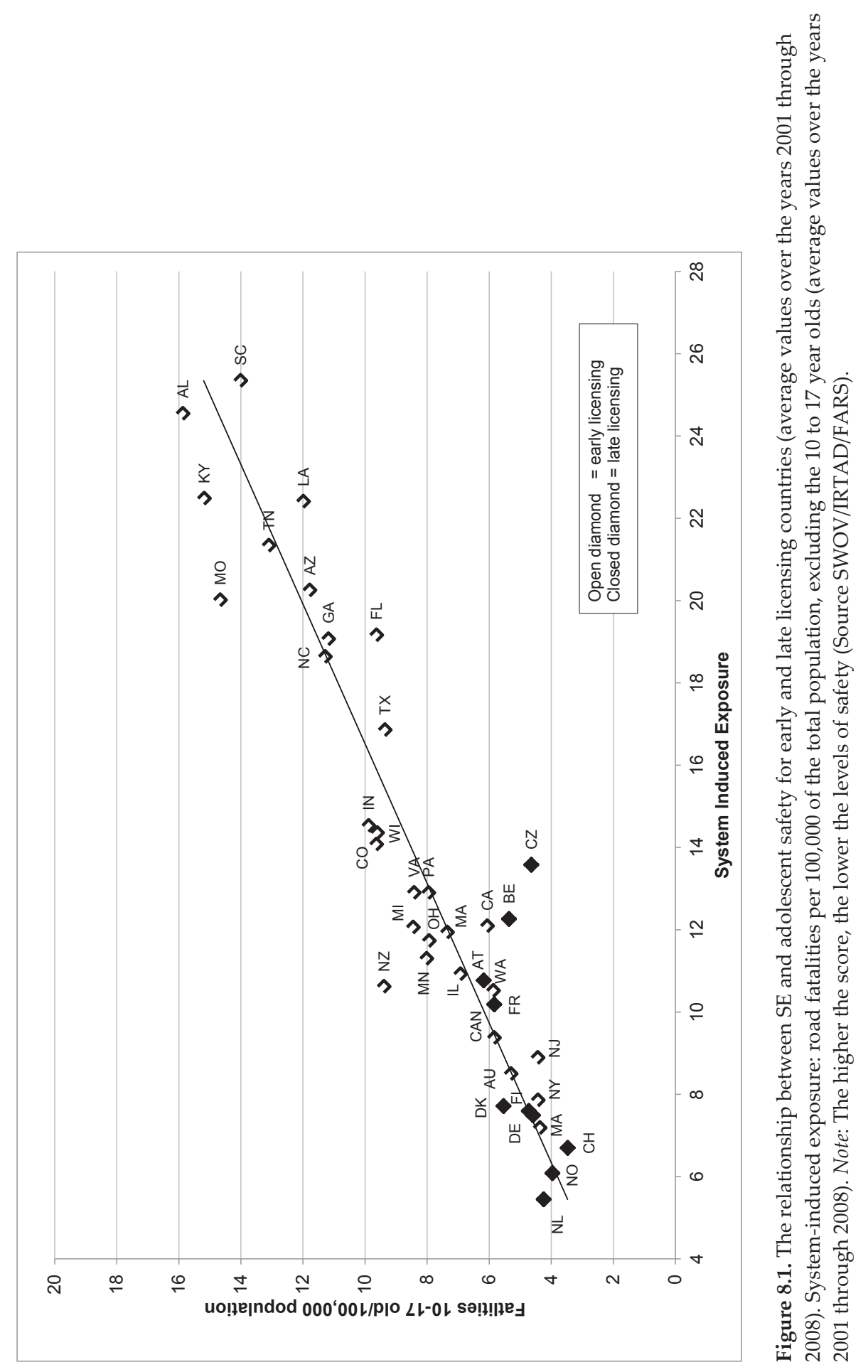


These results provide support for the hypothesis that, after taking care of the serial correlation in the repeated measurements with a Toeplitz covariance structure, and after controlling for the different levels of motorisation, safe road systems (those with low system-induced exposure) have better safety records for young adolescents than road systems with high system-induced exposure. Licensing system - early or late - did not appear to have an effect.

\subsection{Discussion}

Several authors have suggested that creating a safe environment to accommodate adolescent explorative behaviour may protect youngsters from serious harm. The present study aimed to test that hypothesis for adolescent safety on the roads. Using IRTAD and FARS data on road mortality, the study investigated effects of System-induced Exposure (SE) and legal driver licensing age on road mortality among young adolescents (10-17 year olds). Note though, that this study did not aim to assess licensing age in the broader context, including the effects on 18 to 24 year olds, but solely on the 10-17 year olds. For this younger age group, the legal driver licensing age in a country or state affects their available mobility options.

The expectation that road systems with low System-induced Exposure (SE) would protect adolescents significantly better than systems with high SE was confirmed (H1). The influence of driver licensing age on the safety of 10 to 17 year old adolescents was not found to be significant.

The results on the influence of SE from this study support the calls for a system approach in road safety (OECD-ECMT, 2008; Wegman et al., 2008) and for creating an exciting, stimulating, but safe living environment for young adolescents (Crone and Dahl, 2012; Johnson et al., 2010; Keating, 2007; Paus, 2009). Safe road systems could protect adolescents from harm, not by aiming to eliminate their tendency to take risks and explore new behaviours, but by eliminating hazardous conditions from the road system (Wegman et al., 2012). Moreover, opportunities for safe road use may also be beneficial for adolescent mental, physical, social, emotional and cognitive development (Crone and Dahl, 2012). On bicycles, mopeds, and on foot, they may go places, spend time with friends, and explore new worlds, without being dependent on the consent or cooperation of caretakers. A safe traffic system provides the conditions advocated by Johnson et al. (2010), when they refer to the need in present day society to create communities and to design systems that are safe for predictable adolescent exploration, in order "to 
allow adolescents to gain experiences that will help them navigate the transition to adulthood" (p. 9).

Apart from an assessment of the impact of SSA on adolescent road mortality, the present study also serves as an illustration of the relevance of System theory. Raising and protecting young members in society require complex socio-technical systems, with interacting components. Mobility is one of these components, whereby changes in one component may lead to unforeseen or unintended outcomes. Examples of this were the safety benefits that resulted from the introduction of the free public transport pass for youngsters. Meant only as a measure to cut expenses for the government, for youngsters it made travel by public transport far more attractive than driving a car, and subsequently reduced accident involvement of young males by $50 \%$ (Twisk, 2000).

\subsubsection{Study limitations}

Four limitations need further discussion here: a) the confounding of geographical region and cultural differences with driver licensing age, b) the study's correlational design, c) the quality and detail of the available data, and d) the exclusion of injuries among other age groups caused by 10 to 17 olds. Regarding the geographical region, it is clear that all early licensing countries/states studied are located in North America, Australia and New Zealand, and all late licensing countries studied in Europe. These areas differ in many aspects, such as culture, geography, and demographics. Apart from car use in the population, the study did not control for other influences, such as the level of urbanisation, mobility options, and car dependency. Still a comparison between Norway and New Zealand may serve as an illustration of how, in seemingly similar conditions, the man-made traffic system may still generate very different levels of safety. Norway has a population of 4.7 million people and a population density of $14.5 / \mathrm{km} .{ }^{2}$, New Zealand has a population of 4.3 million people and a population density of $16.5 / \mathrm{km}^{2}$. Both are small and relatively thinly populated countries, yet our study showed SE (fatalities per 100,000) to be three times higher in New Zealand than in Norway. As this study shows, advanced linear mixed models allow for the simultaneous analysis of developments in different regions and countries at the same time controlling for known differences, thus yielding better insights into the effects of road safety measures and their evolution over time, see for instance Ehsani, Bingham, and Shope (2013) and Yannis, Papadimitriou, and Folla (2014) for similar applications. 
The present study has only been able to include some crude measures to control for differences among countries/states, as it had to rely on available data that were of sufficient quality for international comparisons. In that context, information on actual mobility patterns among young adolescents would have strengthened the study, as would have the inclusion of countries with known high moped use, such as Italy and Greece, and the inclusion of time series on relevant indicators such as alcohol policies, speed control, and licensing policies. Such detailed information would also enable exploitation of the natural variations within the early and late licensing country groups. Unfortunately, these data were not available or incomplete. It is further worth considering that no information is available on the registration rates in the IRTAD and FARS data bases. The registration rate is the proportion of road fatalities that is included in the data base and it therefore directly affects the estimates used in the present study. Obviously, in case great variations in registration rates would exist among countries and over the years, the robustness of the conclusions is threatened.

Finally, the study conclusions are only based on the effects of SE and legal driver licensing age among adolescents. The study has not taken into account the effect of legal driver licensing age on road users in other age groups killed in crashes in which young adolescents were driving or riding.

\subsection{Conclusions}

The study illustrates that the protection of young adolescents from the dreadful consequences of their risky decision making on the road requires a system approach to safety rather than strategies that solely aim to modify these behaviours by education, training and publicity campaigns. Countries with a safe road system in place have lower fatality rates among young adolescents than countries with a road system that is less safe. These safe road systems protect road users, even in those cases in which they act deliberately dangerously, or behave risky because of other causes such as inexperience or fatigue. No evidence was found for a protective effect of late licensing on pre-license adolescent mortality. This may be due to the high risks associated with alternative transport modes, such as moped riding and bicycling. Also, the focus on the risks to young adolescents themselves and not including the risks they pose to other road users and passengers may have contributed to this finding, since that risk is larger when driving a motor vehicle than when riding a moped or a bicycle. 
The findings on the effect of licensing age not showing significant differences in road mortality of young adolescents need to be explored further by analysing the effects of high moped use in late licensing countries, such as . Italy and Greece. The study further showed that the use of advanced linear mixed models that control for known differences exploit the presence of natural variation between countries, and may help to uncover the contributing factors to these differences. The present study only included some crude measures to control for differences among countries/states. Expansion of the current international data bases with safety related indicators for each country and for each calendar year would enable future studies to provide a deeper insight into the influences of the road system and its components on road mortality. 



\section{Conclusions, discussion, and recommendations}

\subsection{Conceptual model and research questions}

In the Netherlands as well as internationally, the road risk of adolescent car drivers has received considerable policy and research attention (Ministerie van Verkeer en Waterstaat [Ministery of Trafic and Water works], 2008; OECD-ECMT, 2006; Twisk, 1999; Vlakveld, 2005). To date, little is known, however, about the magnitude and nature of road risk in early adolescence, the 10 tot 17 year olds. In late-licensing countries, youngsters in this age group are still too young to drive a car, and are thus not yet exposed to the risks of driving cars while inexperienced. Yet their development toward adulthood, their striving for independence from caretakers and their search for peer approval may make them increasingly vulnerable on the road as well as elsewhere. Recognizing this elevated vulnerability, road safety education (RSE) is frequently used in school settings to educate, train, and sensitize youngsters about these risks. Despite its frequent application, however, the effects of RSE remain largely unknown. Little is known about 'whether RSE is doing the right thing, and whether it is doing it right'.

This dissertation aimed to contribute to the development of high quality education programmes for young adolescents in their roles as cyclists, moped riders and pedestrians. To this end, it focused on the following objectives: (a) a deeper understanding of the magnitude and nature of road risk in early adolescence; (b) the identification of risk-increasing factors; (c) the assessment of the effects of some road safety education programmes used in Dutch schools and (d) the influence of the safety of the road system on adolescent road mortality. In that context, the studies in this dissertation were designed to answer the following research questions for Dutch adolescent road users:

Q1. What is the magnitude and nature of traffic mortality among young adolescents (10-17 years old) in a late-licensing country, such as the Netherlands? (Chapter 2)

Q2. To what extent do mobility patterns change in early adolescence and do these changes contribute to road mortality in this age group? (Chapter 2)

Q3. Are young adolescents sufficiently prepared to meet the task demands of complex traffic situations, such as dealing with blind spots? (Chapter 6)

Q4. What type of risky road behaviours do young adolescents engage in and are these predictive of crashes? (Chapter 4) 
Q5. Are the psychological determinants of risk behaviour that are frequently targeted in RSE indeed predictive of risk behaviour? (Chapter 4)

Q6. Is risky road behaviour an expression of a more general tendency to behave in a risky manner in other domains, such as smoking and alcohol use, as well? (Chapter 5)

Q7. How strong is the relationship between adolescent risky behaviour and risky behaviour in their perceived social environment, especially the behaviour of parents, siblings and friends? (Chapter 5)

Q8. How effective are education programmes in changing risk behaviours? (Chapters 6 \& 7)

Q9. To what extent do safe road systems protect young adolescents from road harm? (Chapter 8 )

Q10. What is more beneficial for young adolescent safety - making a car driver license available for this age group, or licensing them at the later age of 18, which restricts youngsters below the licensing age to the use of bicycles, mopeds, or to walking? (Chapter 8)

The overview of the current understanding in Chapter 3 led to a conceptual model of the potential contributing factors, causal relationships, and impact of three interventions (see Figure 9.1). This model further depicts the interrelationships between the research questions (Q1 to Q10). The structure of the model was inspired by the Logic models developed by Bartholomew et al. (2011) for health behaviour. Just as in their health models, the road safety model consists of two levels: an individual level and a system level. The individual level covers components such as maturation, motivations, abilities, and influences from the social environment. The system level concerns the traffic system that includes the road infrastructure and also regulations such as legal alcohol levels, licensing age and vehicle requirements. Arrows in bold depict the relationships addressed in the dissertation. 


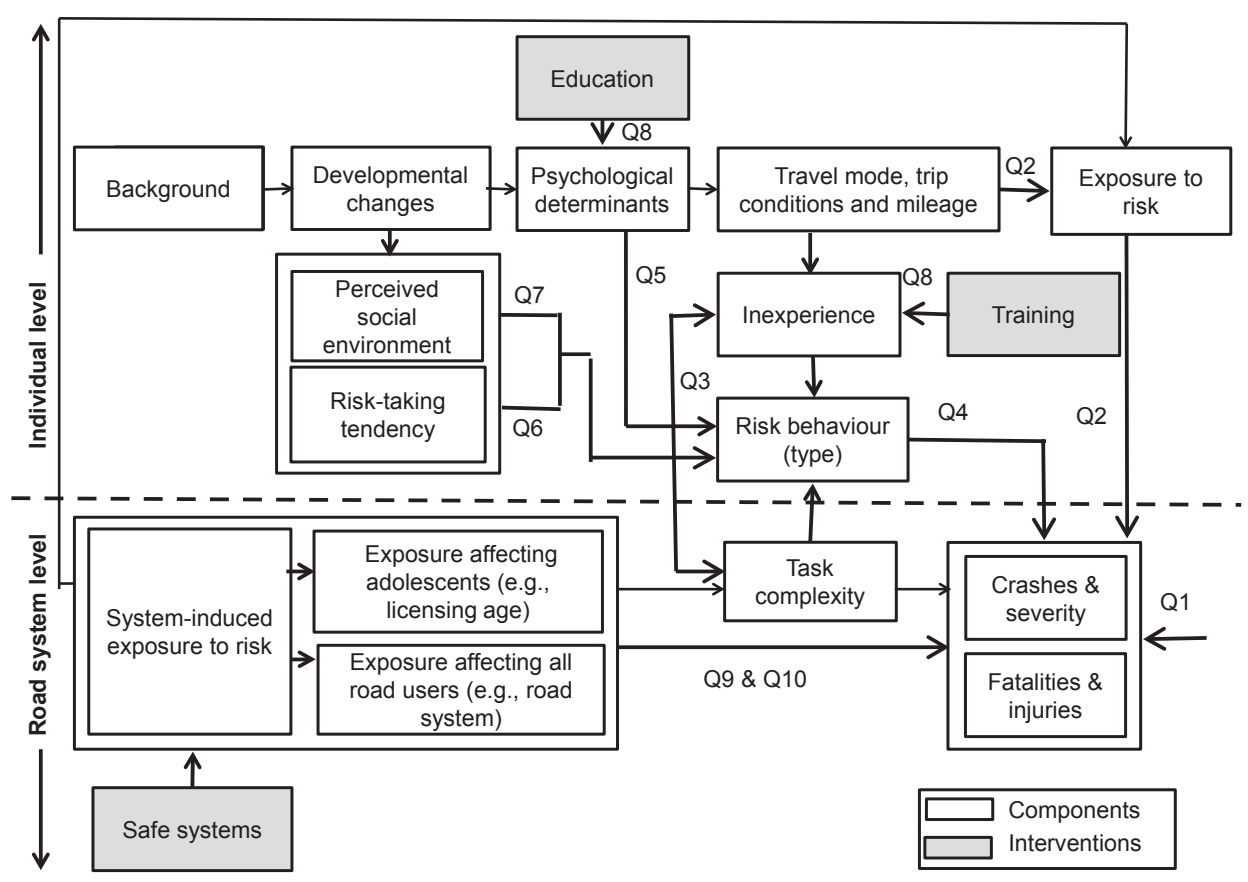

Figure 9.1. Conceptual framework of adolescent road risk, composed of (potentially) contributing components and three interventions. Arrows in bold depict the relationships and numbered research questions addressed in the dissertation.

The remainder of this chapter summarizes, discusses the findings of the studies in this dissertation, and provides the answers the research questions (Sections 9.2 through 9.5). The chapter further reflects on these results in terms of lessons learned and the implications for policy development (Section 9.6). The chapter is concluded with the recommendations for future research (Section 9.7).

\subsection{Road mortality and impact of changing mobility patterns}

Having overcome the frailty of childhood, in adolescence youngsters become the healthiest and fittest members of western society (WHO, 2010). Unfortunately, these health gains are partly lost because of a concurrent sharp increase in injury-related mortality (Dahl, 2004; Sleet et al., 2010). Traffic crashes, are especially responsible, accounting for approximately 35\% to $40 \%$ of the injury-related mortality among young adolescents in Europe (Kumpula and Paavola, 2008; OECD-ECMT, 2006) and the USA (Sleet et al., 
2010). To date, relatively little policy and research attention has been devoted to the 10 to 17 year old age group (Kumpula and Paavola, 2008; OECDECMT, 2004; Sentinella and Keigan, 2005). Recent studies on mental and biological development in adolescence and their impacts on risky behaviour, however, suggest that from age 10, elevated levels of road risk are highly probable (Susman and Rogol, 2004). This effect may even be greater in latelicensing countries such as the Netherlands, where 10 to 17 year olds may not drive cars, but use bicycles or mopeds instead. On average, cyclists have a four times higher fatality risk than car occupants (SWOV, 2013; Wegman et al., 2012), and the trends over time show the safety of cyclists to be less favourable than that of car occupants (Twisk, Vlakveld, Dijkstra, et al., 2013; Weijermars and Van Schagen, 2009). To gain a deeper understanding of the relevance of road mortality, we examined in the dissertation the causes of mortality - including road mortality - for children, adolescents and young adults, and how these changed with age and by gender (Section 9.2.1).

Among the many factors that affect road safety levels, changes in mobility are known to be one of the most influential (e.g., Christie et al., 2007; Hakkert et al., 2002; Twisk, 2000). In adolescence, two psychological characteristics may give rise to such shifts in mobility, namely an increase in novelty seeking, and a shift in social attachments from the family unit toward peers (Spear, 2000). As a result, youngsters may travel more frequently independently from caretakers compared to when they were children, may more frequently travel to unfamiliar places, further away from the family unit, and more frequently in adverse conditions such as in darkness and on slippery roads. Besides these psychological developments, in adolescence their role in society also changes when they leave primary school and start attending secondary school. In the Netherlands, this transition affects mobility, as the network of secondary schools is less finely meshed than that of primary schools. This may result in a longer travel distance between home and school. We studied two factors related to these mobility changes: (a) a high exposure to risk because of an increase in mileage as independent road users and the use of riskier modes of transport, and (b) inexperience with new trip conditions and transport modes (Section 9.2.2).

\subsubsection{Road mortality among pre-license teens}

To examine the relevance of road mortality, the dissertation started off with addressing Research Question 1: 'What is the magnitude and nature of traffic mortality among young adolescents (10-17 years old) in a late-licensing country, such as the Netherlands? To answer this question we have first considered 
road mortality in relation to the overall mortality of youngsters, including that due to other injuries and disease. Second, we examined adolescent road mortality in relation to the overall road mortality in the Netherland. The results presented in Chapter 2 and also published as Twisk, Bos, Shope and Kok (2013) showed that while in the first decade of life, natural death dominates the mortality statistics, in the second decade injuries start to become almost as prominent a mortality cause as natural death. Road mortality is responsible for a large share of that mortality, not only when youngsters get licensed to drive cars, but also in the pre-license period. Road mortality starts to rise from age 10-14 onwards, reaching its peak in the 15 to 17 year old group. This confirms that similar to early-licensing countries countries that license at younger ages than 18 (Sleet et al., 2010), in a latelicensing country road mortality also becomes a main cause of death, even among teens who are not yet exposed to the high risk of driving a car with only little experience. Also, the gender differences reflect those of teen drivers. Whereas, up to age 5-9, road mortality is low and differs only slightly by gender, from age 10-14 it starts to rise for both sexes. Gender differences start to emerge from age 15, when road mortality of males becomes a factor of three higher than that of females. Thus, already in their teens, pre-license males have a higher road mortality rate, resembling that of older males. In terms of traffic roles - passengers or independent travel - the data show that the majority lose their lives travelling independently. Only a quarter of these youngsters die as passengers in cars, whereas the majority (72\%) lose their lives travelling independently as cyclists (40\%), moped riders $(24 \%)$ or as pedestrians $(8 \%)$.

Note that these analyses are only based on fatalities and not on injuries, since the fatality data are most reliable. This limitation results in an underestimation of the magnitude of the problem, because of the short- and long-term consequences of injuries being ignored. Based on observations 24 months after a road crash on Dutch roads, Polinder et al. (2007) concluded that in the Netherlands, $4.5 \%$ of injured road users suffered lifelong disabilities. Using a different method, Vriend et al. (2005), discussed in Lanting and Hoeymans (2008), estimated this proportion to be $8 \%$. Unfortunately, neither study differentiated the results by level of disability or by age group. Assuming that these proportions would not vary with age, it can be estimated that in each calendar year, in the Netherlands between 90 and 160 youngsters will suffer long-term disabilities, because of a road crash. Apart from being personal tragedies, their disabilities also create a great economic loss to society. This loss is even greater for this younger age group 
than for older age groups. Because of their greater physical resilience, their survival rates after injuries will be higher and because of their younger age, more subsequent years will be affected. It is therefore recommended that future research should not only include injuries presented immediately after a crash, but should also address the long-term consequences of such injuries.

\subsubsection{The impact of changing mobility patterns}

\section{Mobility patterns and exposure to risk}

To answer Research Question 2: 'To what extent do mobility patterns change in early adolescence and do these changes contribute to road mortality in this age group?' an epidemiological study was carried relating mobility patterns to road mortality. The results were also reported in Chapter 2 and published as Twisk, Bos, Shope and Kok (2013). The results confirmed the hypothesis that in this late-licensing country, 'independent travel' and the use of riskier modes of transport increase sharply when teens migrate from being car passengers of their parents to being unsupervised users of bicycles and mopeds. This migration was found to be associated with a strong rise in road fatalities. Moped risk - defined as the number of fatalities per distance travelled - was extremely high, especially for young males, and even higher than that for young male car drivers, a known high-risk group (Twisk and Stacey, 2007). These findings illustrate the importance of changing mobility patterns for road safety, especially for this age group.

\section{Mobility, inexperience and the complexity of the road task}

Road traffic is inherently dangerous. Management of this danger requires a skilled road user to foresee and act in dangerous situations even before they emerge (see Cacciabue, 2007; Vlakveld, 2011 for overviews). Frequently, actions need to be taken within an extremely small amount of time and space (Endsley, 1995), putting extra demands on the road user's information processing capacities. Because of these high demands, car drivers, for instance, can only acquire these skills after extensive practice (Twisk, Vlakveld, Mesken, et al., 2013). Moreover, the more complex a task is (for instance, left turns in busy traffic), the more hours of practice are required before behaviour becomes sufficiently safe. Characteristics of the driver task and the acquisition of driving skills have been extensively studied, and these studies have led to application of the results in driver training, road infrastructure and car design. In comparison, little is known about the road skills of young cyclists and pedestrians. One of the few studies among school-aged cyclists in the Netherlands showed that, even in a country where children start cycling at the very early age of four (Van der Houwen et al., 
2003), skills such as keeping balance and following a designated track have not reached expert levels even by around age 12 (Brookhuis et al., 1987).

As part of this dissertation, an experiment was carried out to answer Question 3: Are young adolescents sufficiently prepared to meet the task demands of complex traffic situations, such as dealing with blind spots? The results were reported in Chapter 6 and published as Twisk, et al (2013). In this experiment, youngsters in the final two years of primary school - around 12 years of age - had to select a safe action in a traffic situation involving a truck, thereby taking the driver's blind spots into account. Table-top models of seven traffic scenarios, which differed in complexity, were used for testing. A basic scenario tested the correct identification of the three blind spot areas. Further, six traffic scenarios - three simple and three complex - tested the extent to which the youngsters were able to translate their understanding of these blind spot areas into safe actions in traffic situations. The results showed that $42 \%$ of the youngsters identified the three blind spots correctly. This meant that the majority of youngsters did not know at which locations a driver could or could not see them. Performance deteriorated even further in the traffic scenarios. In the simple traffic scenarios, only one in four youngsters selected an action that was safe. In the complex scenarios, this proportion dropped to only 1 in 20 . These poor choices of action would be even more unsafe in real traffic for two reasons. In the table-top model scenarios, youngsters could take as much time as they needed to come to a conclusion, time that is not available in real traffic situations. Further, the table-top model traffic scenarios were static, whereas real traffic situations continuously change. These dynamic characteristics make the decision process in real traffic even more complex, and yet more important. Overall these results confirm that at this age youngsters are still inexperienced in complex traffic situations.

\subsubsection{Conclusions and potential intervention strategies}

The studies presented here showed that changes in travel mode characteristics and reductions in supervised travel indeed contribute to the rising numbers of road fatalities in early adolescence. Kilometres travelled as car passengers migrate to kilometres travelled as cyclists and in some cases later as moped riders. No large changes were seen in kilometres travelled as pedestrians. Travel by bicycles and mopeds expose youngsters to higher risks than travel as car passengers. Not explored here, but reported elsewhere (Twisk and Reurings, 2013), these bicycle and moped trips will be even more risky in darkness and after the use of alcohol. Further, the study 
confirmed that in addition to exposure, a lack of experience with novel and often more complex traffic situations also plays a role. Given these contributing factors to adolescent road mortality, three intervention strategies are theoretically feasible:

- Accelerate the acquisition of road skills by means of training. This strategy is further explored in Section 9.5.1.

- $\quad$ Reduce exposure to risk by eliminating complex and unsafe road situations. This strategy is further explored in Section 9.5.2.

- $\quad$ Restrict mobility to the safest modes of transport and the safest travel conditions. This strategy is discussed in Section 9.7

Note that the analyses had two main limitations. First, the study only analysed fatalities and did not include injuries. This focus may have led to an underestimation of the magnitude of the problem because there are far more injuries than fatalities. The second limitation is that the study was only based on data from the Netherlands. To explore the generalizability of these results, international comparisons among early- and late-licensing countries may shed light on the extent to which these findings also apply to other countries. In Section 9.5.2, we examine the effect of licensing age on adolescent mortality by comparing early- and late-licensing countries.

\subsection{Road safety education and the predictors of risk behaviour and crashes}

To date only a few studies have investigated what types of risky road behaviour young adolescents engage in as cyclists and pedestrians. Moreover, little is known about the relationships of these behaviours with crashes. Therefore, in the context of this dissertation, a study was conducted to answer Question 4: What type of risky road behaviours do young adolescents engage in and are these predictive of crashes?

Regarding the types of risk behaviours, studies generally differentiate between two types: namely errors and violations (e.g., Harré, 2000; Reason et al., 1990). Consistent with Reason's Generic Error Modelling System (GEMS) (Reason, 1990), in the dissertation an error was defined as an unintentional deviation from a safe line of action. Examples of errors are overlooking a red traffic light, or the misinterpretation of the meaning of a traffic sign. Errors are elicited by factors such as inexperience, fatigue, or confusing traffic conditions. In contrast, violations are intentional transgressions of rules, procedures, and precautions. An example of a violation is a cyclist who sees 
a traffic signal turn red, understands its meaning, and still decides to violate the red light. Intentional risk behaviour originates from motives such as enjoying risks (e.g., driving extremely fast on a motorway in the middle of the night) and impressing friends.

Road safety education (RSE) aims to change both types of risk behaviour and to achieve that by changing the underlying psychological determinants that are presumed to give rise to these behaviours. To date, these RSE programmes have often been based on an intuitive understanding of this 'determinant - behaviour' relationship rather than on empirically tested insights. To assess whether these intuitively-based psychological determinants are indeed predictive of risk behaviour, a survey was carried out to answer Question 5: Are the psychological determinants of risk behaviour that are frequently targeted in RSE indeed predictive of risk behaviour? Figure 9.2 depicts the relationships and concepts that were addressed. The results of this survey were reported in Chapter 4 and submitted for publication (Twisk, Vlakveld, et al., 2014a).

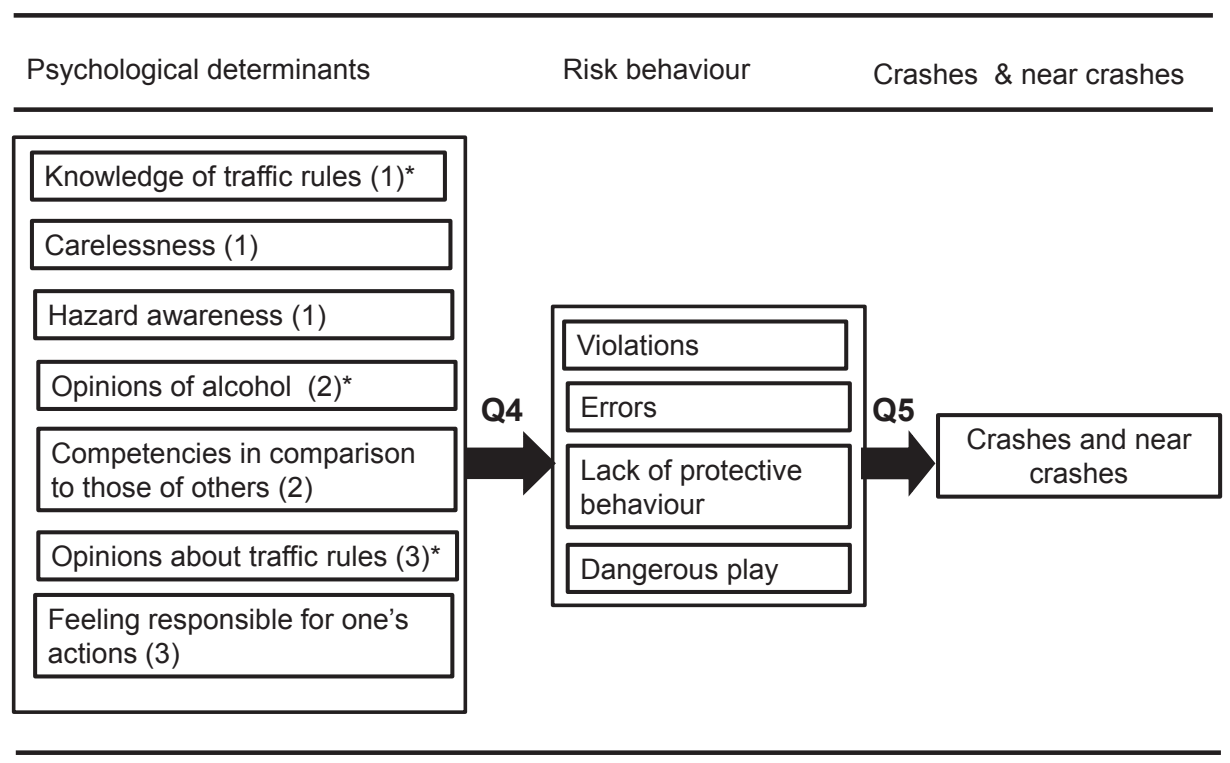

Figure 9.2. Hypothetical model and relationship with research questions about the relationship among psychological determinants, risk behaviour and crashes and near crashes. ${ }^{*} 1$ = younger age group, ${ }^{*} 2=$ older age group, ${ }^{*} 3=$ both age groups. 
The survey was based on the Adolescent road behaviour questionnaire (the ARBQ) (Elliott \& Baughan, 2004) on risk behaviour and extended with items on RSE psychological determinants. The questionnaire was administered to two age groups: 12 to 13 year olds and 14 to 16 year olds.

\subsubsection{The relationship between risk behaviour types and crashes}

Concerning the 'risk behaviour type - crash relationship, the GEMS model, on which the ARBQ was based, has proven to be a useful conceptual framework for examining these relationships for car drivers, by means of the Driver Behaviour questionnaire (DBQ). For instance, a meta-analysis of DBQ studies confirmed that self-reported violations and errors predicted selfreported crashes (De Winter and Dodou, 2010). Until 2011 to our knowledge, only a few studies examined these relationships for young adolescent pedestrians, cyclists and moped riders. In Chapter 4, these studies were reviewed, showing that: (a) in contrast to driver studies, the expected violation-error factor structure was absent in two of the four studies (Elliott and Baughan, 2004; Sullman and Mann, 2009); (b) risk behaviour subtypes were highly correlated (Feenstra et al., 2011; Steg and Van Brussel, 2009), which suggests that youngsters who commit errors also commit violations; (c) errors and violations were not the only predictors of crashes - dangerous play and lack of protective behaviour were as important (Elliott and Baughan, 2004; Sullman and Mann, 2009); and (d) with the exception of one study (Feenstra et al., 2011), significant relationships of risk behaviour with crashes have not been reported. This finding differs from studies on drivers (De Winter and Dodou, 2010).

The results from our ARBQ-based survey showed that the four risk behaviour types - violations, errors, dangerous play, and lack of protective behaviour - formed scales that were reliable and internally consistent, but also were highly correlated. This suggests that a more general measure has been obtained: namely 'unsafe behaviour'. We found 'unsafe behaviour' - all risk behaviour subtypes combined - to predict crashes, explaining $5 \%$ of the variance among the 12 to 13 year olds and 10\% among the 14 to 16 year olds. However, the strength of the individual relationships of errors and violations with crashes differed from those found among car drivers. Whereas for car drivers, Winter and Dodou (2010) reported errors and violations to be about equally strong predictors, our study showed that for young adolescents, violations did not have a unique contribution to the prediction of crashes. Moreover, apart from errors, the study confirmed that lack of protective behaviours and dangerous play also predicted crashes. Lack of protective 
behaviours concerned activities that are not compulsory because of traffic law, but that reduce crash risk. An example of protective behaviour is wearing bright coloured clothing in darkness. These protective behaviours may be motivated by the understanding of potential hazards. Dangerous play concerned activities such as 'Not watching out because of talking to friends'. Our study was not set up to test possible explanations, but its findings suggest that adult reasoning on these relationships - such as that of adult car drivers - may differ from that of young adolescents. Key to this difference may be the interpretation of behaviour as being 'intentional' or not. Dangerous play, lack of protective behaviour, and violations all share the characteristics of an intentional action. Errors - in contrast - are unintentional deviations from safe actions. Adults tend to (mis)perceive their behaviour as conscious, reasoned and intentional, while in fact it is more or less intuitive and automatic, with rationalisations after the fact rather than preceding (Dijksterhuis, 2008; Kahneman, 2003a, 2003b). Compared to adult reasoning, that of adolescents is more often a result of conscious deliberations, and not yet automatic or based on set habits (Blakemore et al., 2007; Blakemore and Frith, 2005; Reyna and Farley, 2006). This characteristic, in combination with adolescents' impulsiveness, not only leads to behaviour patterns that differ from those of adults, but also may affect the 'attributions' as to the cause of the event or the behaviour.

\subsubsection{Determinants targeted in education as predictors of adolescent risk behaviour}

Road safety education (RSE) programmes attempt to change psychological determinants in order to change risk behaviour. The choice in RSE programmes of which psychological determinants to target is seldom based on a thorough empirical analysis, but often merely on an intuitive understanding of these relationships. Unfortunately, most RSE programmes do not explicitly describe the assumptions underlying the education programmes. To obtain this information, descriptions from professionals who were familiar with these programmes were used to identify these implicit 'determinants'. This showed that RSE programmes for 12 to 13 year olds frequently addressed several of the following determinants: 'knowledge of traffic rules, 'opinions about traffic rules', 'carelessness', 'feeling responsible for one's actions', and 'hazard awareness'. RSE programmes for 14 to 16 year olds frequently addressed 'opinions about traffic rules', 'opinions on alcohol use in traffic', 'competencies in comparison to those of others', and 'feeling responsible for one's actions'. 
By means of Path analyses, the direct and indirect effects of the determinants on risk behaviour and crashes were studied. Figure 9.2 depicts the full hypothetical model of the study. The path model showed that all psychological determinants combined explained $40 \%$ of the variance in risk behaviour, among the 12 to 13 year olds, and 31\% among the 14 to 16 year olds, without a distinction being made between errors, violations, dangerous play and lack of protective behaviour. Notably, this relationship is stronger than that between intention and risk behaviour, with intention, according to a similar study by Feenstra, et al. (2010) explaining $23 \%$ of the variance in risky cycling behaviour. However, the strength of the association differed by determinant. For instance, 'knowledge of traffic rules' was only marginally related to risk behaviour. Similarly, in the older age group, 'competencies in comparison to those of others' was only weakly related to risk behaviour, while 'opinions about traffic rules' did not appear to influence risk behaviour at all. The weak relationships with crashes and near crashes for knowledge of traffic rules in the younger group and for opinions about traffic rules in the older age group may be due to measurement error. The questionnaire therefore needs to be revised for these two scales. Conversely, strong relationships existed in the younger age group for 'opinions about traffic rules' and for feeling responsible for one's actions". In the older age group, this was also the case for 'opinions about alcohol' and 'feeling responsible for one's actions. The latter was not completely mediated by risk behaviour, but also had a direct relationship with crashes. This finding suggests that the questionnaire did not sufficiently address the behaviours that were associated with 'feeling responsible for one's actions'.

\subsubsection{Discussion and implications for research and application}

For the development of questionnaires like the ARBQ, as well as for the development of RSE programmes, the models based on adult risk behaviour such as GEMS, may thus be less appropriate than previously thought. For the development of questionnaires to monitor risk behaviour and for the development of RSE programmes to change behaviour, a better understanding is needed of how adolescents interpret the basis of their actions, especially in relation to the role of intentionality.

Highly relevant for the development of RSE programmes is the relatively large contribution of lack of protective behaviour to the prediction of crashes. Our study showed that in both age groups, youngsters seldom reported engaging in protective behaviour. Thus, RSE programmes need to find ways to stimulate these protective behaviours instead of solely focussing on 
aberrant behaviour. For example, the use of music players and mobile phones by cyclists and pedestrians is not forbidden by law, but safety would benefit if cyclists did not use them. The use of these devices deteriorates cycling performance (De Waard et al., 2010) and increases crash risk (Goldenbeld et al., 2012). Therefore, RSE programmes need to be broadened, for instance by also including the training of hazard detection skills.

The findings presented here have the following implications for the understanding of crash causation in relation to (risky) road behaviour, the development of survey methods for the monitoring of risky road behaviour and for the development of effective RSE interventions.

a) Road crashes are not solely predicted by aberrant road behaviour but also by a lack of protective behaviours. Thus, interventions need to also stimulate the uptake of protective behaviours.

b) For survey methods, more insight is needed into how adolescents attribute behaviours and consequences, especially in terms of the intentionality of that behaviour. This fact is relevant for how the items in the survey are worded, and how the issues are addressed in RSE programmes.

\subsection{Multiple risk behaviours and perceived social environment}

Adolescence is a period of great personal and physical growth that is characterized by many changes, such as a sharp increase in a wide range of risk behaviours, a growing importance of peers, and a decrease in parental supervision (Lerner and Steinberg, 2004). The sharp rise of different types of risk behaviour may suggest that there is an underlying 'risk' tendency that feeds these behaviours and may result in youngsters engaging in multiple risk behaviours. The co-occurrence of such risk behaviours, including risky behaviour in traffic, has extensively been studied, but primarily among adolescent car drivers (ages 17 to 24) (e.g., Bingham and Shope, 2004; Jessor, 1987; Jessor, 1992; Jessor et al., 1997; Junger et al., 1994), and has not yet been studied among younger adolescents (10 to 17 years old) in their role as passengers, pedestrians, cyclists, or moped riders. Further, for adolescents, the growing importance of peers and the decline in parental supervision raises the question of to what extent is risk behaviour in the (perceived) social environment related to adolescent risk behaviour. A co-occurrence of risk behaviour and presence of risk behaviour in the perceived social environment may well have implications for the design of RSE interventions. 
If risky road behaviour is strongly related to other risk behaviours, it could be more effective to target this underlying tendency rather than targeting each risk behaviour in isolation. If risk behaviour is strongly related to the social environment and network, then interventions could explicitly address these perceived relationships.

In that context, Chapter 5 reported the results from our study that answered Research Question 6: Is risky road behaviour an expression of a more general tendency to behave in a risky manner in other domains, such as smoking and alcohol use as well? And Question 7: How strong is the relationship between adolescent risky behaviour and risky behaviour in their perceived social environment, especially the behaviour of parents, siblings and friends? To that end, data from the largescale 'Health Behaviour in School-aged Children' (HBSC) 1991-1992 survey, on risk and health compromising behaviour, were reanalysed. The HBSC survey is conducted every four year among children age 10 to 17 in a large number of countries. To enable comparisons across countries and trend analyses, the core of the questionnaire is kept as standard as possible. Only the 1991-1992 survey, included items on adolescent risky road behaviour in the Dutch version, along with items on risky road behaviour among parents, siblings and friends. So far, these items have not been analysed to identify multiple risk behaviours including road behaviour, but only to identify socalled 'hard core risk takers (Wurst, 2002). In our study, analyses were based on the risk behaviours: 'Smoking', 'Drinking', 'Gambling', 'Not wearing safety belts', 'Riding a moped or bicycle when drunk' and 'Riding as a passenger of a driver who has been drinking'. The results showed that youngsters who take risks on the road also tend to engage in other non-traffic related risk behaviours. Regarding the relationship with the (perceived) social environment, the study confirmed strong relationships between self-reported 'own' health behaviours and those perceived of friends. For traffic-related risk behaviour, the relationship with perceived drunk-driving by friends was weak, probably because 'peers' and our participants will be about the same age, and still be too young hold a driving license. The relationship between risky road behaviour and perceived parental drunk-driving was relatively strong. This relationship was partially due to the relatively high number of youngsters reporting having ridden as a passenger of a drinking driver who was their parent. 


\subsubsection{Conclusions and implications}

The current study suggests that problem behaviour is not restricted to the road only, and that the social environment - especially parents and peers may have a large influence on problem behaviour. Because these data were collected about two decades ago, the findings can only serve as an illustration of several plausible relationships. Since then several studies in the health domain have explored the phenomenon of multiple risk behaviours and their relationship with the perceived social environment. So far none of these studies have included risky road behaviour of young adolescents in sufficient detail. The same holds true for the influence of the perceived social environment. Deeper insight in these relationships is a prerequisite for the focus of interventions, for instance whether interventions should target the underlying risk-taking tendency or focus on each single risk behaviour, or whether interventions should include the perceived social environment or only focus on the individual. It is therefore recommended that:

1. Surveys on risk behaviour should also include items on risky road behaviour.

2. The perceived social environment with respect to risky road behaviour should be included in these surveys.

3. The information from these surveys should be used to reconsider the focus of interventions (a) in terms of either addressing the underlying risk-taking tendency or the specific risk behaviours, and (b) in terms of how to include the issues concerning the perceived social environment.

\subsection{Two intervention strategies}

The dissertation also dealt with interventions. Two complementary strategies were considered: (a) changing road user behaviour by means of education and training, which here is referred to as the 'individual approach' and (b) reducing exposure to risk by improving the road system which here is referred to as the safe system approach (SSA). The individual approach assumes that road crashes happen because of inappropriate road behaviour, poor skills and safety motivation, and other individual characteristics. The safe system approach (OECD-ECMT, 2008) postulates that crashes happen because of the user-unfriendly characteristics of the road system. In the dissertation, we studied the effects of education as an example of an 'individual approach' intervention. As an example of SSA, we studied whether safe road systems are also safe for young adolescents, or whether these systems are unable to protect this risk-seeking group. 
Two observations in road safety are central to both the individual approach and SSAs. First, human behaviour is directly or indirectly responsible for an estimated $96 \%$ of all crashes (Sabey and Taylor, 1980). Second, road crashes and injuries are not equally distributed in the road user population. Some road users have a higher crash involvement than others (e.g.,Af Wåhlberg, 2009; Visser et al., 2007). Thus, road user behaviour and road user characteristics are the most important contributors to crashes. Both approaches acknowledge this fact, but differ on the interpretations and the implications for interventions. The individual approach aims to change and correct road user behaviour, so that it is in accordance with the demands of the road system. It uses strategies such as training, education, and deterrence to achieve this aim. SSA, in contrast, aims to adapt the demands of the traffic task to the capacities of the road users. It seeks to understand how human error is elicited by the design of the traffic system, so that these hazardous conditions can be eliminated from the system.

Road Safety Education (RSE) is an example of the individual approach. It helps novices acquire new skills, informs road users, and persuades them to modify their behaviour. For young adolescents, RSE is one of the most frequently used interventions (Dragutinovic and Twisk, 2006; SUPREME, 2007). These types of RSE programmes target different behaviours, but more generally aim to achieve the following objectives: (a) prevent crashes during adolescence by modifying current unsafe behaviours, and (b) invest in future safe adult behaviour by stimulating positive road safety attitudes (Waylen and McKenna, 2008). The question is whether RSE programmes are effective in achieving these objectives. Studies that provide an overview of the effects of RSE (e.g., Dragutinovic and Twisk, 2006; SUPREME, 2007; Williams, 2007) concluded that RSE programmes were seldom evaluated, often lacked theoretical and empirical foundations, and generally did not provide evidence of their effects.

SSA is widely advocated to improve the design of the road system. Haddon's approach (Haddon, 1980b), Reason's model of human error (Reason, 1990), human factors, and operationalisations such as the TRIPOD model (Wagenaar et al., 1990), which is a method to investigate accidents in a wide range of industries, have inspired later SSAs, such as 'Sustainable Safety' in the Netherlands (Wegman and Aarts, 2006), and Vision Zero in Sweden (Tingvall and Haworth, 1999). The OECD-ECMT report 'Towards Zero: Ambitious road safety targets and the safe system approach '(2008) provides 
a more detailed account of the contribution of system approaches to road safety.

This section summarizes the effects of RSE from the evaluation studies presented in Chapters 6 and 7, and the effects of SSA by comparing the safety of adolescents in countries with different levels of system safety, as reported in Chapter 8.

\subsubsection{The effects of RSE}

RSE can be used for two main purposes: to learn new skills or to change existing behaviour. Here we provide examples of the effects of programmes in both categories, and answer Research Question 8: How effective are education programmes in changing risk behaviours? In theory, education is a long-term investment in safety habits. Maio et al. (2007, p. 119) phrase this investment as follows: 'The many habits that now are considered as ordinary everyday behaviours, such as seat belt usage or waste segregation, once started as new behaviours that had to be promoted or implemented. Education of young people who have not yet built a habit for the target behaviour can be influenced before the behaviour is set in place (e.g., by introducing safe habits while learning to drive). Of course, education alone cannot be expected to solve all problems. It is important to support other upstream interventions and ensure that the new behaviours are normatively accepted and easy to sustain." (p. 199). Thus education is beyond question if effective - a long-term investment in the safety of individual road users. The question is, though, how effective education programmes are in teaching young adolescents these desired new skills and habits. This dissertation presented results from evaluation studies of seven RSE programmes. Two of those aimed to improve skills. The other five programmes aimed to achieve a better understanding of road hazards and their implications.

\section{Learning new skills}

As discussed in Section 9.2.2, one of our studies suggested that inexperience contributes to risky decisions among young adolescents, especially in complex traffic situations. Thus, interventions that aim to accelerate the process of skill acquisition may - in theory - be effective. Generally, the acquisition of new skills is a slow and time consuming process (Anderson, 1982; Rasmussen, 1985), requiring extensive and deliberate practice (Ericsson et al., 2007; Shriffrin and Schneider, 1977). Not only do the number of hours of deliberate practice matter, but so do the variety and complexity of traffic situations that are included in the practice sessions (Rothengatter, 1985). 
Complex situations, which come with high information loads and short decision times, require more practice than simple situations that are characterized by low information loads and long decision times.

To explore to what extent current RSE programmes improve safe decisions in traffic situations of different levels of complexity, we studied the effects of two training programmes on youngsters' identification of blind spot hazards around trucks and the application of that skill to traffic situations. The two programmes differed in approach. One programme - the competency programme - aimed to raise competency by means of instructions, demonstrations, and the use of rules of thumb to guide behaviour. The other programme - the awareness programme - aimed to raise risk awareness by highlighting the danger of carelessness. Both programmes brought a real truck into the schoolyard and provided practical demonstrations. The programme effects were evaluated using the table-top method as reported in Section 9.2.2. The results - reported in Chapter 6 and published as Twisk, Vlakveld, et al. (2013) - showed that, the competency programme improved performance, whereas the awareness programme did not. However, the positive results of the competency programme appeared to be limited to an improvement in the correct identification of the blind spot locations, but not in safe behaviour in simple and complex traffic scenarios. This finding suggests that what is learned in a schoolyard does not automatically transfer to safe behaviour in traffic situations.

\section{Changing deliberately risky behaviour}

Aside from programmes that aim to improve skills, a wide range of programmes are available that aim to change the so-called psychological determinants of risk behaviour, as discussed in Section 9.3.2. To study the effects of education programmes on risk behaviour, five of these programmes were evaluated, using the same method (Twisk, Vlakveld, et al., 2014b) (see Chapter 7). The application of the same method enables a comparison of effects across programmes. To that end, self-reported behaviour of the intervention groups was compared with that of the reference groups. In addition to 12 items that differed among the programmes, the questionnaire contained 28 items that were identical for all five programmes. None of these programmes were based on an explicit theoretical framework of behaviour change. Still, the programmes could be categorized into two types: fear-appeal programmes and cognitive programmes. Fear-appeal programmes aimed to raise the perception of threat and perceived vulnerability. Two of the programmes fell into that 
category. Cognitive programmes aimed to change behaviour by providing information and the opportunity to explore the consequences of behaviour. The three other programmes fell into that category. The results indicated that four of the five RSE programmes improved behaviour. However, the proportions of participants who changed their behaviour relative to the reference group were small, ranging between 4 and 20\%. Regarding the effectiveness of the two types of programmes, our study did not find a difference between the programme types. Programmes using a cognitive approach did not differ in effect from programmes that used fear-appeals.

\subsubsection{Safe road systems; protecting young adolescents}

The role of risk behaviour in adolescent road mortality - sometimes deliberate and sometimes from inexperience or other non-deliberate causes is well documented. However, the 'road system' itself may also have an impact on younger adolescents' road mortality. This impact happens by providing an unsafe road environment for all road users, (system-induced exposure [SE]) and for youngsters by allowing access to high-risk vehicles at a young age through the legal driver licensing age. In Chapter 8 , the results were reported of the study which was submitted for publication as (Twisk, Bos, Shope, Commandeur, Kok (2014) that aimed to answer Research Questions 9 and 10: (9) To what extent do safe road systems protect young adolescents from road harm? and (10) What is more beneficial for young adolescent safety, making a car driver license available for this age group, or licensing them at the later age of 18?, which restricts youngsters below the licensing age to the use of bicycles, mopeds, or to walking? The study sought to explore these relationships by analysing the extent to which the road mortality of 10 to 17 year olds in various jurisdictions can be predicted from the jurisdictions' System-induced Exposure (SE) and legal licensing age to drive motor vehicles. SE was operationalized as road fatalities per $10^{5}$ inhabitants/all ages together, but excluding the 10 to 17 year olds. Data from 29 early- and 10 late-licensing jurisdictions were included in the analysis. The study found support for the protective effects of SE on adolescent safety. If SE increased by one unit, the mortality rate of 10 to 17 year olds increased by 0.487 units. No support was found for a protective effect of late licensing for this age group. Thus, compared to young adolescents who are allowed to drive motor vehicles in early-licensing jurisdictions, late licensing does not provide extra protection for youngsters who are still below the licensing age. This finding is probably the result of the high risk associated with transport modes such as moped riding and bicycling in late-licensing countries. Also, the fact that the study only included risks to young adolescents themselves and did not include the 
risks they might pose to other road users and passengers, may have resulted in an underestimation of the effect on road mortality. Risks to others, i.e., passengers and other road users, are greater from motor vehicles than mopeds or bicycles.

\subsection{Lessons learned}

We present here a point-by-point overview of the dissertation findings and implications. What are the lessons learned on young adolescent road risk and on the potential of RSE?

\subsubsection{Lessons learned about road risk in early adolescence}

1. In the Netherlands adolescent road mortality is an unrecognized public health problem. Young adolescents die from 'preventable' injuries not from 'incurable' disease.

For the prevention of disease, life style factors such as smoking, alcohol use, and obesity have generated considerable interest and many research projects and intervention strategies target these life style factors. Whether a person will be affected by disease is - aside from these life style factors - also related to his predisposition and genetic factors. This fact makes the prevention of disease 'a battle that is hard to win'. In contrast, injuries such as road injuries, occur as a result of external factors, and the influence of predisposition - with the exception of predisposing personality factors - and of genetics is small. This fact makes road injuries, in theory, largely preventable. Given these characteristics, the Centers for Disease Control and Prevention (CDC) in the US speak of road safety 'as a winnable battle', stating on its website "CDC has identified motor vehicle injury prevention as a Winnable Battle. With additional effort and support for evidence-based, cost-effective strategies that we can implement now, we will have a significant impact on our nation's health" (http://www.cdc.gov/WinnableBattles/MotorVehicleInjury/). To date, such a 'vision' has not yet reached the Netherlands. Road safety is not seen as a public health issue, whereas the prevention of road crashes among adolescents is one of the best buys in public health. Even the words need changes. A crash killing or maiming a youngster is not an accident, as it is not an event beyond human control. It is an event that is predictable and preventable (see Sleet and Branche, 2004 for a detailed discussion on this issue). Such a slight change of words - accident versus crash - is not semantic pedantry. Wording changes of this type have been shown to affect the 
perception of social problems and the social acceptance of measures as well as (Thibodeau and Boroditsky, 2011).

2. To target interventions effectively, it is necessary to monitor the development in adolescent risky road behaviours and their psychological determinants.

Our research showed that youngsters who report engaging in risky behaviour are also more often involved in crashes, and that several psychological determinants are predictive of risk behaviours. This suggests that it is possible - by regular monitoring of these risk behaviours and psychological determinants - to identify developments as well as potential risk groups and to target interventions directly at the risky behaviours. An example is the increasing prevalence of the use of smartphones among young adolescent cyclists, and the associated elevated crash risk. Thus, similar to surveys aiming to monitor health risks (such as the Health Behaviour in School Children (HBSC) of the World Health Organisation (WHO), it is recommended to use surveys such as the one developed in this series of studies, to monitor road risks among this age group. Further, because risk behaviour co-occurs across different risk domains, integrating the road safety survey with surveys on health behaviour such as the HBSC, would be beneficial for understanding shifts in risk-taking tendencies and the identification of subgroups that are at risk.

3. Teen thinking differs from adult thinking, which has implications for surveys and interventions.

Most interventions are based on an intuitive understanding of the nature of adolescent risk behaviour, or are derived from studies on adult car drivers. Our study showed that the models and concepts developed for adult car drivers are - in their current form - of limited use for young adolescents' risk behaviour. Apparently, adolescents' motives for and understanding of risk behaviours differ from those of adults. Thus, more research is needed to gain deeper insight so that interventions are indeed addressing these 'adolescentspecific' processes.

Errors and violations are often seen as an important differentiation in aberrant behaviour. This might be the case for car drivers, but not for adolescents. In this age group, dangerous play and lack of protective behaviour also contribute to crashes. In education programmes, protective behaviour appears to be a neglected area, and more work is needed to improve the items used in surveys, as well as to redirect interventions. 


\section{Inexperience and poor hazard perception are factors in need of mediation.}

Whereas many studies have focussed on the role of deliberate risk taking as one of the most important explanations of the rise in adolescent mortality, the dissertation found evidence for changes in exposure to risk, which results in young adolescents using riskier means of transport, compared to children. In addition we found evidence for young adolescents making errors in complex traffic situations, suggesting that inexperience still plays a role in their risky decision-making. In early adolescence, youngsters shift from being car passengers to being road users who travel independently from their caretakers, using modes of transport that offer little protection i.e. as pedestrian, cyclist or moped rider. In that context, more detailed insight into the hazard perception skills of young adolescents is needed, as well as insight into the ways in which to improve those skills. The development of such skills may also be beneficial for future traffic roles as car, truck and bus drivers.

\subsubsection{Lessons learned about road safety education programmes}

1. The acquisition of safety critical skills requires intensive learning by doing, rather than by watching demonstrations or learning simple rules of thumb.

One of the dilemmas RSE faces is expressed in the saying "For the things we have to learn before we can do them, we learn by doing them" (Michon, 1981 quoting Aristotle). This dilemma also holds for the acquisition of road skills. In our studies we saw that only providing youngsters with practice in a schoolyard is insufficient for safe decision making, but the interaction with real traffic in complex situations would be far too dangerous. Road safety education needs to find teaching methods that provide real life training, resulting in safe behaviour, without exposing youngsters to unacceptable risks. Serious gaming and virtual reality may provide such a training environment. Simulator training has been shown to be a viable tool in hazard perception training for candidate drivers, using simple animated traffic environments, for instance on a PC or tablet (Vlakveld et al., 2011). In addition, parents may be encouraged to be active supervisors when they accompany their children in traffic. This approach would require an intervention to motivate parents, which amongst other approaches should include the provision of practical guidelines on 'safe road procedures' and supervision strategies for different age groups. Johnson et al. (2010b) refers to studies that show that for many parents, parenting teens is quite a challenge, and at times frustrating and unrewarding. Such experiences, in combination with a belief that their teens are sufficiently capable of 'looking after themselves' may result in parents withdrawing during this stage. Providing 
support to parents and help in understanding how normal adolescent development affects behaviour, might improve parenting skills (Johnson et al., 2010).

2. Effects of 'short' RSE programmes are probably not as great as they may appear. Evaluation studies are needed to provide an accurate estimate of the outcome of each programme.

The evaluation studies presented in the dissertation showed that RSE only had small effects or no effects at all, whereas these programmes were selected on the basis of positive recommendations from education professionals working with these programmes. Moreover, the fact that the effects differed among the programmes and that a few did not lead to any change at all, illustrates the pitfalls of intuition and the importance of evaluation studies for developing effective RSE. As also shown by this study, evaluations of RSE programmes are feasible - though not perfect - in field studies. Therefore, no convincing reason exists as to why RSE programmes that are used in schools should not be evaluated as a standard requirement. In this way, 'ineffective' programmes will be eliminated, and the scarcely available financial resources will go toward the best performing programmes. In the Netherlands, such a procedure has already been applied to interventions in the health domain. For information on this Dutch system of Intervention Accreditation, see http://www.loketgezondleven.nl/algemeen/english/.

3. To discourage deliberate risk-taking, the actual design and delivery of an RSE programme has more impact on effects than the choice for either a 'fear-appeal' or a 'cognitive'approach.

How to deter youngsters from deliberate risk taking is one of the main challenges in the design of prevention strategies in RSE. The two main types of persuasion include improving the understanding of road risk (cognitive approach) or inducing fear (fear-appeal approach). For a recent overview on these types of persuasion we refer to Ruiter, Kessels, Peters \& Kok (2014). In our evaluation study, both approaches were represented. The effects of the two approaches did not differ; for both approaches we found programmes that changed behaviour and programmes that did not. Thus the actual design and delivery of the programme appears to have more impact than the choice of one of the two approaches. The fact that we did not find an overall effect of approach type needs to be interpreted with care, as the effect was confounded with age - the cognitive programmes were solely delivered to the younger age group, whereas the fear-appeal programmes were only delivered to the older age group (15-17 year olds). 
4. Adolescent safety benefits from implementation of a safe road environment in combination with effective RSE. This provides conditions for protection and individual growth.

The comparison among countries with different safety levels showed that there is a strong effect from road system types. A safe traffic system provides the conditions advocated by Johnson et al. (2010), referring to the need in present day society to create communities and to design systems that are safe for predictable adolescent exploration, in order "to allow adolescents to gain experience that will help them navigate the transition to adulthood". Animal behaviour studies show that risk taking is a necessary component of maturation. It provides adolescents of many species - rodents up to primates - the necessary experiences to learn about 'who they are' and 'what they can or cannot achieve'. As such, modest risk taking, despite its dangers, is a rational and even an 'optimal' developmental strategy (see Spear, 2013 for a review of these topics). Johnson and colleagues (2010) state "Viewed this way, adolescents are not, as Males (2009) argues neurodevelopmental scientists view them, victims of faulty wiring, bad brains, or mistakes of nature" (p. 9). The combination of a safe systems approach and an individual approach in road safety education would provide the strengths of both to produce a safe environment that empowers individuals.

\subsection{Recommendations for future research}

Several recommendations for future research and development have already been discussed in the individual studies presented in this dissertation. But by taking a more meta-perspective, these recommendations can be condensed into four main topics: the aetiology of risky road behaviour in adolescence, the integrative approach to risky behaviours also including other domains such as health, criminology, and sexuality, the evaluation of interventions, and the development of advanced research methods to examine pedestrian, cyclist and moped rider behaviour.

1. Studies are needed to deepen our understanding of the aetiology of risky road behaviour.

The reasons why young adolescents behave in a risky manner in traffic is very complicated. This dissertation could only touch on a few of the relevant issues. Several issues need to be addressed in future research. These issues are related to risk taking in relation to brain maturation, the adolescent attribution of risky decisions and traffic events, and the nature of inexperience and training in relation to brain plasticity. 
In studies on brain maturation and risk-taking decision tasks are used whereby risk is modelled as the chance of winning or losing a reward. Frequently, the results of this type of risk taking are then generalized to risk taking in daily life, such as in traffic. However, risk in traffic is not a task about winning or losing, but about actual threats that may be directly related to a 'fear response'. These fear responses might be activated by the brain processes, and may create a deep impression (marker). In this context, the practical application of findings from brain research would be facilitated if the stimulus material (task) were more valid for the traffic task. Such studies have been carried out for by Callan, Osu, Yamagishi, Callan \& Inoue (2009), who also examined the areas of the brain that were related to threat, and the perception and evaluation of hazards. To date such studies have only been carried out on adult participants, so an extension to adolescents would be valuable.

'Attribution' is concerned with how adolescents interpret events and how this relates to their thinking and (risky) behaviour. For instance, do adolescents see risky traffic situations as resulting from deliberately risky action or do they see these as resulting from external factors? To illustrate, a narrow escape after a red light violation can be interpreted as follows: 'Normally, you can violate these lights without any risks, but only today some other (crazy?) driver almost hit me. He must have been running a red light'. Furthermore, our findings suggest that adolescent reasoning and attributions about risky events on the roads may differ from that of adults, especially with respect to risky behaviour being intentional or not. These forms of self-justification, blaming-others, and intention-labelling are powerful mechanisms that affect the way in which the world is perceived in relation to one's actions, how feedback is interpreted, risks are assessed, and interventions are accepted. Thus, findings from adults, frequently car drivers, should not be generalized to young adolescents. Adolescent attributions first need to be understood in order to monitor the determinants of risk behaviour reliably and to target interventions successfully (Goldenbeld et al., 2008).

Concerning inexperience, a deeper insight is needed into the competencies of adolescent road users, especially in complex traffic situations. A central discussion regarding adolescent brain development is the extent to which the plasticity of the adolescent brain can be exploited to accelerate learning processes, including safe road behaviour. In a review of our current understanding of adolescent neurodevelopment, Spear (2013) refers to the 
policy implications of this topic and says: 'Although it is clear that environmental circumstances of the adolescent matter and that the maturing brain during adolescence is sensitive to these experiences, many critical questions remain'(p. S11). Apart from questions on the way in which the brain adapts to experiences, and the extent to which experiences are beneficial or detrimental, the review by Spear also mentions the role of training. 'Can the plasticity of the brain be exploited to train adolescents to enhance their self-control under emotional circumstances or to accelerate neural maturation of regions critical for self-control? If such training is effective, would training to minimize the natural course of adolescence be advisable?' (p. S11). Based on the findings in this dissertation, we advise not restricting the studies to the influence of training on self-control, but also addressing other 'adolescent weaknesses' relevant for road safety, such as hazard perception, which is the ability to recognize and respond to hazards, and 'perspective taking' which is the ability to take the viewpoint of another person.

2. Because risk behaviour is not limited to the road, but also occurs in other domains, a more integrated research approach is needed.

Risk behaviour is a central feature of young adolescents' development. This behaviour appears to be related to 'hot' decision making (under high emotional conditions), the influence of peers, conflicts with parents, and reward sensitivity (Spear, 2013). So far, research has been fragmented. Most projects address these issues but only for specific problem behaviour such as smoking or petty crime. This leads to the situation that in the Netherlands, for instance, an abundance of studies examined peer pressure, but each of them for a different risk behaviour and none of them capturing the full picture (Twisk and Stelling, 2014). Research in these areas would be improved if looked at in a more integrated approach. Such an approach might also lead to more effective prevention programmes. Peters et al. (2013, p. 1), for instance, evaluated the effects of a curriculum at secondary schools that addressed the psychosocial determinants and behaviours in the domains of smoking and safe sex. The programmes not only had an effect on these targeted behaviours, but also had an effect on "determinants and behaviors in three domains about which no lessons were taught (consumption of alcohol, fruit and breakfast)" (p.1). Until 2014, we did not know of evaluation studies that considered these potential 'transfer effects' on road behaviour. 
3. An initiative is needed to ensure that all road safety education programmes used in schools are proven effective.

Today, interventions to prevent risk behaviour among young adolescents are seldom based on a clear understanding of the determinants of that behaviour, the identification of factors amenable to change, and an assessment of the effects of educational interventions. This is not only true for RSE but also for interventions in the road systems. This state of affairs also has an ethical component. For road safety education in schools we expose youngsters without their explicit consent to programmes of which the effects are unknown. Because the effects may even be counterproductive, all programmes delivered in schools should be evaluated by methods that provide reliable estimates of the effects on risky behaviour. For the road system, the ethical component is related to the fact that mobility is an inherent part of social life. For their development, education, and the acquisition of social skills, youngsters have to go to school, have to meet friends, and have to go out to explore the world. Thus, they are bound to use the roads, whether these roads are safe or not. There is no alternative.

4. To enable a deeper insight into problems and interventions for adolescent cyclists, pedestrians and moped riders, more advanced research methodologies need to be developed.

For our studies we used rather 'simple' methodologies to study adolescent risk behaviour, the reason being that more advanced methods have not yet been developed. To understand the nature of risky decisions in traffic, more advanced methods such as simulators need to be employed. Simulators for instance, which enable traffic conditions to be systematically varied without exposing road users to unacceptable risks, have greatly contributed to the design of instrumentation in cars, road design and driver training. To date simulators and other advanced techniques such as animations and virtual reality are only sparsely available, and therefore only sparsely used. The other field of advanced techniques concerns the use of 'functional magnetic resonance imaging (fMRI). The aim of studies that use fMRI is to detect correlations between brain activation and a task the subject performs during the MRI scan, or with the specific emotions and cognitive states, such as anxiety, and recognition, induced in the participants. fMRI studies have also been used to study risky adolescent behaviour, for instance in a gambling task. Although the findings of these studies have frequently been generalized to risk behaviour on the road, to date most of these generalizations lack external validity. These fMRI studies would gain in social relevance if the experiments were designed to explicitly address risk behaviour on the road. 


\subsection{Conclusions}

Given that most studies in road safety have focussed on adolescent drivers, late licensing is seen as a beneficial safety measure. However, now that active road use - such as cycling and walking - is being promoted for health reasons to young adolescents, the choices of transport modes are restricted to bicycles and mopeds, and recent studies brain development show risk taking to be highest among young adolescents, more insight is needed into the road safety of young adolescent road users who are too young to be licensed to drive a car. How beneficial is late licensing for this age group and how effective are measures such as road safety education and a safe road environment? To provide answers to these questions and to contribute to the development of high quality education programmes for young adolescent road users, in particular cyclists, this dissertation aimed to achieve (a) a deeper understanding of the magnitude and nature of road risk in early adolescence; (b) the identification of risk increasing factors; (c) the assessment of the effects of some road safety education programmes used in Dutch schools and (d) the influence of the safety of the road system on adolescent road mortality.

We have identified a strong rise in road fatalities from age 10 onwards. Four factors contribute to this rise: (a) higher exposure to risk because of increased use of more risky transport modes, (b) deliberate risky road behaviour, which also extends to other domains such as health behaviour, (c) risky behaviour due to inexperience, (d) a risky road environment. In terms of interventions to prevent risky traffic behaviour, the dissertation showed that RSE programmes may be ineffective and that at present there is no systematic strategy to detect programmes that fail to achieve the desired outcome. A safe road environment was also shown to protect young adolescents, while providing them with some opportunity for safe 'exploration' and moderate 'risk-taking'. Still, several questions remain that require a considerable research effort in order to design intervention strategies that 'will help determine the degree to which communities, schools and families should focus efforts to promote specific context and experiences for adolescents while discouraging others' (Spear, 2013, p. S11). This effort requires detailed monitoring of risky road behaviour and the development of programmes that are evidence-based. However, "the clear presence of a problem prompts action, but the clear absence of a solution prompts caution" (Poulter and McKenna, 2010, p. 166). 


\section{References}

Adair, J.G., Sharpe, D., Huynh, C.-L., 1989. Hawthorne control procedures in educational experiments: A Reconsideration of their use and effectiveness. Review of Educational Research 59 (2), 215228.

Adams-Guppy, J., Guppy, A., 1995. Speeding in relation to perceptions of risk, utility and driving style by British company car drivers. Ergonomics 38 (12), 2525-2535.

Af Wåhlberg, A., 2009. Driver behaviour and accident research methodology: unresolved problems. Ashgate Publishing limited, Farnham, Surrey, England.

Af Wåhlberg, A.E., Dorn, L., Kline, T., 2010. The effect of social desirability on self reported and recorded road traffic accidents. Transportation Research Part F: Traffic Psychology and Behaviour 13 (2), 106 - 114.

Anderson, J.R., 1982. The acquisition of cognitive skill. Psychological review 89 (4), 396-406.

Arbuckle, J.L., 2013. IBM SPSS: Amos ${ }^{\mathrm{TM}} 19$ User's Guide

Armitage, C.J., Conner, K.R., 2001. Efficacy of the theory of planned behaviour. British Journal of Social psychology 40 (4), 471-499.

Baker, S.P., Chen, L.H., Li, G., 2007. Nationwide review of Graduated Driver Licensing. AAA Foundation for Traffic Safety, Washington, DC.

Bandura, A., 1989. Social cognitive theory. In: Vasta, R. (Ed.), Annals of child development; Six theories of child development. JAI Press, Greenwich, CT, Vol. 6, pp. 1-60.

Barnett, S.M., Ceci, S.J., 2002. When and where do we apply what we learn? A taxonomy for far transfer. Psychological Bulletin 128 (4), 612-637.

Bartholomew, L.K., Parcel, G.S., Kok, G., Gottlieb, N.H., Fernandez, M.E., 2011. Planning health promotion programs: An intervention mapping approach $(3 \mathrm{ed}$.). Jossy-Bass books San Fransisco.

Beck, K.H., Lockhart, S.J., 1992. A model of parental involvement in adolescent drinking and driving. Journal of Youth and Adolescence 21, 35-51.

Bianchi, A., Summala, H., 2004. The "genetics" of driving behavior: parents' driving style predicts their children's driving style. Accident Analysis \& Prevention 36 (4), 655-659.

Bingham, C.R., Shope, J.T., 2004. Adolescent problem behavior and problem driving in young adulthood. Journal of Adolescent Research 19 (2), 205-223.

Blakemore, S.-J., Den Ouden, H., Choudhury, S., Frith, C., 2007. Adolescent development of the neural circuitry for thinking about intentions. Social Cognitive and Affective Neuroscience 2 (2), 130139.

Blakemore, S.-J., Frith, U., 2005. The learning brain: Lessons for education : a précis. Developmental Science 8 (6), 459-471.

Blakemore, S.J., Choudhury, S., 2006. Development of the adolescent brain: implications for executive function and social cognition. Journal of Child Psychology and Psychiatry 47 (3-4), 296-312.

Bollen, K.A., Long, J.S., 1993. Testing structural equation models. Sage., Newbury Park, CA.

Boyer, T.W., 2006. The development of risk-taking: A multi-perspective review. Developmental Review 26 (3), 291-345.

Bradburn, N.M., Rips, L.J., Shevell, S.K., 1987. Answering autobiographical questions: the impact of memory and inference on surveys. Science 236 (4798), 157-161.

Braimaister, L., Hakkert, A.-S., Van Schagen, I.N.L.G., 2002. The uses of exposure and risk in road safety studies. In: Proceedings of the European Transport Conference. Homerton College, Cambridge.

Brijs, K., Ruiter, R., Brijs, T., 2009. Naar een evidence-based en doelgroep-specifieke verkeerseducatie: Enkele recente inzichten met betrekking tot risicogedrag bij jonge adolescenten. [Towards an evidence based and target group specific road safety education: recent insights concerning the risk behaviour of young adolescents]. In: Jaarboek Verkeersveiligheid 2009. Vlaamse Stichting Verkeerskunde, Mechelen. 
Brookhuis, K., Van Schagen, I.N.L.G., Wierda, M., 1987. Wat denkt de fietser. Wat kan de fietser. Wat doet de fietser? [What does the cyclist think. How capable is the cyclist. What does the cyclist do? ]. VK 87-23 Rijksuniversiteit Groningen RUG, Verkeerskundig Studiecentrum VSC, Haren

Brown, B., 2004. Adolescents' relationships with peers. In: Lerner, R., Steinberg, L. (Eds.), Handbook of adolescent psychology. Wiley\& Sons., New York.

Brown, I.D., 1982. Exposure and experience are a confounded nuisance in research on driver behaviour. Accident Analysis \& Prevention 14 (5), 345-352.

Brown, I.D., Groeger, J.A., 1987. Is driver training contributing enough towards road safety? In: Rothengatter, J.A., De Bruin, R.A. (Eds.), Road users and traffic safety. Van Gorcum, Assen, the Netherlands, pp. 135-156.

Buckley, L., Chapman, R., L., Sheehan, M., 2012. Adolescent involvement in anti-social and delinquent behaviours: predicting future injury risk. Accident Analysis and Prevention 48 518-522.

Byrne, B.M., 2001. Structural equation modeling with Amos: Basic concepts, applications, and programming. Routledge.

Byrnes, J.P., Miller, D.C., Schafer, W.D., 1999. Gender differences in risk taking: A meta-analysis. Psychological Bulletin 125 (3), 367-383.

Cacciabue, P.C.e., 2007. Modelling driver behaviour in automotive environments : critical issues in driver interactions with intelligent transport system. Springer, Berlin.

Caird, J., White, C., 2009. The effects of passenger conversation and gender on looked-but-failed-to-see (lbfts) errors. In: 21th world Congress of International Traffic Medicine Association. The Hague World Congress: Safe Mobility for Young and Old The Hague.

Callan, A.M., Osu, R., Yamagishi, Y., Callan, D.E., Inoue, N., 2009. Neural correlates of resolving uncertainty in driver's decision making. Human Brain Mapping 30 (9), 2804-2812.

Casey, B.J., Getz, S., Galvan, A., 2008. The adolescent brain. Developmental Review 28 (1), 62-77.

CBS. 2009. Jaarrapport 2009 Landelijke Jeugdmonitor [Year report 2009 National youth monitor]. Centraal Bureau voor de Statistiek CBS, Den Haag.

Chalmers, I., 2003. Trying to do more good than harm in policy and practice: The role of rigorous, transparent, up-to-date evaluations. Annals of the American Academy of Political and Social Science 589 (1), 22-40.

Champion, V.L., Skinner, C.S., 2008. The health belief model. In: Glanz, K., Rimer, B.K., Viswanath, K. (Eds.), Health behavior and health education. Theory, research and practice. Jossey-Bass., San Fransisco, 4 ed., pp. 45-65.

Christie, N., Cairns, S., Towner, E., Ward, H., 2007. How exposure information can enhance our understanding of child traffic 'death leagues'. Injury Prevention 13 (2), 125-129.

Cohen, J., 1988. Statistical Power Analysis for the Behavioral Sciences (2 ed.). L. Erlbaum Associates., Hillsdale, NJ.

Cook, T.D., Campbell, D.T., 1979. Quasi-experimentation: Design and analysis for field settings. Rand McNally, Chicago, Illinois.

Cronbach, L.J., 1951. Coefficient alpha and the internal structure of tests. Psychometrika 16 (3), $297-334$.

Crone, E.A., Dahl, R.E., 2012. Understanding adolescence as a period of social-affective engagement and goal flexibility. Nature Review Neuroscience 13 (9), 636-650.

Dahl, R.E., 2004. Adolescent brain development: A period of vulnerabilities and opportunities. Keynote address. Annals of the New York Academy of Sciences 1021, 1-22.

Damasio, A.R., Everitt, B.J., Bishop, D., 1996. The somatic marker hypothesis and the possible functions of the prefrontal cortex. Philosophical Transactions: Biological Sciences 351 (1346), 1413-1420.

De Craen, S., 2010. The X-factor; a longitudinal study of calibration in young, novice drivers. Dissertation Thesis. SWOV-Dissertatiereeks. Stichting Wetenschappelijk Onderzoek Verkeersveiligheid SWOV, Leidschendam.

De Hartog, J.J., Boogaard, H., Nijland, H., Hoek, G., 2010. Do the health benefits of cycling outweigh the risks? Environmental Health Perspectives 118 (8), 1109-1116.

De Looze, M.E.e.a., 2011. Early risk behaviors and adolescent injury in 25 European and North American countries: a cross-national consistent relationship. Journal of Early Adolescence

De Waard, D., Schepers, P., Ormel, W., Brookhuis, K., 2010. Mobile phone use while cycling: Incidence and effects on behaviour and safety. Ergonomics 53 (1), 30-42. 
De Winter, J.C.F., Dodou, D., 2010. The Driver Behaviour Questionnaire as a predictor of accidents: A meta-analysis. Journal of Safety Research 41 (6), 463-470.

Dekker, S.W.A., 2005. Why we need new accident models, Technical Report 2005-02. Lund University School of Aviation Ljungbyhed, Sweden.

Delhomme, P., De Dobbeleer, W., Forward, S., Simões, A., 2009. Manual for designing, implementing, and evaluating road safety communication campaigns. CAST-project: Deliverable 2.3. INRETS, Paris.

Dijksterhuis, A.P., 2008. Het slimme onbewuste; denken met gevoel [The smart unconscious mind; thinking with emotion]. Bert Bakker, Amsterdam.

Dorsselaer, S., Van Zeijl, E., Eeckhout, S., Van den Bogt, T., Ter Vollebergh, W., 2007. HBSC 2005 Gezondheid en welzijn van jongeren in Nederland [HBSC 2005 Health and well-being of youth in the Netherlands. Trimbos-instituut, Utrecht.

Dragutinovic, N., Twisk, D.A.M., 2006. The effectiveness of road safety education, a literature review. R-2006-6. SWOV Institute for Road Safety Research, Leidschendam.

Dreyfus, S.E., Dreyfus, H.L.F., 1980. A five-stage model of the mental activities Involved in directed skill acquisition. Washington, DC: Storming Media. Retrieved June 13, 2010.

Dunlop, S.M., Romer, D., 2010. Adolescent and young adult crash risk: sensation seeking, substance use propensity and substance use behaviors. Journal of Adolescent Health 46 (1), 90-92.

Duperrex, O.J., Roberts, I.G., Bunn, F., 2009. Safety education of pedestrians for injury prevention. Cochrane Injuries Group Cochrane Database of Systematic Reviews.

Eby, D.W., Molnar, L.J., 1999. Matching traffic safety strategies to youth characteristics, a literature review of cognitive development. 808 927. UMTRI, The University of Michigan Transport Research Institute, Ann Arbor.

Eccles, J.S., Wigfield, A., 2002. Motivational beliefs, values, and goals. Annual Review of Psychology 53 (1), 109-132.

Ehsani, J.P., Bingham, R.C., Shope, J.T., 2013. The effect of the learner license Graduated Driver Licensing components on teen drivers' crashes. Accident Analysis \& Prevention 59 (Oct ), 327336.

Eksler, V., Lassarre, S., Thomas, I., 2008. Regional analysis of road mortality in Europe. Public Health $122(9), 826-837$.

Elliott, M.A., Baughan, C.J., 2004. Developing a self-report method for investigating adolescent road user behaviour. Transportation Research Part F: Traffic Psychology and Behaviour 7 (6), 373393.

Endsley, M.R., 1995. Toward a theory of situation awareness in dynamic systems. Human Factors 37 (1), 32-64.

Engström, I., 2008. Group dynamics and cohesiveness among young drivers and their passengers. Dissertation thesis

Ericsson, A.K., Prietula, M.J., Cokely, E.T., 2007. The making of an expert. Harvard Business Review Article July.

Ericsson, K.A., 2005. Recent advances in expertise research: a commentary on the contributions to the special issue. Applied Cognitive Psychology 19 (2), 233-241.

ETSC. 2001. Transport safety performance indicators. ETSC European Transport Safety Council, Brussel.

ETSC. 2009. Road Safety Performance Index: Reducing child deaths on European roads. ETSC European Traffic Safety Council, Brussels.

European Commission. 2010. Towards a European road safety area: policy orientations on road safety 2011-2020. COM(2010) 389 final. EC, Brussels.

European Road Safety Observatory. 2010a. Traffic Safety Basic Facts: Children aged < 15. DaCoTA, project

European Road Safety Observatory. 2010b. Traffic Safety Basic Facts: Youngsters aged 15-17. DaCoTA, project

Eurostat. 2009. Illustrated Glossary for Transport Statistics EUROSTAT - ITF - UNECE (2009) http://www.internationaltransportforum.org/Pub/pdf/09GloStat.pdf. In Eurostat (Ed.). Brussels. 
Ezinga, M.A.J., Weerman, F.M., Westenberg, P.M., Bijleveld, C.C.J.H., 2008. Early adolescence and delinquency: Levels of psychosocial development and self-control as an explanation of misbehaviour and delinquency. Psychology, Crime \& Law 14 (4), 339-356.

Feenstra, H., Ruiter, R., Kok, G., 2010. Social-cognitive correlates of risky adolescent cycling behavior. BMC Public Health 10 (1), 408.

Feenstra, H., Ruiter, R.A.C., Kok, G., 2012. Go Fast! Reaction time differences between adults and adolescents in evaluating risky traffic situations. Journal of Health Psychology 17 (3), 343-349.

Feenstra, H., Ruiter, R.A.C., Schepers, G.J., Kok, G., 2011. Measuring risky adolescent cycling behaviour. International journal of injury control and safety promotion ifirst, 1-7.

FHWA. Traffic Volume Trends of the Federal Highway Administration (FHWA). http://www.fhwa.dot.gov/policyinformation/travel monitoring/tvt.cfm.

Field, A., 2009. Discovering statistics using SPSS (3 ed.). Sage publications Ltd, London UK.

Fietsberaad. 2009. Overzicht campagnes in het fietsbeleid [Overview of campaigns used in bicycle policy plans]. Fietsberaad, Utrecht.

Fischhoff, B., Bruine de Bruin, W., Parker, A.M., Millstein, S.G., Halpern-Felsher, B.L., 2010. Adolescents' perceived risk of dying. Journal of Adolescent Health 46 (3), 265-269.

Fuller, R., 2005. Towards a general theory on driving behaviour. Accident Analysis \& Prevention 27 (3), 461-472.

Fuller, R., 2008. Driver Training and assessment: implications of the task-difficulty homeostasis model. In Dorn, L. (Ed.), Driver behaviour and training, Vol. 3. Ashgate publishing Limited, Aldershot.

Gardner, M., Steinberg, L., 2005. Peer influence on risk taking, risk preference, and risky decision making in adolescence and adulthood: An experimental study. Developmental Psychology 41 (4), 625-635.

Gerrard, M., Gibbons, F.X., Houlihan, A.E., Stock, M.L., Pomery, E.A., 2008. A dual-process approach to health risk decision making: The prototype willingness model. Developmental Review 28 (1), 29-61.

Gibbons, F.X., Houlihan, A.E., Gerrard, M., 2009. Reason and reaction: The utility of a dual-focus, dualprocessing perspective on promotion and prevention of adolescent health risk behaviour. British Journal of Health Psychology 14, 231-248.

Gibbons, F.X., Lane, D.J., Gerrard, M., Pomery, E.A., Lautrup, C.L., 2002. Drinking and driving: A prospective assessment of the relation between risk cognitions and risk behaviour. Risk, Decision and Policy 7, 267-283.

Giedd, J.N., 2008. The Teen Brain: Insights from neuroimaging. Journal of Adolescent Health 42 (4), 335-343.

Glanz, K., Rimer, B.K., Viswanath, K., 2008. Health behavior and health education. Theory, research and practice, 4 ed. Jossey-Bass, San Fransisco.

Glanz, K., Stryker, J.E., Kris, H., 2008. Health behavior and risk factors. In: International Encyclopedia of Public Health. Academic Press, Oxford, pp. 146-152.

Glendon, A.I., Bryan, E.P., 2011. Neuroscience and young drivers. In: Handbook of Traffic Psychology. Academic Press, San Diego, pp. 109-125.

Goldenbeld, C., Houtenbos, M., Ehlers, E., De Waard, D., 2012. The use and risk of portable electronic devices while cycling among different age groups. Journal of Safety Research. 43 (1), 1-8.

Goldenbeld, C., Twisk, D., Houwing, S., 2008. Effects of persuasive communication and group discussions on acceptability of anti-speeding policies for male and female drivers. Transportation Research Part F: Traffic Psychology and Behaviour 11 (3), 207-220.

Grayson, G.B., 1981. The identification of training objectives: What shall we tell the children? Accident Analysis \& Prevention 13 (3), 169-173.

Haddon, W., 1980a. Advances in the epidemiology of injuries as a basis for public policy. Public Health 95 (5), 411-421.

Haddon, W.J., 1980b. Options for the prevention of motor vehicle crash injury. Israel Journal of Medical Science. Jan. 16 (1), 45-65. 
Hakkert, A.S., Braimaister, L., Van Schagen, I., 2002. The uses of exposure and risk in road safety studies. In: Proceedings of the European Transport Conference. Homerton College, Cambridge.

Hakkert, A.S., Gitelman, V., 2007. Road Safety Performance Indicators: Manual. Deliverable D3.8 of the EU FP6 project SafetyNet.

Hampson, S.E., Andrews, J.A., Barckley, M., 2007. Predictors of the development of elementary-school children's intentions to smoke cigarettes: Hostility, prototypes, and subjective norms. Nicotine \& Tobacco Research 9 (7), $751-760$.

Harms, L., 2006. Anders onderweg: De mobiliteit van allochtonen en autochtonen vergeleken. Een verkennend onderzoek in opdracht van het ministerie van Verkeer en Waterstaat [Different in Mobility: comparing the travel patterns of non-native and native Dutch citizins. An exploration commissioned by the Ministery of transport and water works]. Sociaal en Cultureel Planbureau, Den Haag.

Harré, N., 2000. Risk evaluation, driving, and adolescents: A typology. Developmental Review 20 (2), 206-226.

Hauer, E., 2008. How many accidents are needed to show a difference? Accident Analysis \& Prevention 40 (4), 1634-1635.

Hendriksen, I., Van Gijlswijk, R., 2010. Fietsen is groen, gezond en voordelig: Onderbouwing van 10 argumenten om te fietsen [Cycle use is green, healty and cheap: Evidence in support of 10 reasons to use bicycles] TNO Kwaliteit van Leven: Preventie en Zorg, Leiden.

Hjalmarsson, R., Lindquist, M.J., 2010. Driving under the influence of our fathers, B.E. Journal of Economic Analysis \& Policy, Vol. 10, pp. 100.

IBM. 2012. IBM SPSS Advanced Statistics 21.

IRTAD. 2013. International Transport Forum. Joint OECD/ECMT Transport Research Centre http://www.internationaltransportforum.org/jtrc/safety/safety.html.

Janssen, W., 1994. Seat-belt wearing and driving behavior: an instrumented-vehicle study. Accident Analysis \& Prevention 26 (2), 249-261.

Jessor, R., 1987. Risky driving and adolescent problem behaviour: An extension of Problem-Behaviour Theory. Alcohol, Drugs, and Driving 3 (3-4), 1-11.

Jessor, R., 1992. Risk behavior in adolescence: A psychosocial framework for understanding and action. Developmental Review 12 (4), 374-390.

Jessor, R., Turbin, M.S., Costa, F.M., 1997. Predicting developmental change in risky driving: The transition to young adulthood. Applied Developmental Science 1 (1), 4-16.

Johnson, S.B., Blum, R.W., Giedd, J.N., 2009. Adolescent maturity and the brain: The promise and pitfalls of neuroscience research in adolescent health policy. Journal of Adolescent Health 45 (3), 216-221.

Johnson, S.B., Sudhinaraset, M., Blum, R., 2010. Neuromaturation and adolescent risk taking: Why development is not determinism. Journal of Adolescent Research 25 (1), 4-23.

Jones, B., 2009. Split-plot designs: What, why, and how. Journal of quality technology 41 (4).

Jost, G., Popolizio, M., Allsop, R., Eksler, V., 2010. Road safety target in sight: Making up for lost time. European Transport Safety Council ETSC, Brussels

Junger, M., Mesman, J., Meeus, W., 2003. Psychosociale problemen bij adolescenten, prevalentie, risicofactoren en preventie [Psychosocial problems among adolescents, prevalence, risk fators and prevention]. Van Gorcum, Assen.

Junger, M., Terlouw, G.J., van der Heijden, P.G.M., 1994. Crime and accident involvement in young road users. In: Behavioural research in road safety V. Nottingham University.

Kahneman, D., 2003a. Maps of bounded rationality: A perspective on intuitive judgment and choice. In: Frangsmyr, T. (Ed.), Les Prix Nobel: The Nobel Prizes 2002 The Nobel Foundation, Stockholm, pp. 449-489.

Kahneman, D., 2003b. Maps of Bounded Rationality: Psychology for behavioral economics. The American Economic Review 93 (5), 1449-1475.

Kaiser, H.F., 1960. The application of electronic computers to factor analysis. Educational and Psychological Measurement 20 (141-151). 
Keating, D.P., 2004. Cognitive and brain development. In: Lerner, R.M., Steinberg, L.D. (Eds.), Handbook of adolescent psychology. John Wiley and Sons, Hoboken, New Jersey, 2 ed., pp. 45-85.

Keating, D.P., 2007. Understanding adolescent development: Implications for driving safety. Journal of Safety Research 38 (2), 147-157.

Keating, D.P., Halpern-Felsher, B.L., 2008. Adolescent drivers: A developmental perspective on risk, proficiency, and safety. American Journal of Preventive Medicine 35 (3, Supplement 1), S272S277.

Kemler, H.J., Ormel, W., Jonkhoff, L., Klein Wolt, K., Veling, M., Buuron, I., et al., 2009. De fietshelm bij kinderen en jongeren: Onderzoek naar de voor en nadelen Stichting Consument en Veiligheid, Amsterdam

Kline, P., 1999. The handbook of psychological testing (2 ed.). Routledge, London.

Koops, W., Zuckerman, M., 2003. Introduction: A historical developmental approach to adolescence. The History of the Family 8 (3), 345-354.

Koornstra, M., Lynam, D., Nilsson, G., Noordzij, P., Petterson, H.-E., Wegman, F., et al., 2003. SUNflower: a comparative study of the development of road safety in Sweden, the United Kingdom, and the Netherlands.

Kumpula, H., Paavola, M., 2008. Injuries and risk-taking among young people in Europe - The European situation analysis EU-Project AdRisk, 2008. KTL (National Public Health Institute) Helsinki.

Lanting, L.C., Hoeymans, N., 2008. Let op letsels, Preventie van letsels door ongevallen, geweld en suïcide [Observing injuries. Prevention of injuries due to accidents, violence, and suicide] RIVM-rapportnummer: 270102001. RIVM Rijksinstituut voor Volksgezondheid en Milieu, Bilthoven.

Larsson, P., Dekker, S.W.A., Tingvall, C., 2010. The need for a system theory approach to road safety. Safety Science 48, 1167-1174.

Latendresse, S.J., Rose, R.J., Viken, R.J., Pulkkinen, L., Kaprio, J., Dick, D.M., 2008. Parenting mechanisms in links between parents' and adolescents' alcohol use behaviors. Alcoholism: Clinical and Experimental Research 23 (2), 322-330.

Lenroot, R.K., Giedd, J.N., 2010. Sex differences in the adolescent brain. Brain and Cognition 72 (1), $46-$ 55.

Lerner, R.M., Steinberg, L.D., 2004. Handbook of adolescent psychology. John Wiley and Sons, Hoboken, New Jersey

Lynam, D., Nilsson, G., Morsink, P., Sexton, B., Twisk, D.A.M., Goldenbeld, C., et al., 2002. SUNflower: A comparative study of the development of road safety in Sweden, the United Kingdom, and the Netherlands. SWOV Institute for Road Safety Research / Crowthorne, Berkshire, Transport Research Laboratory TRL / Linköping, Swedish National Road and Transport Research Institute VTI, Leidschendam, The Netherlands.

Maio, G.R., Verplanken, B., Manstead, A.S.R., Stroebe, W., Abraham, C., Sheeran, P., et al., 2007. Social psychological factors in lifestyle change and their relevance to policy. Social Issues and Policy Review 1 (1), 99-137.

Males, M., 2009. Does the adolescent brain make risk taking inevitable? A skeptical appraisal. Journal of Adolescent Research 24, 3 - 20.

Maycock, G., Lockwood, C.R., Lester, J.F., 1991. The accident liability of car drivers. 315. Transport Research Laboratory TRL, Crowthorne.

Meulman, J.J., Heiser, W.J., 1999. Categories 10.0. SPSS Inc., Chicago.

Michon, J.A., 1981. Preface. Accident Analysis \& Prevention 13 (3), 161-161.

Ministerie van Verkeer en Waterstaat [Ministery of Trafic and Water works]. 2008. Strategisch Plan Verkeersveiligheid 2008-2020: Van, voor en door iedereen [Strategic road safety plan 2008 2020]. Ministerie van Verkeer en Waterstaat, Den Haag, The Netherlands.

Montano, D.E., Kasprzyk, D., 2008. Theory of reasoned action, theory of planned behavior, and the integrated behavioral model. In: Glanz, K., Rimer, B.K., Viswanath, K. (Eds.), Health behavior and health education. Theory, research and practice. Jossey-Bass., San Fransisco, 4 ed., pp. 6796. 
Morgan, M., Grube, J.W., 1989. Adolescent cigarette smoking; a developmental analysis of influences. British Journal of Developmental Psychology 7, 179-189.

Näätänen, R., Summala, H., 1974. A model for the role of motivational factors in drivers' decisionmaking. Accident Analysis \& Prevention 6 (3-4), 243-261.

NHTSA. 2013. Fatalities USA by state and age group were derived from the FARS data files of the National Highway Traffic Safety Administration. http://www.nhtsa.gov/FARS.

Nieuwenhuijzen, M., Junger, M., Klein Velderman, M., Wiefferink, K., Paulussen, T., Hox, J., et al., 2009. Clustering of health-compromising behavior and delinquency in adolescents and adults in the Dutch population. Preventive Medicine 48, 572-578.

Norman, D.A., 1988. The design of everyday things. Basic books.

O'Brien, G., Rooney, F., Carey, C., Fuller, R., 2002. Evaluation of the effectiveness of a dramatic presentation on attitudes to road safety. In: Behavioural Research in Road Safety XII, Vol. Proceedings of the 12th seminar on Behavioural Research in Road Safety Department for Transport, London, pp. 195-207.

OECD-ECMT. 2004. Keeping children safe in traffic. OECD Organisation for Economic Co-operation and Development; ECMT European Conference of Ministers of Transport Paris.

OECD-ECMT. 2006. Young drivers: the road to safety. OECD Organisation for Economic Co-operation and Development; ECMT European Conference of Ministers of Transport, Paris.

OECD-ECMT. 2008. Towards Zero: Ambitious Road Safety Targets and the Safe System Approach. OECD Organisation for Economic Co-operation and Development; ECMT European Conference of Ministers of Transport Paris.

Parker, D., Manstead, A.S.R., Stradling, S.G., Reason, J.T., 1992. Determinants of intention to commit driving violations. Accident Analysis \& Prevention 24 (2), 117-131.

Parker, J., Benson, M., 2004. Parent-adolescent relations and adolescent functioning: Self-esteem, substance abuse, and delinquency. Adolescence 39 (155), 519-530.

Paus, T., 2009. Brain development In: Lerner, R., Steinberg, L. (Eds.), Handbook of adolescent psychology. . New York:Wiley\& Sons., Vol. 1: Individual bases of adolescent development, pp. 95-115.

Peden, M., Scurfield, D., Sleet, D., Mohan, D., Hyder, A., Jarawan, E., et al., 2004. World report on Road Traffic Injury Prevention. World Health Organisation (WHO), Geneva.

Peters, G.-J.Y., Ruiter, R.A.C., Kok, G., 2012. Threatening communication: a critical re-analysis and a revised meta-analytic test of fear appeal theory. Health Psychology Review, 1-24.

Peters, L., Ten Dam, G.T.M., Kocken, P.L., Buijs, G.J., Dusseldorp, E., Paulussen, T.G.M.W., 2013. Effects of transfer-oriented curriculum on multiple behaviors in the Netherlands Health Promotion International, 1 -19

Pickett, W., Schmid, H., Boyce, W.F., Simpson, K., Scheidt, P.C., Mazur, J., et al., 2002. Multiple risk behavior and injury: An international analysis of young people. Archives of Pediatrics and Adolescent Medicine 156 (8), 786-793.

Podsakoff, P.M., MacKenzie, S.B., Lee, J.-Y., Podsakoff, N.P., 2003. Common method biases in behavioral research: A critical review of the literature and recommended remedies. Journal of Applied Psychology 88 (5), 879-903.

Polinder, S., Van Beeck, E.F., Essink-Bot, M.L., Toet, H., Looman, C.W.N., Mulder, S., et al., 2007. Functional outcome at 2.5, 5, 9, and 24 months after injury in the Netherlands. The Journal of Trauma 62 (1), 133-141

Population Reference Bureau. 2011. DataFinder, Vintage estimate www.prb.org.

Poulter, D.R., McKenna, F.P., 2010. Evaluating the effectiveness of a road safety education intervention for pre-drivers: An application of the theory of planned behaviour. British Journal of Educational Psychology (80), 163-181.

Randolph, J.J., Edmondson, R.S., 2005. Using the Binomial Effect Size Display (BESD) to present the magnitude of effect sizes to the evaluation audience. Practical Assessment, Research \& Evaluation 10 (14).

Rasmussen, J., 1985. Trends in human reliability analysis. Ergonomics 28 (8), 1185-1195.

Reason, J., 1990. Human Error. Cambridge University Press, Cambridge, UK. 
Reason, J., Manstead, A., Stradling, S., Baxter, J., Campbell, K., 1990. Errors and violations on the roads: A real distinction? Ergonomics 33, 1315-1332.

Resnick, M., Ireland, M., Borowsky, I., 2004. Youth violence perpetration: What protects? What predicts? Findings from the National Longitudinal Study of Adolescent Health. Journal of Adolescent Health 35 (5), 1 - 10.

Reurings, M.C.B., Bos, N.M., Van Kampen, L.T.B., 2007. Berekening van het werkelijk aantal in ziekenhuizen opgenomen verkeersgewonden, 1997-2003: methode en resultaten van koppeling en ophoging van bestanden [Calculating the actual number of hospitalized injured traffic casualies, 1997-2003: Method and results of a merging and weighing procedure using data sources]. R-2007-8. Stichting Wetenschappelijk Onderzoek Verkeersveiligheid SWOV, Leidschendam.

Reyna, V.F., Farley, F., 2006. Risk and rationality in adolescent decision making: implications for theory, practice and public policy. Psychological science in the public interest, A Supplement to Psychological Science 7 (1), 1-44.

Reyna, V.F., Rivers, S.E., 2008. Current theories of risk and rational decision making. Developmental Review 28 (1), 1-11.

Rosnow, R.L., Rosenthal, R., 2005. Beginning behavioral research; A conceptual primer (5 ed.). Pearson/Prentice-Hall, Englewood Cliffs (NJ).

Rothengatter, J.A., 1985. Gedragsbeinvloeding in het verkeer: methoden en modellen. Verkeerskunde 36 (7), 335-337.

Ruiter, R.A.C., Abraham, C., Kok, G., 2001. Scary warnings and rational precautions: A review of the psychology of fear appeals. Psychology \& Health 16 (6), 613-630.

Ruiter, R.A.C., Kessels, L.T.E., Peters, G.-J.Y., Kok, G., 2014. Sixty years of fear appeal research: Current state of the evidence. International Journal of Psychology 49 (2), 63-70.

Sabey, B.E., Taylor, H., 1980. The known risks we are running: the highway. In: Schwing, R.C., Albers, W.A. (Eds.), Societal Risk Assesment: How safe is safe enough? Plenum Press, New York.

Sagberg, Fosser, Saetermo. 1997. An investigation of behavioural adaptation to airbags and antilock brakes among taxi drivers. Accident Analysis and Prevention 29, 293-302.

Salmon, P.M., Lenné, M.G., Stanton, N.A., Jenkins, D.P., Walker, G.H., 2010. Managing error on the open road: The contribution of human error models and methods. Safety Science 48 (10), 12251235.

Salmon, P.M., McClure, R., Stanton, N.A., 2012. Road transport in drift? Applying contemporary systems thinking to road safety. Safety Science 50, 1829 - 1838.

Schoon, C.C., Doumen, M.J.A., De Bruin, D., 2008. De toedracht van dodehoekongevallen en maatregelen voor de korte en lange termijn: Een ongevallenanalyse over de jaren 1997-2007, verkeersobservaties en enquêtes onder fietsers en vrachtautochauffeurs [The causes of bind spot crashes and counter measures for the short and long term: A crash analyses for the period 1997-2007, traffic observations and surveys among cyclists and truck drivers]. R-200811A. SWOV Institute for Road Safety Research, Leidschendam.

Séguin, J.R., Arseneault, L., Tremblay, R.E., 2007. The contribution of "cool" and "hot" components of decision-making in adolescence: Implications for developmental psychopathology. Cognitive Development 22 (4), 530-543.

Senserrick, T.M., 2006. Reducing young driver road trauma: guidance and optimism for the future. Injury Prevention 12 (suppl_1), i56-60.

Sentinella, J., Keigan, M., 2005. Young adolescent pedestrians' and cyclists' road deaths : analysis of police accident files. TRL - 2005-620. Transport and Road Research Laboratory, Crowthorne, United Kingdom.

Sethi, D., Racioppi, F., Mitis, F., 2007. Youth and road safety in Europe: policy briefing. World Health Organization WHO, Geneva.

Shinar, D., 2012. Safety and mobility of vulnerable road users: Pedestrians, bicyclists, and motorcyclists. Accident Analysis \& Prevention 44 (1), 1-2.

Shope, J.T., 2007. Graduated driver licensing: Review of evaluation results since 2002. Journal of Safety Research 38 (2), 165-175. 
Shriffrin, R.M., Schneider, W., 1977. Controlled and automatic information processing II. Perceptual learning, automatic attending and a general theory. Psychological Review 84 (127), 127-190.

Siegrist, S., 1999. Driver training, testing and licensing: towards theory-based management of young drivers' injury risk in road traffic. Results of EU-project Guarding Automobile Drivers through Guidance Education and Technology GADGET, Work package 3. Schweizerische Beratungsstelle für Unfallverhütung BfU, Bern.

Simons-Morton, B.G., 2009. The Naturalistic Teenage Driving Study: Kinematic data by passenger.Unpublished manuscript, Washington DC.

Simons-Morton, B.G., Bingham, C.R., Falk, E.B., Li, K., Pradhan, A.K., Ouimet, M.C., et al., 2014. Experimental effects of injunctive norms on simulated risky driving among teenage males. Health Psychology 33 (7), 616 - 627.

Sleet, D.A., Ballesteros, M.F., Borse, N.N., 2010. A review of unintentional injuries in adolescents. Annual Review of Public Health 31 (1), 195-212.

Sleet, D.A., Branche, C.M., 2004. Road safety is no accident. Journal of Safety Research 35 (2), 173-174.

Spear, L.P., 2000. The adolescent brain and age-related behavioral manifestations. Neuroscience \& Biobehavioral Reviews 24 (4), 417-463.

Spear, L.P., 2013. Adolescent Neurodevelopment. Journal of Adolescent Health 52 (2, Supplement 2), S7-S13.

Speelman, C.P., Kirsner, K., 2005. Chapter 2. Skill acquisition: History, questions, and theories, Beyond the Learning Curve, Vol. 1, pp. 27-67. Oxford Scholarship Online Monographs, Oxford.

Steg, L., Van Brussel, A., 2009. Accidents, aberrant behaviours, and speeding of young moped riders. Transportation Research Part F: Traffic Psychology and Behaviour 12 (6), 503-511.

Steinberg, L., 2008. A social neuroscience perspective on adolescent risk-taking. Developmental Review 28 (1), 78-106.

Steinberg, L., Albert, D., Cauffman, E., Banich, M., Graham, S., Woolard, J., 2008. Age differences in sensation seeking and impulsivity as indexed by behavior and self-report: Evidence for a dual systems model. Developmental Psychology 44 (6), 1764-1778.

Steinberg, L., Monahan, K.C., 2007. Age differences in resistance to peer influence. Developmental Psychology 43 (6), 1531-1543.

Stipdonk, H.L., Reurings, M.C.B., 2010. The safety-effect of mobility exchange between car and bicycle. R-2010-18. SWOV Institute for Road Safety Research Leidschendam, the Netherlands

Strecher, V.J., Shope, J., Bauermeister, J.A., Chang, C., McHale, N.-B., Boonin, A., et al., 2007. Review of judgement and decision-making literature pertinent to the development of traffic offender training improvement programmes S301Q Technical Report. Department for Transport, London.

Stroup, W.W., 2013. Generalized linear mixed models: Modern concepts, methods and applications. Chapman \& Hall/CRC.

Sullman, M.J.M., Mann, H.N., 2009. The road user behaviour of New Zealand adolescents. Transportation Research Part F: Traffic Psychology and Behaviour 12 (6), 494-502.

Summala, H., 1988. Risk control is not risk adjustment: the zero-risk theory of driver behavior and control Ergonomics 31 (4), 491-506.

Sumter, S.R., Bokhorst, C.L., Steinberg, L., Westenberg, P.M., 2009. The developmental pattern of resistance to peer influence in adolescence: Will the teenager ever be able to resist? Journal of Adolescence 32, 1009-1021.

SUPREME. 2007. SUPREME: summary and publication of best practices in road safety in the member states: thematic report education and campaigns. Kuratorium für Verkehrssicherheit (KFV), Vienna.

Susman, E., J., Rogol, A., 2004. Puberty and psychological development. In: Richard M. Lerner, Steinberg, L.D. (Eds.), Handbook of adolescent psychology. John Wiley and Sons, Hoboken, New Jersey., 2 ed., pp. 15-45.

SWOV. 2009a. Fact sheet: Fear-based information campaigns. SWOV Institute for Road Safety Research, Leidschendam.

SWOV. 2009b. Fact sheet: Moped and light-moped riders. SWOV Institute for Road Safety Research Leidschendam. 
SWOV. 2009c. Fact sheet: Risk in traffic. SWOV Institute for Road Safety Research, Leidschendam.

SWOV. 2012 Fact sheet: Young drivers and their young passengers. SWOV Institute for Road Safety Research, Leidschendam.

SWOV. 2013. Fact sheet: Cyclists. SWOV Institute for Road Safety Research, Leidschendam.

Tabachnick, B., Fidell, L., 2007. Using multivariate statistics. Harper Collins, New York.

Taubman - Ben-Ari, O., Mikulincer, M., Gillath, O., 2005. From parents to children--similarity in parents and offspring driving styles. Transportation Research Part F: Traffic Psychology and Behaviour 8 (1), 19-29.

Thibodeau, P.H., Boroditsky, L., 2011. Metaphors we think with: The role of metaphor in reasoning. PLOS ONE 6 (2).

Tingvall, C., Haworth, N., 1999. Vision Zero - An ethical approach to safety and mobility. In: 6th ITE International Conference Road Safety \& Traffic Enforcement: Beyond 2000. Monash University Accident Research Centre, Melbourne.

Tolmie, A.K., Thomson, J.A., Foot, H.C., O'Connor, R., Karagiannidou, E., Banks, M., et al., 2009. Influences on pedestrian risk-taking in young adolescents: the conflicting role of parents and peers In: Behavioural Research in Road Safety 2007: Seventeenth Seminar.

Twisk, D., Bos, N., Shope, J.T., Commandeur, J., Kok, G., 2014. Quantifying the influence of safe road systems and legal licensing age on road mortality among young adolescents (accepted for publication). Accident Analysis and Prevention

Twisk, D., Bos, N., Shope, J.T., Kok, G., 2013. Changing mobility patterns and road mortality among pre-license teens in a late licensing country: an epidemiological study. BMC Public Health 13 (333), .

Twisk, D., Kuiken, M.J., 2006. Education. In: Wegman, F.C.M., Aarts, L. (Eds.), Advancing Sustainable Safety. SWOV Institute for Road Safety Research, Leidschendam.

Twisk, D., Reurings, M., 2013. An epidemiological study of the risk of cycling in the dark: The role of visual perception,conspicuity and alcohol use. Accident Analysis \& Prevention 60, 134- 140.

Twisk, D., Stelling, A., 2014. Risicogedrag van jongeren vraagt integrale aanpak [Risk behaviour of youngsters requires an integrated approach]. R-2014-9. SWOV Institute for Road Safety Research, The Hague.

Twisk, D., Vlakveld, W., Commandeur, J., Shope, J.T., Kok, G., 2014a. The relationships among psychological determinants, risk behaviour, and road crashes, and their implications for road safety education programmes (submitted for publication). Journal of Transport Studies, Part F.

Twisk, D., Vlakveld, W., Dijkstra, A., Reurings, M., Wijnen, W., 2013. From bicycle crashes to measures: Brief overview of what we know and do not know (yet). SWOV Institute for Road Safety Research Leidschendam.

Twisk, D., Vlakveld, W., Mesken, J., Shope, J.T., Kok, G., 2013. Inexperience and risky decisions of young adolescents in interactions with lorries, and the effects of competency versus awareness education. Accident Analysis and Prevention 55, 219-225.

Twisk, D.A.M., 1992. Verstandelijke ontwikkeling: Bouwstenen voor educatie en verkeersdeelname [Cognitive development: building blocks for education and traffic participation]. R-92-49. Stichting Wetenschappelijk Onderzoek Verkeersveiligheid SWOV, Leidschendam.

Twisk, D.A.M., 1995. The accident liability of young/novice drivers and the effectiveness of driver licensing systems. D-95-5. SWOV Institute for Road Safety Research, Leidschendam.

Twisk, D.A.M., 1999. Kansrijke maatregelen voor beginnende bestuurders. Eindrapport: uitgangspunten, effectiviteit en uitvoerbaarheid. [Promising counter measures for novice drivers: Final report concerning framework, effectiveness and practical considerations for implementation]. R-98-63 /R-98-63A /R-98-63B. SWOV Stichting Wetenschappelijk Onderzoek Verkeersveiligheid, Leidschendam.

Twisk, D.A.M., 2000. Why did the accident involvement of young (male) drivers drop about 50\%? In: Behavioural research in road safety $X$ : proceedings of the 10th seminar on behavioural research in road safety. Esher, United Kingdom, pp. 109-117.

Twisk, D.A.M., Stacey, C., 2007. Trends in young driver risk and countermeasures in European countries. Journal of Safety Research 38 (2), 245-257. 
Twisk, D.A.M., Vlakveld, W.P., 2010. Recent findings on risky acts in adolescence: implications for understanding European drivers. In: Dorn, L. (Ed.), Driver behaviour and Training Ashgate Aldershot, UK, Vol. 4.

Twisk, D.A.M., Vlakveld, W.P., Commandeur, J.J.F., Shope, J.T., Kok, G., 2014b. Five road safety education programmes for young adolescents: a multi-programme evaluation in field settings. Accident Analysis and Prevention 66, 55-61.

Twisk, J.R., 2013. Applied Longitudinal Data Analysis for Epidemiology: a practical guide (2 ed.). Cambridge University Press.

Van der Houwen, K., Goossen, J., Veling, I., 2003. Reisgedrag kinderen basisschool [Travel behaviour among children commuting to primary schools]. Traffic Test bv, Veenendaal.

Van Vlierden, K., 2006. Verkeersgetuigen: Literatuurstudie over confronterende voorlichting. Steunpunt Verkeersveiligheid Diepenbeek.

Vanlaar, W., Mayhew, D., Marcoux, K., Wets, G., Brijs, T., Shope, J., 2009. An evaluation of graduated driver licensing programs in North America using a meta-analytic approach. Accident Analysis \& Prevention 41 (5), 1104-1111.

Visser, E., Pijl, Y.J., Stolk, R.P., Neeleman, J., Rosmalen, J.G.M., 2007. Accident proneness, does it exist? A review and meta-analysis. Accident Analysis \& Prevention 39 (3), 556-564.

Vlakveld, W., Romoser, M.R.E., Mehranian, H., Diete, F., Pollatsek, A.P., Fisher, D.L., 2011. Does the experience of crashes and near crashes in a simulator-based training program enhance novice driver's visual search for latent hazards? Transportation Research Board (2265), 154-160.

Vlakveld, W.P., 2005. Jonge beginnende automobilisten, hun ongevalsrisico en maatregelen om dit terug te dringen: een literatuurstudie [Young novice drivers, their crash risk, and preventive measures: a review of the literature]. R-2005-3. Stichting Wetenschappelijk Onderzoek Verkeersveiligheid SWOV, Leidschendam.

Vlakveld, W.P., 2011. Hazard anticipation of young novice drivers; Assessing and enhancing the capabilities of young novice drivers to anticipate latent hazards in road and traffic situations. Dissertation Thesis. SWOV-Dissertation series. SWOV Institute for Road Safety Research Leidschendam.

Vriend, I., Van Kampen, B., Schmikli, S., Eckhardt, J., Schoots, W., Den Hertog, P., 2005. Ongevallen en Bewegen in Nederland. Ongevalsletsels en sportblessures in kaart gebracht [Accidents and exercise and sport: mapping the injuries] Consument en Veiligheid, Amsterdam, Netherlands

Wagenaar, W., Reason, J., 1990. Types and tokens in road accident causation. Ergonomics 33 (10-11), 1365-1375.

Wagenaar, W.A., Hudson, P.T.W., Reason, J.T., 1990. Cognitive failures and accidents. Applied Cognitive Psychology 4 (4), 273-294.

Walker, I., 2007. Drivers overtaking bicyclists: Objective data on the effects of riding position, helmet use, vehicle type and apparent gender. Accident Analysis \& Prevention 39 (2), 417-425.

Wallis, C., 2008. What makes teens tick, Time Magazine online.

Waylen, A.E., McKenna, F.P., 2008. Risky attitudes towards road use in pre-drivers. Accident Analysis \& Prevention 40 (3), 905-911.

Webb, T.L., Sheeran, P., 2006. Does changing behavioral intentions engender behavior change? A metaanalysis of the experimental evidence. Psychological Bulletin 132 (2), 249-268.

Wegman, F., Aarts, L., Bax, C., 2008. Advancing Sustainable Safety: National road safety outlook for The Netherlands for 2005-2020. Safety Science 46 (2), 323-343.

Wegman, F., Zhang, F., Dijkstra, A., 2012. How to make more cycling good for road safety? Accident Analysis \& Prevention 44, 19-29.

Wegman, F.C.M., Eksler, V., Hayes, S., Lynam, D., Morsink, P., Oppe, S., 2006. SUNflower+6: a comparative study of the development of road safety in the SUNflower+6 countries. SWOV Institute for Road Safety Research, Leidschendam.

Wegman, F.M., Aarts, L., 2006. Advancing Sustainable Safety: National road safety outlook for 20052020. SWOV Institute for Road Safety Research Leidschendam.

Weijermars, W.A.M., Van Schagen, I.N.L.G., 2009. Tien jaar Duurzaam Veilig, Verkeersveiligheidsbalans 1998-2007 [Ten years Sustainable Safety, 1998-2007]. SWOV Institute for Road Safety Research, Leidschendam, the Netherlands. 
Westenberg, P.M., 2008. De jeugd van tegenwoordig [Contempary youth] De Psycholoog 10 (43), 546552.

White, C., Caird, J., 2009. The blind data: the effects of passenger conversatin and gender on LookedBut-Fail-To-See (LBFTS) errors In: Fifth International Driving Symposium on Human Factors in Driver Assessment, Training and Vehicle Design. Big Sky, Montana.

WHO. 2010. Quantifying the burden of disease from mortality and morbidity http://www.who.int/healthinfo/global burden disease/metrics daly/en/. World Health Organisation (WHO), Geneva.

Wilde, G., 1982. The theory of risk homeostasis: implications for safety and health. Risk Analysis 2 (4), 209-225.

Williams, A.F., 2007. Public information and education in the promotion of highway safety. Transport Reserach Board (TRB) of the National Academy of Sciences, Washington.

Witte, K., Allen, M., 2000. A meta-analysis of fear appeals: Implications for effective public health campaigns. Health Education \& Behaviour 27 (5), 608-632.

Woldringh, C., Katteler, H., 2002. Kennis, houding en gedrag ten aanzien van verkeersveiligheid bij leerlingen in de basisvorming., Nijmegen.

Wurst, T., 2002. "Hardcore" problem groups among adolescents: their magnitude and nature, and the implications for road safety policies. R-2002-25. SWOV Institute for Road Safety Research, Leidschendam.

Yannis, G., Papadimitriou, E., Folla, K., 2014. Effect of GDP changes on road traffic fatalities. Safety Science 63 (March), 42-49. 


\section{Appendix A Questionnaire for age group 12-13}
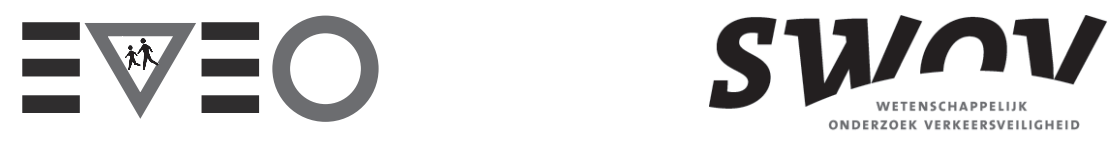

Effecten van VerkeersEducatie Onderzoek

Vragenlijst 'Verkeersmarkt' Groningen

\section{Lees dit eerst}

$\mathrm{We}^{11}$ vragen je deze vragenlijst in te vullen, omdat we willen weten hoe lessen over verkeersveiligheid werken. Het gaat hier niet om een proefwerk of examen. We willen uiteindelijk niet weten hoe goed jij bent, maar hoe goed lessen in verkeersveiligheid zijn. We kunnen daar alleen maar achter komen door te kijken of leerlingen door die lessen anders over verkeersveiligheid gaan denken en zich anders in het verkeer gaan gedragen. Die veranderingen kunnen we 'meten' met behulp van o.a. jouw antwoorden op deze vragenlijst.

Je krijgt deze vragenlijst twee keer voorgelegd. Sommige van jullie zullen tussendoor de 'Verkeersmarkt' bezoeken en anderen niet. Zo kunnen we zien of leerlingen die de lessen krijgen, zich anders gedragen dan leerlingen die geen lessen krijgen.

Bij de vragen over je gedrag en houding gaat het niet om 'goed' of 'fout'. Wel willen we graag dat je eerlijk antwoord geeft. Je hoeft niet bang te zijn dat anderen (b.v. je ouders of de school) te weten zullen komen wat jij geantwoord hebt. Alleen de onderzoekers krijgen dat te weten en die mogen wat jij geantwoord hebt niet aan anderen doorvertellen. Het is soms niet mogelijk om een precies antwoord te geven, wij zijn alleen benieuwd naar je algemene indruk. Denk dus niet te lang na over de vraag.

11 Dit onderzoek wordt uitgevoerd door de Stichting Wetenschappelijk Onderzoek Verkeersveiligheid (SWOV). Al meer dan 40 jaar verricht de SWOV onderzoek om de verkeersveiligheid te verbeteren. Één van de onderzoeken die de SWOV momenteel uitvoert gaat over de effecten van verkeerseducatie. Dit is het EVEO-project. Op www.swov.nl kun je meer lezen over het werk van de SWOV en het EVEO-project. 
Als je tot de ontdekking komt dat je eigenlijk een verkeerd hokje hebt aangekruist, laat dat kruis dan staan en kleur het juiste hokje helemaal in (zie voorbeeld).

Stel je hebt de volgende vraag eerst zo beantwoord:

\section{Heb je een fiets?}

$\begin{array}{ll}\text { Ja } & \square \\ \text { Nee } & \square\end{array}$

Daarna besef je dat je toch geen fiets hebt. Het goede antwoord moet dus zijn 'Nee'. Dit corrigeer je zo:

1. Heb je een fiets?

$\begin{array}{ll}\mathrm{Ja} & \mathbf{X} \\ \mathrm{Nee} & \end{array}$

Veel succes met het invullen. 
Vul dit eerst in

De eerste letter van je voornaam

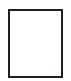

De eerste drie letters van je achternaam

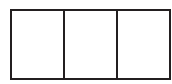

Je geboortedatum (dag-maand-jaar)

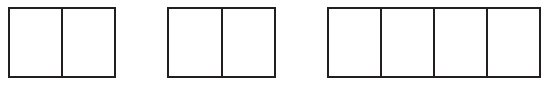

De datum van vandaag (dag-maand-jaar)
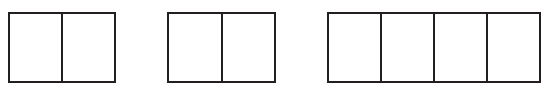

Wat is de naam van je school?

\section{Algemene vragen}

1. Ben je meisje of jongen?

Meisje

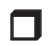

Jongen

\section{$\square$}

2. Hoe oud ben je?

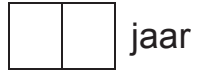

3. Op wat voor school(type) zit je?
a. VBO
b. VMBO Beroepsgericht
$\square$
c. VMBO Theoriegericht
$\square$
d. HAVO
e. Gecombineerd HAVO/VWO
$\square$
f. VWO
$\square$
g. Anders, nl 
4. In welke klas zit je?

klas

5. Heb je een fiets?

$\begin{array}{lll}\text { Ja } & \square \\ \text { Nee } & \square & \begin{array}{l}\text { Ga naar vraag 1 op } \\ \text { pagina 4 }\end{array}\end{array}$

6. Hoeveel keer per week gebruik je de fiets?

Gemiddeld $\quad$ Keer

7. Hoelang zit je meestal per keer op je fiets?

Gemiddeld $\square$ Minuten

8. Doet het voor- en achterlicht van je fiets het?

Ja, allebei

Nee, alleen het voorlicht

Nee, alleen het achterlicht

Nee, geen van beide

9. Ben je de afgelopen maand wel eens op je fiets gestapt terwijl je daarvoor iets met alcohol erin (mixdrank, bier, breezer) gedronken had?

Nee, nooit

Ja, één keer

Ja, enkele keren

10. Heb je het afgelopen jaar één of meer ongeval(len) gehad toen op je fiets zat? Een ongeval is als je botst met iemand. Het kan zijn dat hierbij iets kapot gaat of dat iemand zich pijn doet. Jouw fiets kan kapot zijn gegaan of jij kan jezelf pijn hebben gedaan. Maar het kan ook zijn dat bij degene waar je tegenaan bent gereden iets kapot is gegaan of dat diegene zich pijn heeft gedaan. Ook als er geen anderen waren (je bent b.v. in een sloot gereden) dan noem je dat een ongeval.

Ja, $\square \square$ Ongeval(len)

Nee 


\section{Vragen over dingen die je in het verkeer doet of die je in het verkeer overkomen}

Hieronder staat een lijst met dingen die jongeren in het verkeer doen of die kunnen gebeuren. Bij elke situatie wordt gevraagd hoe vaak jij dit de afgelopen maand hebt gedaan of dat het jou is overkomen. Je kunt je antwoord geven door in één van de hokjes een kruisje te zetten.

1. Naar beide kanten kijken voordat je oversteekt

2. Met losse handen fietsen

3. Als het donker is alleen op plaatsen oversteken die goed verlicht zijn

4. Je laten voorttrekken door een brommer als je op de fiets zit

5. Met iemand achterop fietsen

6. Speciale kleren aantrekken (b.v. reflecterende kleren) waardoor autobestuurders je beter kunnen zien als je oversteekt

7. Op je fiets door een rood stoplicht rijden

8. Met je fiets voor een auto uit over de straat slingeren om je vrienden te laten zien dat jij dat durft

9. Een klein gaatje in de stroom van voorbij rijdende auto's zien en dan snel oversteken

10. Op de weg skaten of skeeleren (in plaats van op de stoep of het fietspad)

11. Vergeten om goed op het verkeer te letten, omdat je met vrienden aan het praten bent

12. Op je fiets zonder om te kijken linksaf slaan, omdat je veel haast hebt

13. Op je fiets plotseling moeten remmen voor een auto die sneller op je af kwam dan je eerst dacht

14. Over hekken klimmen tussen de stoep en de weg, zodat je op de weg komt

15. In een bocht de weg oversteken

16. Vergeten goed op het verkeer te letten als je mobiel aan het bellen bent

Nooit Een Regel- Vaak Heel Altijd
paar matig
keer
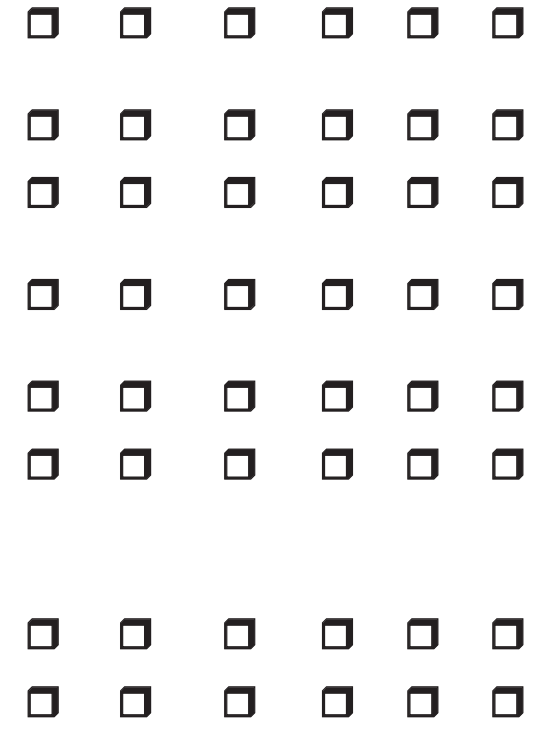

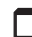

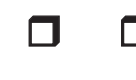

$\square \square$

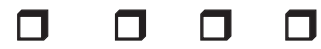

$\square$
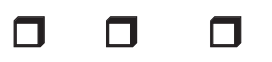

$\square$
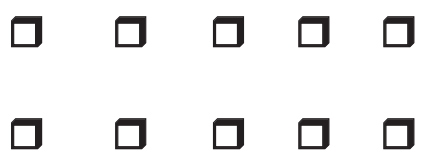
17. Tijdens het oversteken terug naar de stoep moeten gaan om niet aangereden te worden

18. Als je in het donker fietst, bemerken dat je vergeten bent om je licht aan te doen

19. Al pratend met een groepje vrienden of vriendinnen over de weg slenteren

20. Met een MP3-speler op over straat lopen

21. Plotseling zonder uit te kijken de weg op rennen wanneer je aan het voetballen of spelen bent

22. Op de weg lopen in plaats van op de stoep

23. Een auto die uit een uitrit of een klein zijstraatje komt pas heel laat zien als je voorbij loopt

24. Op de fiets een langere weg nemen om niet een gevaarlijk kruispunt over hoeven te steken of op een weg zonder fietspad te moeten rijden

25. Je hand uitsteken als je met je fiets van richting verandert

26. Als je fietst niet op het verkeer te letten, omdat je aan andere dingen denkt

27. Zomaar de straat oversteken, of er nu verkeer aankomt of niet. Ze zullen toch wel voor je stoppen

28. Bemerken dat je een straat bent ingereden waar in jouw rijrichting niet gefietst mag worden, omdat je het bord met eenrichtingsverkeer niet had gezien

29. Met een groepje achter elkaar gaan lopen wanneer je op de weg loopt, omdat er geen stoep is

30. De weg oversteken terwijl er even verderop een zebrapad is

31. In een winkelstraat waar niet gefietst mag worden, toch fietsen

32. Met z'n drieën naast elkaar fietsen

Nooit Een Regel- Vaak Heel Altijd
paar matig
vaak

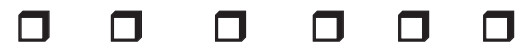

$\begin{array}{llllll}\square & \square & \square & \square & \square & \square\end{array}$

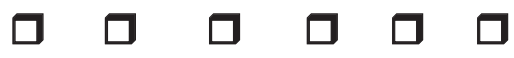

$\square \square \square \square \square$
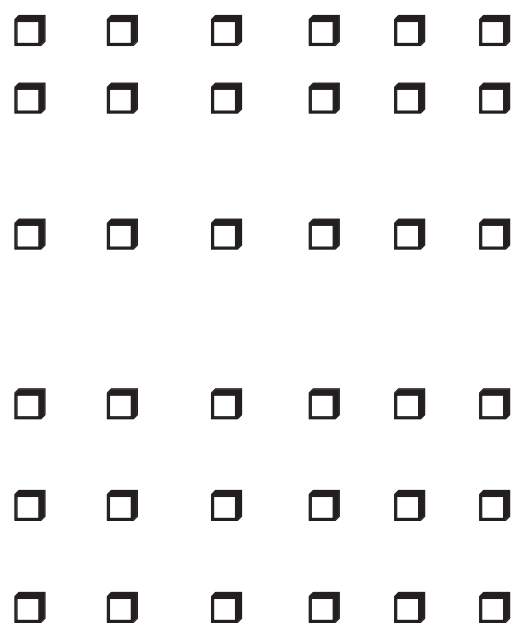

$\begin{array}{llllll}\square & \square & \square & \square & \square & \square\end{array}$
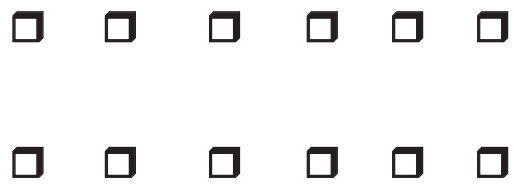

$\begin{array}{llllll}\square & \square & \square & \square & \square & \square\end{array}$

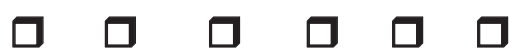


Nooit $\begin{gathered}\text { Een Regel- Vaak Heel Altijd } \\ \text { paar matig } \\ \text { keer }\end{gathered}$
vaak

33. Als je met vrienden bent, expres vlak voor naderend verkeer oversteken om te laten

$\square \quad \square \quad \square \quad \square \quad \square \quad \square$ zien dat jij zoiets durft

34. Pas oversteken bij een zebra nadat je zeker weet dat de aankomende auto's echt gestopt zijn

35. Zo dicht naast elkaar fietsen dat de sturen elkaar raken en je bijna valt

36. Op een bromfiets rijden terwijl je nog geen 16 bent

37. Op je fiets snel moeten uitwijken om niet onder een bus of vrachtwagen te komen die rechtsaf aan het slaan is

38. Zondergoed te kijken de straat over rennen om nog net een bus of tram te kunnen halen

39. Als je op de weg fiets bemerken dat er een fietspad is waarop je had moeten rijden

40. Zonder helm op achter op een bromfiets zitten

41. Met alcohol op fietsen
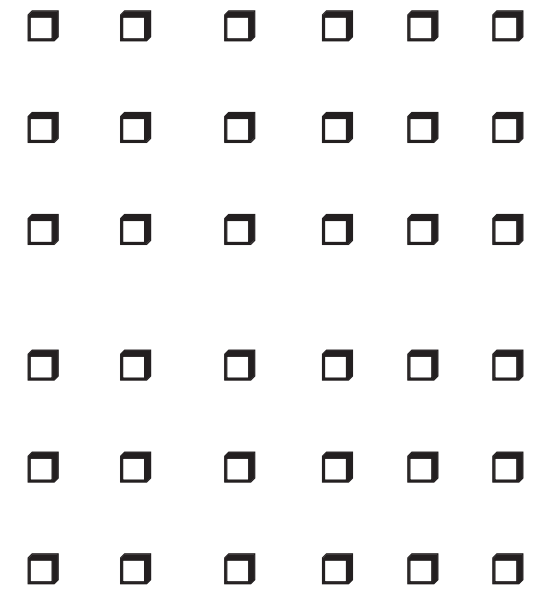


\section{Vragen over je kennis van verkeersregels}

Je ziet een aantal plaatjes met steeds twee of meer verkeersdeelnemers die gelijk op een kruispunt aankomen. Wie gaat er voor?

1. Karin (B) wil rechtdoor, de bestelauto (A) gaat ook rechtdoor. Moet Karin de bestelauto voor laten gaan?

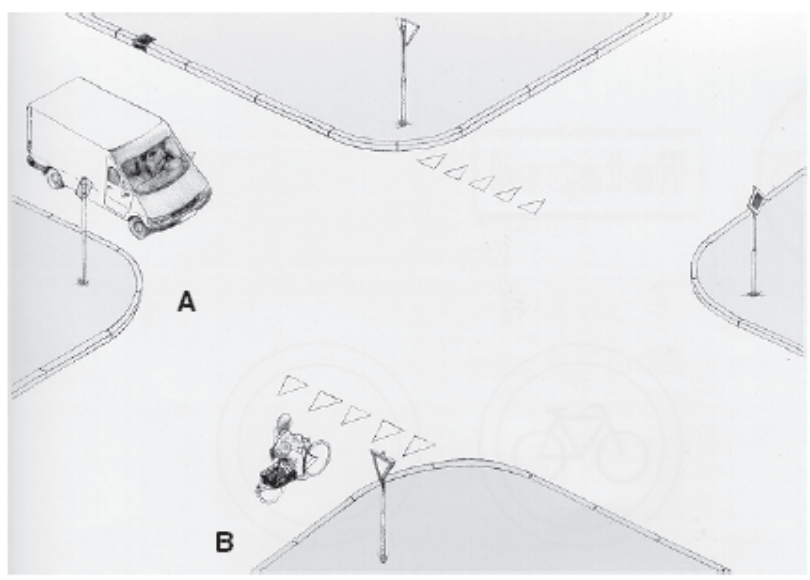

Ja, de bestelauto gaat voor

Nee, Karin gaat voo

Weet niet

2. Leila (B) wil linksaf, de bromfietser (A) gaat rechtdoor. Moet Leila de bromfietser voor laten gaan?

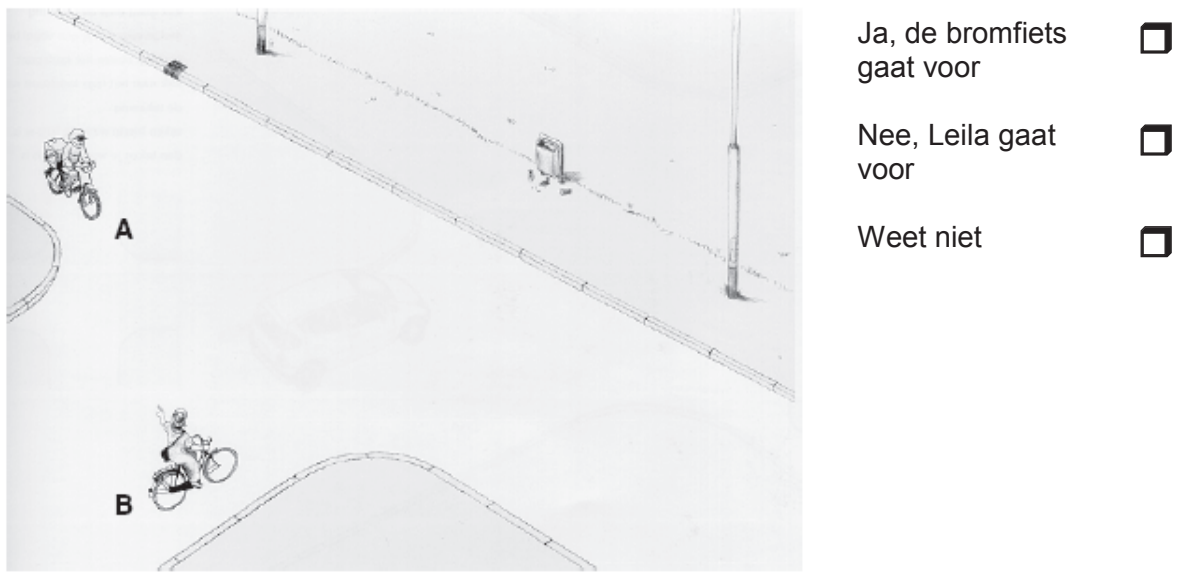


3. Karin (B) wil rechtdoor, de auto (A) gaat ook rechtdoor. Moet Karin de auto voor laten gaan?

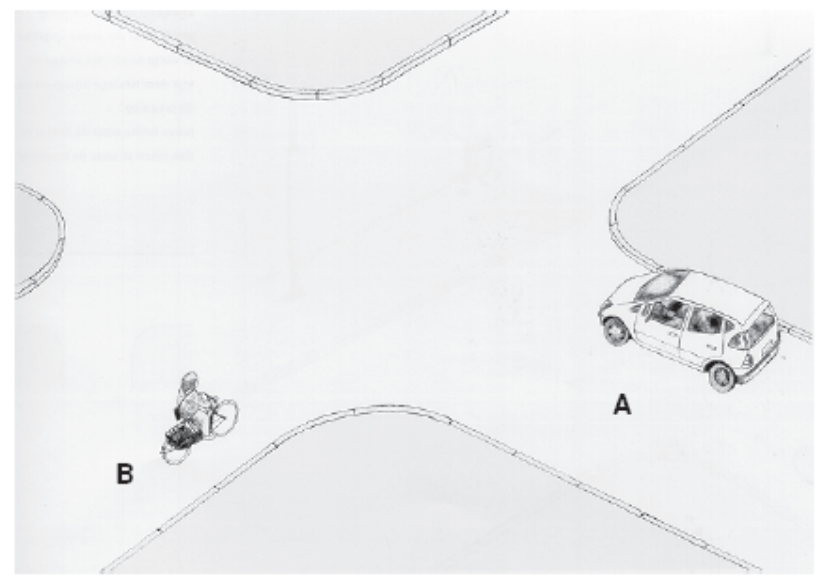

Ja, de auto gaat voor

Nee, Karin gaat voor

Weet niet

4. Leila (B) wil rechtdoor, de auto (A) slaat linksaf. Moet Leila de auto voor laten gaan?

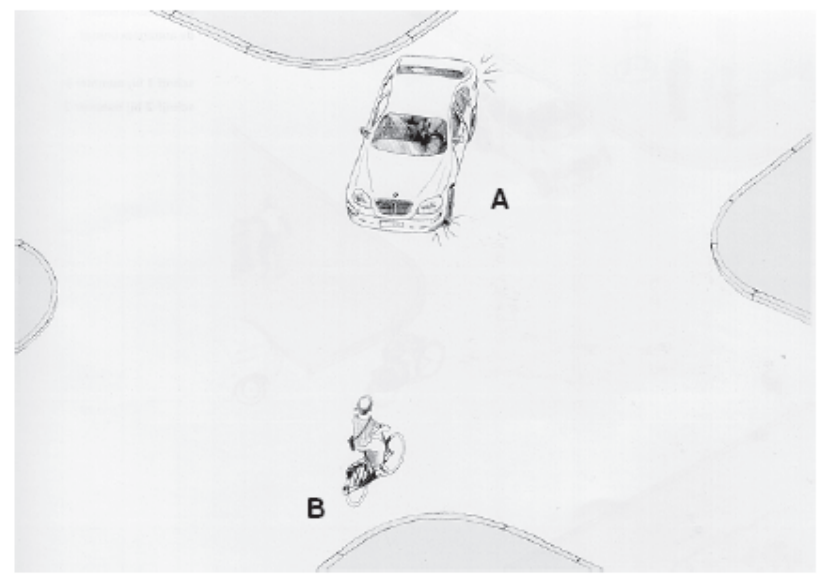

Ja, de auto gaat voor

Nee, Leila gaat

voor

Weet niet 
5. Leila (C) wil rechtdoor. De auto van rechts (A) gaat ook rechtdoor. De auto van links (B) gaat linksaf. Moet Leila de auto's voor laten gaan?

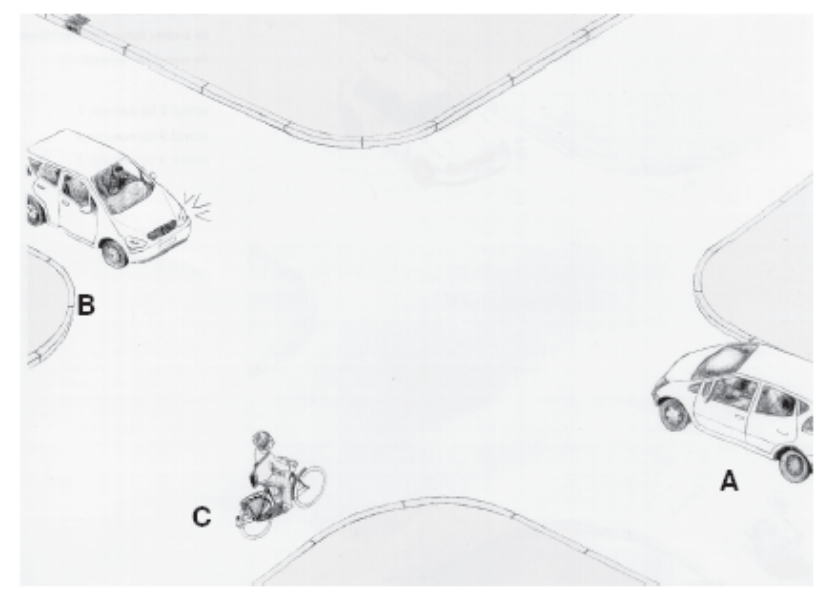

Ja, Leila moet beide auto's voor laten gaan

Leila moet alleen auto $\mathrm{A}$ voor laten gaan

Leila moet alleen auto $B$ voor laten gaan

6. Karin (C) gaat rechtdoor. De andere fietser (A) gaat ook rechtdoor. De auto (B) slaat linksaf. Moet Karin beide voor laten gaan?

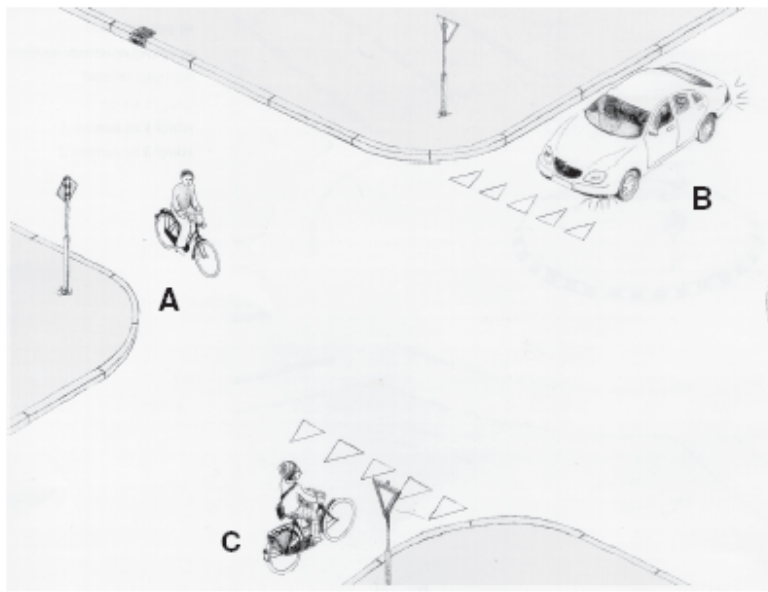

Ja, Karin moet de andere fietser én de auto voor laten gaan

Karin moet alleen de andere fietser voor laten gaan

Karin moet alleen de auto voor laten gaan

Nee, Karin gaat voor de andere fietser

Weet niet 
7. Een jongen op de fiets (1) ziet een auto van links komen. Moet de jongen de auto voor laten gaan?

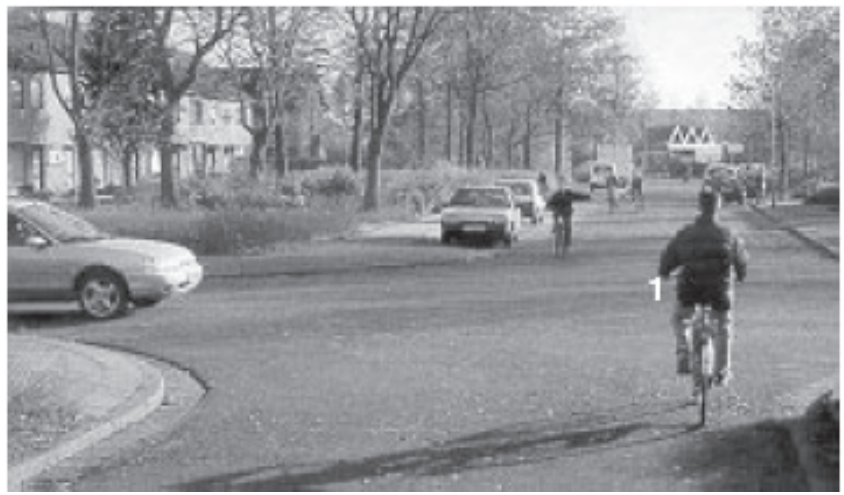

$\mathrm{Ja}$,

Nee

Weet niet

8. De auto wil naar rechts. De fietser wil doorgaan op de rotonde. Moet de fietser de auto voorrang geven?

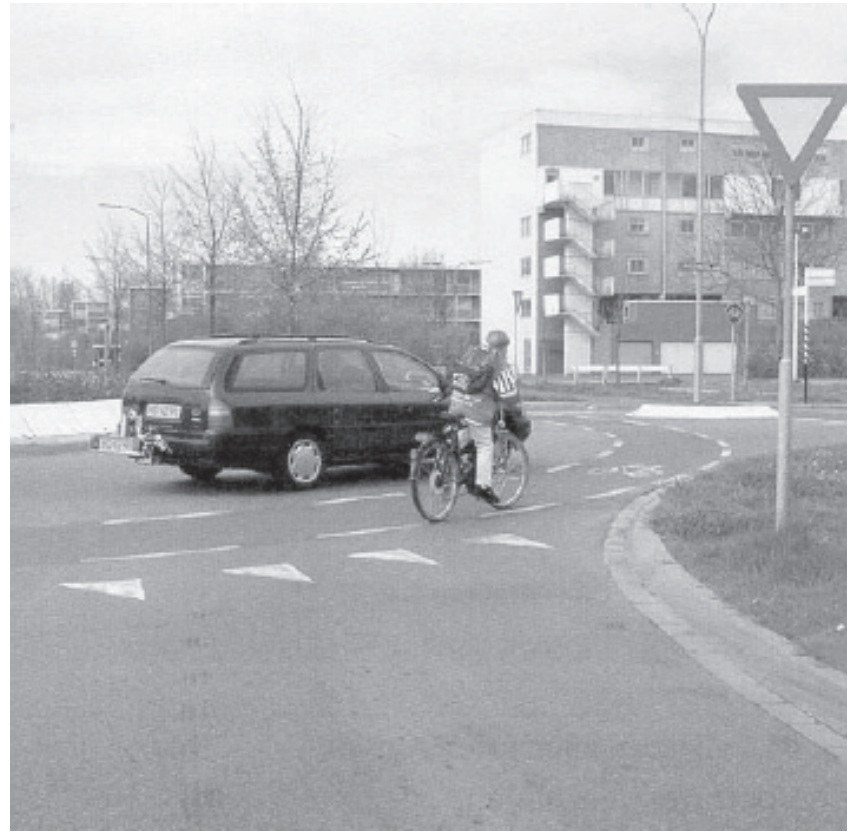

$\mathrm{Ja}$,

Nee

Weet niet 
9. Twee jongens op de fiets komen bij een smal gedeelte in de weg: een wegversmalling. Moeten zij de auto voor laten gaan?

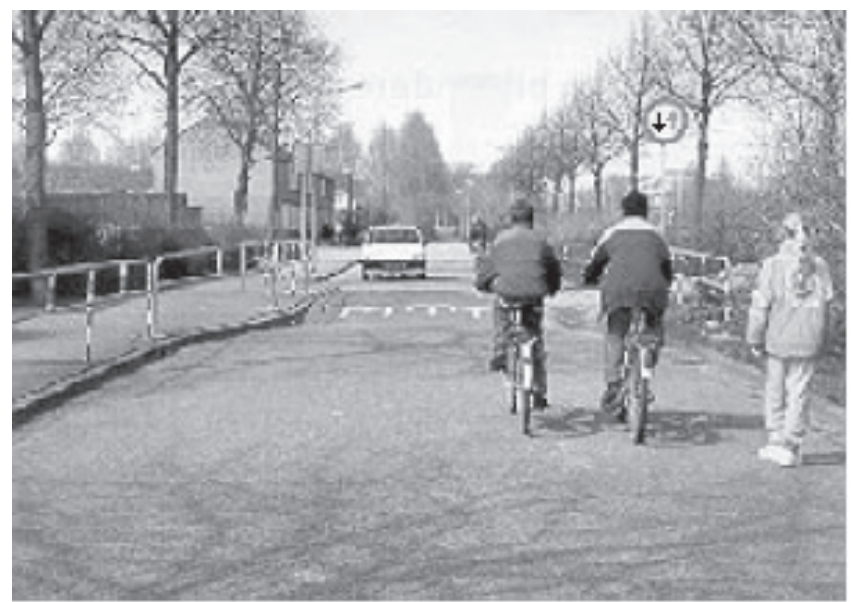

Ja,

Nee

Weet niet

10. Het meisje op de fiets wil rechtdoor fietsen. Moet ze de auto voor laten gaan?

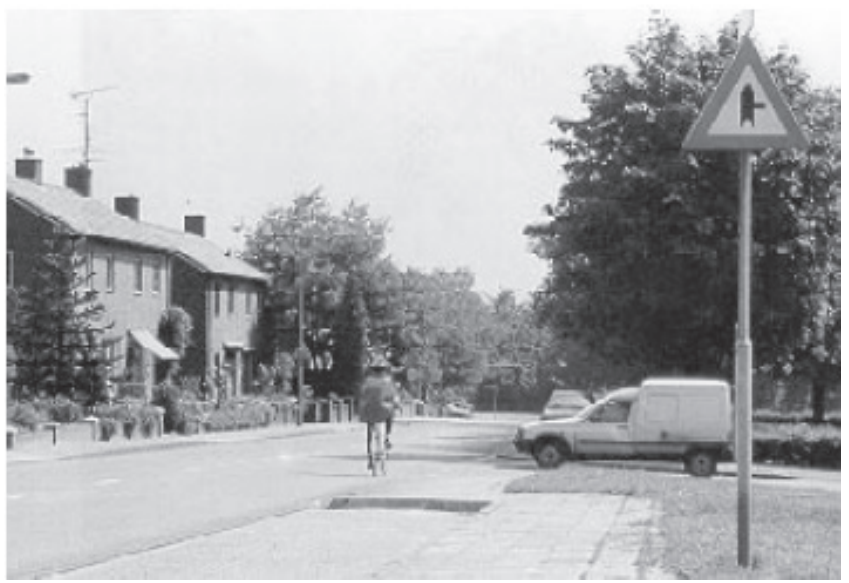

$\mathrm{Ja}$

Nee

Weet niet 


\section{Houding in het verkeer}

Hieronder volgen enkele uitspraken over het belang en het nut die verkeersregels voor jou hebben. Geef aan hoe eens of oneens je het ermee bent

1. Ik moet zelf kunnen uitmaken of ik me aan de verkeersregels houd of niet

$\begin{array}{ccccc}\begin{array}{c}\text { Helemaal } \\ \text { niet mee }\end{array} & \text { Niet } & \text { Neutraal } & \text { Mee } & \text { Helemaal } \\ \text { eens } & \text { mee } \\ \text { eens } & \text { eens } & & & \text { eens } \\ \square & \square & \square & \square & \square\end{array}$

2. Ik vind het goed dat er verkeersregels zijn

3. Verkeersregels zijn soms zo onhandig dat ik ze wel moet overtreden

4. Als niemand er last van heeft, mag ik best de verkeersregels overtreden

5. Ik vind het prettig dat ik weet waar ik me aan te houden heb in het verkeer

6. Ik vind de meeste verkeersregels niet echt nodig

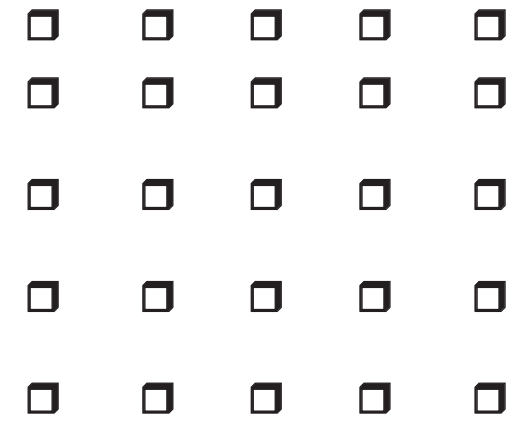

Welke omschrijving past het beste bij jou? (maar één vakje aankruisen)

Ik ben iemand die zich weinig aantrekt van verkeersregels

Ik ben iemand die zich soms aan de verkeersregels houdt, maar meestal niet

Ik ben iemand die zich meestal wel aan de verkeersregels houdt

Ik ben iemand die zich altijd aan de verkeersregels houdt

Bij welke van de hier beschreven types pas jij het beste? (maar één vakje aankruisen)

Ik ga mijn eigen gang en trek me nergens iets van aan

Alleen als het echt gevaarlijk is, let ik op het verkeer

Ik gedraag me meestal volgend de regels, maar dat lukt niet altijd

Ik probeer me altijd volgens de regels te gedragen in het verkeer 
Hoe eens of oneens ben je het met de volgende uitspraken

1. Als klasgenoten klieren op het fietspad, Helemaal Niet Neutraal Mee Helemaal niet mee mee eens mee vind ik dat ik daar iets van moet zeggen

2. Als anderen met $z$ 'n drieën naast elkaar willen fietsen, doe ik altijd mee

3. Als anderen in een groep oversteken, kijk ik toch altijd of dat wel veilig is

4. Als ik alleen fiets dan houd ik me vaker aan de regels dan wanneer ik met anderen fiets

5. Als anderen door rood fietsen, fiets ik meestal mee door rood

6. Als ik iets gevaarlijks doe in het verkeer, schaam ik mij daar achteraf niet voor

7. Als ik dingen doe op de fiets die alleen gevaarlijk zijn voor mijzelf, moet ik dat helemaal zelf weten

8. Ik vind het belangrijk geen dingen te doen waardoor anderen een ongeval kunnen krijgen

9. Ik zou het erg vinden wanneer iemand anders door mijn schuld valt

10. Ik voel me rot wanneer een ander in het verkeer door mijn schuld bijna door een auto wordt aangereden

11. Ook al gaat een voetganger op een zebrapad vóór, ik fiets door als hij aarzelt en niet direct oversteekt

12. Als een ander voorrang heeft en die voorrang niet meteen neemt, vind ik het normaal om zelf voorrang te nemen 


\section{Omgaan met gevaar in het verkeer}

Wil je bij de volgende uitspraken aangeven of je dat nooit, soms vaak of altijd doet?

Nooit Soms Vaak Altijd

1. Ook al heb ik voorrang op een auto, dan kijk ik toch of de chauffeur me gezien heeft

2. Als ik kinderen zie spelen, let ik goed op

3. Ik laat op de weg anderen goed merken waar ik heen wil

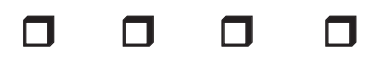

4. Als we met $z$ 'n drieën fietsen, letten we goed op of dat lastig is voor anderen

5. Ik laat een fietser of voetganger die oud of gehandicapt is voorgaan, ook als het niet moet
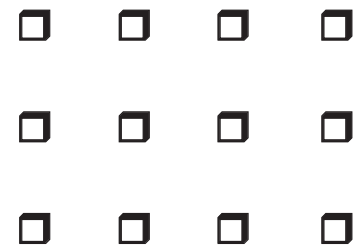

Alcohol in het verkeer

In hoeverre ben jij het eens met de volgende uitspraken over alcohol en drugs in het verkeer

1. Als iemand half dronken is, mag hij

Helemaal Eens Niet eens/ Oneens Helemaal eens Niet oneens van mij nog best fietsen.

2. lemand mag van mij na een feestje best met een paar glazen teveel op naar huis fietsen.

3. Als iemand na een feestje op de fiets naar huis wil, moet die daar bij het drinken rekening mee houden.

4. ledereen die aan het verkeer deelneemt (dus ook bromfietsers en fietsers) moet alcoholvrij zijn.

5. Als je geblowd hebt kun je best nog veilig fietsen. 
Wat doe je bij de volgende omstandigheden?

Je rijdt op je fiets en nadert een stoplicht dat net op groen is gesprongen. Je wilt rechtdoor. Voor je staat bij het stoplicht een vrachtwagen nog stil die aangeeft rechtsaf te willen. Stel dat niet dit kind op de foto, maar jij daar op je fiets zat, wat zou je doen?

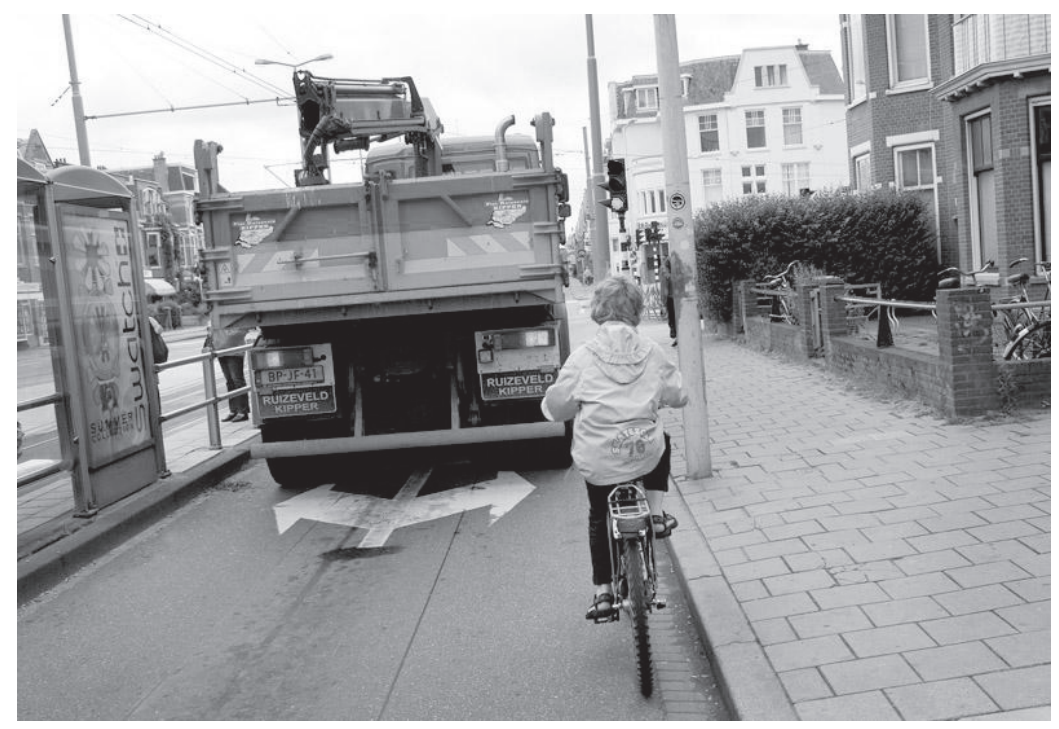

Je stopt achter de vrachtwagen, omdat de vrachtwagen voorrang heeft op fietsers

Je rijdt door langs de vrachtwagen, omdat je voorrang hebt: want rechtdoorgaand verkeer heeft voorrang op afslaand verkeer

Je stopt achter de vrachtwagen en wacht tot de vrachtwagen rechtsaf geslagen is: want ondanks dat je voorrang hebt kun je maar beter wachten, omdat de chauffeur jou niet goed kan zien

Je rijdt rechts langs de vrachtwagen 
Op een kruispunt sta met je fiets aan de rechterkant van de weg (er is geen fietspad) vlak achter de stopstreep te wachten voor een stoplicht dat op rood staat. Je wilt rechtdoor. Links naast je komt een vrachtwagen te staan waarvan de rechter richtingaanwijzer knippert. Stel dat niet dit kind op de foto, maar jij daar op je fiets zat, wat zou je doen?

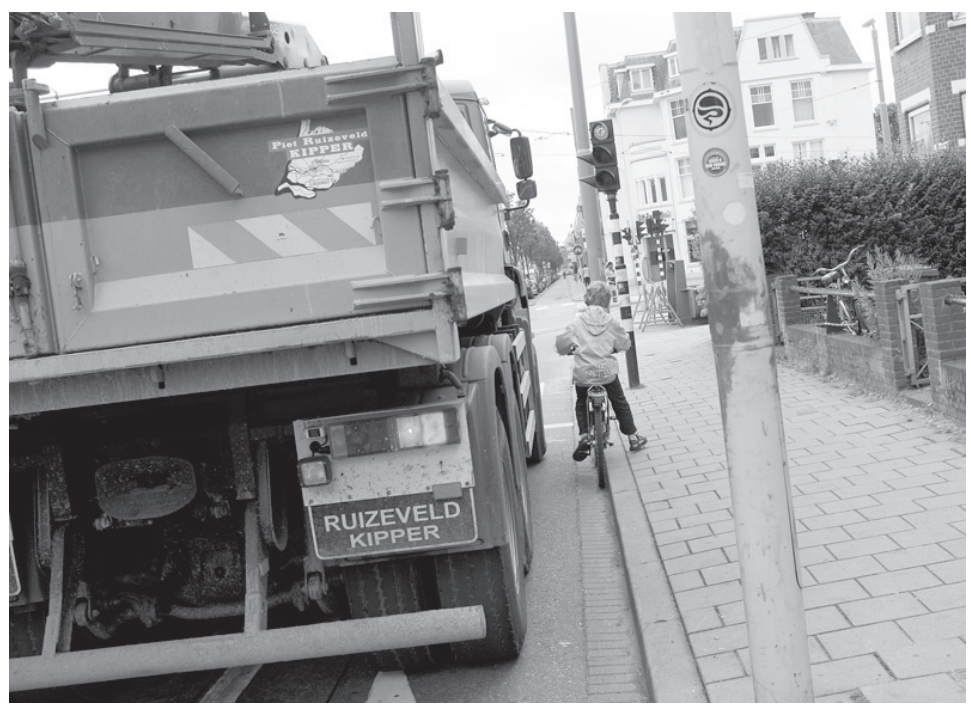

Snel wegfietsen zodra het stoplicht op groen springt, omdat de vrachtwagen rechtsaf zal slaan

Afstappen en met de fiets aan de hand op de stoep gaan staan. Nadat het stoplicht op groen is gesprongen wacht je totdat de vrachtwagen rechtsaf is geslagen. De chauffeur kan jou niet goed zien en omdat je zo ver mogelijk naar rechts bent gaan staan kan j niet onder de vrachtwagen komen

Rustig gaan fietsen zodra het stoplicht op groen is gesprongen. Rechtdoorgaand verkeer gaat immers voor afslaand verkeer

Je blijft wachten op dezelfde plek nadat het stoplicht op groen is gesprongen, omdat vrachtwagens voorrang hebben op fietsers 
ledereen maakt in het verkeer wel eens iets mee wat gevaarlijk is. Of doet iets stoms. Kun je aangeven hoe gevaarlijk jij de volgende situaties vindt?

1. Je slaat op een drukke weg linksaf, zonder goed Nauwelijks Beetje Erg gevaarlijk gevaarlijk gevaarlijk achterom te kijken

2. Je fietst met $z$ 'n drieën naast elkaar op een fietspad met tegenliggers

3. Je rijdt in het donker zonder achterlicht

4. Je slaat op een rustige weg linksaf, zonder goed achterom te kijken

5. Je fietst buiten de stad met z'n drieën naast elkaar op een weg waar ook auto's mogen rijden

6. Wachtend voor een rood stoplicht houd je je vast aan een vrachtauto

7. Je steekt niet je hand uit als je op een drukke weg linksaf slaat

8. Je loopt een spoorlijn over als de spoorbomen al aan het zaken zijn, omdat je de trein nog wilt halen

9. Je schoolboeken in een rugzak scheef op je rug hebben als je fietst

10. Met een MP3 speler op fietsen die hard aanstaat

\section{Hartelijk bedankt voor je medewerking!}




\section{Appendix B Questionnaire for age group 14-17}

This appendix presents the translation in English of the Dutch questionnaire for the 14 to 17 year olds. The data from this questionnaire were used in the Chapters 4 and 7.

\section{Read this first}

With this questionnaire, we try to learn more about the behaviour of youngsters in traffic. There are not 'right' or 'wrong' answers. It is important though to answer 'truthfully'. Your answers will not be passed on to other persons (e.g., school or police). Only researchers will read your answers, but they are also not allowed to pass information on to other persons. One part of the questionnaire is for moped riders; the other part is for cyclists only. Those questions that you can skip are clearly marked. Don't think too long about an answer. Just select the response that 'feels like you'. Only tick one answer. On some questions, you may provide more than one answer. Those questions are clearly marked.

Good luck with completing this questionnaire.

1. The first letter of your Christian Name

2. The first three letters of you family name

3. Your date of birth (day-month-year)

4. What is the name of your school?

5. Are you a boy or a girl? Girl=1/Boy=2

6. How old are you?

7. What kind of school are you attending?

$\mathrm{VBO}$

VMBO Beroepsgericht

VMBO Theoriegericht
1 HAVO 4

2 Gecombineerd HAVO/VWO 5

3 VWO 6

Other 7

8. Which class/year?

9. Are you riding a moped? (yes/no)

10. Opinions about traffic rules ( $1=$ totally agree, $2=$ agree, $3=$ not agree nor disagree, 4 = disagree, 5 = totally disagree) 
Some people adhere to traffic rules better than others do. Do you agree or disagree with the following statements.

- I have the freedom to decide for myself to adhere to traffic rules or not.

- Without question, everyone should adhere to traffic rules,

- Traffic rules are sometimes so unpractical, that I am not able to observe them.

- If no other traffic is approaching, I find it nonsense to wait at a red light.

- Violating a red light is $\mathrm{OK}$, if it does not cause any trouble for other road users.

11. Risk-acceptance $(1=$ not any risk, $2=$ A little bit of risk, $3=$ Some risk, 4 $=$ Considerable risk, $5=\mathrm{A}$ lot of risk)

Do you take risks in traffic?

- As a moped rider/cyclist, when you are alone

- As a moped rider/cyclist, when you are with friends

- As a pedestrian.

12. Do you agree or disagree with the following statements? ( $1=$ Totally agree, $2=$ agree, $3=$ Nor agree or disagree, $4=$ disagree, $5=$ Totally disagree)

- If a person is tipsy, I do not find it a problem that he is cycling.

- If a person is tipsy, I do not find it a problem that he is riding his moped.

- $\quad$ Out on the road, no one should use alcohol.

- While partying one should be aware of how to get home safely

13. Do you agree or disagree with the following statements? $(1=$ Totally agree, $2=$ agree, $3=$ Nor agree or disagree, $4=$ disagree, $5=$ Totally disagree)

- If my actions only endanger myself and no other road users, that is my own freedom of choice.

- I find it important, to behave always correct in traffic; not only when the police is in the area.

- I find it important not to endanger my safety by my own doing.

14. Feelings $(1=$ Totally agree, $2=$ agree, $3=$ Nor agree or disagree, $4=$ disagree, $5=$ Totally disagree)

- $\quad$ Everyone knows that traffic might be dangerous. So if a person might 
get hurt because of an error on my part that is just bad luck.

- I find it important not to endanger the safety of others by my actions.

- I hate the idea that because of my doing another person might have got hurt.

- If I behave dangerously, in hind side I do not feel ashamed.

- To cause an accident is one of the worst things that might happen to me.

- I find traffic rather scary

15. How often do you ride a bicycle?

- Never or almost never

- Only a few times a month

- $\quad$ Once or twice a week

- Two to three times a week

- Almost everyday

16. Are both lights of your bicycle in working order?

- Yes, both

- No, only rear light

- No, only head light

- No head light or rear light

17. Have you been cycling after drinking alcohol in the last month?

- No, never

- Yes, only once

- Yes, several times

18. Questions about events that in traffic happen to you, and about your own actions ( $1=$ never, $2=$ a few times, $3=$ regularly, $4=$ often, $5=$ regularly, $6=$ =always)

This list contains descriptions about events and actions. About every event, you are asked how often this has happened to you in the last month. Please tick the appropriate box.

- $\quad$ Almost colliding with a pedestrian just after you made a right hand turn.

- $\quad$ Swerving around pedestrians who use a pedestrian crossing

- As a cyclist being pulled, or pushed by a moped rider

- $\quad$ Forgetting to look behind you when making a left hand turn.

- Cycling in the dark without a working rear or head light.

- $\quad$ Forgetting to indicate when changing directions 
- To use a mobile phone while cycling

- Noticing too late that you use the main road, while there is also a cycle path

- To wait behind a left turning truck, while there is sufficient space to wait at the right hand side of that truck.

- When you use a bicycle you are not familiar with, and noticing a little bit late that the brakes are working differently from your own bicycle.

- As bicyclist violating a red light

- To overlook a car that is exiting an alley.

- Cycling after you have been using illegal drugs.

- Cycling with three persons side by side

- Cycling after drinking alcohol

- Noticing too late that you enter a one way street from the wrong direction

- Needing to brake strongly because of a oncoming car with a higher speed than you expected

- $\quad$ To cycle on the side walk

- Cycling on a roundabout and not having a clear understanding of who should go first.

- Almost falling because you cycled too closely together, with the result that the handlebars touched

- Cycling on a slippery road and you could easily fall.

- On a bicycle, needing to perform an emergency manoeuvre to avoid being overrun by a right turning truck.

19. Sometimes it happens that you as a cyclist make an error that results into a dangerous traffic situation $(1=$ never, $2=$ a few times, $3=$ regularly, $4=$ often, $5=$ regularly, $6=$ always)

For instances because you do not know which traffic rules should be followed in that situation, or you are occupied with other things and not watching other traffic.

- In the past month, how often have you made such an error that resulted in a potentially dangerous situation?

- In the coming month, how often do you expect to make such a dangerous errror that may result in a potentially dangerous traffic situation?

20. Once in a while, everyone commits a traffic violation. ( $1=$ never, $2=a$ few times, $3=$ regularly, $4=$ often, $5=$ regularly, $6=$ always) 
Sometimes this is a deliberate choice, such as violating a red light when there is no other traffic. Sometimes this is not on purpose, for instance your rear light is not working but you have not noticed it.

- In the past month, how often have you deliberately violated a traffic rule?

- In the next month how often do you intent to deliberately violate the traffic rules?

- In the past month how often have probably unintentionally violated a traffic rule?

- In the next month, how often do you expect you might unintentionally violate a traffic rule?

21. How large do you think is the chance that you as a cyclist might get involved into a traffic accident (only one answer possible: $1=$ much larger, 2 = larger, $3=$ equal, $4=$ smaller, $5=$ much smaller)

In comparison to cyclists of the same age and gender I belief my chance of getting an accident is ...

22. How good are you in in comparison to other cyclists of the same gender and age as you are, at ..... (only one answer possible: $1=$ much better, $2=$ better, $3=$ equal, $4=$ worse, $5=$ a lot worse)

- Cycling ( controlling and handling your bicycle)

- Knowing how to correctly apply the traffic rules

- Understanding traffic ( to foresee a dangerous situation, to be able to predict correctly what other road users might do)

- To withstand peer pressure ( e.g., withstand the challenge to behave dangerously)

23. Answer these questions from the perspective of you as a pedestrian. How often do the following situations happen to you. ( $1=$ never, $2=\mathrm{a}$ few times, $3=$ regularly, $4=$ often, $5=$ regularly, $6=$ always)

- During darkness, intentionally crossing the street near a road light, so other traffic can see you better

- Crossing while the pedestrian light is still red.

- In heavy traffic, running across the street while the gap between the cars is just large enough

- As a pedestrian to cross the road in a bend

- Needing to return to the kerb, because of the gap being too small

- Walking in the road, talking with friends without paying attention to other traffic.

- Walking in the road instead of the side walk 
- $\quad$ Because of being in a hurry, running accross the street without watching other traffic. (for instance to catch a bus)

- Crossing the street without watching other traffic in the expectation that other traffic will stop and give way.

- Not bother walking to a nearby pedestrian to cross the street

- Walk in single file on roads without pavements

- Only crossing a pedestrian crossing, when cars have definitely stopped.

24. Sometimes it happens that you as a pedestrian makes an error that results into a dangerous traffic situation $(1=$ never, $2=a$ few times, $3=$ regularly, $4=$ often, $5=$ regularly, $6=$ always)

For instance because you do not know which traffic rules should be followed in that situation, or you are occupied with other things and not watching other traffic.

- In the past month, how often have you made such an error that resulted in a potentially dangerous situation?

- In the coming month, how often do you expect to make such an error that may result in a potentially dangerous traffic situation?

25. As a pedestrian everybody commits a traffic violation once in a while ( $1=$ never, $2=$ a few times, $3=$ regularly, $4=$ often, $5=$ regularly, $6=$ always $)$

Sometimes this is a deliberate choice, such as violating a red light when there is no other traffic. Sometimes this is not on purpose, for instance because of absent-mindedness.

- In the past month, how often have you deliberately violated a traffic rule?

- In the next month how often do you intent to deliberately violate the traffic rules

- In the past month how often have probably unintentionally violated a traffic rule

- In the next month, how often do you expect you might unintentionally violate a traffic rule

26. How do you generally behave in traffic? $(1=$ never, $2=$ a few times, $3=$ regularly, $4=$ often, $5=$ regularly, $6=$ always)

- $\quad$ Forgetting to watch other traffic, because of talking with your friends.

- As a moped passenger not wearing a helmet

- Participating in traffic while using an MP3-player or walkman

- As a car passenger not wearing a seat belt

- When playing sports on the road (e.g., badminton or playing soccer) noticing an oncoming car too late 
- $\quad$ Forgetting to watch other traffic, because of talking with your friends.

- $\quad$ Riding a moped while you are under aged or not in the possession of a moped license.

27. In the last two years, have you been in an accident that was so serious that you needed to see a doctor, or to go to a hospital?

- No

- Did have an accident, but no injuries

- $\quad$ yes, needed to see a doctor

- $\quad y e s$, was admitted to a hospital

28. Have you been in an accident in the last two years that only resulted in damage to your moped or bicycle

- No

- Yes, once

- Yes, 2 times

- Yes, more often

29. Did you have that accident as a :

- Cyclist

- $\quad$ Light moped rider

- Moped rider

- Pedestrian

30. How often did it happen that you almost had an accident, but it did not come to the worse?

- $\quad$ Very seldom

- A few times a year

- (almost) every month

- $\quad$ (almost) every week

31. Was it your fault?

- Yes, most of the cases

- Sometimes it is, sometimes it is not

- No

- I do not know

32. Opinions about behaviour in traffic ( $1=$ Totally agree, $2=$ Agree, $3=$ Neutral, $4=$ Disagree, $5=$ Totally disagree) 
These are statements about attitudes and behaviour in traffic. Here are some statements about opinions and behaviours in traffic. Indicate to what extent you agree with these.

- Youngsters underestimate the dangers in traffic

- Traffic accidents that almost kill you have serious negative consequences for the rest of your life

- One should decide for oneself whether to use a seat belt or helmet or not.

- I feel rather awkward, when a traffic lights switches to red and I wait while others still cross.

- If I see a friend acting dangerously in traffic, I speak up.

- If in doubt about the intentions of other road users, it is better to give way, even if the other is not entitled to it. Taking priority may create dangerous situations.

- A small accident is not a real problem. Risks in traffic are inevitable.

33. To what extent have people of your social circle been injured in traffic. You can choose one or more alternatives $(1=$ slightly injured, $2=$ a seriously injured person, $3=$ a fatality, $4=$ never .

- Family members

- Friends

- Acquaintances/ neighbours

- Class or school mates

- Someone else you know

Thank you for your cooperation 


\section{Appendix C Scenarios for blind spot situations}

This appendix provides the scenarios used in Chapter 6. The instructions were given in Dutch.

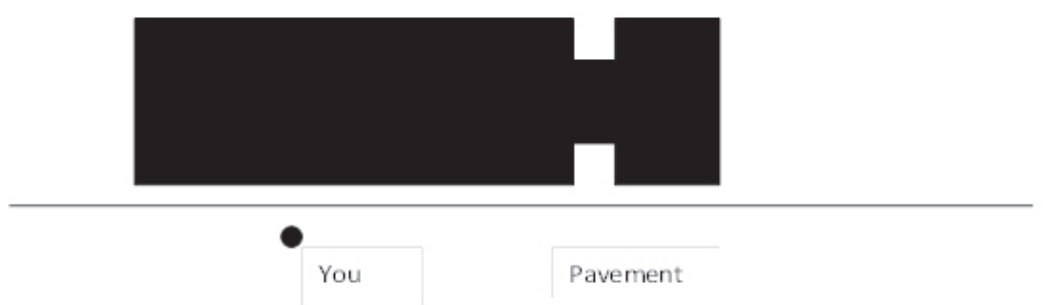

Situation 1 (simple)

Instruction Situation 1

"The truck is waiting, and you hear its motor running. This is you (the experimenter points to the manikin. You want to cross the street and there are no other cars approaching. Where are you going to cross?"

Scoring:

The correct behaviour is either about 3 meters in front of the truck or 3 meters behind it. A correct response $=2$ points; an incorrect response $=0$ points. 


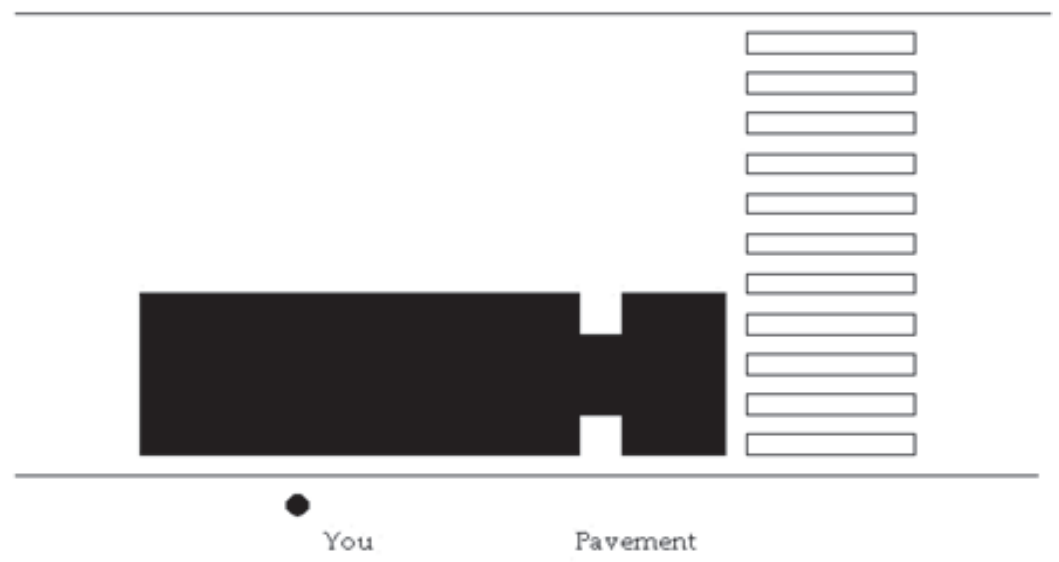

Situation 2 (complex)

Instruction Situation 2

'The truck is waiting just in front of the pedestrian crossing, and you hear its motor running. This is you (the experiment leader points to the manikin). You want to cross the street. Take the manikin and show how and where you are going to cross. Tell me what you do and why you do it.

Scoring: the correct behaviour is 'go over the pavement to the pedestrian crossing and cross using the utmost right side of the pedestrian crossing. A correct response $=2$ points; an incorrect response $=0$ points. 

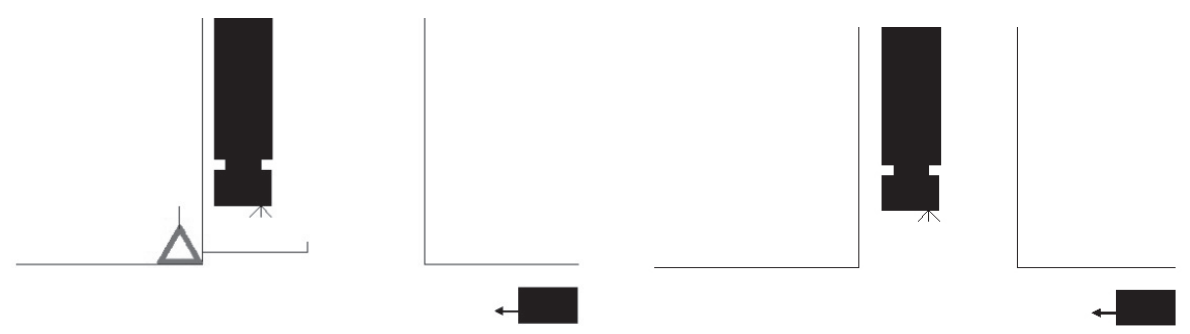

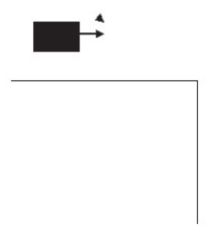

Situation 3 (simple)
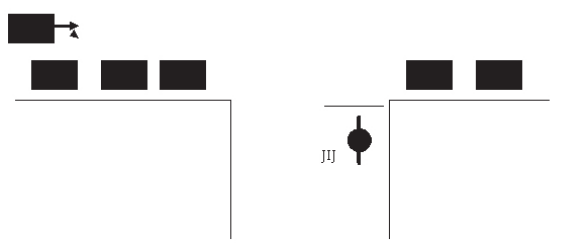

Situation 4 (complex)

\section{Instructions Situation 3}

You approach the intersection on your bicycle and you want to turn left. From the right and the left cars are approaching. In the street in front of you a truck is approaching. It indicates using is blinkers that it intends to turn left. Take the manikin cyclist and position it where you would wait before turning left.

Score: the correct place is immediately behind the stopping line. Instructions

\section{Instruction Situation 4}

You are this cyclist. You are waiting behind the stopping line and you want to cross into the opposite street. Because of the parked cars you cannot see sufficiently whether cars are coming from the right or from the left. In the opposite street a truck is approaching the intersection. Its blinkers tell you that it intends to turn left. Take the manikin cyclists and show precisely how you are going to cross.

Score: The correct behaviour is; Waiting behind the stopping line until the truck is out of the way or crossing the stopping line but only so far that the cyclists still stays at the same line as the parked cars. A correct response $=2$ points; an incorrect response $=0$ points. 


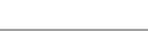

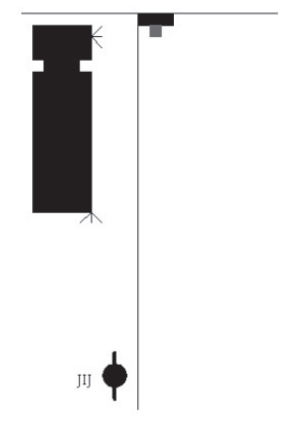

Situation 5 (simple)

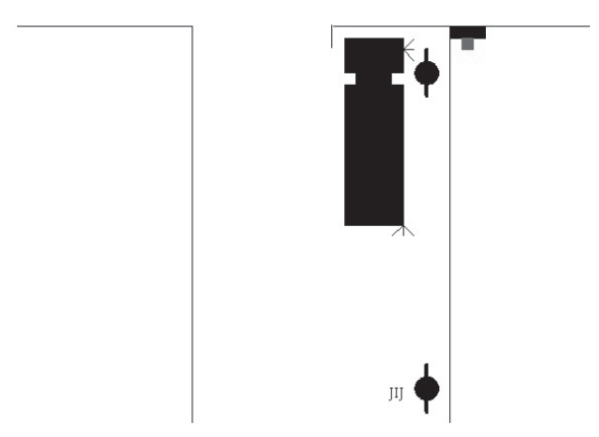

Situation 6(complex)

\section{Instruction Situation 5}

On your bicycle, you are approaching this intersection. The traffic light is red. The truck waits at the stopping line, and uses its blinkers that it wants to turn right. You also want to turn right. Position the bicycle manikin where you would wait while the traffic light is still red.

Score: The correct location is at some distance of the truck. A correct response $=2$ points; an incorrect response $=0$ points.

\section{Instructions Situation 6}

On your bicycle, you are approaching this intersection. The traffic light is red. In front of you a cyclist and a truck are waiting behind the stopping line. The truck's blinkers show that it wants to turn right. You also want to turn right. Position the bicycle manikin where you would wait while the traffic light is still red.

Score: The correct location is at some distance rear right of the truck. A correct response $=2$ points; an incorrect response $=0$ points. 


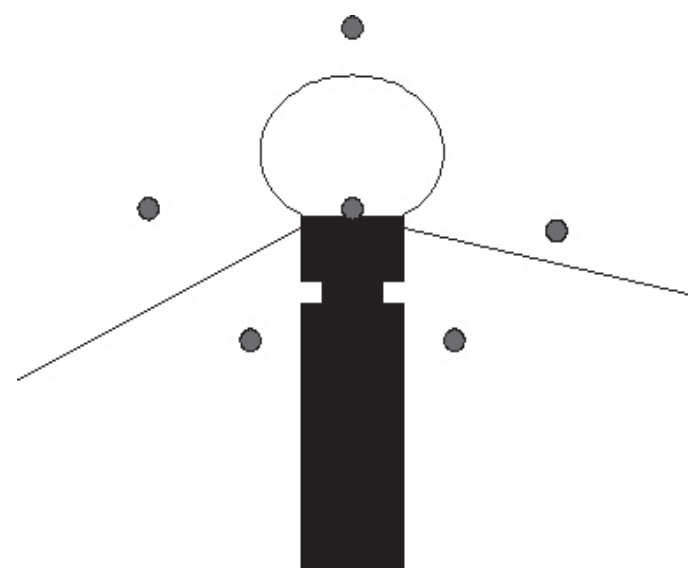

Situation 7 (basic)

This scenario differs from the previous ones as the test is conducted on a plain table top. The research assistant places the manikin at 6 different locations: 3 times at a location where the driver - without the use of mirrors can see the child, and 3 times at locations where the driver cannot see the child without the use of mirrors.

The instruction Situation 7

Tell me, can the driver see the child here, when he does not use the mirrors? Each correct answer 1 point. 



\section{Summary}

Having overcome the frailty of childhood, adolescents become the healthiest and fittest members of western society. Unfortunately, this health gain is partly lost because of a concurrent sharp increase in injury-related mortality. Traffic crashes are responsible for approximately 35\% to $40 \%$ of the injuryrelated mortality among adolescents in Europe and the USA. To date, most prevention efforts have concentrated on reducing the exceptionally high crash risk among adolescent car drivers. In contrast, relatively little policy and research attention has been devoted to young adolescents of 10 to 17 years of age, who in a late-licensing country are still too young to have a driving license.

There are two main reasons that make this attention important. First, recent studies on mental and biological development in adolescence and its impact on risky behaviour suggest that from age 10 onward, elevated levels of road risk are highly probable. However, risky behaviour in traffic is not monitored. Second, little is known about the effects of road safety education in terms of the relevance of risk behaviours that are targeted and the aetiology of these behaviours. The dissertation aims to contribute to the development of high quality education programmes for young adolescent road users. To this end, it focuses on the following objectives: (a) a deeper understanding of the magnitude and nature of road risk in early adolescence; (b) the identification of risk-increasing factors; (c) the assessment of the effects of some road safety education programmes used in Dutch schools and (d) the influence of the safety of the road system on young adolescent road mortality.

Chapter 2 explores the magnitude and nature of pre-license road risk, by analysing epidemiological data from the Netherlands. The hypothesis was that in this late-licensing country, 'independent travel' and the use of riskier modes of transport increase among pre-license teens of 10 to 17 years of age, resulting in higher fatality rates, with 'experience' and 'gender' as riskmodification factors. To that end, national travel and fatality data of prelicense adolescents were analysed by traffic role (cyclist, pedestrian, car passenger and moped rider), and compared to data from a younger age group (0-9 years) and an older age group (18+ years). The travel data showed that teens migrate from being car occupants to being users of riskier modes of transport, specifically bicycles and mopeds. This migration resulted in a 
strong rise in road fatalities, illustrating the importance of mobility patterns for understanding changes in road risks in this age group. The data further suggested a protective role of early cycle experience for young adolescent cyclists, particularly for young males. But further study into the underlying mechanism is needed to confirm this relationship. Moped risk was extremely high, especially among young males, even higher than that of young male car drivers. The study confirmed the importance of changes in mobility patterns for understanding the rising road mortality when youngsters enter into their teenage years. The focus on fatalities has led to an underestimation of the magnitude of the problem because the physical resilience of young adolescents leads to high survival rates but probably also to long term disabilities. To explore the generalizability of these results, international comparisons among and between early- and late-licensing countries are necessary, especially in relation to moped riding as an alternative for car driving.

Chapter 3 contains a review of the relevant literature and provides the theoretical basis for the dissertation, which is set in the practical domain of road safety interventions, with a focus on road safety education (RSE). From this practical perspective, the study draws from a wide range of theoretical fields, such as safety theory, human factors, skill acquisition theory, and social, developmental and neuro-psychology. This chapter discusses the relevance of these perspectives for understanding adolescent road risk and the prospects for effective road safety education. The chapter concludes with a graphical presentation of a theoretical framework for the study adolescent road risk (see Figure 1) and an overview of the research questions, which were the following:

Q1. What is the magnitude and nature of traffic mortality among young adolescents (10-17 years old) in a late-licensing country, such as the Netherlands? (Chapter 2)

Q2. To what extent do mobility patterns change in early adolescence and do these changes contribute to road mortality in this age group? (Chapter 2)

Q3. Are young adolescents sufficiently prepared to meet the task demands of complex traffic situations, such as dealing with blind spots? (Chapter 6)

Q4. What type of risky road behaviours do young adolescents engage in and are these predictive of crashes? (Chapter 4)

Q5. Are the psychological determinants of risk behaviour that are frequently targeted in RSE indeed predictive of risk behaviour? (Chapter 4) 
Q6. Is risky road behaviour an expression of a more general tendency to behave in a risky manner in other domains, such as smoking and alcohol use, as well? (Chapter 5)

Q7. How strong is the relationship between adolescent risky behaviour and risky behaviour in their perceived social environment, especially the behaviour of parents, siblings and friends? (Chapter 5)

Q8. How effective are education programmes in changing risk behaviours? (Chapters 6 \& 7)

Q9. To what extent do safe road systems protect young adolescents from road harm? (Chapter 8)

Q10. What is more beneficial for young adolescent safety - making a car driver license available for this age group, or licensing them at the later age of 18 , which restricts youngsters below the licensing age to the use of bicycles, mopeds, or to walking? (Chapter 8)

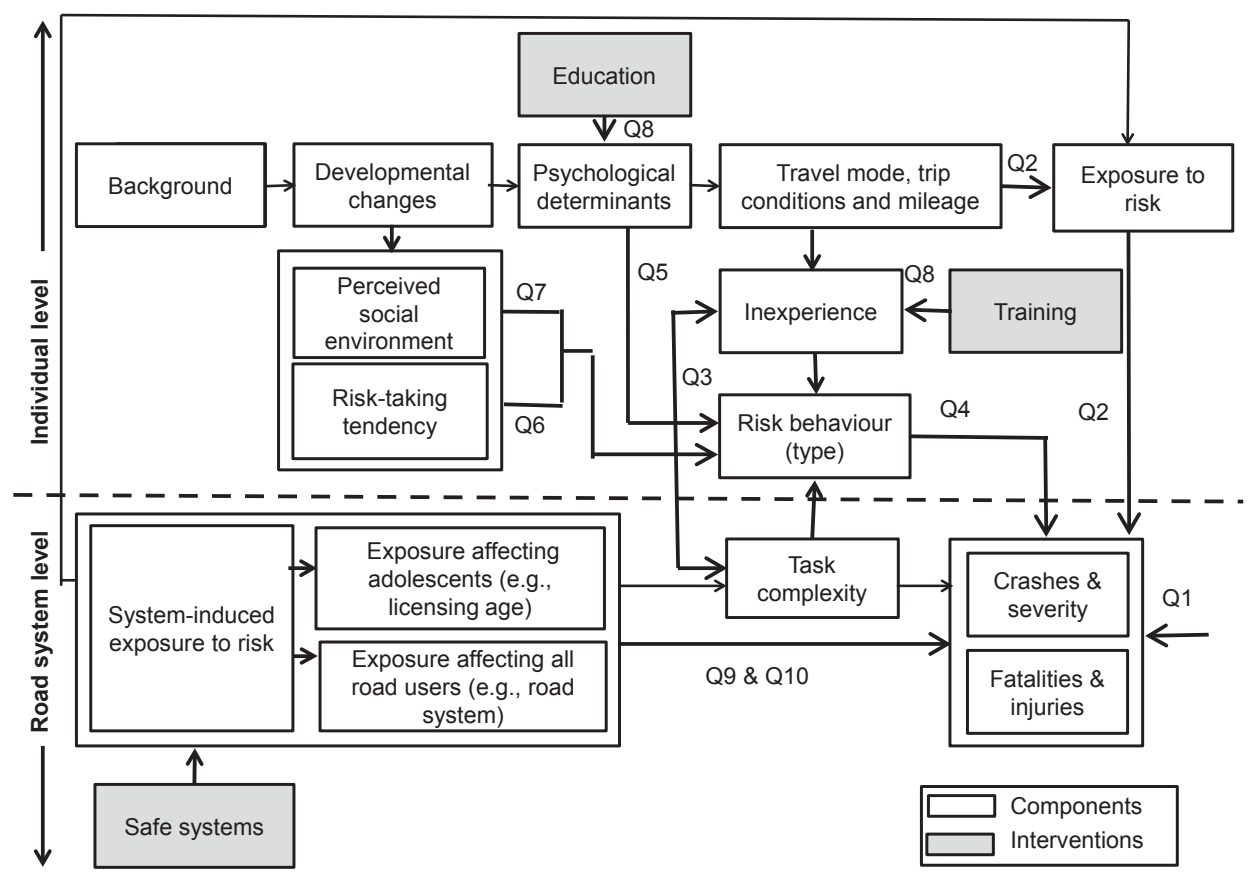

Figure 1. Conceptual framework of adolescent road risk, composed of (potentially) contributing components and three interventions. Arrows in bold depict the relationships and numbered research questions addressed in the dissertation 
Chapter 4 reports a study that investigated the theoretical model and determinants of risk behaviour, different types of risk behaviour and road risk that implicitly underpin several RSE programmes. To that end, 1372 youngsters 12 and 13 years old and 938 youngsters 14 through 16 years old completed a questionnaire at school during regular class. The questionnaire concerned pedestrian and cyclist behaviour, was modified after the adolescent road behaviour questionnaire (ARBQ), and was based on the underlying theories of the Driver Behaviour Questionnaire. This study showed that self-reported 'violations' and 'errors', known to predict crashes among adult car drivers, may differ in the extent to which they predict crashes among young adolescent cyclists and pedestrians. In the adolescents in the study, only errors, dangerous play and lack of protective behaviours predicted crashes, whereas violations did not. To increase the robustness of this finding and to facilitate its use in RSE programmes, further research is needed into the intentionality of adolescents' risky behaviours. Regarding the psychological determinants, the study showed that most of those addressed in RSE, but not all, are indeed predictors of risk behaviours.

Chapter 5 presents the results of a study of adolescents that examined multiple risk behaviours and influences from the perceived social environment. Problem Behaviour Theory (PBT) suggests that risky road behaviour in adolescence is best understood as an expression of a general tendency to engage in risky activities. Furthermore, the incidence of risk behaviour is expected to be higher in adolescents who perceive their parents and peers (the perceived social environment) as engaging in these behaviours. Although such associations might have implications for the design of intervention strategies, little is known about these patterns among Dutch young adolescents. To explore multiple risk behaviours and social influences, this study reanalysed data from the 'Health Behaviour in Schoolaged Children' (HBSC) study conducted in 1991-1992 among 5360 Dutch adolescents (mean age 13.5; $\mathrm{SD}=1.8$ ). As an exception, the 1991-1992 version of the HBSC survey also contained questions on road behaviour. The analyses showed clear evidence of the co-occurrence of risk behaviours, as well as an association with risk behaviours in the perceived social environment. However, given the fact that the data were collected more than two decades ago these findings can only serve as an illustration of the possible connection between risk behaviours and adolescents' perceived social environment. 
Chapter 6 reports the results from our study that examined the possible role of inexperience in the risky decisions of young adolescents around trucks. The study also examined whether RSE improves safe decision making, comparing two types of programmes. One programme aimed to improve traffic competency and another programme aimed to raise risk awareness. The study first assessed competencies of 10 to 13 year olds by examining their decisions - as pedestrians and cyclists - in dealing with blind spot areas around trucks (the pre-test), followed by an assessment after the participants had been involved in one of the two programmes (the post-test). For the assessment, table-top models were used, representing seven scenarios that differed in complexity: a basic scenario to test the identification of blind spot areas, and six traffic scenarios to test behaviour in traffic situations of low or high task complexity. The results on the pre-test showed that young lacked essential competencies relevant for safety. On the basic scenarios only $42 \%$ of the youngsters could correctly identify all three blind spots. Only a quarter of the youngsters were able to make safe decisions in the simple traffic scenarios and $5 \%$ in the complex scenarios. In comparison to the control group, the competency programme yielded improved performance on the basic scenario but not on the traffic scenarios, whereas the awareness programme did not result in any improvement. These findings showed that young adolescents have not yet mastered the necessary skills for safe performance in simple and complex traffic situations, thus underlining the need for more effective prevention programmes. RSE may improve the understanding of blind spot areas but this understanding does not 'automatically' transfer to improved performance in (real) traffic situations.

Chapter 7 presents the results from a multi-programme evaluation. For that purpose, a practical approach was developed to assess and compare the effects of five short road safety education (RSE) programmes for young adolescents that does not rely on injury or crash data but uses self-reported risk behaviour. For the evaluations, questionnaires were administered just before and about one month after participation in the RSE programmes, both to youngsters who had participated in a RSE programme, the intervention group, and to a comparable group of youngsters who had not, the reference group. For each RSE programme, responses to the questionnaire items in the pre- and post-tests were checked for internal consistency and then condensed into a single safety score using categorical principal components analysis. Next, an analysis of covariance was performed on the obtained safety scores in order to compare the post-test scores of the intervention and reference groups, corrected for their corresponding pre-test scores. The study showed 
that three out of five RSE programmes resulted in significantly improved self-reported safety behaviour. However, the proportions of participants who changed their behaviour relative to the reference group were small, ranging from $3 \%$ to $20 \%$. Comparisons among programme types showed that cognitive approaches did not differ in effect from programmes that used fear-appeal approaches. The evaluation method used provides a practical tool to assess and compare the effects of different road safety education programmes on self-reported behaviour.

Chapter 8 takes a different perspective from those in the previous chapters that deal with the role of risk behaviour of adolescents. Relatively little is known about the extent to which the 'road system' itself may have an impact on young adolescents' road mortality. The road system contributes to safety by providing a safe or unsafe road environment for all road users (systeminduced exposure) and by allowing access to high-risk vehicles at a younger or older age through the legal driver licensing age. The study presented in Chapter 8 sought to explore these relationships by analysing the extent to which the road mortality of 10 to 17 year olds in various jurisdictions could be predicted from its system-induced exposure (SE) and from its legal licensing age to drive motor vehicles. SE was operationalized as road fatalities per $10^{5}$ inhabitants/all ages together, but excluding the 10 to 17 year olds. Data on road fatalities during the years 2001 through 2008 were obtained from the Organisation of Economic Cooperation and Development (OECD) International Road Traffic Accident Database (IRTAD) and from the United States' National Highway Traffic Safety Administration's Fatality Analysis Reporting System (FARS) database for 29 early- and 10 latelicensing jurisdictions. Linear mixed models were fitted with annual 'adolescent road mortality per capita' for 2001 through 2008 as the dependent variable, and time-dependent 'SE' and time-independent 'licensing system' as predictor variables. To control for different levels of motorisation, the time-dependent variable 'Annual per capita vehicle distance travelled' was used as a covariate. Licensing system of a jurisdiction was entered as a categorical predictor with late-licensing countries as a baseline group. The study found support for the protective effects of SE on adolescent safety. If SE increased by one unit, the mortality rate of 10 to 17 year olds increased by 0.487 units. No support was found for a protective effect of late licensing for this age group. Thus, compared to young adolescents who are allowed to drive motor vehicles in early-licensing jurisdictions, late licensing does not provide extra protection for pre-license adolescents. This finding is probably the result of the high risks associated with alternative transport modes such 
as moped riding and bicycling. Also, the fact that the study only included risks to young adolescents themselves, and did not include the risks they might pose to other road users and passengers, may have contributed to this finding, because such risks are greater when driving a motor vehicle than when riding a moped or a bicycle.

Chapter 9 presents the conclusions and discusses the results. It further provides a list of lessons learned about road risk in early adolescence, implications for policy and needs for further research.

1. In the Netherlands adolescent road mortality is an unrecognized public health problem. Young adolescents die from 'preventable' injuries not from 'incurable' disease.

2. To target interventions effectively, it is necessary to monitor adolescent risky road behaviour.

3. Teen thinking differs from adult thinking, which has implications for surveys and interventions.

4. Inexperience and poor hazard perception are factors in need of mediation.

On the effects on road safety education the following lessons were learned:

1. The acquisition of safety critical skills requires intensive learning by doing, rather than by demonstrations or simple rules of thumb.

2. Effects of 'short' RSE programmes are probably not as great as expected. Evaluation studies are needed to provide an accurate estimate of the outcome of each programme.

3. To discourage deliberate risk-taking, the actual design and delivery of a programme has more impact on effects than the choice for either a 'fear appeal' or a 'cognitive 'approach.

4. Adolescent safety benefits from a safe road environment in combination with effective RSE. This provides conditions for protection and individual growth.

On the need of further research the dissertation concludes the following:

1. Because the aetiology of risk behaviour of adolescents appears to differ from that of adults, we should not base our interventions on our understanding of adult risk, but deepen our understanding of adolescent risk behaviour

2. Because adolescent risk behaviour is not limited to the road, and also occurs in other areas, the added value of interventions targeting these general risk taking tendencies needs to be explored further. 
3. An initiative is needed to ensure that all road safety education programmes used in schools are proven effective.

4. To enable a deeper insight into problems and interventions for adolescent cyclists, pedestrians and moped riders, more advanced research methodologies need to be developed. 


\section{Samenvatting}

$\mathrm{Na}$ de kwetsbare periode in hun kindertijd worden adolescenten de gezondste en sterkste leden van onze westerse samenleving. Zijn in de kindertijd ziekten en medische aandoeningen nog de belangrijkste doodsoorzaken, in de adolescentie nemen deze sterk af maar neemt de sterfte door niet-natuurlijke oorzaken sterk toe. Verkeersongevallen behoren tot de meest voorkomende doodsoorzaken binnen deze groep. In Europa zijn verkeersongevallen verantwoordelijk voor $35 \%$ van de sterfte onder jongeren tussen de 10 en 24 jaar. Tot nu toe heeft de preventie zich vooral gericht op het zeer hoge ongevalsrisico van jonge, onervaren automobilisten in deze leeftijdsgroep. De jongere leeftijdsgroep die nog niet auto mag rijden heeft nog weinig aandacht gekregen. In tegenstelling tot landen als de Verenigde Staten, waar op een jongere leeftijd - soms al vanaf 16 jaar - auto mag worden gereden, is in de meeste Europese landen de vervoerskeuze van Europese jongeren tussen de 10 en 17 jaar beperkt tot de fiets, bromfiets en het openbaar vervoer. Er is weinig bekend over de verkeersveiligheid van deze 'nog-geen-rijbewijs'-jongeren.

Er zijn twee redenen waarom meer kennis over de veiligheid van deze 'noggeen-rijbewijs'-jongeren toch van belang is. Allereerst doen resultaten uit recent onderzoek naar de cognitieve en biologische ontwikkeling van jongeren vermoeden dat vanaf het tiende levensjaar gevaarlijk gedrag in het verkeer sterk zou kunnen toenemen. Of dat ook echt het geval is, is tot nu toe onvoldoende onderzocht. De tweede reden betreft het gebrek aan kennis over de effecten van verkeerseducatie. Verkeerseducatie wordt op grote schaal toegepast in scholen, terwijl over de effecten van de educatieprogramma's zeer weinig bekend is. Vragen als: 'Richten verkeerseducatieprogramma's zich op de belangrijkste problemen? en 'Worden deze problemen op een effectieve manier aangepakt? wachten nog steeds op antwoord. Dit proefschrift had tot doel bij te dragen aan de ontwikkeling van kwalitatief goede verkeerseducatieprogramma's voor jonge adolescenten. Hiervoor richtte het zich op de volgende doelen: (a) het verwerven van een beter inzicht in de omvang en de aard van de verkeersonveiligheid van deze leeftijdsgroep, (b) het in kaart brengen van de risicofactoren; (c) het vaststellen van het effect van een aantal verkeerseducatieprogramma's voor Nederlandse scholen, en (d) het exploreren van de invloed van het verkeerssysteem op de veiligheid van deze jongeren, zoals de veiligheid van wegen en fietspaden, en de leeftijd waarop autogereden mag worden. 
Om inzicht te krijgen in de verkeersmortaliteit onder 10- tot 17-jarigen, zijn in Hoofdstuk 2 de epidemiologische gegevens uit Nederland over doodsoorzaken en de verkeersmobiliteit geanalyseerd. Omdat in Nederland jongeren pas op hun $18^{\text {de }}$ een rijbewijs kunnen behalen was de verwachting dat onder de 10tot 17-jarigen de zelfstandige mobiliteit wel toe zou nemen, maar dat daarvoor vervoerswijzen zouden worden gekozen die in feite gevaarlijker zijn dan het vervoer per auto. Mocht deze vooronderstelling bevestigd worden dan zouden deze mobiliteitspatronen deels verantwoordelijk kunnen zijn voor een toename in de verkeersmortaliteit. Daarnaast is nagegaan of onervarenheid, leeftijd en geslacht van invloed zijn op de stijging van de mortaliteit. Uit onze resultaten bleek dat de mobiliteitspatronen inderdaad veranderen wanneer kinderen ouder worden. Kinderen van 0 tot 9 jaar verplaatsen zich voornamelijk als autopassagier. Vanaf hun tiende jaar veranderen ze van passagiers in zelfstandige verkeersdeelnemers, eerst als fietser en vanaf hun $16^{\text {de }}$ als bromfietser. Zestienjarigen bijvoorbeeld leggen eenderde van hun kilometers af als fietser. Helaas kent een afgelegde kilometer op de fiets een veel hoger ongevals- en letselrisico dan een kilometer als autopassagier. Analyse van de doodsoorzakenstatistiek liet zien dat deze vervanging van autokilometers door fiets- en bromfietskilometers inderdaad een hogere verkeersmortaliteit tot gevolg heeft. Hoewel vaak gedacht wordt dat moedwillig gevaarlijk gedrag door jongeren de belangrijkste oorzaak is van verkeersongevallen in deze levensfase, illustreren onze resultaten dat de vervoerskeuze en de veranderingen daarin een onderbelichte risicofactor is. De resultaten wijzen verder op een mogelijk positief effect van ervaring op fietsveiligheid. Dit geldt vooral voor fietsende jongens. Voor 16-jarigen op een bromfiets is de kans op een dodelijk ongeval juist zeer hoog, zelfs hoger dan dat voor jonge automobilisten.

Overigens is de verkeersmortaliteit slechts een deel van het probleem. Vanwege de grotere betrouwbaarheid van de gegevens voor overleden slachtoffers, heeft onze studie zich alleen gericht op overleden slachtoffers en zijn ernstig verkeersgewonden buiten beschouwing gelaten. Er zijn aanwijzingen, dat onder jongeren juist het aantal gewonden en de daarmee samenhangende langetermijngevolgen veel groter zijn dan van voor welke andere leeftijdsgroep dan ook. Omdat jongeren fysiek sterker zijn dan andere leeftijdsgroepen, kunnen zij ongevallen overleven die voor anderen dodelijk zouden zijn geweest. De keerzijde hiervan is de mogelijkheid dat een deel van deze jongeren de rest van hun leven zullen kampen met lichamelijke beperkingen. Nader onderzoek naar deze langdurige gevolgen van verkeersongevallen zijn dus vooral deze leeftijdsgroep van belang om een afweging 
te kunnen maken tussen de kosten van interventies en het verwachte veiligheidsrendement.

Samenvattend:

1. In een land dat op 18-jarige leeftijd de mogelijkheid biedt om auto te rijden, stijgt de verkeersmortaliteit sterk onder 10- tot 17-jarigen.

2. De stijgende mortaliteit is in belangrijke mate het gevolg van een verschuiving van relatief veilige mobiliteit als auto-inzittende naar een relatief onveilige zelfstandige verkeersdeelname als fietser en op 16jarige leeftijd als brom- en snorfietser.

Om meer inzicht te krijgen in de mogelijke achterliggende oorzaken en de potentiële effecten van verkeerseducatie en het verkeerssysteem zelf, had Hoofdstuk 3 tot doel een theoretisch kader te vormen, dat als basis kon dienen voor de onderzoeksvragen en hypothesen. Voor dit theoretische kader is gebruikgemaakt van een breed scala aan kennisgebieden, zoals veiligheidstheorieën, Human Factors, theorieën over het verwerven van vaardigheden, maar ook sociale psychologie, ontwikkelingspsychologie, neuropsychologie en fysiologie. Het hoofdstuk sluit af met een grafische presentatie van een theoretisch kader voor de studie, zie Figuur 1. Deze laat zien dat de factoren die van invloed zijn op de verkeersmortaliteit van jongeren te verdelen zijn in twee niveaus: het individuele niveau en het systeemniveau. Individuele factoren betreffen bijvoorbeeld de vervoerskeuzes, de meningen en overtuigingen die ten grondslag liggen aan het (verkeers)gedrag, de invloeden vanuit de sociale omgeving, en het vaardigheidsniveau. De systeemfactoren betreffen bijvoorbeeld complexe verkeerssituaties die fouten uitlokken, of wetgeving waardoor jongeren met te weinig ervaring al wel met een 'gevaarlijk' voertuig het verkeer in mogen.

De volgende onderzoeksvragen zijn uit dit theoretische kader afgeleid:

Q1. Wat is de omvang en de aard van de verkeersmortaliteit onder jonge adolescenten (10-17 jaar oud) in een land waar jongeren vanaf hun $18^{\text {de }}$ jaar auto mogen rijden? (al eerder aan de orde gekomen in Hoofdstuk 2)

Q2. In welke mate veranderen de mobiliteitspatronen in de vroege adolescentie? Leiden deze veranderingen tot een verandering in de verkeersmortaliteit? (al eerder aan de orde gekomen in Hoofdstuk 2)

Q3. Zijn jonge adolescenten voldoende voorbereid op de zware taakvereisten in complexe verkeerssituaties, zoals het rekening houden met de blinde hoeken van vrachtwagens? (Hoofdstuk 6) 
Q4. Wat voor soort riskant verkeersgedrag vertonen jonge adolescenten? Krijgen jongeren die dit gedrag vertonen ook vaker ongevallen dan jongeren die dat niet doen? (Hoofdstuk 4)

Q5. Zijn de psychologische determinanten die vaak in verkeerseducatie aan de orde komen inderdaad voorspellend voor risicogedrag? (Hoofdstuk 4)

Q6. Is riskant rijgedrag een uiting van een gedragskenmerk dat ook aan andere risicogedragingen ten grondslag ligt zoals aan roken, gokken en alcoholgebruik? (Hoofdstuk 5)

Q7. Hoe sterk is de relatie tussen het risicogedrag van jonge adolescenten en de aanwezigheid van dat gedrag in hun sociale omgeving, zoals bij ouders, broers en zussen, en vrienden? (Hoofdstuk 5)

Q8. Hoe effectief zijn verkeerseducatieprogramma's in het veranderen van risicogedrag in het verkeer? (Hoofdstukken 6 en 7)

Q9. In hoeverre beschermen veilige verkeerssystemen ook de jonge adolescenten? (Hoofdstuk 8)

Q10. Wat is gunstiger voor de verkeersveiligheid van jonge adolescenten, een jongere leeftijd waarop je je autorijbewijs mag halen zoals in de VS of op de oudere leeftijd van 18 jaar, zoals in Europa? In het eerste geval worden jongeren al jong blootgesteld aan de gevaren van autorijden, maar worden zij wel beschermd door de veiligheidseigenschappen van de auto. In het laatste geval worden zij nog niet blootgesteld aan de gevaren van autorijden, maar worden zij wel blootgesteld aan de hogere risico's van fietsen en bromfietsen. 


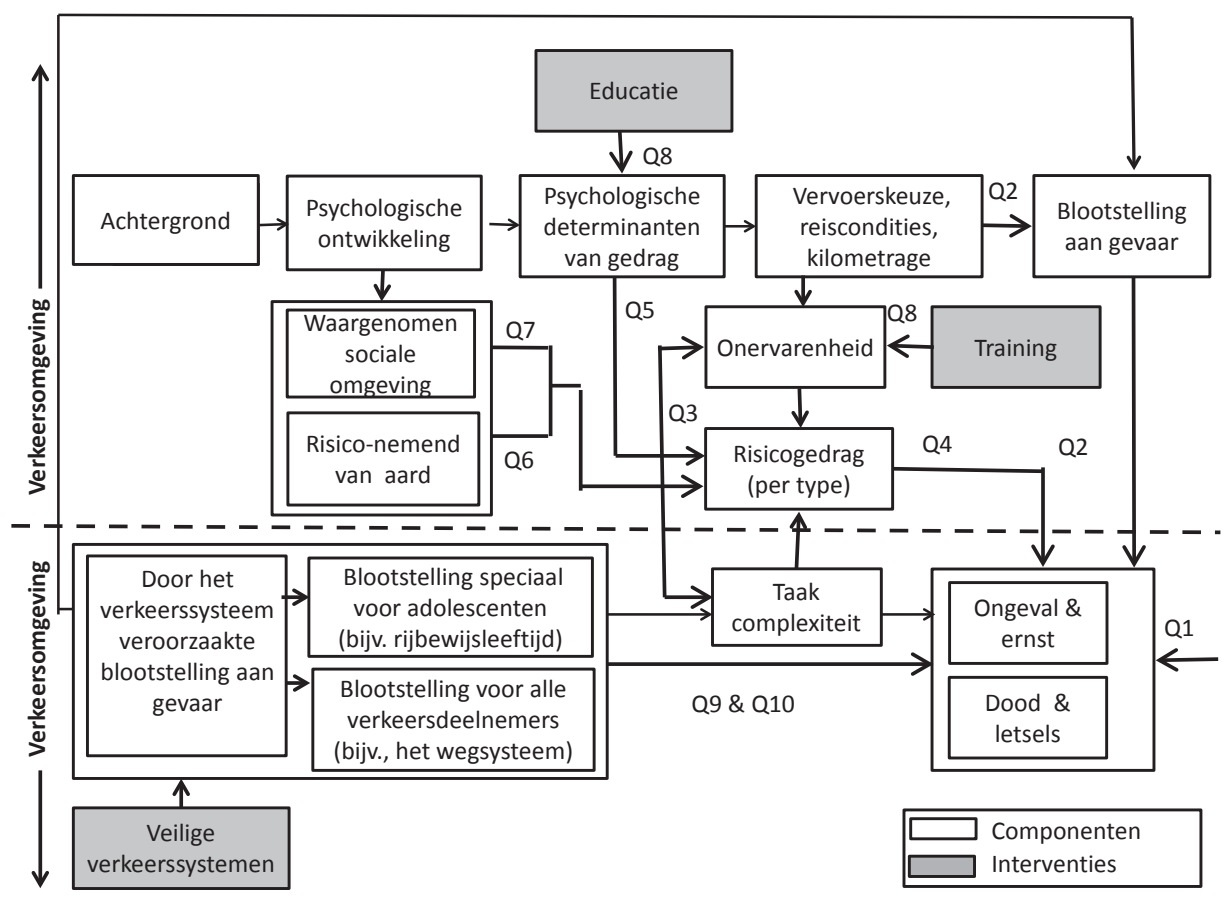

Figuur 1. Conceptueel kader van de invloeden die een rol spelen bij de verklaring van de verkeersmortaliteit onder jongeren, en de aangrijpingspunten van drie interventies. Dikke pijlen geven de invloeden weer die in deze dissertatie zijn onderzocht, met daarbij de genummerde onderzoeksvragen.

Om te begrijpen of verkeerseducatie effectief kan zijn, is in Hoofdstuk 4 onderzocht of de achterliggende oorzaken van gedrag die vaak in educatieprogramma's aan de orde komen ook echt belangrijk zijn voor de verkeersveiligheid. In verkeerseducatieprogramma's wordt immers aangenomen dat deze achterliggende oorzaken (bijvoorbeeld gebrekkige kennis van de verkeersregels) van invloed zijn op gevaarlijk gedrag (bijvoorbeeld op het negeren van de voorrangsregels). De daarop volgende aanname is dat dit risicogedrag de kans op een ongeval vergroot. In het kort noemen we deze beide aannamen het theoretische model van de verkeerseducatie. Om te onderzoeken of dit theoretische model klopt is op scholen een vragenlijst afgenomen bij 1372 jongeren van 12 en 13 jaar en 938 jongeren van 14 tot en met 16 jaar. Deze vragenlijst is gebaseerd op het GEMS-model (Generic Error Modelling System). Dit model is eerder voornamelijk toegepast om het risicogedrag van autobestuurders te onderzoeken. In deze automobilistenstudies bleek een belangrijk onderscheid te bestaan tussen 'vergissingen' enerzijds en 'overtredingen' anderzijds. Het belangrijkste verschil is dat bij 
vergissingen bestuurders niet de bedoeling hebben zich gevaarlijk te gedragen, en bij overtredingen wel. Uit deze studies bleek dat automobilisten die vaak overtredingen begingen of zich vergisten ook vaker in ongevallen terechtkwamen. Voor jongeren ligt dat mogelijk anders. Allereerst laat onze studie zien dat vooral vergissingen ongevalsbetrokkenheid voorspelden en dat overtredingen dat nauwelijks deden. Bovendien bleek 'een gebrek aan zelf-beschermend gedrag' zoals oversteken op plaatsen waar je slecht zichtbaar bent, een minstens zo belangrijke voorspeller te zijn als vergissingen en bewuste overtredingen. Dit laat om te beginnen zien dat uit het gedrag van volwassen automobilisten geen lering getrokken kan worden over het gedrag van adolescenten die nog geen autorijden. Meer onderzoek is nodig naar de vraag wat jongeren zelf zien als de reden van hun gedrag. Bovendien wijst de relatie tussen een gebrek aan zelf-beschermend gedrag en ongevallen op het belang om educatieprogramma's niet alleen te richten op ongewenst gedrag, maar ook op beschermend gedrag.

De vraag is verder of het riskante gedrag in het verkeer op zichzelf staat, of dat het samengaat met risicogedragingen op andere gebieden. Mocht dat laatste het geval zijn, dan kan preventie zich richten op deze samenhang en de onderliggende oorzaken daarvan in plaats van zich te richten op de symptomen ervan.

Een vraag die daarmee samenhangt is wat de invloed is van de sociale omgeving op het verkeersgedrag van jongeren. Als bijvoorbeeld ouders onder invloed rijden, doen hun kinderen dat dan ook? Om antwoord te kunnen geven op deze vragen hebben we een oudere bestaande dataset opnieuw geanalyseerd (zie Hoofdstuk 5). Voor deze analyses is het theoretische kader van de Probleemgedrag Theorie gebruikt. Deze theorie veronderstelt dat risicogedragingen zoals die in het verkeer het best begrepen kunnen worden als uitingen van een algemene onderliggende risicotendens. Bovendien veronderstelt PBT dat adolescenten zich vaker riskant zullen gedragen als zij zelf de indruk hebben dat anderen in hun sociale omgeving zoals ouders, broers, zussen en vrienden dat ook doen. In dat geval zouden interventies zich niet alleen op de jongeren zelf moeten richten maar vooral ook op hun beeld van het gedrag van anderen. De meeste studies op dit terrein zijn gedaan in andere landen, en tot nu toe is er weinig bekend over Nederlandse jongeren. Daarom is voor deze dissertatie de dataset van de 'Health Behaviour in School-aged Children' (HBSC) studie uit 1991-1992 opnieuw geanalyseerd. Deze dataset bevat gegevens van 5.360 Nederlandse jongeren (gemiddelde leeftijd 13,5 jaar, $\mathrm{SD}=1,8$ ). Bij wijze van uitzondering, werden in deze 1991-1992-versie naast vragen over gezondheid, 
welbevinden, gokken en pesten ook vragen over verkeersgedrag opgenomen. In onze nieuwe analyses hebben we gekeken naar de samenhang tussen riskant verkeersgedrag, roken, alcoholgebruik en gokken. Hieruit blijkt dat probleemgedrag in het verkeer niet op zichzelf staat maar samenhangt met deze andere risicovolle gedragingen. Ook blijkt dat jongeren die de indruk hadden dat bepaalde risicogedragingen in hun omgeving vaak voorkwamen vaker zeiden dit gedrag ook zelf te vertonen. Helaas is de gebruikte dataset zeer oud en zijn er daarna in Nederland geen soortgelijke studies van voldoende kwaliteit meer uitgevoerd. Daarom kunnen onze bevindingen alleen dienen als illustratie en aanwijzing voor het belang van soortgelijk onderzoek onder hedendaagse jongeren.

Geen van de voorgaande studies richt zich op de vraag of - naast 'bewust' risicogedrag - ook onervarenheid in het verkeer een rol zou kunnen spelen in de ongevallen van jonge adolescenten. Wanneer jongeren de basisschool verlaten om naar de middelbare school te gaan, verlaten ze daarmee ook de relatief veilige omgeving van de buitenwijken en de dorpen, en worden ze op hun weg naar de middelbare school blootgesteld aan de gevaren van het (grootstedelijke) verkeer. In deze dissertatie - zie Hoofdstuk 6 - is onderzocht hoe veilig jongeren, in de leeftijd tussen 10 en 13 jaar zich gedragen in de directe omgeving van vrachtwagens. Houden ze bijvoorbeeld rekening met de dode hoek in het blikveld van de bestuurder? Na dit te hebben vastgesteld, hebben we vervolgens gekeken of de beslissingen van de jongeren veiliger werden als gevolg van dodehoekprogramma's. De effecten van twee dodehoekprogramma's zijn vergeleken met verschillende didactische benaderingen. Het ene programma richtte zich op het verbeteren van de verkeerscompetenties. Het andere programma richtte zich op het vergroten van het gevaarbewustzijn. Voor de beoordeling van de beslissingen van de jongeren zijn driedimensionale maquettes gebruikt van zeven verkeerssituaties die verschilden in complexiteit. Met het basisscenario werd de kennis over de locaties van de dode hoek vastgesteld. Bij de zes verkeersscenario's werden de deelnemers gevraagd waar ze zouden oversteken en waar ze zouden wachten. Drie verkeersscenario's waren eenvoudig en de overige drie waren complex. Voorafgaande aan de programma's kon in het basisscenario $42 \%$ van de jongeren alle drie dode hoeken correct aanwijzen. In de simpele verkeerssituaties bleek een kwart van de jongeren een veilige gedragskeuze te maken. In de complexe verkeerssituaties deed slechts 5\% dat. Vervolgens hebben we gekeken of de keuzes veiliger werden door de educatieprogramma's. Jongeren die het competentieprogramma gevolgd hadden konden vaker dan daarvoor alle drie dode hoeken aanwijzen, maar hun 
keuzes in de verkeersscenario's werden niet veiliger. Het programma dat zich richtte op gevaarbewustzijn leidde niet tot verbeteringen; niet bij het basisscenario en ook niet bij de simpele en complexe verkeersscenario's. Deze bevindingen illustreren dat jonge adolescenten aan het einde van de basisschool, net voordat ze naar de middelbare school gaan, nog onvoldoende in staat zijn veilige keuzes te maken in complexe verkeerssituaties. Educatie kan de herkenning van de dode hoeken verbeteren, maar deze verbeterde herkenning leidt niet automatisch tot veiliger keuzes op straat. Uit eerdere onderzoeken naar leerprocessen in het verkeer weten we dat het voor veiliger verkeersgedrag nodig is om te oefenen in situaties die lijken op het echte verkeer.

In het voorgaande zijn twee programma's vergeleken die zich richten op het specifieke probleem rond de dode hoek. Er zijn ook programma's die zich richten op veilig verkeersgedrag in het algemeen. Ook voor deze programma's is het de vraag of ze leiden tot gedragsveranderingen, en welk type programma het meest effectief is. Om dit te kunnen onderzoeken is in deze dissertatie een methode ontwikkeld om de effecten van verschillende programma's te kunnen vergelijken (zie Hoofdstuk 7). Vervolgens is deze methode toegepast en zijn de effecten van vijf programma's onderling vergeleken. De methode maakte gebruik van een vragenlijst waarin jongeren gevraagd werd of en hoe vaak ze bepaald risicogedrag vertoonden. De jongeren vulden deze vragenlijsten in vlak voordat ze aan het programma deelnamen, en vervolgens opnieuw een maand na afloop van het programma. De controlegroep deed hetzelfde, maar zonder deelname aan een van de programma's. Na statistische correcties en datareductie via Principale Componenten Analyse kreeg elke deelnemer een veiligheidsscore. Vervolgens werd de veiligheidsscore voorafgaande aan het programma vergeleken met die na afloop, waarbij de controlegroep als vergelijking diende. Hieruit is gebleken dat na drie van de vijf educatieprogramma's de veiligheidsscore verbeterde. Afhankelijk van het programma en in vergelijking tot de controlegroep, verbeterden tussen de 3 en $20 \%$ van de jongeren hun gedrag na afloop van het programma. Programma's die zich richten op het vergroten van inzicht (de cognitieve programma's) en programma's die zich richten op het vergroten van angst (angstaanjagende programma's) blijken niet te verschillen in de omvang van het effect. Ook blijkt de keuze voor een van beide didactische benaderingen geen garantie voor succes. Onder beide typen kwamen programma's voor die geen effect hadden. 
De hiervoor besproken hoofdstukken gingen over het risicogedrag van jongeren zelf en de mogelijkheden om dat te veranderen. In het theoretische model (Figuur 1) is dat het individuele niveau genoemd. In dit theoretische model is ook de optie genoemd om de gevolgen van het risicogedrag te beperken door het verkeerssysteem voor jongeren veiliger te maken. De vraag is dus of de inrichting en de kwaliteit van dit verkeerssysteem van invloed zijn op de mortaliteit van jonge adolescenten. Zijn verkeersveilige landen ook veilig voor adolescenten? Een van de onderdelen van het verkeerssysteem betreft de leeftijd waarop jongeren een autorijbewijs kunnen behalen. Wat is veiliger, al op jonge leeftijd een auto rijbewijs te mogen halen, of dat pas op latere leeftijd te mogen doen? In het laatste geval hebben jongeren alleen de beschikking over fietsen en bromfietsen. Dit onderzoek is uitgevoerd door de verkeersmortaliteit van verschillende landen onderling te vergelijken, en vervolgens deze landen in te delen in twee categorieën: landen waar jongeren ruim voor hun $18^{\text {de }}$ zelfstandig mogen autorijden (dus zonder begeleiding) en landen waar dat pas kan na de $18^{\text {de }}$ verjaardag. Deze studie is gerapporteerd in Hoofdstuk 8. Gegevens over het aantal verkeersdoden in de jaren 2001 tot en met 2008 werden verkregen uit de International Road Traffic Accident Database (IRTAD) van de Organisatie voor Economische Samenwerking en Ontwikkeling (OESO) en uit het Fatality Analysis Reporting System (FARS) van de National Highway Traffic Safety Administration (NHTSA) van de Verenigde Staten. De onveiligheid van een land werd uitgedrukt als het aantal verkeersdoden per 100.000 inwoners (verkeersmortaliteit), maar zonder die van 10- tot 17-jarigen. Daarnaast werd in de analyses rekening gehouden met de graad van motorisatie in een land, uitgedrukt als de jaarlijks per inwoner met een motorvoertuig afgelegde kilometers. In onze studie is steun gevonden voor de beschermende invloed van veilige verkeerssystemen voor jonge adolescenten. Als de onveiligheid in een land met een eenheid stijgt, neemt de verkeersmortaliteit van 10- tot 17jarigen met 0,487 eenheden toe. Geen ondersteuning is gevonden voor een extra beschermend effect - bovenop die van de algemene veiligheid van het verkeerssysteem - van een hogere wettelijke rijbewijsleeftijd. Voor 10- tot 17jarigen is het dus niet veiliger om in een land te wonen waar ze nog niet mogen auto rijden, dan in een land waar dat al wel mag. Dit is waarschijnlijk het gevolg van de relatief hoge letselrisico's van vervoerswijzen zoals bromfietsen en fietsen. Ook het feit dat in deze studie alleen is gekeken naar het 'eigen' risico en niet de risico's voor andere verkeersdeelnemers, zal hebben bijgedragen aan deze bevinding. Immers, de kans dat een jongere in een ongeval een andere verkeersdeelnemer dodelijk verwondt is vele malen groter in een auto dan op de fiets of bromfiets. 
Zoals gebruikelijk in dissertaties, bevat het laatste hoofdstuk - Hoofdstuk 9 de conclusies, discussie, en aanbevelingen voor beleid en nader onderzoek. Deze zijn samengevat in de volgende bevindingen en aanbevelingen:

1. In Nederland is de verkeersmortaliteit onder jongeren een onderschat volksgezondheidsprobleem. In vergelijking tot de kindertijd is onder jonge adolescenten (10 tot 17 jaar) de mortaliteit door aandoeningen en ziekten veel lager, maar stijgt de mortaliteit als gevolg van verkeersletsels. Jonge adolescenten sterven dus vaker aan 'vermijdbare' (verkeers)letsels en minder vaak aan 'ongeneeslijke' ziekten en aandoeningen.

2. Om interventies voor jonge adolescenten te kunnen richten op de gedragingen die voor veiligheid het verschil maken, is het nodig inzicht te krijgen in de aard en de onderliggende oorzaken van hun risicogedrag.

3. Jonge adolescenten lijken op een andere manier te denken over de oorzaak van hun risicogedrag in het verkeer dan volwassenen. Als dat bevestigd wordt in verder onderzoek heeft dat ook gevolgen voor de inrichting van educatieprogramma's.

4. Ook gebrek aan ervaring speelt een rol in het risicogedrag van jongeren in het verkeer. Dit betekent dat er ook behoefte is aan educatieprogramma's die zich hierop richten.

Over de effecten van verkeerseducatie kan het volgende geconcludeerd worden:

1. Het geven van demonstraties of het aanleren van vuistregels zonder deze in de praktijk toe te leren passen is niet voldoende om jongeren voor te bereiden op complexe en potentieel gevaarlijke verkeerssituaties. Er is behoefte aan programma's die jongeren in die complexe verkeerssituaties laten oefenen zonder ze daarbij bloot te stellen aan de gevaren.

2. Effecten van 'kortdurende' verkeerseducatie zijn niet zo groot als wel wordt gedacht. Door elk programma te evalueren wordt een realistischer beeld verkregen over de effecten.

3. Angstaanjagende educatieprogramma's blijken opnieuw niet effectiever dan programma's die zich vooral richten op verkeersinzicht.

4. Interventies hoeven zich niet alleen op het risicogedrag van de jongere zelf te richten. Ook jongeren profiteren van een veiliger verkeersomgeving, ondanks hun drang naar vrijheid, nieuwe ervaringen en voorliefde voor 'thrills and kicks'. 
Over de noodzaak van verder onderzoek concluderen wij het volgende:

1. Voor de invulling van interventies gericht op jongeren is meer kennis nodig over de manier waarop jongeren de oorzaken van hun eigen risicogedrag interpreteren.

2. Omdat het risicogedrag van adolescenten zich niet beperkt tot het verkeer en ook voorkomt op andere gebieden, heeft het meerwaarde om eerst vast te stellen of er gemeenschappelijke achterliggende oorzaken zijn, om vervolgens daar de interventies op te richten.

3. Omdat verkeerseducatieprogramma's ineffectief kunnen zijn is het in het belang van kosteneffectiviteit dat scholen alleen programma's gebruiken, en overheden alleen programma's financieren waarvan de effecten door evaluatieonderzoek zijn aangetoond. Een dergelijke gedragslijn is een stimulans voor aanbieders van educatieprogramma's om hun producten te laten evalueren. Iets wat tot nu toe nauwelijks gebeurt.

4. Omdat er nog weinig methoden zijn om het gedrag van nietautorijdende verkeersdeelnemer te onderzoek, beperken studies onder jongeren zich tot vragenlijsten en simpele observaties. Voor een verdere verdieping van de inzichten zijn meer geavanceerde methoden nodig, zoals fietssimulatoren, geïnstrumenteerde fietsen en 'virtual reality'toepassingen. 



\section{Curriculum Vitae}

Divera Alida Maria Twisk was born in 1952 in the Noord Oost Polder. After obtaining a degree in Social work from the Catholic Social Academy in Enschede, she worked for a period of 5 years as a social worker. In 1979 she moved to the United Kingdom, where she received in 1982 a Bachelor degree in Psychology and Sociology from the University of Keele. After her return to the Netherlands, she received in 1985 a Master's degree in Experimental Psychology from the University of Groningen. She worked for almost two years at the Medical Biological Laboratory of the Institute of Applied Research (TNO), where she contributed to the study on the effects of occupational exposure to low doses of organic solvents on the human central nervous system, first as a trainee and later as researcher. These studies have contributed to the reduction of occupational exposure to such substances. In 1986 she started her work at SWOV, the Dutch institute for research into road safety. At SWOV she conducted studies into a wide range of topics, such as young driver's safety, learning and training processes, police enforcement and road design. She further contributed to several international and European projects such as GADGET, DAN, PROMISING, and CAST. She was a member of the advisory group to the Ministry of Transport and Infrastructure concerning the licensing of drivers with early stages of Alzheimer's disease and other forms of dementia. She further chaired the OECD work group 'Young drivers and effective countermeasures' and coauthored and edited the OECD rapport 'Young Drivers: the road to safety'. Later she became a member of the Transport Research Board Young Driver subcommittee. Since 2010 she has coordinated SWOV's research on cycle safety and is one of the founding members of the National research agenda on cycle safety in the Netherlands (NOaF). 



\section{SWOV-Dissertatiereeks}

In deze reeks zijn eerder verschenen:

Jolieke Mesken (2006). Determinants and consequences of drivers' emotions.

Ragnhild Davidse (2007). Assisting the older driver: Intersection design and in-car devices to improve the safety of the older driver.

Maura Houtenbos (2008). Expecting the unexpected: A study of interaction behaviour at intersections.

Frits Bijleveld (2008). Time series analysis in road safety research using state space methods.

Saskia de Craen (2010). The X-factor; A longitudinal study of calibration in young novice drivers.

Atze Dijkstra (2011). En route to safer roads; How road structure and road classification can affect road safety.

Charlotte Bax (2011). Processes and patterns; The utilisation of knowledge in Dutch road safety policy.

Willem Vlakveld (2011). Hazard anticipation of young novice drivers; Assessing and enhancing the capabilities of young novice drivers to anticipate latent hazards in road and traffic situations.

Sjoerd Houwing (2013). Estimating the risk of driving under the influence of psychoactive substances.

Henk Stipdonk (2013). Road safety in bits and pieces; for a better understanding of the development of the number of road fatalities.

Paul Schepers (2013). A safer road environment for cyclists. 